\title{
Atmospheric pollutant outflow from southern Asia: a review
}

\author{
M. G. Lawrence ${ }^{1,2}$ and J. Lelieveld ${ }^{1,3}$ \\ ${ }^{1}$ Max Planck Institut for Chemistry, Atmospheric Chemistry Department, Mainz, Germany \\ ${ }^{2}$ University of Mainz, Institute for Physics of the Atmosphere, Mainz, Germany \\ ${ }^{3}$ Cyprus Institute, Nicosia, Cyprus
}

Received: 28 February 2010 - Published in Atmos. Chem. Phys. Discuss.: 15 April 2010

Revised: 15 October 2010 - Accepted: 19 October 2010 - Published: 25 November 2010

\begin{abstract}
Southern Asia, extending from Pakistan and Afghanistan to Indonesia and Papua New Guinea, is one of the most heavily populated regions of the world. Biofuel and biomass burning play a disproportionately large role in the emissions of most key pollutant gases and aerosols there, in contrast to much of the rest of the Northern Hemisphere, where fossil fuel burning and industrial processes tend to dominate. This results in polluted air masses which are enriched in carbon-containing aerosols, carbon monoxide, and hydrocarbons. The outflow and long-distance transport of these polluted air masses is characterized by three distinct seasonal circulation patterns: the winter monsoon, the summer monsoon, and the monsoon transition periods. During winter, the near-surface flow is mostly northeasterly, and the regional pollution forms a thick haze layer in the lower troposphere which spreads out over millions of square $\mathrm{km}$ between southern Asia and the Intertropical Convergence Zone (ITCZ), located several degrees south of the equator over the Indian Ocean during this period. During summer, the heavy monsoon rains effectively remove soluble gases and aerosols. Less soluble species, on the other hand, are lifted to the upper troposphere in deep convective clouds, and are then transported away from the region by strong upper tropospheric winds, particularly towards northern Africa and the Mediterranean in the tropical easterly jet. Part of the pollution can reach the tropical tropopause layer, the gateway to the stratosphere. During the monsoon transition periods, the flow across the Indian Ocean is primarily zonal, and strong pollution plumes originating from both southeastern Asia and from Africa spread across the central Indian Ocean. This paper provides a review of the current state of knowledge based on the many observational and modeling studies over the last decades that have examined the southern Asian
\end{abstract}

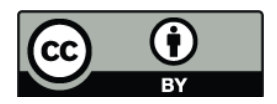

Correspondence to: M. G. Lawrence (mark.lawrence@mpic.de) atmospheric pollutant outflow and its large scale effects. An outlook is provided as a guideline for future research, pointing out particularly critical issues such as: resolving discrepancies between top down and bottom up emissions estimates; assessing the processing and aging of the pollutant outflow; developing a better understanding of the observed elevated pollutant layers and their relationship to local sea breeze and large scale monsoon circulations; and determining the impacts of the pollutant outflow on the Asian monsoon meteorology and the regional hydrological cycle, in particular the mountain cryospheric reservoirs and the fresh water supply, which in turn directly impact the lives of over a billion inhabitants of southern Asia.

\section{Introduction}

In 1999, several hundred scientists from around the world gathered in the Maldives, located in the northern Indian Ocean, as well as onboard two research ships and at several Indian coastal sites, to carry out the Indian Ocean Experiment (INDOEX). A central idea was to make use of the "unique natural laboratory" offered by the Indian Ocean troposphere, "probably the only place in the world where an intense source of continental aerosols, anthropogenic trace species and their reaction products (e.g., sulfates and ozone) from the Northern Hemisphere is directly connected to the pristine air of the Southern Hemisphere by a cross equatorial monsoonal flow into the intertropical convergence zone (ITCZ)" (see http://www-indoex.ucsd. edu/publications/proposal/). INDOEX had two basic objectives: understanding the anthropogenic contribution to the regional aerosol distribution and the resulting impacts on radiative forcing and climate; and understanding the influence of regional emissions on ozone and oxidant chemistry. During the several years leading up to the 1999 campaign, INDOEX grew into a major international undertaking,

Published by Copernicus Publications on behalf of the European Geosciences Union. 
including several pre-INDOEX cruises, the development of ground stations with various instrumentation, and culminating in an Intensive Field Phase (IFP) from January to April 1999, which included two research vessels, five aircraft, balloon sondes, constant level balloons, and retrievals from several satellites. INDOEX was exemplary in integrating these field and satellite measurements with chemistrytransport and climate modeling. The findings have resulted in several hundred publications, including: overview papers for the campaign logistics and the aerosol measurements (Ramanathan et al., 2001) and for the ozone chemistry (Lelieveld et al., 2001); two special sections each in the American Journal of Geophysical Research and the Indian journal Current Science; and dozens of other publications in these and other journals.

INDOEX made it clear that the large-scale pollutant export from southern Asia was much more substantial than had been expected, and modeling studies have even predicted that the Asian air pollution emissions (also from other parts of Asia) will play an increasingly important role in the air quality of North America and Europe (Lelieveld and Dentener, 2000). The international science teams during INDOEX encountered a surprisingly thick layer of sunlightabsorbing aerosols which covers much of the region of the northern Indian Ocean down to the ITCZ during this period, which can be clearly seen in visible satellite images, and which is responsible for a significant perturbation to the regional atmospheric energy balance. Shortly after INDOEX, this aerosol layer came to be known as the "Asian Brown Cloud," or "ABC". Since then, it has been broadly accepted that the acronym "ABC" should be generalized to "Atmospheric Brown Clouds" (Ramanathan and Crutzen, 2003), in recognition of the fact that pollutant outflow layers like this, containing various types of aerosols and trace gases, are by no means confined to the southern Asian region. A major international effort to better understand such pollution layers which has grown out of this is the UNEP ABC program (http://www.rrcap.unep.org/abc/). The first focus of $\mathrm{UNEP} / \mathrm{ABC}$ has been the ABC-Asia component, which has set up an array of monitoring sites and produced several assessments of the Asian ABCs and their effects.

INDOEX was not the only experiment that has been focused on pollutant outflow in this region; a number of other smaller to medium-sized field campaigns and independent modeling studies have also provided information on the composition of the regional atmosphere and ocean during the winter months. Furthermore, the winter monsoon is not the only period of interest for pollutant outflow. During INDOEX, several of the scientists participating in the campaign began thinking forward and posed the question "what happens to all that pollution during the summertime, when the summer monsoon deep convection is prevalent over the Indian subcontinent?" We were especially curious if any of this pollution could make its way over to Europe in the upper tropospheric easterlies. This seed eventually grew into the

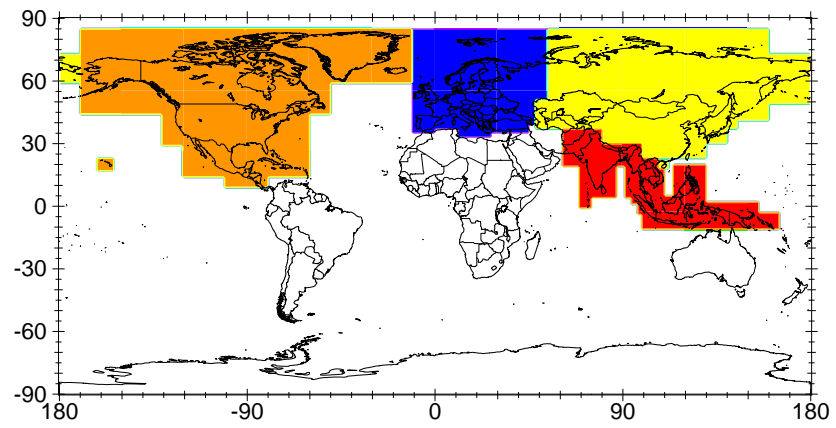

Fig. 1. Depiction of the regions used for the computation of the emissions summaries in Tables 2 and 3. Red: Southern Asia; yellow: Northern Asia; blue: Europe; Orange: North America.

field campaign MINOS (Mediterranean Intensive Oxidants Study), which was based out of Crete in 2001. MINOS provided clear evidence that the airspace above the Mediterranean is a "crossroads" of pollution (Lelieveld et al., 2002) from Europe, North America, and indeed from the summer monsoon outflow of southern Asia. A further insight into the seasonality of the air pollution over the northern Indian Ocean and its relationship to southern Asian outflow has come from examining the characteristics of the monsoon transition periods, when zonal winds are effective at transporting pollution from Southeast Asia and Africa into this region.

During the decade since INDOEX, the advancement in our understanding of pollutant export from southern Asia has been tremendous. In this review, we discuss the most salient findings on this topic. For the sake of this review, we consider southern Asia to be the region depicted in Fig. 1 (which includes the regions which are often separately referred to as "South Asia" and "southeastern Asia"). We begin by describing the current state of knowledge of pollutant emissions from this region (Sect. 2), and then give an overview of the seasonal regional meteorological characteristics (Sect. 3). Following this, we review the studies characterizing the pollutant export during each of the three key periods: the winter monsoon (Sect. 4), the summer monsoon (Sect. 5) and the monsoon transition periods (Sect. 6). Finally, we conclude (Sect. 7) with a summary of the major lessons learned over the last decade and an outlook to remaining research needs on this topic during the coming decades. Parts of this review build on an earlier review of the southern Asian pollution outflow (Lawrence, 2004), which is occasionally referred to in order to indicate the development in our state of understanding since then. 
Table 1. Listing of acronyms used in the paper.

\begin{tabular}{|c|c|}
\hline Acronym & Meaning \\
\hline $\mathrm{ABC}$ & $\begin{array}{l}\text { Atmospheric Brown Clouds } \\
\text { (UNEP Project) }\end{array}$ \\
\hline AI & Aerosol Index \\
\hline AOD & Aerosol Optical Depth \\
\hline AOT40 & $\begin{array}{l}\text { Accumulated exposure Over a Threshold } \\
\text { of } 40 \mathrm{nmol} / \mathrm{mol}\end{array}$ \\
\hline ARFI & $\begin{array}{l}\text { Aerosol Radiative Forcing } \\
\text { over India }\end{array}$ \\
\hline ARMEX & Arabian Sea Monsoon Experiment \\
\hline AS & Arabian Sea \\
\hline a.s.l. & above sea level \\
\hline AUAV & Automated Unmanned Aerial Vehicles \\
\hline $\mathrm{A}+\mathrm{W}$ & $\begin{array}{l}\text { Agricultural processes plus } \\
\text { waste handling }\end{array}$ \\
\hline $\mathrm{BC}$ & Black Carbon \\
\hline BFB & Biofuel Burning \\
\hline BMB & Biomass Burning \\
\hline BOB & Bay of Bengal \\
\hline BOBEX & Bay of Bengal Experiment \\
\hline CARIBIC & $\begin{array}{l}\text { Civil Aircraft for Regular Investigation } \\
\text { of the atmosphere Based on an } \\
\text { Instrument Container }\end{array}$ \\
\hline $\mathrm{EC}$ & Elemental Carbon \\
\hline EDGAR & $\begin{array}{l}\text { Emissions Database for Global } \\
\text { Atmospheric Research }\end{array}$ \\
\hline ETIO & Eastern Tropical Indian Ocean region \\
\hline FFB & Fossil Fuel Burning \\
\hline FFP & First Field Phase \\
\hline GCM & General Circulation Model \\
\hline GOME & Global Ozone Monitoring Experiment \\
\hline ICARB & $\begin{array}{l}\text { Integrated Campaign for Aerosol, } \\
\text { gases, and Radiation Budget }\end{array}$ \\
\hline IFP & Intensive Field Phase \\
\hline IND & Industrial emissions processes \\
\hline INDOEX & Indian Ocean Experiment \\
\hline IOM & Inorganic Oxidized Material \\
\hline ISRO-GBP & $\begin{array}{l}\text { Geosphere Biosphere Programme of the } \\
\text { Indian Space Research Organization }\end{array}$ \\
\hline ITCZ & Intertropical Convergence Zone \\
\hline $\mathrm{KCO}$ & Kaashidhoo Climate Observatory \\
\hline LT & Lower Troposphere \\
\hline MAC & Maldives AUAV Campaign \\
\hline MBL & Marine boundary layer \\
\hline $\mathrm{MCOH}$ & $\begin{array}{l}\text { Maldives Climate Observatory } \\
\text { in Hanimadhoo }\end{array}$ \\
\hline MINOS & Mediterranean Intensive Oxidants Study \\
\hline MLS & Microwave Limb Sounder \\
\hline MOPITT & $\begin{array}{l}\text { Measurements Of Pollution In The } \\
\text { Troposphere, satellite instrument }\end{array}$ \\
\hline MT & Middle Troposphere \\
\hline MTP & Monsoon Transition Period \\
\hline NCEP-GFS & $\begin{array}{l}\text { National Centers for Environmental Predic- } \\
\text { tion - Global Forecasting System }\end{array}$ \\
\hline $\mathrm{NE}$ & Northeast \\
\hline NH & Northern Hemisphere \\
\hline $\mathrm{NHc}$ & Northern Hemisphere continental \\
\hline NHcT & Northern Hemisphere continental Tropical \\
\hline $\mathrm{NHcX}$ & $\begin{array}{l}\text { Northern Hemisphere continental } \\
\text { extratropics }\end{array}$ \\
\hline $\mathrm{NHmE}$ & Northern Hemisphere maritime equatorial \\
\hline $\mathrm{NHmT}$ & Northern Hemisphere maritime Tropical \\
\hline
\end{tabular}

Table 1. Continued.

\begin{tabular}{|c|c|}
\hline Acronym & Meaning \\
\hline NMVOC & Non-Methane Volatile Organic Compound \\
\hline \multirow{2}{*}{ OECD } & Organization of Economic \\
\hline & Co-operation and Development \\
\hline $\mathrm{OM}$ & Organic Matter \\
\hline PAH & Polycyclic Aromatic Hydrocarbon \\
\hline PESO & Pilot Expedition to the Southern Ocean \\
\hline \multirow[t]{2}{*}{ PM1 } & Particulate Matter less than \\
\hline & $1 \mu m$ aerodynamic diameter \\
\hline \multirow[t]{2}{*}{ PM2.5 } & Particulate Matter less than \\
\hline & $2.5 \mu \mathrm{m}$ aerodynamic diameter \\
\hline \multirow[t]{2}{*}{ PM10 } & Particulate Matter less than \\
\hline & $10 \mu m$ aerodynamic diameter \\
\hline POM & Particulate Organic Matter \\
\hline ROM & Refractory Organic Matter \\
\hline SAW-ABC & $\begin{array}{l}\text { Southern Asian Wintertime Atmospheric } \\
\text { Brown Cloud }\end{array}$ \\
\hline $\mathrm{SC}$ & Soot Carbon \\
\hline \multirow[t]{2}{*}{ SCIAMACHY } & $\begin{array}{l}\text { Scanning Imaging Absorption Spectrome- } \\
\text { ter }\end{array}$ \\
\hline & for Atmospheric CHartographY \\
\hline SHmE & Hemisphere maritime equatorial \\
\hline $\mathrm{SHmT}$ & Southern Hemisphere maritime tropical \\
\hline SHmX & $\begin{array}{l}\text { Southern Hemisphere maritime } \\
\text { extratropical }\end{array}$ \\
\hline SOA & Secondary Organic Aerosols \\
\hline SSA & Single Scattering Albedo \\
\hline SST & Sea Surface Temperature \\
\hline SW & Southwest \\
\hline TEJ & Tropical Easterly Jet stream \\
\hline TOA & Top Of the Atmosphere \\
\hline TTL & Tropical Tropopause Layer \\
\hline UNEP & United Nations Environmental Program \\
\hline UT & Upper Troposphere \\
\hline VOC & Volatile Organic Compound \\
\hline W_ICARB & Second phase of ICARB \\
\hline WTIO & Western Tropical Indian Ocean region \\
\hline
\end{tabular}

\section{Estimates of current southern Asian emissions and future increases}

Southern Asia is a region with a vibrant mixture of cultures which comprises over a quarter of the world's population. Stretching from Afghanistan and Pakistan in the west to Indonesia and Papua New Guinea in the east, and bounded on the north by China and the former Soviet Union and on the south by the Indian Ocean, the widelyvarying landscape includes seashores, tropical rainforests, vast plains, and the foothills of the Himalayas. People dominate much of this landscape, partly gathered in megacities like Delhi and Bangkok, but also dotting the extensive rural environment in small villages, many without electricity and running water. One activity that is common to all people amidst this immense diversity is fuel consumption for energy production, for instance biofuel burning in cookstoves, fossil fuel burning in vehicles, and burning coal and 
natural gas to produce electricity. Although the amount of energy usage and fuel consumption per capita still pales in comparison to the industrialized nations in the Western Hemisphere, the sheer size and rapid growth of the southern Asian population and the often poorly-controlled burning conditions lead to large emissions of various pollutants, including: greenhouse gases like carbon dioxide $\left(\mathrm{CO}_{2}\right)$ and methane $\left(\mathrm{CH}_{4}\right)$; ozone precursors such as nitrogen oxides $\left(\mathrm{NO}_{\mathrm{x}}=\mathrm{NO}+\mathrm{NO}_{2}\right)$, carbon monoxide $(\mathrm{CO})$ and nonmethane volatile organic compounds (NMVOCs); aerosol particle precursors such as sulfur dioxide $\left(\mathrm{SO}_{2}\right)$; and primary particles comprised of various materials or mixtures such as soot and organic compounds.

\subsection{Regional trace gas emissions}

Pollutant sources in Asia are changing so rapidly that any overview of current emissions only provides a snapshot, with a relatively large degree of uncertainty. Various sources of information on Asian emissions exist, such as official national databases, and gridded databases developed for regional modeling studies (e.g., Streets et al., 2003, 2006; Akimoto et al., 2006; Ohara et al., 2007; Cofala et al., 2007). In order to make an internally consistent comparison of the characteristics of southern Asian emissions with those from other major emitter regions of the Northern Hemisphere $(\mathrm{NH})$, here we make use of the global emissions data in the Emissions Database for Global Atmospheric Research (EDGAR, version 3.2FT2000; Olivier et al., 2005). These data, which are for the year 2000, should be representative of the prevailing conditions during the INDOEX and MINOS campaigns (1999 and 2001, respectively). Four regions are selected for comparison here, as depicted in Fig. 1. The total emissions of several trace gases for these regions, along with the global totals for each gas, are listed in Table 2, broken down into several major source categories. Table 3 lists the percentages of the global totals represented by each region, along with the relative contribution of each major source category to the total emissions for each region. This is an extension of the comparison that we presented previously in Lelieveld et al. (2001), but based on newer information, with different regional definitions, and different emissions classes (including biomass burning, which was not reported by Lelieveld et al., 2001).

As noted above, there is a considerable degree of uncertainty in most of these values. The emissions are mostly computed as the products of activity data (e.g., mass of fuel burned) times emissions factors (mass of emissions per unit of activity). The activity data, especially for residential activities like cooking with stoves, can be very difficult to ascertain, and some emissions factors are based on upscaling of only one or a few measurements appropriate to the various combustion or other industrial processes in different regions. In most cases a serious, quantitative uncertainty estimate is not even possible at present. This is reflected in the
Table 2. Emissions of key trace gases segregated by source category for the world, for southern Asia, and for three other key emissions regions in the $\mathrm{NH}$ (depicted in Fig. 1). The source categories are: FFB - Fossil Fuel Burning (including shipping emissions within the defined regions, but excluding emissions from aircraft); IND - industrial processes; BFB - biofuel burning; BMB - biomass burning; $\mathrm{A}+\mathrm{W}-$ agricultural processes and waste handling (including waste burning). The units are specified individually for each gas. Data is from the EDGAR 3.2FT2000 database (Olivier et al., 2005); see the text for details.

\begin{tabular}{|c|c|c|c|c|c|}
\hline Source & Global & S. Asia & N. Asia & N. America & Europe \\
\hline \multicolumn{6}{|c|}{$\mathrm{CO}_{2}\left(\mathrm{Pg}\left(\mathrm{CO}_{2}\right) / \mathrm{yr}\right)$} \\
\hline Total & 36.15 & 3.03 & 7.00 & 7.66 & 6.77 \\
\hline FFB & 25.46 & 2.02 & 6.26 & 6.99 & 6.52 \\
\hline IND & 0.83 & 0.10 & 0.38 & 0.07 & 0.16 \\
\hline BFB & 0.57 & 0.23 & 0.12 & 0.03 & 0.03 \\
\hline BMB & 9.30 & 0.68 & 0.25 & 0.57 & 0.07 \\
\hline $\mathrm{A}+\mathrm{W}$ & 0.00 & 0.00 & 0.00 & 0.00 & 0.00 \\
\hline \multicolumn{6}{|c|}{$\mathrm{NO}_{\mathrm{x}}(\mathrm{Tg}(\mathrm{N}) / \mathrm{yr})$} \\
\hline Total & 43.12 & 4.89 & 7.03 & 8.24 & 7.02 \\
\hline FFB & 29.13 & 2.98 & 5.35 & 7.27 & 6.16 \\
\hline IND & 2.19 & 0.20 & 0.91 & 0.22 & 0.59 \\
\hline $\mathrm{BFB}$ & 2.48 & 1.03 & 0.49 & 0.14 & 0.12 \\
\hline BMB & 9.04 & 0.63 & 0.26 & 0.56 & 0.07 \\
\hline $\mathrm{A}+\mathrm{W}$ & 0.27 & 0.04 & 0.03 & 0.04 & 0.07 \\
\hline \multicolumn{6}{|c|}{$\mathrm{CO}(\mathrm{Tg}(\mathrm{CO}) / \mathrm{yr})$} \\
\hline Total & 983.89 & 160.13 & 127.30 & 123.41 & 76.98 \\
\hline FFB & 243.21 & 19.04 & 46.94 & 78.64 & 47.99 \\
\hline IND & 34.49 & 1.35 & 14.93 & 3.00 & 11.98 \\
\hline BFB & 250.28 & 103.93 & 50.66 & 10.23 & 8.33 \\
\hline BMB & 435.75 & 32.57 & 12.69 & 28.10 & 3.38 \\
\hline $\mathrm{A}+\mathrm{W}$ & 20.17 & 3.24 & 2.09 & 3.43 & 5.31 \\
\hline \multicolumn{6}{|c|}{ NMVOC $(\operatorname{Tg}(\mathrm{C}) / \mathrm{yr})$} \\
\hline Total & 129.02 & 19.07 & 19.76 & 20.93 & 22.07 \\
\hline FFB & 61.78 & 6.25 & 9.76 & 12.04 & 13.50 \\
\hline IND & 20.44 & 1.41 & 4.31 & 5.82 & 6.59 \\
\hline $\mathrm{BFB}$ & 22.98 & 9.42 & 4.64 & 1.01 & 0.78 \\
\hline BMB & 20.21 & 1.57 & 0.52 & 1.24 & 0.14 \\
\hline $\mathrm{A}+\mathrm{W}$ & 3.60 & 0.43 & 0.54 & 0.81 & 1.06 \\
\hline \multicolumn{6}{|c|}{$\mathrm{SO}_{2}\left(\mathrm{Tg}\left(\mathrm{SO}_{2}\right) / \mathrm{yr}\right)$} \\
\hline Total & 152.11 & 14.53 & 48.92 & 25.26 & 33.07 \\
\hline FFB & 117.61 & 1.16 & 36.85 & 23.06 & 25.62 \\
\hline IND & 28.69 & 1.37 & 11.45 & 1.94 & 7.33 \\
\hline BFB & 3.16 & 1.78 & 0.49 & 0.04 & 0.03 \\
\hline BMB & 2.42 & 0.18 & 0.09 & 0.18 & 0.02 \\
\hline $\mathrm{A}+\mathrm{W}$ & 0.22 & 0.03 & 0.02 & 0.04 & 0.06 \\
\hline
\end{tabular}

significant quantitative differences which have been shown to exist between various emissions datasets, including EDGAR (e.g., Butler et al., 2008). Furthermore, for the Asian region large discrepancies have been found between bottomup emissions inventories like these, versus top-down emissions estimates based on combining observations and model 
simulation results. Kasibhatla et al. (2002) showed that topdown estimates based on $\mathrm{CO}$ observations downwind of eastern Asia implied much higher emissions rates than in emissions datasets available at that time. Indeed, follow-up work by Streets et al. (2006) has confirmed this and revised the $\mathrm{CO}$ emissions estimates from China substantially upward, particularly due to industrial processes like cement and brick kilns and iron and steel production, and furthermore conclude that "emissions from the residential sector might still be underestimated." Nevertheless, despite these uncertainties, data such as these are currently the best available for global modeling studies and as a basis for mitigation efforts, and a few basic, qualitative features in the emissions distribution are clearly evident from the comparison in Tables 2 and 3.

One of the clearest features is that emissions from southern Asia are strongly influenced by inefficient combustion processes, especially emissions from biofuel burning in cookstoves. This can be seen clearly in Table 3, which shows that biofuel burning (BFB) is responsible for a relatively large component of the trace pollutant emissions in southern Asia (ranging from $7.5 \%$ for $\mathrm{CO}_{2}$ to nearly $65 \%$ for $\mathrm{CO}$ ), compared to a much smaller contribution from BFB in any of the other three regions, or in the world as a whole (for which the BFB source ranges from about $2-25 \%$ of the total emissions). Other types of inefficient combustion are also prevalent in southern Asia, such as the widespread use of two-stroke engines, which are often made even more inefficient by running them on adulterated fuels (e.g., kerosene mixed in with diesel). Compared to more efficient combustion (e.g., modern automobiles), these inefficient combustion processes burn at lower temperatures, resulting in less emissions of $\mathrm{NO}_{\mathrm{x}}$, and they burn less well to completion, resulting in higher $\mathrm{CO} / \mathrm{CO}_{2}$ ratios and a greater content of unburned or only partially oxidized VOCs. This is also reflected in Table 3: southern Asia contributes a disproportionally large share to the total global emissions of CO and NMVOC, approximately 1.5 times as large as its relative contribution to the total global $\mathrm{CO}_{2}$ and $\mathrm{NO}_{\mathrm{x}}$ emissions. Similar tendencies are seen in an analysis of emissions from individual Asian countries (Wuebbles et al., 2007) based on the data from Streets et al. (2003); such analyses show that the emissions from the southern and northern Asian regions (based on Fig. 1) are dominated by India and China, respectively, with these two countries accounting for $60 \%, 64 \%$, and $54 \%$ of the total Asian emissions of $\mathrm{NO}_{\mathrm{x}}, \mathrm{CO}$ and NMVOC, respectively.

A few other broad features of the emissions distributions are clear in Tables 2 and 3. First, in southern Asia, biomass burning (BMB) is also a significant source of most of the gases (except $\mathrm{SO}_{2}$ ), representing a notably larger fraction of the regional emissions for most of the gases than is contributed by biomass burning in the other three main $\mathrm{NH}$ emitter regions (especially for $\mathrm{CO}_{2}$, though with a few exceptions, such as CO in North America, due to unusually strong fires in the northwestern USA during the year 2000). On
Table 3. Relative emissions of key trace gases. The source categories and regions are the same as in Table 2. All values are in percent $(\%)$, rounded to the nearest integer (more accurate percentages can be derived from Table 2). The percentages in the top row for each gas are regional contributions relative to the global total for that gas (for all source processes combined). The percentages in each of the other rows are the contribution from that category to the total emissions of that gas in that particular region.

\begin{tabular}{|c|c|c|c|c|c|}
\hline Source & Global & S. Asia & N. Asia & N. America & Europe \\
\hline \multicolumn{6}{|l|}{$\mathrm{CO}_{2}$} \\
\hline Total & 100 & 8 & 19 & 21 & 19 \\
\hline FFB & 70 & 67 & 89 & 91 & 96 \\
\hline IND & 2 & 3 & 5 & 1 & 2 \\
\hline BFB & 2 & 8 & 2 & 0 & 0 \\
\hline BMB & 26 & 22 & 4 & 7 & 1 \\
\hline $\mathrm{A}+\mathrm{W}$ & 0 & 0 & 0 & 0 & 0 \\
\hline \multicolumn{6}{|l|}{$\mathrm{NO}_{\mathrm{X}}$} \\
\hline Total & 100 & 11 & 16 & 19 & 16 \\
\hline FFB & 68 & 61 & 76 & 88 & 89 \\
\hline IND & 5 & 4 & 13 & 3 & 8 \\
\hline BFB & 6 & 21 & 7 & 2 & 2 \\
\hline BMB & 21 & 13 & 4 & 7 & 1 \\
\hline $\mathrm{A}+\mathrm{W}$ & 1 & 1 & 0 & 1 & 1 \\
\hline \multicolumn{6}{|l|}{$\mathrm{CO}$} \\
\hline Total & 100 & 16 & 13 & 13 & 8 \\
\hline FFB & 25 & 12 & 37 & 64 & 62 \\
\hline IND & 4 & 1 & 12 & 2 & 16 \\
\hline BFB & 25 & 65 & 40 & 8 & 11 \\
\hline BMB & 44 & 20 & 10 & 23 & 4 \\
\hline $\mathrm{A}+\mathrm{W}$ & 2 & 2 & 2 & 3 & 7 \\
\hline \multicolumn{6}{|l|}{ NMVOC } \\
\hline Total & 100 & 15 & 15 & 16 & 17 \\
\hline FFB & 48 & 33 & 49 & 58 & 61 \\
\hline IND & 16 & 7 & 22 & 28 & 30 \\
\hline BFB & 18 & 49 & 24 & 5 & 4 \\
\hline BMB & 16 & 8 & 3 & 6 & 1 \\
\hline $\mathrm{A}+\mathrm{W}$ & 3 & 2 & 3 & 4 & 5 \\
\hline \multicolumn{6}{|l|}{$\mathrm{SO}_{2}$} \\
\hline Total & 100 & 10 & 32 & 17 & 22 \\
\hline FFB & 77 & 77 & 75 & 91 & 78 \\
\hline IND & 19 & 10 & 23 & 8 & 22 \\
\hline BFB & 2 & 12 & 1 & 0 & 0 \\
\hline BMB & 2 & 1 & 0 & 1 & 0 \\
\hline $\mathrm{A}+\mathrm{W}$ & 0 & 0 & 0 & 0 & 0 \\
\hline
\end{tabular}

the other hand, the fraction of biomass burning emissions in southern Asia is smaller than in the global total emissions for all of the gases, which is due to the predominance in this category of emissions from deforestation in Africa and South America. Second, the per capita energy usage in southern Asia is considerably smaller than in Europe or North America. This is reflected clearly in the $\mathrm{CO}_{2}$ emissions, as southern Asia is responsible for only about $8.4 \%$ of the global total, less than half as much as each of the other three regions 
a) Population Density (persons $/ \mathrm{km}^{2}$ )

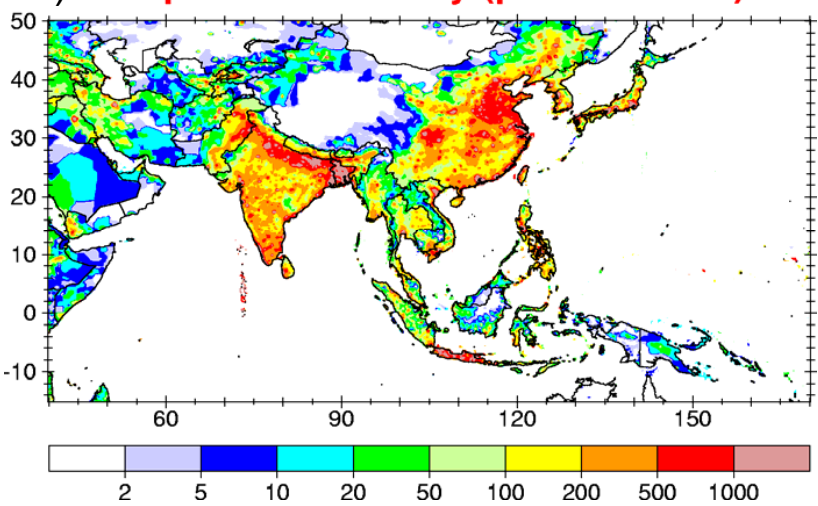

b) $\mathrm{NO}_{x}$ emissions $\left(10^{-12} \mathrm{~kg}(\mathrm{~N}) \mathrm{m}^{-2} \mathrm{~s}^{-1}\right)$

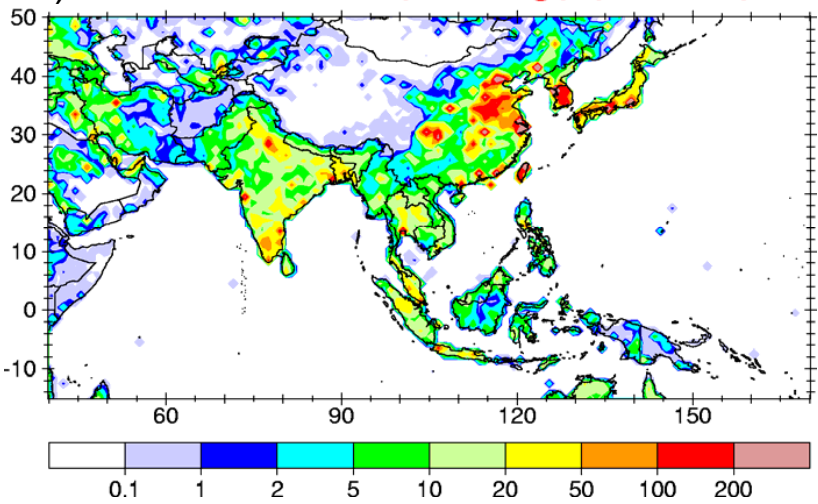

c) $\mathrm{CO}$ emissions $\left(10^{-12} \mathrm{~kg}(\mathrm{CO}) \mathrm{m}^{-2} \mathrm{~s}^{-1}\right)$

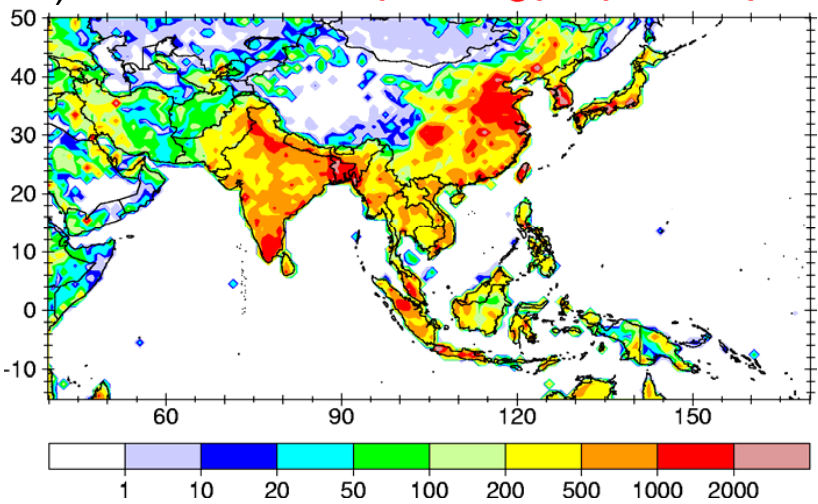

Fig. 2. Distributions of (a) population density (persons per square $\mathrm{km}), \mathbf{b})$, emissions of $\mathrm{NO}_{\mathrm{x}}\left(10^{-12} \mathrm{~kg}(\mathrm{~N}) \mathrm{m}^{-2} \mathrm{~s}^{-1}\right)$, and (c) emissions of $\mathrm{CO}\left(10^{-12} \mathrm{~kg}(\mathrm{CO}) \mathrm{m}^{-2} \mathrm{~s}^{-1}\right)$. (Population density is based on $0.25^{\circ}$ gridded data for 2000 from the Center for International Earth Science Information Network (CIESIN) at Columbia University, http://sedac.ciesin.columbia.edu/gpw/; Emissions data are the same as in Table 2, sum of all categories.)

(all around 20\%), despite the larger population in southern Asia. Finally, the emissions from northern Asia are similar to Europe and North America for $\mathrm{CO}_{2}$ and $\mathrm{NO}_{\mathrm{x}}$ in terms of their distribution across the source categories, being dominated by fossil fuel burning. However, they differ notably for $\mathrm{CO}$ and NMVOCs, for which biofuel burning becomes particularly important in northern Asia, and for which the other source categories such as industrial processes play strongly varying roles. Northern Asia is also responsible for a disproportionately large fraction of the global total $\mathrm{SO}_{2}$ emissions, mainly due to the sulfur-rich coal which is burned in Chinese power plants.

The spatial distributions of total $\mathrm{NO}_{\mathrm{x}}$ and $\mathrm{CO}$ emissions in Asia are shown in Fig. 2, along with the regional population distribution. Particularly densely-populated regions in southern Asia include the northern part of India (the Indo-Gangetic Plain) and the southern tip of India, Bangladesh, Indonesia (primarily Java) and the Philippines, along with several major cities like Mumbai, Bangkok and Hanoi. In northern Asia the most densely-populated regions include northeast China, the Szechuan Basin, the Pearl River Delta (including Hong Kong), Korea, and Japan. The emissions distributions for both $\mathrm{NO}_{\mathrm{x}}$ and $\mathrm{CO}$ largely follow the population distribution, which is not surprising, given that in global emissions inventories like EDGAR, the emissions from several of the source categories are distributed primarily by population. There are, however, a few notable exceptions, including the disproportionately high $\mathrm{CO}$ emissions compared to population in several regions, especially where biofuel and biomass burning in less populated rural regions are prevalent, such as throughout parts of Myanmar, Thailand, Laos, Cambodia, Vietnam, and especially the islands of Borneo and western Sumatra. In contrast to this, the $\mathrm{NO}_{\mathrm{x}}$ emission distribution tends to be clustered more tightly around the most densely-populated regions, especially in northeastern China, and is generally less spread out than $\mathrm{CO}$ emissions, due to the greater $\mathrm{CO}$ emissions from distributed and rural sources, especially biomass burning. (Note that the total Asian $\mathrm{CO}$ emissions are about 25 times as large as the total $\mathrm{NO}_{\mathrm{x}}$ emissions (see Table 2); since the scales of the two figures differ by a factor of 10 , the $\mathrm{NO}_{\mathrm{x}}$ emissions are effectively color-shifted approximately one color contour lower than the $\mathrm{CO}$ emissions).

Finally, the emissions of most gaseous pollutants in Asia (both northern and southern) are growing at a tremendous rate (e.g., Akimoto, 2003), due to growing populations, accompanied by rapid industrialization and agricultural developments. This anticipated rapid growth in Asia is depicted in Fig. 3, and is compared with the anticipated changes for the nations of the OECD (Organization of Economic Cooperation and Development). While there is a considerable spread in the likely range of changes for each gas, it is clear that the emissions of nearly all gases are expected to increase in Asia, while emissions of most gases from the OECD nations could either increase or decrease (with the exception of $\mathrm{SO}_{2}$, which will almost certainly decrease, and $\mathrm{CO}_{2}$, which will almost certainly increase). There is, however, an even greater uncertainty in future scenario estimates than in the current emissions inventories discussed above. In the end, the actual increase in anthropogenic emissions of various 
a)
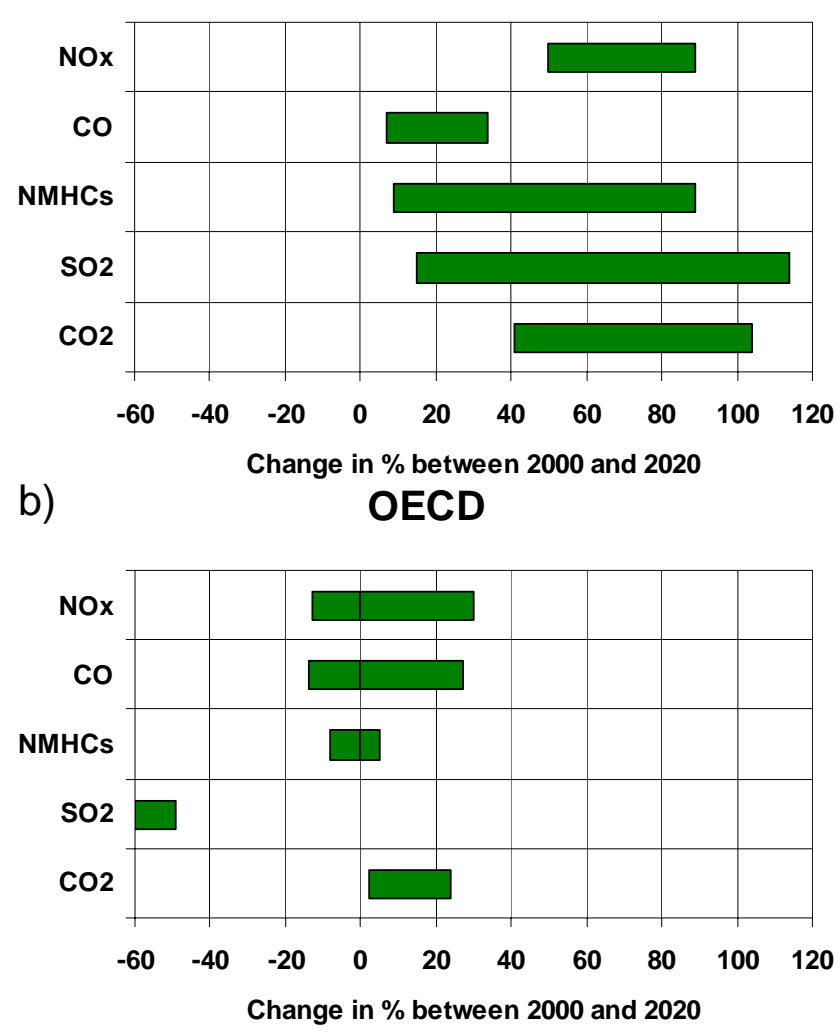

Fig. 3. Expected increases in trace gas emissions during the period 2000-2020 for (a) Asia and (b) the OECD nations (Based on data published in IPCC Emission Scenarios 2000, http://www.ipcc.ch/ ipccreports/sres/emission/index.php?idp=0).

pollutants will depend on which new regulations are implemented and enforced in the individual countries, which will in turn depend in part on the local tolerance for increasing pollution levels, from the perspective of it being one of many daunting social issues, and will also depend on the detailed scientific information on emissions and their impacts which is available to policy makers.

\subsection{Regional aerosol emissions}

In addition to the trace gases discussed in the previous section, southern Asia also has substantial and growing emissions of aerosols and aerosol precursors, with trends in the emissions similar to those discussed in the previous section for gases. In most regions, these are even more important than trace gases for health and climate effects. Sulfate aerosols, which derive mostly from $\mathrm{SO}_{2}$, can make an important contribution to the air pollution in some regions, but on the whole are a much larger problem in northern Asia (especially in China) than in southern Asia (see Table 2). The same applies to desert dust particles, being of natural origin, as the Chinese-Mongolian Gobi desert is one of the largest sources of mineral aerosol particles in the world. Nevertheless, in southern Asia the great Indian Thar desert can be of regional significance, too, contributing about $10 \%$ of the particulate mass observed over the northern Indian Ocean (Lelieveld et al., 2001). On the other hand, southern Asia is particularly influenced by emissions of carbon-containing aerosols and precursors, since these tend to be most strongly emitted by inefficient combustion processes. Organic carbon primary aerosols and precursors of secondary organic aerosols (SOA) tend to generally be closely related to gasphase NMVOC emissions, which were discussed in the previous section (see Tables 2 and 3). Another important product of inefficient combustion is black carbon (BC; note that the terminology used for black carbon varies from study to study, with some authors using "elemental carbon (EC)", "refractory carbon", "refractory organic matter (ROM)", "soot", and "soot carbon (SC)" interchangeably with BC, and others using these terms to denote some specific subset of the total $\mathrm{BC}$, often dependent on which measurement techniques are employed). BC is an effective absorber of sunlight, in contrast to most other aerosols, which are effective scatterers, and thus it plays a unique role in the regional anthropogenic climate effects, as discussed below in Sect. 4.

The uncertainties in $\mathrm{BC}$ emissions are very large. The total BC emissions from India have been estimated by Venkataraman et al. (2005) to be $0.41 \mathrm{Tg}(\mathrm{BC}) / \mathrm{yr}$, with $0.17 \mathrm{Tg}(\mathrm{BC}) / \mathrm{yr}$ from biofuel burning (especially fuelwood in cookstoves), $0.14 \mathrm{Tg}$ (BC)/yr from open biomass burning, and $0.1 \mathrm{Tg}(\mathrm{BC}) / \mathrm{yr}$ from fossil fuel burning. As noted above in Table 3 for CO and NMVOC, in India (and generally in southern Asia) biofuel burning makes a much larger relative contribution to the total $\mathrm{BC}$ emissions than throughout most of the rest of the world. One uncertainty which remains to be resolved was pointed out by Dickerson et al. (2002). Like the study of Venkataraman et al. (2005), most emissions inventories indicate a total BC source from India of approximately $0.5 \mathrm{Tg}(\mathrm{BC}) / \mathrm{yr}$ (or $\sim 0.7 \mathrm{Tg}(\mathrm{BC}) / \mathrm{yr}$ from southern Asia, with an upper limit of $\sim 1 \mathrm{Tg}(\mathrm{BC}) / \mathrm{yr})$. However, top down estimates based on in situ measurements of $\mathrm{BC}$ made during INDOEX (Dickerson et al., 2002) suggest that a much larger source, of the order of $2-3 \mathrm{Tg}(\mathrm{BC}) / \mathrm{yr}$, is necessary to explain the measured concentrations. This difference in top down and bottom up estimates is similarly reflected in computations of the radiative forcing of $\mathrm{BC}$ : Ramanathan and Carmichael (2008) compute a global mean forcing of $0.9 \mathrm{~W} \mathrm{~m}^{-2}$ based on observations, which they contrast with the considerably smaller forcing of about $0.3 \mathrm{~W} \mathrm{~m}^{-2}$ computed by many GCMs (general circulation models), which make use of bottom up emissions databases. Given the large global and especially regional radiative forcing of $\mathrm{BC}$, it will be very important to sort out the uncertainty in the BC source magnitude.

Another uncertainty which has proven very difficult to resolve, as was already apparent shortly after INDOEX, is to determine whether the dominant source for $\mathrm{BC}$ in the 


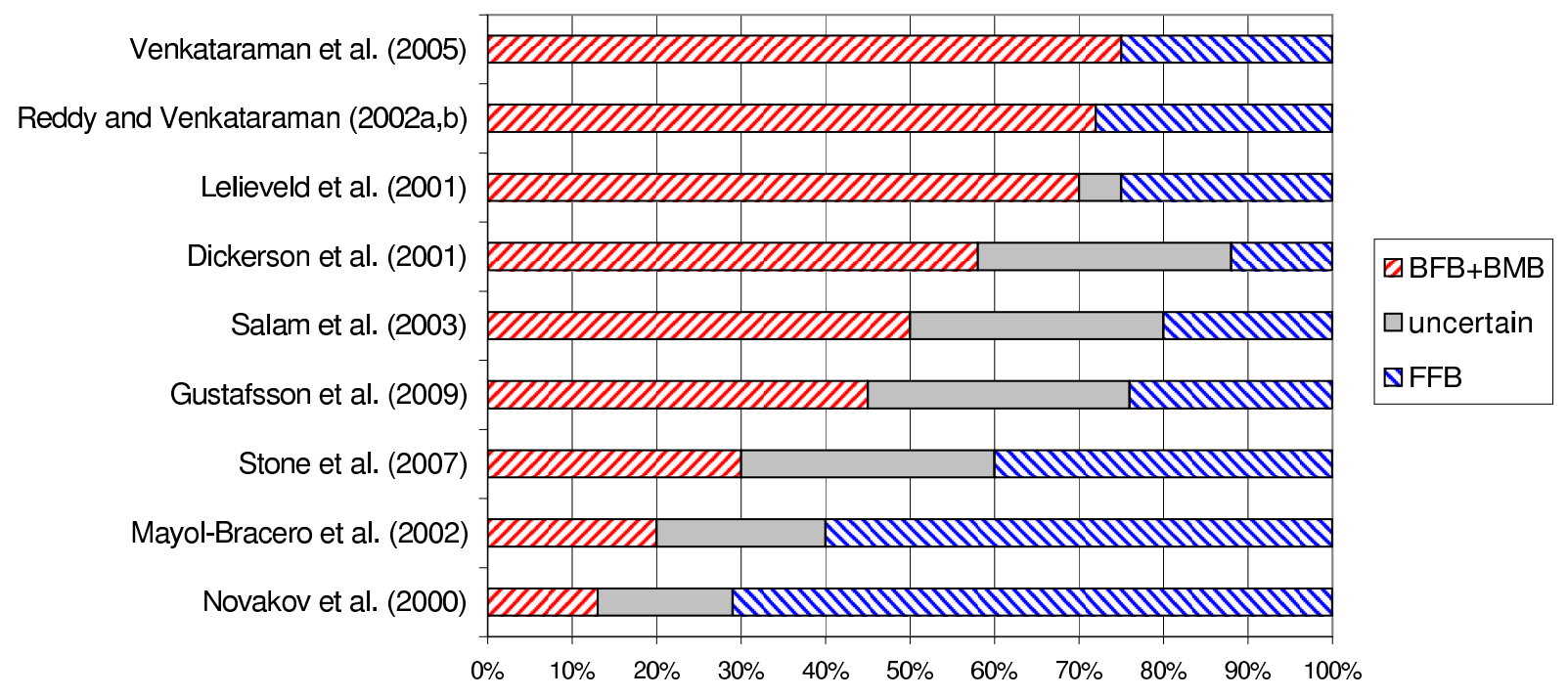

Fig. 4. Relative contributions (in \%) of biofuel burning (BFB) plus biomass burning (BMB) versus fossil fuel burning (FFB) processes, either to the total $\mathrm{BC}$ emissions from India, or to the southern Asian outflow, depending on the study; the uncertainty in the range given in each study is represented by the gray shaded area; see the text for more information on the individual studies.

southern Asian outflow is fossil fuel burning (FFB) or biofuel and biomass burning (BFB + BMB). This is important basic information for the development of mitigation strategies. Several studies have concluded FFB must be the main BC source (from just over half to up to $90 \%$ of the total). These studies have employed top down approaches, such as measuring ratios of $\mathrm{BC}$ to total carbon (the sum of $\mathrm{BC}$ and organic carbon), as well as ratios of $\mathrm{BC}$ to other aerosol components such as potassium, water-soluble ions, organic markers and trace metals (Novakov et al., 2000; Mayol-Bracero et al., 2002; Salam et al., 2003; Stone et al., 2007). However, other top down studies have instead concluded that $\mathrm{BFB}+\mathrm{BMB}$ is likely to be the primary BC source, based on the concentrations of biomass burning tracers like potassium and acetonitrile (Guazotti et al., 2003), the ratio of BC to CO (Dickerson et al., 2002), the ratio of radiocarbon monoxide $\left({ }^{14} \mathrm{CO}\right)$ to $\mathrm{CO}$ north and south of the ITCZ (Lelieveld et al., 2001), and by considering correlations of aerosol optical depth with fire count data based on satellite observations with the ATSR instrument (Léon et al., 2001). Yet others, such as Ball et al. (2003), found that BC was well-correlated with markers for both FFB and BFB + BMB, indicating a mixture of the two sources, and speculating that perhaps some other unaccounted processes could be involved. Guazotti et al. (2003) offer a particularly useful insight which may help to explain at least some of the discrepancy in these top down studies: for airmasses from India, they found BFB + BMB to be the dominant source ( $74 \%$ of the total), while for airmasses originating from the Arabian peninsula, FFB was found to be dominant (63\%). Furthermore, based on "bottom up" studies using regional and global emissions inventories (Reddy and Venkataraman, 2002a, b; Dickerson et al., 2002;
Mayol-Bracero et al., 2002; Bond et al., 2004; Venkataraman et al., 2005; Parashar et al., 2005), one would also expect the largest source of $\mathrm{BC}$ for aerosols from India and neighboring countries to be from BFB + BMB. In particular, Venkataraman et al. (2005) distinguished between BFB and $\mathrm{BMB}$ sources, and computed that BFB makes the largest relative contribution $(42 \%)$ to total $\mathrm{BC}$ emissions, followed by BMB $(33 \%)$ and FFB (25\%). The wide range of different conclusions in these studies is depicted in Fig. 4.

After this decade of debate, a major new step towards resolving this discrepancy has been made by the recent study of Gustafsson et al. (2009), which uses the alternate approach of measuring the ${ }^{14} \mathrm{C}$ content of the aerosol particles. This unambiguously indicates the fraction originating from FFB versus $\mathrm{BFB}+\mathrm{BMB}$, since fossil fuels are completely depleted in ${ }^{14} \mathrm{C}$ (which has a half-life of 5730 years), while aerosols deriving from $\mathrm{BFB}+\mathrm{BMB}$ will have $\mathrm{a}{ }^{14} \mathrm{C}$ concentration (relative to ${ }^{12} \mathrm{C}$ ) which is the same as measured in contemporary biomass (a small uncertainty, of the order of $10 \%$, arises due to the difference in ${ }^{14} \mathrm{C}$ enrichments found in freshly-produced living biomass compared to wood from old or dead trees, especially due to the influence of elevated atmospheric ${ }^{14} \mathrm{CO}_{2}$ levels in the mid-1900s which resulted from nuclear bomb testing). Using measurements from a site on the west coast of India and from a site on the Maldives (southwest of India), made during the offshore flow period of the winter monsoon (see Sect. 3), they found that about two-thirds of the bulk carbonaceous aerosols (including both $\mathrm{BC}$ and organic carbon) were produced by $\mathrm{BFB}+\mathrm{BMB}$, the other third originating from FFB. This result is very consistent between the two sites. They also employed two different techniques of separating out the $\mathrm{BC}$ component from the total 
a) June - September

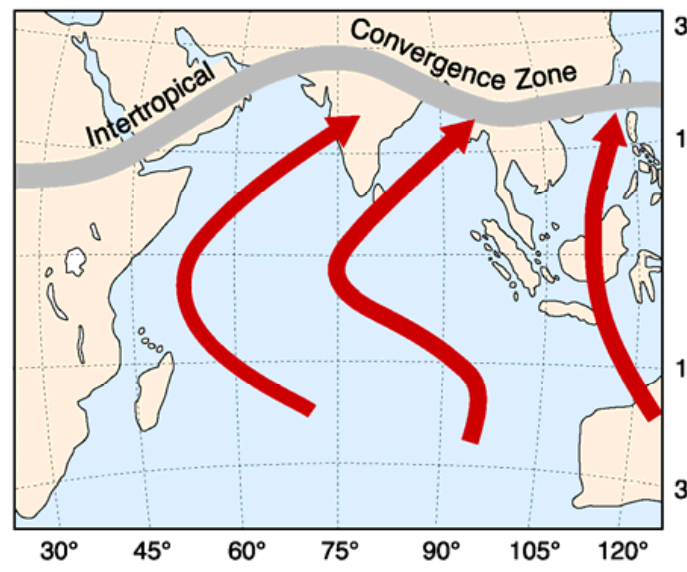

b) November - March

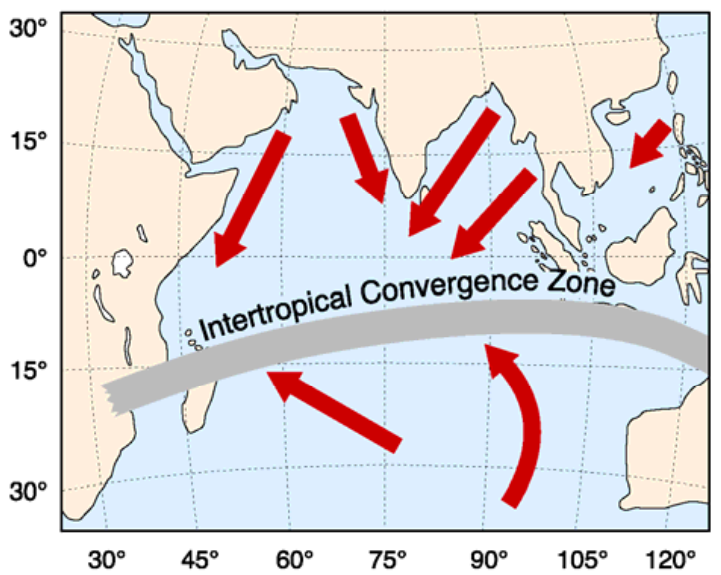

Fig. 5. Transport pathways for near-surface flow over the Indian Ocean during the (a) summer and (b) winter monsoon periods.

carbonaceous aerosol. For one method of isolating the BC (yielding "soot carbon", or SC), a similar fraction of about $2 / 3$ from BFB + BMB was computed, again being nearly the same for the two measurement sites. For the other isolation method (yielding "elemental carbon", or EC), however, only about half was computed to originate from BFB + BMB, the other half from FFB; furthermore, for this component, the results differed notably between the two sites, with the Indian coastal site aerosols indicating about $60 \%$ of the EC derived from $\mathrm{BFB}+\mathrm{BMB}$. The reason for this difference is unclear; although it may be related to the regional origins of the airmasses being sampled at the two sites (as noted above based on the study of Guazotti et al., 2003), a clear dependence was not apparent based on the back-trajectories analyzed by Gustafsson et al. (2009). Despite this and other remaining uncertainties, it has now become clear that for effective mitigation efforts to reduce the regional $\mathrm{BC}$ aerosol load, BFB + BMB will be the most critical processes to focus on, but FFB processes will be important to target as well.

The aerosol and gas emission characteristics discussed in this section are one of the key elements in determining the characteristics of southern Asian pollution outflow. Another key element is the regional meteorology, which exhibits important variations on various timescales, from diurnal and synoptic up to seasonal and interannual. The key characteristics of the regional meteorology are described in the next section, prior to discussing the combined effects of emissions and meteorology on the pollution outflow in the sections following that.

\section{Meteorological setting of southern Asia}

The regional meteorology of southern Asia is dominated by the Asian monsoon circulation. A schematic picture of the key surface-level monsoon flow regimes is provided in Fig. 5. This is based on numerous previous studies of the regional flow patterns, especially for INDOEX (e.g., Verver et al., 2001). The main characteristics of these flow patterns are recurrent every year, though there is some interannual variability (discussed for the winter monsoon later in Sect. 4.5). A more detailed overview of the near-surface flow patterns is provided in Fig. 6, which depicts monthly mean surface wind fields; these fields are shown for 2006, corresponding to the ICARB campaign (see Sect. 4.1). Here one can see the remarkably stable southern Asian flow patterns, which persist over long periods of several months each year. The monsoon meteorology can be broken down into three basic periods: the summer or southwest (SW) monsoon (June-September), the winter or northeast (NE) monsoon (November-March), and the monsoon transition periods (MTP), which vary in their exact timing each year, but mostly occur during April and May for the winter-to-summer transition, and in late September to October for the summer-to-winter transition.

The torrential rains of the Asian summer monsoon are well known - for example, Cherrapunji in eastern India receives almost $12 \mathrm{~m}$ of rain per year. Every summer, steady onshore winds bring air from the ocean over the continent (Fig. 5a), which has been heated by the tropical overhead sun. The moist, hot air in the surface layer rises, due to buoyancy as well as orographic forcing over features such as the Western Ghats Mountains at the Indian coast. The rising air cools, causing water to condense, forming cloud droplets and heating the airmasses due to the enthalpy (latent heating) of condensation, which reinforces the buoyant rising motion. This results in moist, deep convection, in which the air parcels can ascend several $\mathrm{km}$ in the cores of cumulus convective towers, often reaching and sometimes even penetrating the tropopause. The lofted air then spreads out, forming massive cirrus anvil clouds which can be clearly seen as a major 

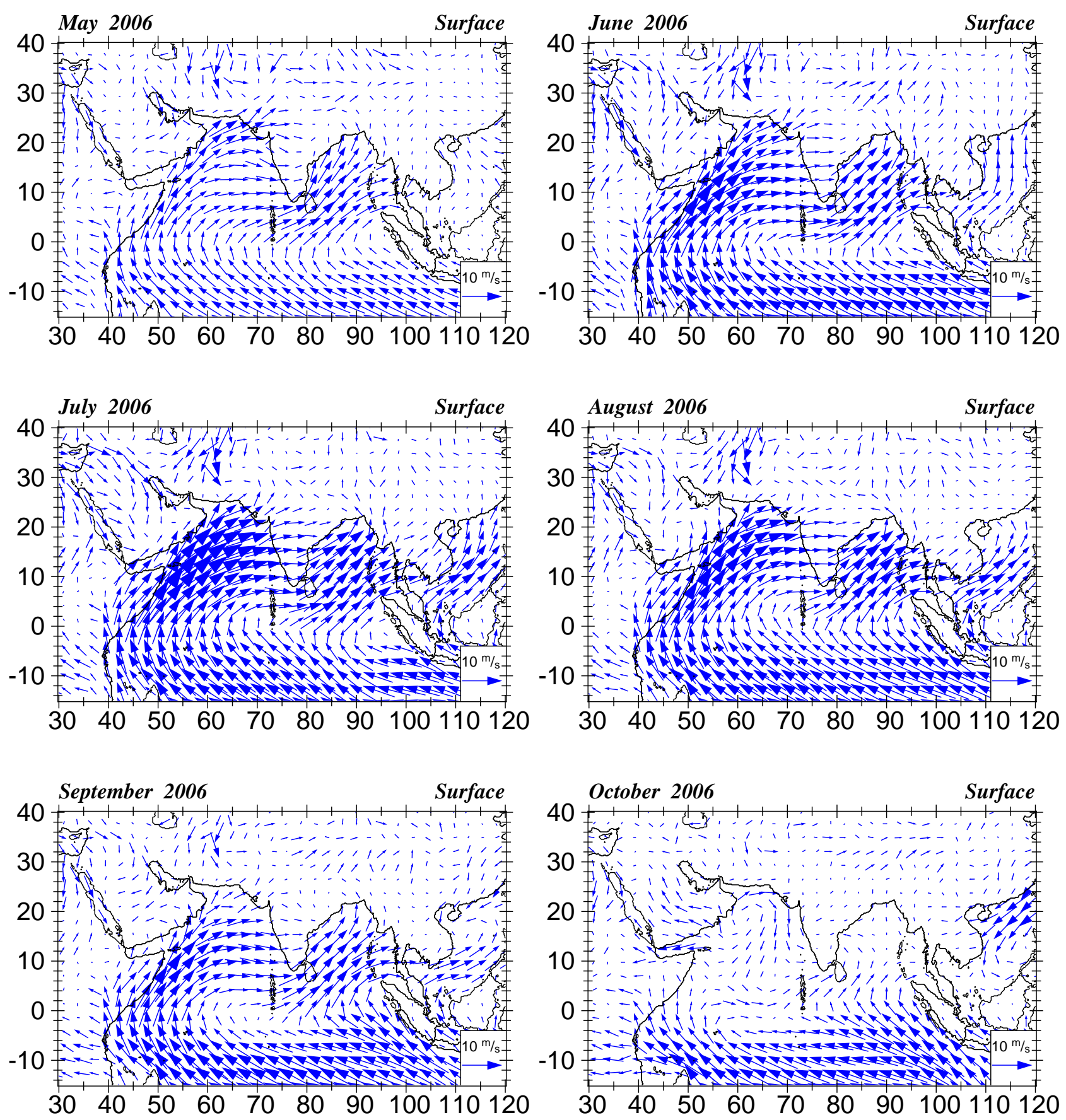

Fig. 6. Surface wind fields over southern Asia for each month in 2006, based on NCEP-GFS data, showing the typical summer and winter monsoon flow patterns that are depicted schematically in Fig. 5.

feature of the region in satellite images. Deep convection can build up to virtually explosive energies, with updraft speeds in this region often exceeding $1 \mathrm{~m} / \mathrm{s}$, and sometimes exceeding $10 \mathrm{~m} / \mathrm{s}$, and can transport largely intact air parcels from the surface to the upper troposphere (UT) in less than an hour.

Once the air reaches the UT, it typically encounters much faster winds than those which are found near the surface. Over southern Asia, the convergence of air masses from the outflow of the monsoon convection results in a high pressure region in the UT typically centered somewhat south of Tibet, around which air tends to flow in an anti-cyclonic (clockwise) direction. Another prevalent UT anticyclone is located to the west of this over Arabia. A snapshot of these two anticyclones is depicted in Fig. 7a. The two anticyclones meander back and forth to the east and west, so that averaged over a month their central north-south branches tend to 

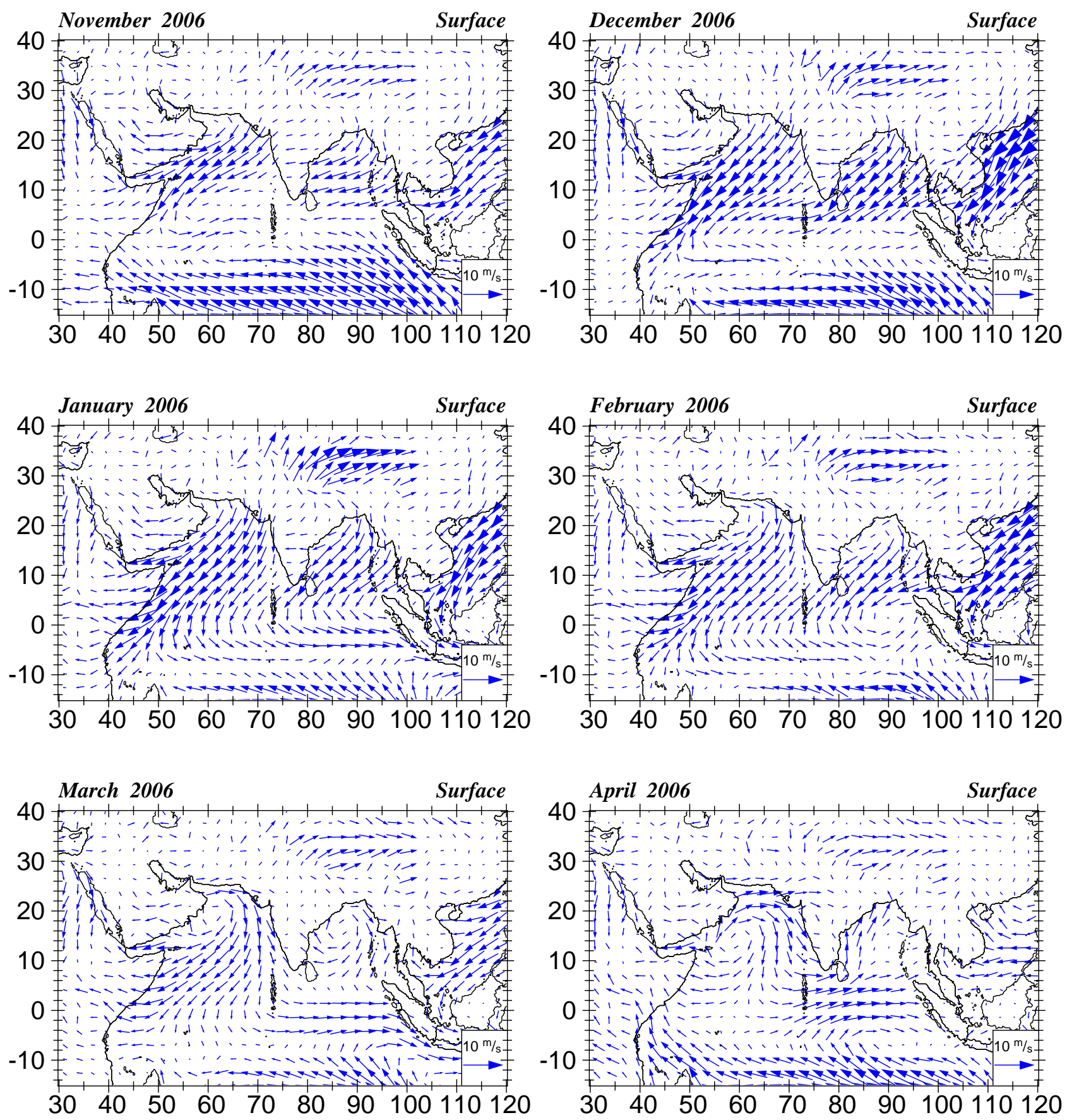

Fig. 6. Continued.

cancel each other out, and the mean circulation of the region is dominated by a large, elongated anticyclone, depicted in Fig. 7b. The combined east-to-west branches on the south side form the tropical easterly jet, which is in contrast to the westerlies which usually prevail in the UT of the NH tropics.

During the summer monsoon, the most frequent intense convection is found in the ITCZ, where air masses from the meteorological Northern and Southern Hemispheres converge. Throughout most of the world the ITCZ is located within a few degrees of the equator. Over Asia in summer, in contrast, it is generally located between $5^{\circ} \mathrm{N}$ and $30^{\circ} \mathrm{N}$, directly over many of the highly populated and polluted regions of southern Asia.

During the winter, the ITCZ migrates south with the solar heating, and is typically found between about $5^{\circ} \mathrm{S}$ and $15^{\circ} \mathrm{S}$. The wintertime winds over much of southern Asia 


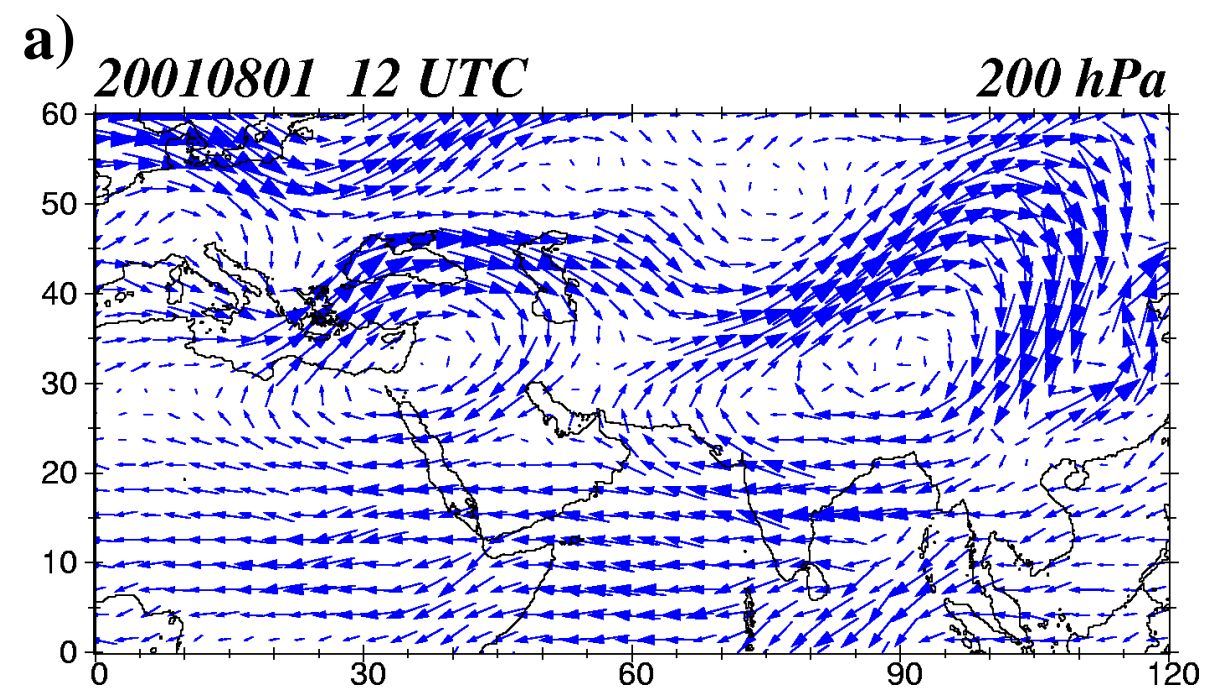

b)

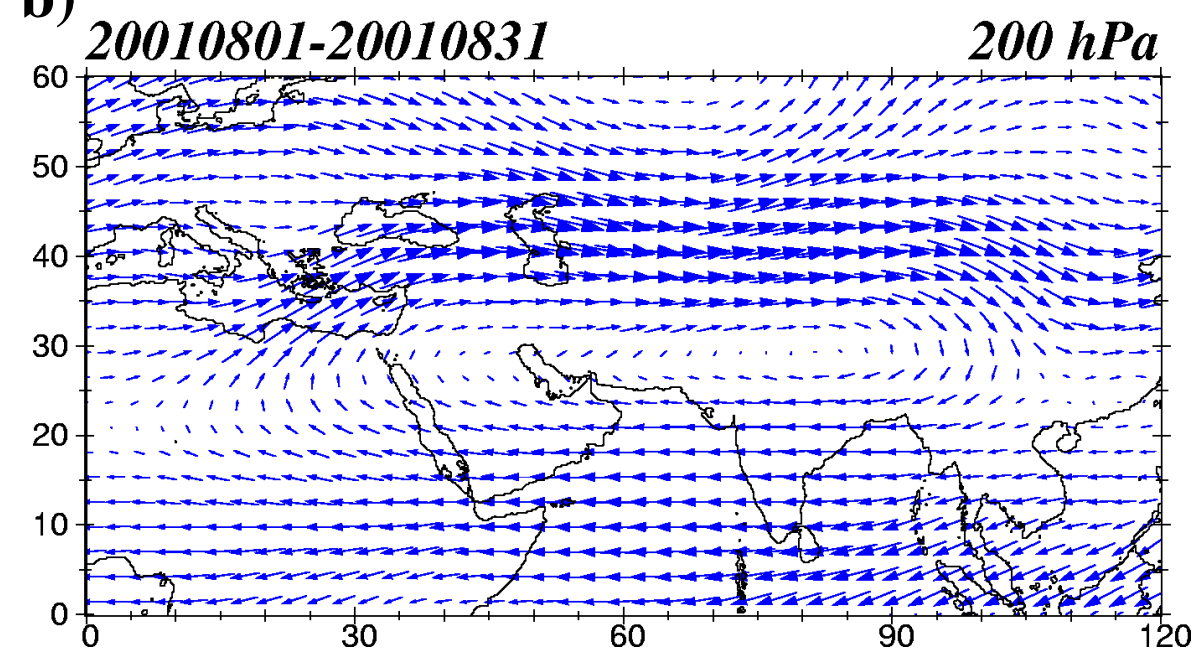

Fig. 7. Wind vector fields over southern Asia, eastern Europe and northern Africa at $200 \mathrm{hPa}$ : (a) instantaneous winds for 12:00 UTC, 1 August 2001; (b) average for August 2001 (based on NCEP-GFS data, adopted from a similar figure in Lawrence et al., 2003a, copyright 2003 by the European Geophysical Union, modified with permission).

are generally from the NE to the SW (see Fig. 6), with some exceptions, especially the easterlies over central India, and the northwesterlies near the Himalayas. This period is known by various terms, including the "northeast monsoon", the "winter monsoon", or alternatively the "dry season". There is little rain or deep convection over southern Asia during this period, and the UT is chemically effectively disconnected from the surface layer (Kunhikrishnan et al., 2004a). Offshore flowing air encounters a largely cloudfree northern Indian Ocean down to the equator. Typical travel times are about 7-10 days to reach the ITCZ (Ethé et al., 2002; de Gouw et al., 2001), where much of the air is then transported upwards in deep convective clouds. A nice demonstration of the typical flow patterns and variability during this period can be seen in the trajectories (Fig. 8) of 17 constant-level balloons which were released from the Indian coastal city of Goa (near Mumbai).

Finally, during the MTP (April-May and SeptemberOctober, see Fig. 6), the ITCZ moves tens of degrees to the north or south over a period of several weeks, the meridional monsoon winds weaken, and strong zonal winds transport emissions from Africa and southeast Asia over the central Indian Ocean.

The rest of this review will focus on the export of pollutants during the winter monsoon (Sect. 4), the summer monsoon (Sect. 5) and the MTPs (Sect. 6). From a meteorological standpoint, the summer monsoon has been studied in far greater depth, particularly by Indian meteorologists over the last century, due to its essential role in the supply of fresh water and thus in human health and agriculture. There 


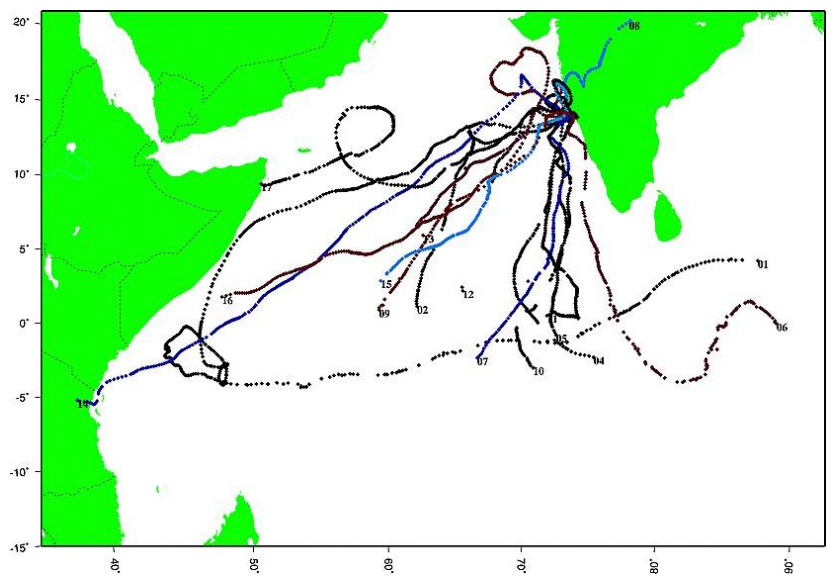

Fig. 8. Trajectories of 17 constant-level balloons launched from Goa, India, during INDOEX (January-March 1999) at pressure levels between about 900 and $800 \mathrm{hPa}$ (from Ethé et al., 2002, copyright 2002 by the American Geophysical Union, reproduced with permission; the data are also presented in Appu et al., 2001).

are various theories about the factors controlling the monsoon behavior, especially the characteristics of the summer rainy period, including the overall amount and distribution of precipitation (spatial and temporal, including the "breaks" in the monsoon rains), which are discussed in a number of reviews of the monsoons (e.g., Gadgil, 2003; Webster et al., 1998). On the other hand, from the perspective of atmospheric chemistry and the export of pollution, the winter monsoon has thus far received the largest amount of attention. This is related to the much reduced removal rate of pollutants in the dry season and the associated potential for near-surface transport, as studied in the INDOEX and preINDOEX field campaigns which are discussed in the next section. The few measurements and modeling studies of long-range export of pollution during the summer monsoon and the MTPs are discussed after that.

\section{The wintertime brown cloud}

This section provides an overview of our understanding of the outflow of atmospheric pollutants from southern Asia during the wintertime, when the monsoon flow is primarily offshore towards the south (Fig. 5b). This outflow results in a thick layer of sunlight reflecting and absorbing aerosols and gases, an "Atmospheric Brown Cloud" covering much of the region, both over continental southern Asia and over the Indian Ocean down past the equator to the ITCZ. This pollution outflow can readily be seen in visible satellite images (see Fig. 9 for an example), and is responsible for a significant perturbation to the regional atmospheric energy balance, especially due to the presence of a significant component of sunlight-absorbing carbonaceous aerosols. In this

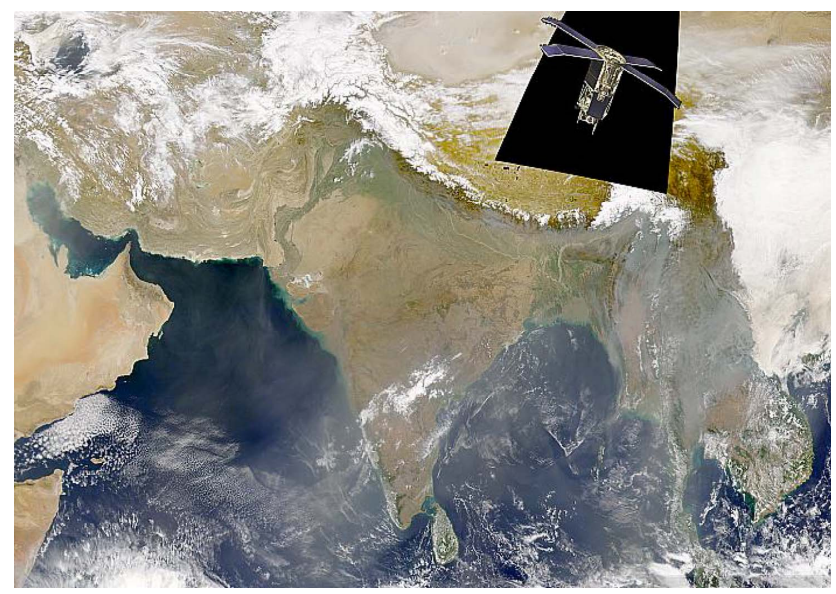

Fig. 9. Satellite image of the SAW-ABC, showing a composite over several days in March, 1999, during the INDOEX campaign (Provided courtesy of the SeaWiFS Project, the NASA/Goddard Space Flight Center and ORBIMAGE).

section we will use the term "Southern Asian Wintertime Atmospheric Brown Cloud" (SAW-ABC) to refer to this loweratmospheric pollution layer.

Numerous studies have examined the vast extent of the SAW-ABC, as well as its origins, chemical composition, and effects on the regional climate. Many of these publications are based on INDOEX, and on subsequent analyses of the INDOEX observations and closely-related modeling studies. However, there have also been several other smaller field campaigns which took place before or after the INDOEX intensive field phase, as well as independent modeling and satellite-based studies that have provided further information on the composition of the atmosphere in this region during the winter months. In this section, we first give an overview of INDOEX and other field campaigns which have examined the SAW-ABC, then describe the meteorological characteristics of the outflow, followed by a discussion of our state of knowledge about the pollutant origins, the chemical composition and chemical processing of gases and aerosols in the SAW-ABC, and its annual variability and potential future trends. We conclude the section with a discussion of the main observed, simulated, and anticipated future effects of the wintertime southern Asian $\mathrm{ABC}$ on the regional climate, e.g., on the surface and lower atmospheric radiation budgets, and on the onset of the summer monsoon and its precipitation characteristics.

\subsection{Overview of INDOEX and other regional field campaigns}

Most of our understanding of the outflow in the SAW-ABC derives from the Indian Ocean Experiment (INDOEX), a massive undertaking in several phases extending over five years, starting with an exploratory pre-INDOEX cruise in 

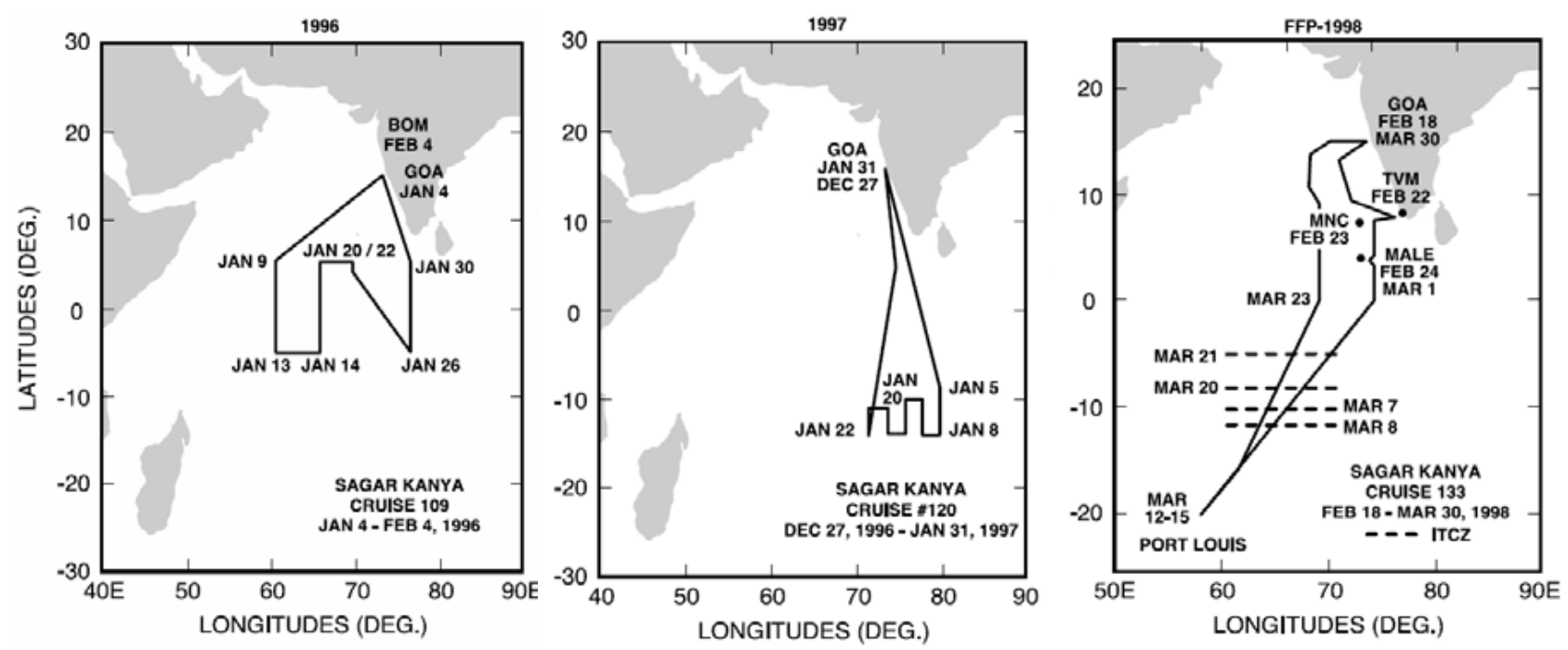

Fig. 10. Cruise tracks of the 1996, 1997 and 1998 RV Sagar Kaya cruises (redrawn from Mitra, 1999, copyright 1999 by the Indian Academy of Sciences, reproduced with permission).

Table 4. Listing of the ship cruises performed during the preINDOEX and INDOEX campaigns.

\begin{tabular}{ll}
\hline Ship (origin) & Period \\
\hline RV Malcolm Baldridge (USA) & 12 Mar-22 Apr 1995 \\
RV Sagar Kanya (India) & 4 Jan-4 Feb 1996 \\
RV Sagar Kanya (India) & 27 Dec 1996-31 Jan 1997 \\
RV Sagar Kanya (India) & 18 Feb-30 Mar 1998 \\
RV Sagar Kanya (India) & 20 Jan-12 Mar 1999 \\
RV Ronald H. Brown (USA) & 22 Feb-1 Apr 1999* \\
\hline
\end{tabular}

* Note that data was also collected on the RV Ronald H. Brown in the southern Indian Ocean during the period 11-19 February, as part of the Aerosols99 campaign (Bates et al., 2002).

1995 and culminating in an Intensive Field Phase (IFP) from January to April 1999. This section provides an overview of INDOEX and several smaller field campaigns along with ongoing satellite observations and model studies.

Three major, interrelated objectives were noted in the INDOEX proposal (http://www-indoex.ucsd.edu/publications/ proposal/):

- assess the significance of sulfates and other continental aerosols for global radiative forcing;

- assess the magnitude of the solar absorption at the surface and in the troposphere including the ITCZ cloud systems; and

- assess the role of the ITCZ in the transport of trace species and pollutants and their resultant radiative forcing.

As made clear in the discussion below, substantial progress was made not only on these objectives, but also on many other issues relevant to understanding the SAW$\mathrm{ABC}$ and its effects. In order to achieve this, various types of measurements from numerous platforms were needed. Summaries of these are provided in various INDOEX publications, including the INDOEX Operations Plan (Moore et al., 1999) and the main campaign overview paper (Ramanathan et al., 2001), as well as several other overviews (Mitra, 1999, 2001, 2004; Lelieveld et al., 1999, 2001). INDOEX consisted of a First Field Phase (FFP) in 1998 and an Intensive Field Phase (IFP) in 1999, along with a few cruises and ground-based observations during the preINDOEX phase (1995-1997). Table 4 provides a listing of the ship cruises during the various phases of INDOEX. The tracks of the 1996-1999 cruises are shown in Figs. 10 and 11 (the 1995 cruise is not shown; the track was from Durban, South Africa to Colombo, Sri Lanka, mostly on a south-tonorth route along about $55^{\circ} \mathrm{E}$ ). Five aircraft were involved in the INDOEX IFP. Three were based out of the Malé Airport in the Maldives: the NCAR C-130, the Dutch Cessna Citation, and the French Mystére 20 ("M20"). In addition, two aircraft were based out of the Seychelles, as part of the APE-THESEO campaign (Stefanutti et al., 2004): the German DLR Falcon, and the Russian Geophysica. The operations of these two aircraft were coordinated with the INDOEX operations; however, they were mostly focused on cirrus properties in the upper troposphere, and will not be referred to in the discussion in this section. The flight trajectories for the two main aircraft measuring the SAW-ABC outflow in the northern Indian Ocean, the NCAR C-130 and the Dutch Citation, are shown in Figs. 12 and 13, respectively. The French Mystére 20 flights with a backscatter lidar were mostly flown into the continental outflow to the north of the Maldives. 

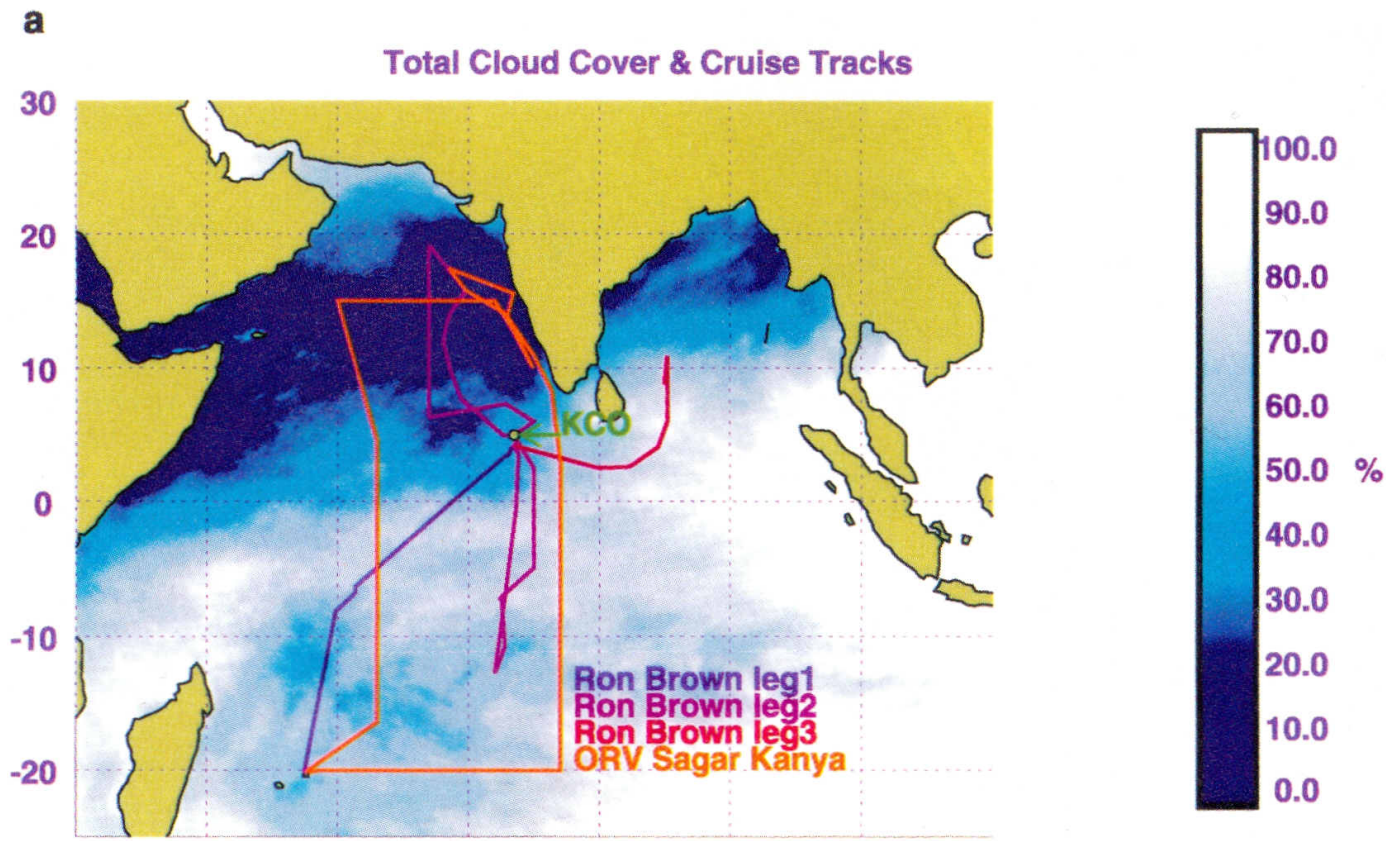

Fig. 11. Cruise tracks of the 1999 RV Sagar Kaya and RV Ronald H. Brown cruises, overlaid on the mean total cloud cover from JanuaryMarch 1999 (retrieved from the METEOSAT-5 satellite radiances) (from Ramanathan et al., 2001, copyright 2001 by the American Geophysical Union, reproduced with permission).

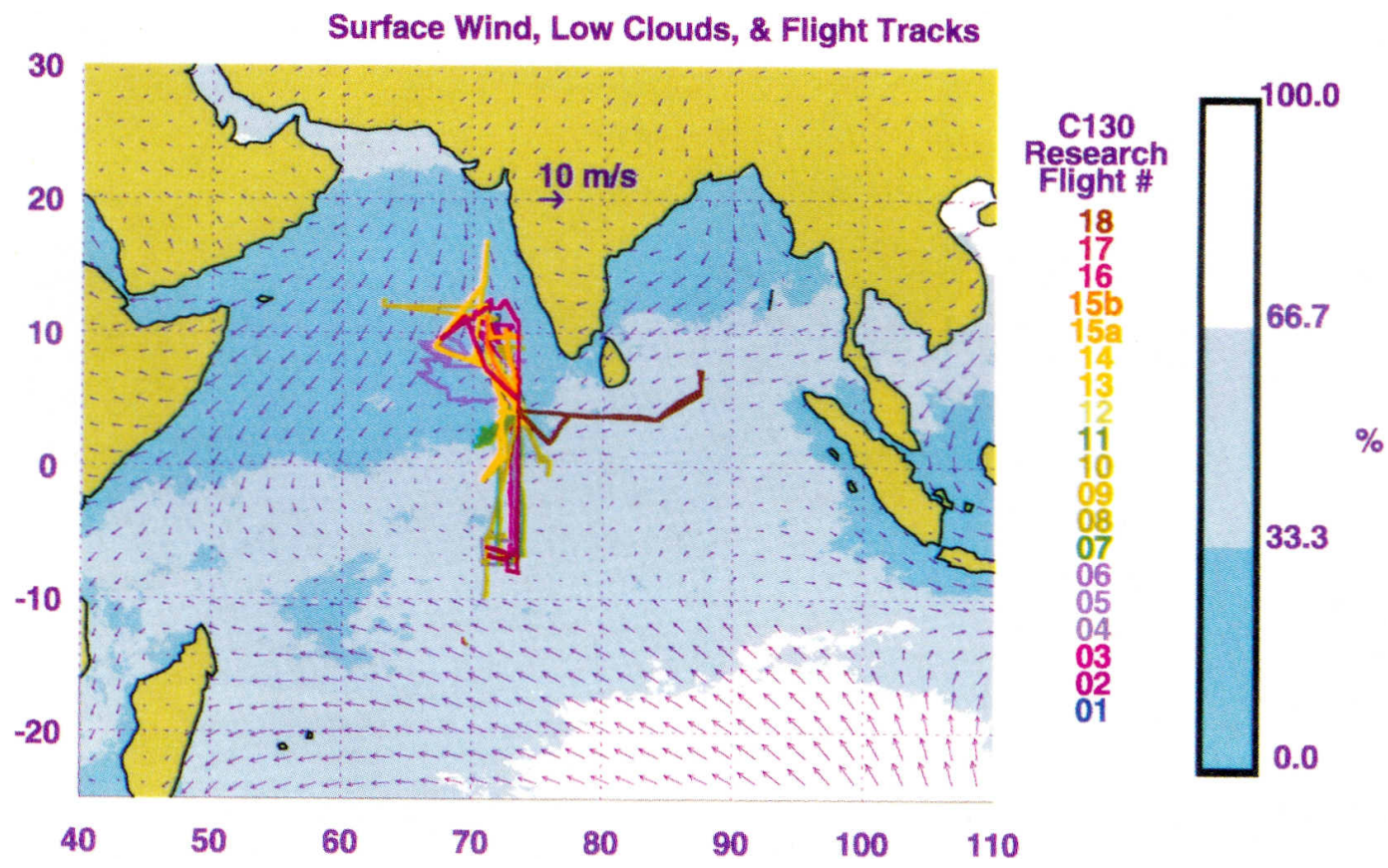

Fig. 12. Flight tracks of the NCAR C-130 during the INDOEX intensive field phase (IFP), overlaid on the mean surface wind data from the NCEP/NCAR reanalysis (from Ramanathan et al., 2001, copyright 2001 by the American Geophysical Union, reproduced with permission).

For the INDOEX IFP, along with the ships and aircraft, a ground station with extensive instrumentation was installed at the Kaashidhoo Climate Observatory (KCO) in the Maldives, and surface observations were made at several sites along the Indian west coast, including Trivandrum and Goa. Balloon sondes were launched from $\mathrm{KCO}$ and from the ships, measuring ozone and meteorological parameters, and constant level balloons to observe air mass trajectories were 
launched from Goa (see Fig. 8). Finally, retrievals were made available from several satellites, among them the EUMETSAT (European Organisation for the Exploitation of Meteorological Satellites) geostationary weather satellite Meteosat5, which was relocated in early 1998 to $63^{\circ} \mathrm{E}$, over the Indian Ocean, to support the campaign.

In addition to these diverse observations, numerous model simulations were performed in support of the INDOEX measurements, both in the planning phase prior to the campaign, as well as for guiding the measurements during the campaign through meteorological forecasts and "chemical weather forecasts". The chemical weather forecasts encompassed both aerosols (Collins et al., 2001; Rasch et al., 2001) and ozone-related gases (Lawrence et al., 2003a); INDOEX was the first field campaign to use global, tropospheric, chemical weather forecasts, and their successful application paved the way for making such forecasts an important component of the flight planning of nearly all atmospheric chemistry field campaigns already during the first few years after INDOEX, as summarized in Lawrence et al. (2003a; 2005).

After INDOEX, numerous individual research cruises were conducted examining the SAW-ABC outflow in the Arabian Sea, the Bay of Bengal, and the central Indian Ocean. Among these were: a cruise with the Dutch RV Pelagia in the western Indian Ocean in April 2000 (Warneke and de Gouw, 2001); the BOBEX (Bay of Bengal Experiment) cruise with the RV Sagar Kanya during FebruaryMarch 2001 (Naja et al., 2004; Lal et al., 2006; Ramachandran and Jayaraman, 2003); the PESO (Pilot Expedition to the Southern Ocean) cruise with the RV Sagar Kanya during January to April 2004, from western India down to the Southern Ocean and back (Moorthy et al., 2005a; Pant et al., 2009), and a similar cruise during January to April 2006, reaching Antarctica with the Russian RV Akademik Boris Petrov (Vinoj et al., 2007). These have been complimented by island measurements, in particular ongoing measurements in the Maldives at the ABC Maldives Climate Observatory in Hanimadhoo ("MCOH"; Ramanathan et al., 2007a), along with others, for instance, aerosol observations made on Minicoy island in the Arabian Sea (Moorthy and Satheesh, 2000) and Port Blair in the Bay of Bengal (Moorthy et al., 2003). An effort to integrate some of the observations from the mainland and islands into a focused network is underway in a new program called ARFI (Aerosol Radiative Forcing over India; Satheesh et al., 2009). A particular highlight of the island-based measurements has been a small campaign called MAC (Maldives AUAV Campaign), which took place in March 2006, using AUAVs (automated unmanned aerial vehicles) flying in a stacked configuration to investigate the modification of the solar radiation budget by aerosols in the SAW-ABC (Ramanathan et al., 2007b; Ramana et al., 2007; Corrigan et al., 2008).

By far the largest effort following INDOEX has been the Integrated Campaign for Aerosol, gases, and Radiation Budget (ICARB, sponsored by the Geosphere Biosphere

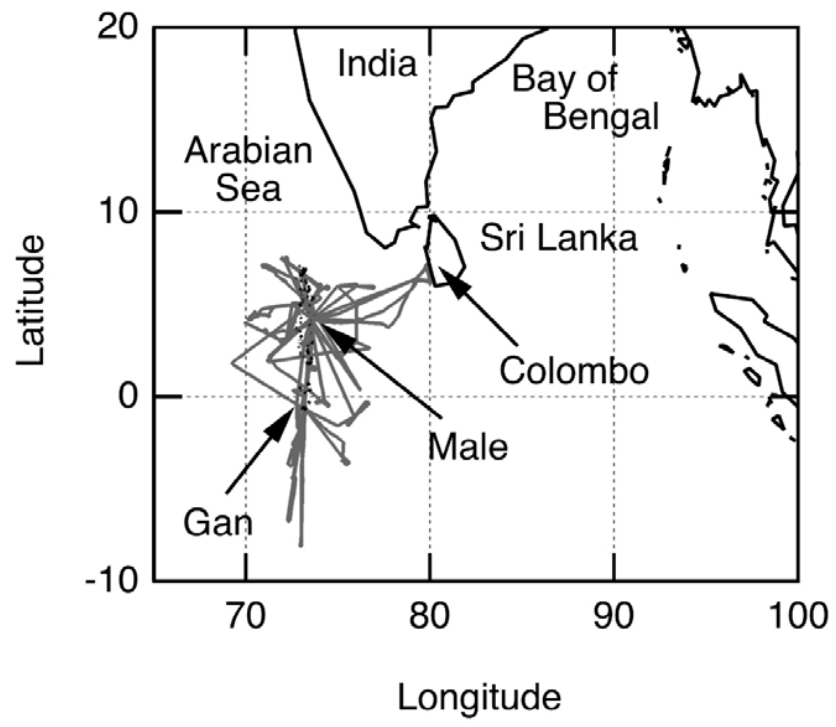

Fig. 13. Flight tracks of the Dutch Cessna Citation during the INDOEX intensive field phase (IFP) (from de Gouw et al., 2001, copyright 2001 by the American Geophysical Union, reproduced with permission).

Programme of the Indian Space Research Organization ISRO-GBP), conducted over the Arabian Sea, the Bay of Bengal and northern Indian Ocean during March-May 2006. An overview of the campaign is given by Moorthy et al. (2008), and numerous papers with results relevant to the SAW-ABC are in a special issue of the Journal of Earth System Science (vol. 117, No. S1, July 2008), along with further results being published elsewhere (e.g., Satheesh et al., 2009). The primary objective of ICARB was "to characterize the physico-chemical properties and radiative effects of atmospheric aerosols and trace gases over the Indian landmass and the adjoining oceanic regions of the Arabian Sea, northern Indian Ocean, and Bay of Bengal" (Moorthy et al., 2008). An overview schematic of the campaign operations is given in Fig. 14. ICARB included ground-based measurements at various sites in India and on island stations (Colombo, Minicoy and Port Blair), an extensive ship cruise with the RV Sagar Kanya, and 26 flights with the Indian NRSA Beechcraft 200 aircraft, based out of five different locations in India during the campaign (see Fig. 15 for details). The observations period bridges the winter monsoon period and the monsoon transition period of late spring; in particular, the ICARB Sagar Kanya cruise leg in the Bay of Bengal was still during the winter monsoon, and some of these results will be noted in this section, while the Arabian Sea leg was mainly during the monsoon transition period, and will be discussed in Sect. 6. A second phase of ICARB, known as W_ICARB, was conducted during December, 2008 and January, 2009, with an extensive cruise of the RV Sagar Kanya covering much of the Bay of Bengal, and flights with the NRSA Beechcraft 200 across southern India and over the 


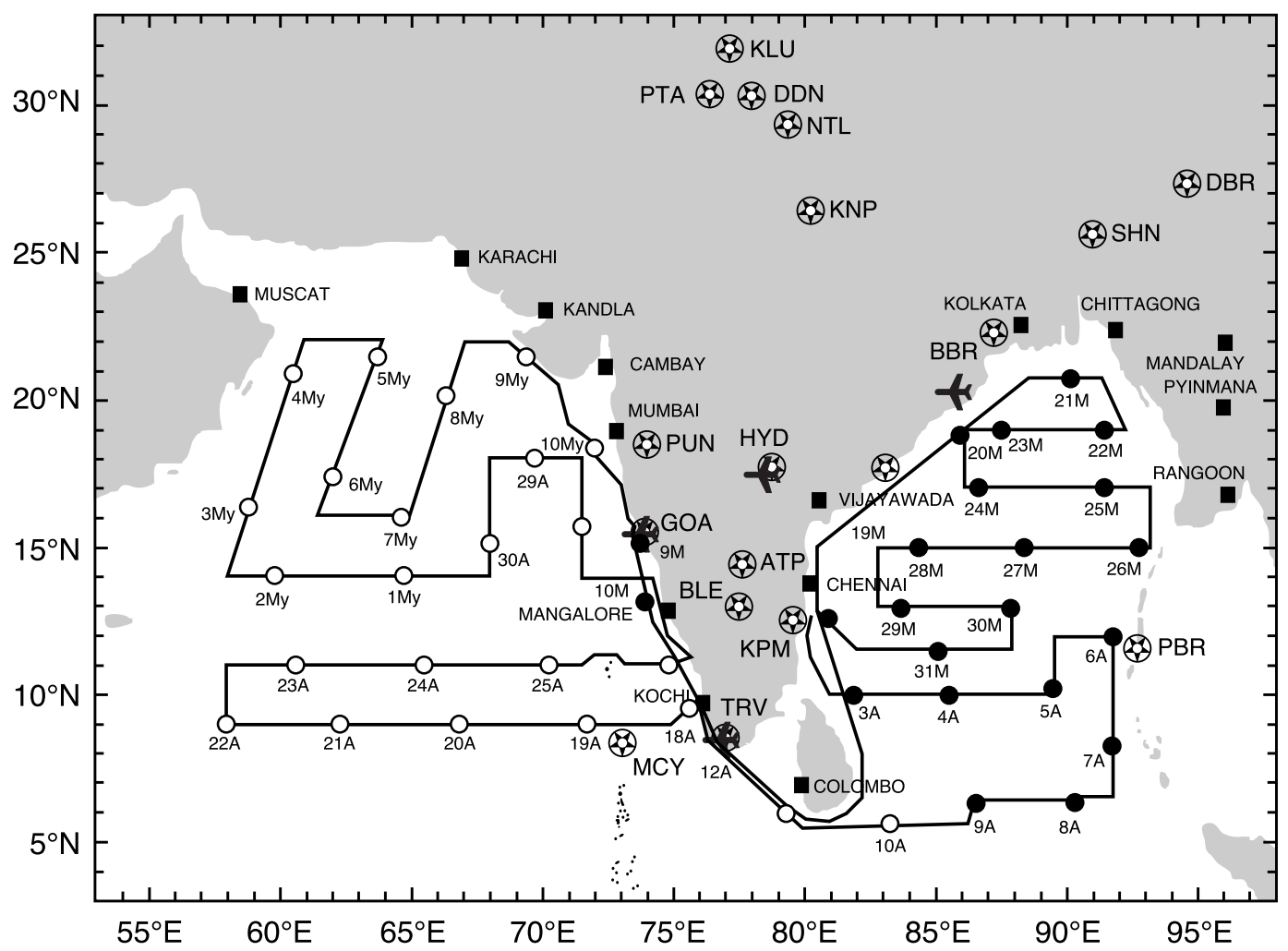

Fig. 14. Schematic representation of the operational phase of ICARB during March-May 2006. The continuous line across the ocean shows the SK223 cruise track. The points on the lines indicate the ship's location at 05:30 UTC for the date identified below it; the number stands for the day and the month is indicated by M for March, A for April, and My for May. The aircraft symbols show the bases from which the aircraft sorties were made. The other points represent the fixed stations on land where aerosol and gas measurements were made (redrawn from Moorthy et al., 2008, copyright 2008 by the Indian Academy of Sciences, reproduced with permission).

eastern Arabian Sea; papers on W_ICARB are just beginning to appear in the literature (e.g., Asatar and Nair, 2010; Babu et al., 2010; Subrahamanyam et al., 2010), and are expected to lead to an improved understanding of the distribution and origins of pollution in the broader Bay of Bengal region; a few initial highlights have been included in the discussion below.

It is worth noting that in addition to these observations in the SAW-ABC outflow, many continental source-region observations have been made at sites throughout India and other southern Asian countries, which have provided numerous insights into urban and rural aerosol and gas pollutants. Although several observations, particularly at coastal sites, will be referred to in the following sections in order to support various points, since the focus in this paper is on the pollutant outflow, we will not attempt to provide a comprehensive overview of the continental observations as well. However, in the context of this section it is worth briefly discussing two recent, major field campaigns which have provided significant information on the continental pollution levels over the last several years: ICARB (2006), and a 2-part campaign, also sponsored by the ISRO-GBP, in February and December 2004. ICARB was already noted above; in addition to the outflow observations, it included an intense, coordinated sampling at several continental sites (e.g., Beegum et al., 2008; Dumka et al., 2008; Singh et al., 2008; Badarinath and Kharol, 2008; Niranjan et al., 2008).

The first of the 2004 ISRO-GBP campaigns (February 2004) was focused on using mobile labs which traveled over $15000 \mathrm{~km}$ together and covered a substantial crosssection of India. This campaign found notable pollution levels throughout the country (Moorthy et al., 2005b; Niranjan et al., 2005; Jayaraman et al., 2006; Nair et al., 2006; Singh et al., 2006). Coastal regions were found to usually have higher aerosol mass densities $\left(50-150 \mu \mathrm{g} / \mathrm{m}^{3}\right)$ than in the semiarid interior continent (typically around or below $30 \mu \mathrm{g} / \mathrm{m}^{3}$ ); small regions of enhanced aerosol mass densities were found around industrialized and urban centers in both coastal and inland regions. An interesting hypothesis put forth from the observations along the eastern coast (Niranjan et al., 2005) is that part of the aerosol outflow from the eastern Indo-Gangetic Plain over the Bay of Bengal, where the small urban aerosols will pick up moisture and tend to grow rapidly into accumulation mode, may end up being recirculated back over the central and southern eastern Indian coast, contributing substantially to the high aerosol optical 


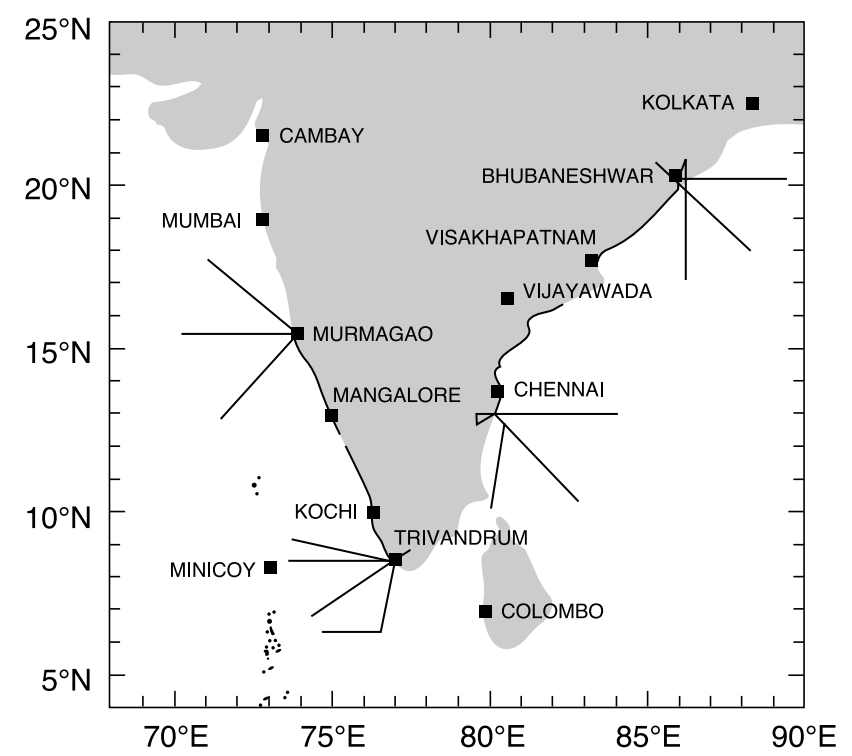

Fig. 15. Flight tracks of the Indian NRSA Beechcraft 200 during the ICARB campaign (redrawn from Moorthy et al., 2008, copyright 2008 by the Indian Academy of Sciences, reproduced with permission).

depths (AODs) observed there (the AOD is an indication of the amount of radiation at a given wavelength that is scattered or absorbed as the beam passes through the atmosphere; for an AOD of 1.0, the amount of radiation which is transmitted is $\mathrm{e}^{-1}$ of the intensity it had before passing through the atmosphere). Another important finding from this campaign was that ozone levels tended to be higher downwind of heavily populated regions than in the urban centers (Lal et al., 2008b; this is discussed further in Sect. 4.3.2).

The second ISRO-GBP campaign (December 2004) focused particularly on the Indo-Gangetic Plain region, which was expected to be highly polluted based both on the impressions from the first campaign, as well as expectations from emissions distributions and population density databases (see the examples in Fig. 2). During the campaign, seven stations were located in the Indo-Gangetic Plain region, plus one station in the Himalayas slightly to the north, providing a contrast in the pollution levels. The urban sites included a station in New Delhi, which was especially focused on understanding the "Delhi fog", severe haze events which occur repeatedly during the wintertime, with substantial ramifications such as regular shut-downs of the international airport (also extending to other urban regions around Delhi). The measurements (Tripathi et al., 2006; Ganguly et al., 2006; Ramachandran et al., 2006; Dey and Tripathi, 2007; Nair et al., 2007) clearly showed the high levels of aerosol pollution in this region; similarly, trace gas observations (Lal et al., 2008a) showed very high levels of CO (frequently above $1000 \mathrm{nmol} / \mathrm{mol}$ ) and $\mathrm{NO}_{\mathrm{x}}$ (frequently exceeding $20 \mathrm{nmol} / \mathrm{mol}$ ). The mean aerosol loads were about
$280 \mu \mathrm{g} / \mathrm{m}^{3}$, ranging from $100-400 \mu \mathrm{g} / \mathrm{m}^{3}$, resulting in mean aerosol optical depths (at $500 \mathrm{~nm}$ wavelength) in the range of 0.4-1.4. The single scattering albedo (SSA, the ratio of scattering to the sum of scattering and absorption) was as low as 0.76 (at $500 \mathrm{~nm}$ wavelength) during fog events at the Hissar site (to the north of Delhi), indicating substantial absorption in some regions; this is in turn due to significant BC levels, measured to typically be in the range of $10-30 \mu \mathrm{g} / \mathrm{m}^{3}$, up to $65 \mu \mathrm{g} / \mathrm{m}^{3}$ during fog events in Delhi. As we will discuss below, in the continental outflow single scattering albedos are typically somewhat higher than this, suggesting that during transport the atmospheric processing of the particulates may still add scattering compounds such as sulfate and organics, whereas deposition processes of the presumably well-mixed aerosols efficiently removes all types of aerosol compounds, including BC.

\subsection{Outflow characteristics}

\subsubsection{Outflow channels and layers}

The outflow of pollutants contributing to the SAW-ABC occurs primarily in two distinct layers: a pollutant plume within the marine boundary layer (MBL), from the surface to the MBL cap at about $800-1000 \mathrm{~m}$, and in an elevated layer between about $1-3 \mathrm{~km}$. The flow in these two layers is qualitatively similar and dominated by the NE monsoon flow, though in the upper layer the airmasses generally have a slightly more easterly origin (Ramanathan et al., 2001; Lobert and Harris, 2002). The flow in the surface layer has been characterized into several different channels, which are similar near the surface and in the elevated outflow layer, except that the airmasses in the elevated layer will generally originate more frequently from the heavily populated regions towards the east, in southern and southeastern Asia. Three primary flow channels were initially suggested by $\mathrm{Kr}$ ishnamurthi (1997a, b), and a fourth was added following INDOEX by Verver et al. (2001). These four channels are depicted in Fig. 5b; from east to west they are: (1) western Arabian Sea; (2) Indo-Pakistan Desert off the Indian west coast; (3) western Bay of Bengal; (4) SE Asia. The channels are active intermittently, depending on the weather systems that are present in the region. Table 5 shows that channel 1 was the most persistent during the core INDOEX IFP, being active over $80 \%$ of the time, while channels 2 and 3 were active about half of the time, and channel 4 only about $1 / 3$ of the time. Channels 2 and 3 were most relevant to the SAWABC measurements during the INDOEX campaign, which were made mainly in the region south and southwest of the Indian subcontinent (Lelieveld et al., 2001). An interesting side-note on the outflow channels is worth making here: it was recently discovered (Anderson, 2009) that the airflows basic to the SAW-ABC are also relevant for the traveling routes of insects, helping to explain the sudden appearance each year starting in October of millions of dragonflies on 
Table 5. Number of days (and relative frequency in \%) that each of the four flow channels was present over the north Indian Ocean area during February and March 1999 (from Verver et al., 2001, copyright 2001 by the American Geophysical Union, reproduced with permission).

\begin{tabular}{lrrrr}
\hline & $\begin{array}{r}\text { Channel 1 } \\
\text { (West Arabian Sea) }\end{array}$ & $\begin{array}{r}\text { Channel 2 } \\
\text { (Indo-Pakistan Desert off } \\
\text { West Coast of India) }\end{array}$ & $\begin{array}{r}\text { Channel 3 } \\
\text { (West Bay of Bengal) }\end{array}$ & $\begin{array}{r}\text { Channel 4 } \\
\text { (SE Asia) }\end{array}$ \\
\hline February 1999 & $26(44 \%)$ & $12(20 \%)$ & $26(44 \%)$ & $15(25 \%)$ \\
March 1999 & $24(41 \%)$ & $21(36 \%)$ & $6(10 \%)$ & $5(8 \%)$ \\
Total & $50(85 \%)$ & $33(56 \%)$ & $32(54 \%)$ & $20(34 \%)$ \\
\hline
\end{tabular}

the Maldives, where they would normally not be expected in significant numbers (since they cannot reproduce there due to the lack of open fresh water). The insects may even be providing sustenance for migratory birds that also make use of the tailwind to travel between India and Africa. It is unclear whether the substantial pollution in the SAW-ABC may be having an impact on these insects and migratory birds.

The separation of the outflow into a surface and an elevated layer was observed repeatedly during INDOEX and has been brought out in numerous analyses of the observations. The origin of the elevated layers was initially the subject of considerable debate following INDOEX. Since then, they have been clearly attributed to the effects of the land-sea breeze, a well-known meteorological phenomenon (Miller et al., 2003) which is caused by the temperature differences over the sea and the land near the coast. During the day, the land heats up to temperatures exceeding the sea surface temperature (SST); the dry convective lofting of the warmed surface-layer airmasses over the land combined with the resultant pressure gradient results in a circulation with onshore flow ("sea breeze") near the surface and a return flow at about 800-1000 $\mathrm{m}$ altitude, as depicted in Fig. 16. At night, the land cools off to temperatures below the SST, and the reverse circulation ("land breeze", see Fig. 20) develops. Due to the largely cloud-free conditions and the strong tropical solar radiation, a relatively strong land-sea breeze develops at the Indian east coast, although it is somewhat complicated by orographic flows due to the Western Ghats coastal mountain range (Mohanty et al., 2001), which have a mean altitude of about $800 \mathrm{~m}$ a.s.l. (above sea level).

The coastal airmasses lofted by the sea breeze into the region above the MBL are known as the "land plume"; in the context of the SAW-ABC they have also often been referred to simply as the "elevated layer". Evidence of a strong land plume had already been noted during the pre-INDOEX cruises, based on temperature profiles from radiosondes ( $\mathrm{Ra}-$ man et al., 2002), but the substantial implications that this has for aerosol and trace gas pollutant outflow first became clear during INDOEX. During the campaign, the elevated pollution layer was observed in various aerosol and trace gas measurements from several platforms, and it quickly became clear that for many components, the majority of the outflow (e.g., in terms of AOD or component mass) occurs in this elevated layer, rather than directly in the MBL (e.g., Manghnani et al., 2000; Lelieveld et al., 2001; Ramanathan et al., 2001; Léon et al., 2001; Reiner et al., 2001; Müller et al., 2001a, b; Sheridan et al., 2002; Chazette, 2003; Franke et al., 2003); similar observations have also been made since INDOEX, for example lidar aerosol vertical profile measurements clearly showing this phenomenon at Pune (Raj et al., 2008) and off both the east and west coasts during ICARB (Satheesh et al., 2009). Furthermore, although most of the studies of the elevated layers have been based on the INDOEX observations in the Arabian Sea, similar elevated pollution layers have also been observed off the east coast of India over the Bay of Bengal, especially during ICARB (e.g., Moorthy et al., 2008; Babu et al., 2008; Murugavel et al., 2008).

The formation mechanism of the land plume, based on the analysis of Simpson and Raman (2004), is sketched in Fig. 16a, and its effect on the potential temperature profiles near the surface is shown in Fig. 16b. Over land, the strong heating at the surface causes a superadiabatic (unstable) temperature profile immediately above the surface, and a wellmixed boundary layer, with a constant potential temperature, which then increases again in the stable layer above the planetary boundary layer. In the MBL close to the coast, the temperature profile is stable, transitioning to a well-mixed MBL capped by an inversion a few hundred $\mathrm{km}$ away from the coast. An observation of a potential temperature profile closely matching these idealized characteristics is shown in Fig. 17a, along with the collocated ozone profile (Fig. 17b), depicting the elevated pollution levels in the land plume. The elevated pollution layers vary in their form and degree of pollution, with a further example of an extreme case of a land plume with $\mathrm{O}_{3}$ mixing ratios approaching $100 \mathrm{nmol} / \mathrm{mol}$ shown in Fig. 18c. In this case, the land plume is connected to relatively rapid outflow (Fig. 18a), and to a shift in the wind direction to more easterly origins above the boundary layer (Fig. 18b), characteristic for the wind direction profiles in this region. Numerous gases as well as aerosol properties such as absorption and scattering were observed to be present at enhanced mixing ratios in the elevated layers, as depicted in the examples in Fig. 19 (note that in the text, we will use the SI units nmol/mol, although this and several other figures 
(a)

NOT TO SCALE

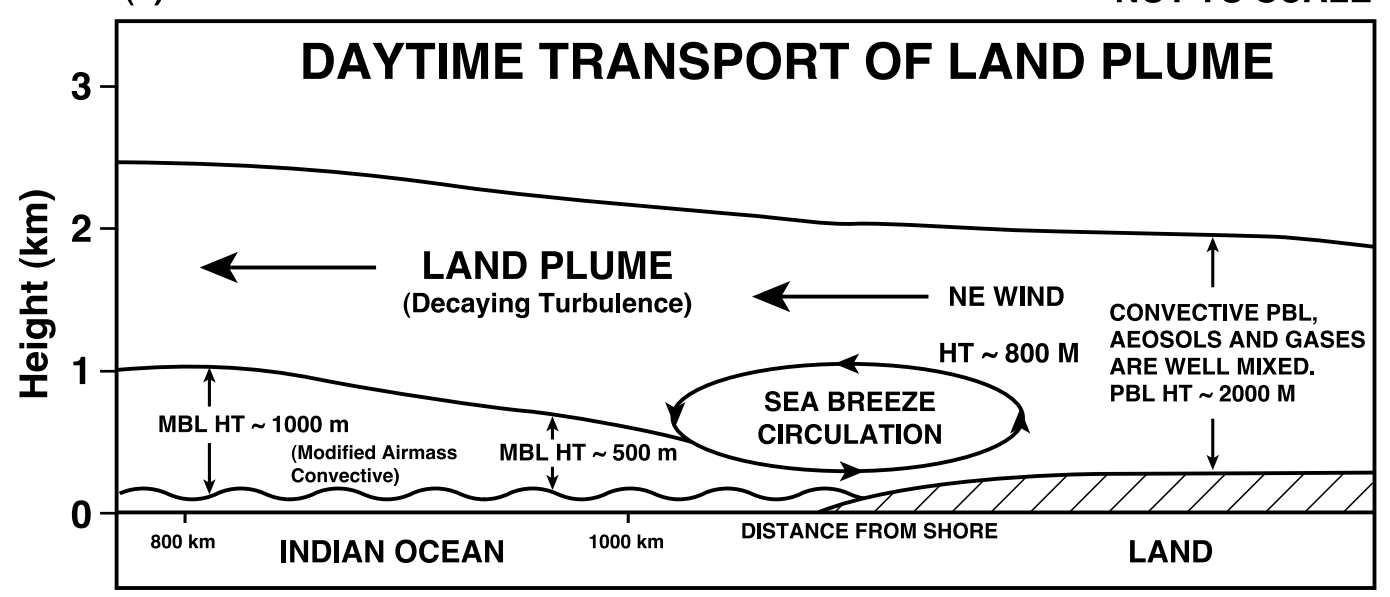

(b)

NOT TO SCALE

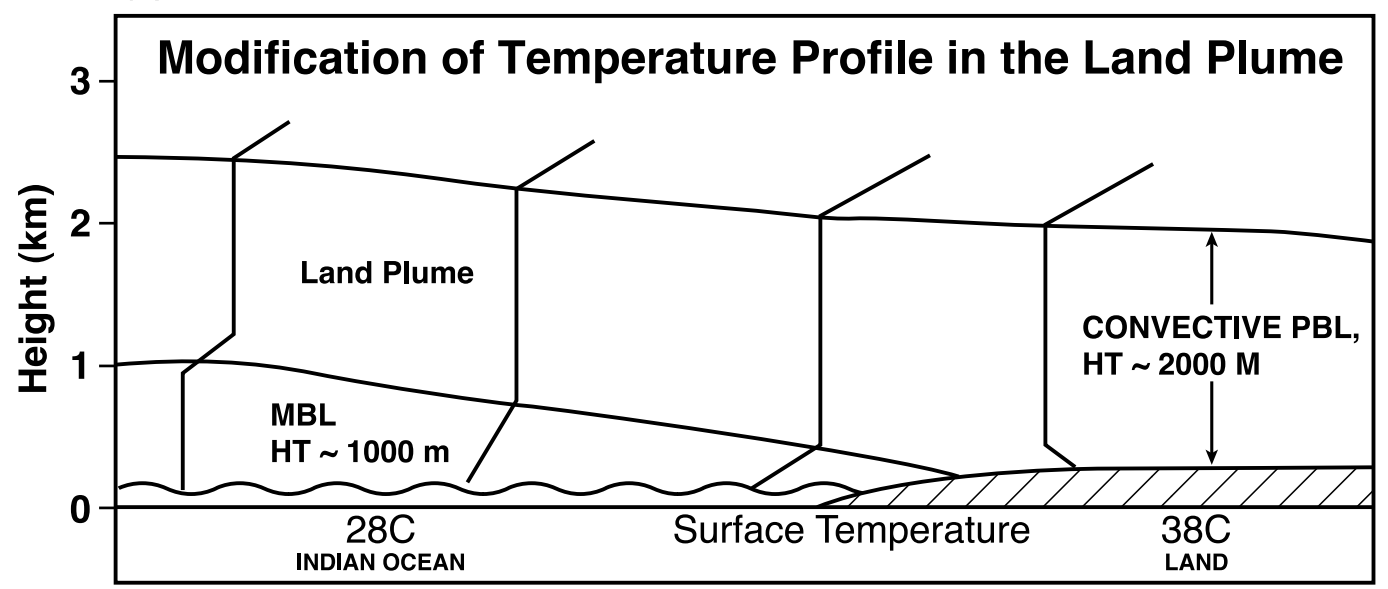

Fig. 16. Conceptual depiction of the interaction between the coastal sea breeze circulation and the land plume over the Indian Ocean during day (redrawn from Simpson and Raman, 2004, copyright 2004 by the Springer Verlag, reproduced with permission).

taken from the published literature use the equivalent units "ppb" or "ppbv" - parts per billion volume fraction, implying a molar fraction for an ideal gas). Elevated layers such as these are frequently - though not always - present in observations made in the region during INDOEX and other measurements campaigns. Due to the horizontal scale on which the land-sea breeze occurs, which off the Indian west coast was found to be between 80 and $130 \mathrm{~km}$ (Subrahamanyam et al., 2001), it is generally difficult to capture these effects with global models, as has been noted by de Laat et al. (2001a) and Lelieveld et al. (2001). Additional mechanisms may also contribute to the formation of the elevated layers, especially over the Bay of Bengal, where a continental high pressure system over the Indian peninsula links the pollution outflow back to the Indo-Gangetic Plain region of northern central India, and also partially inhibits the direct transport of polluted airmasses from India out over the Bay of Bengal. For this region, Aloysius et al. (2008) have hypothesized that the convergence of winds from central and northern India at higher altitudes (around 500-600 hPa), together with subsidence associated with negative vorticity in the region, could potentially contribute to elevated pollution layer over the Bay of Bengal. Their data show a correlation of AOD with aerosol flux convergence and flux vorticity, supporting a role for this mechanism.

Despite the potential contributions to the elevated layers from various mechanisms, recent strong support for the primary role of the land-sea breeze in producing these elevated layers has been provided by simulations with a mesoscale model (Simpson and Raman, 2006) and with a global model which includes a zoom feature allowing the resolution to be increased to better than $0.5^{\circ}$ in the horizontal over the zoom region (Verma et al., 2006); the high zoom resolution of the global model allows it to reproduce 

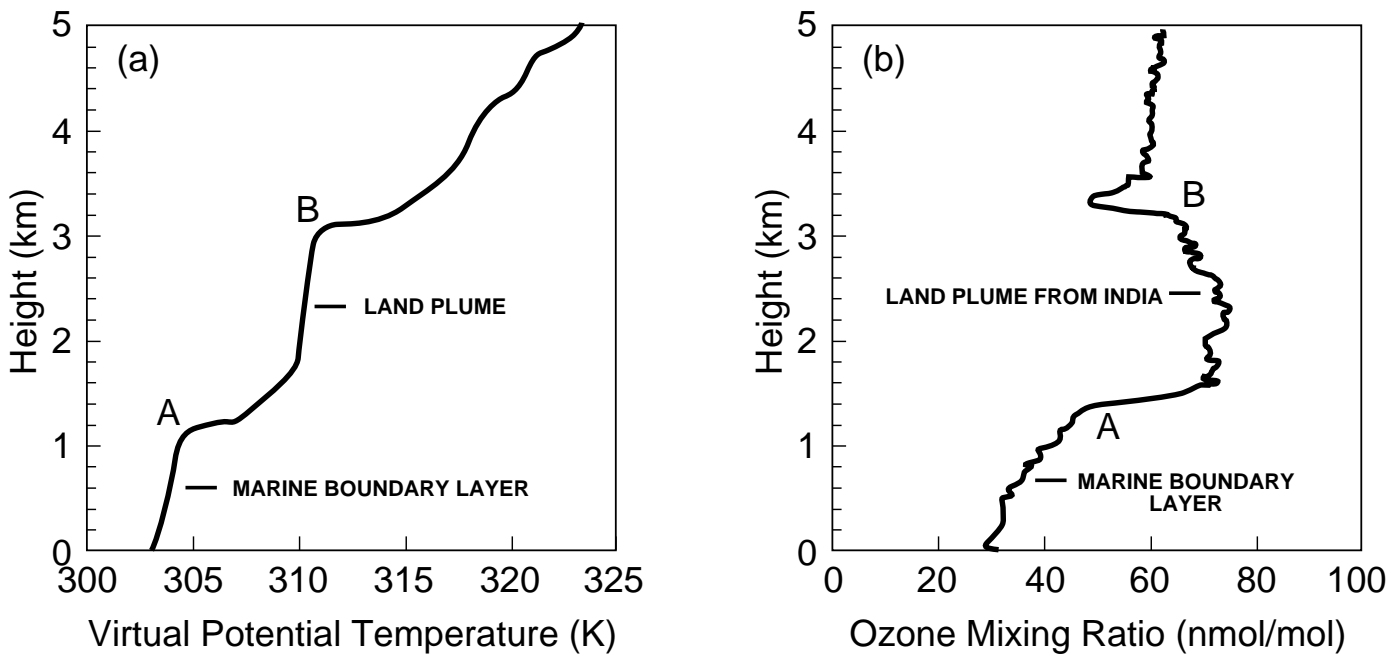

Fig. 17. Example of (a) the temperature profile showing the land plume and (b) the corresponding elevated ozone layer in the land plume, based on balloon soundings from the RV Ronald H. Brown on 7 March 1999, at $11.3^{\circ} \mathrm{N}$ and $68.3^{\circ} \mathrm{E}$ over the Indian Ocean (figure redrawn from Simpson and Raman, 2004, copyright 2004 by the Springer Verlag, reproduced with permission).
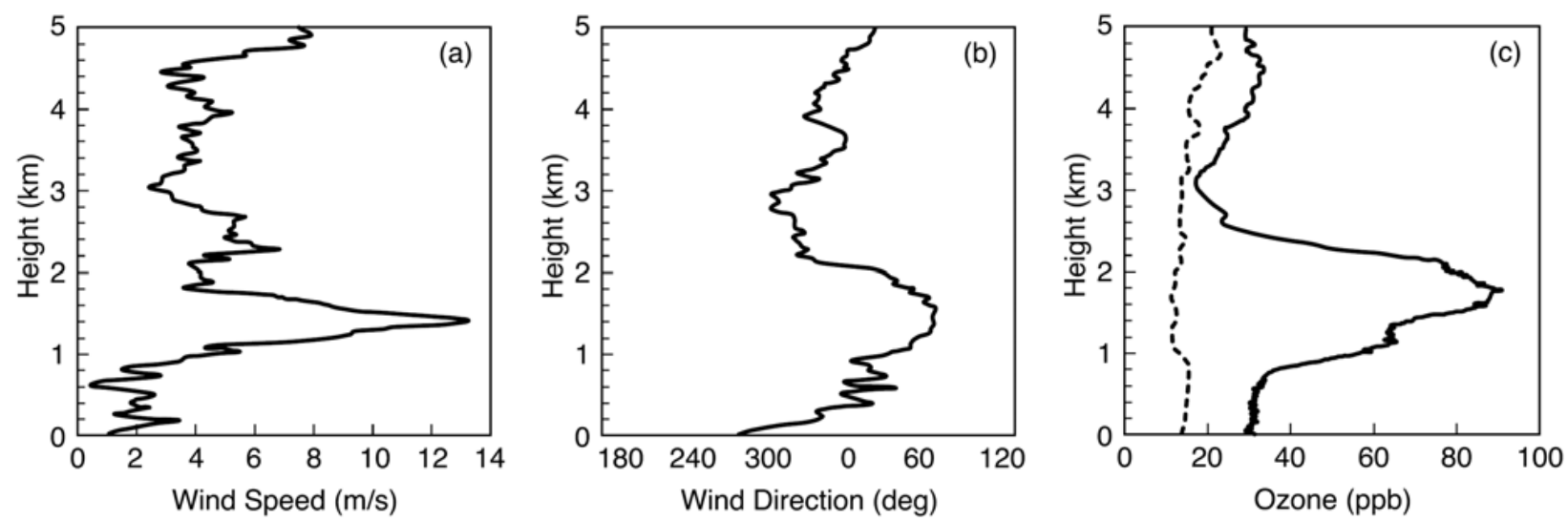

Fig. 18. Vertical profiles of (a) wind, (b) wind direction, and (c) ozone, showing an example of an elevated ozone-rich layer; based on balloon sonde measurements at the Kaashidhoo Climate Observatory (KCO) on 9 March 1999 (solid lines) and 5 February 1999 (dashed line) (redrawn from Simpson and Raman, 2004, copyright 2004 by the Springer Verlag, reproduced with permission).

the land-sea breeze circulation, whereas it is not represented in the lower resolutions typically used in global models. Several features emerge from these two studies taken together. First, the extensive and strong nature of the land-sea breeze in this region is shown, with infrared satellite images showing it to extend up to $200 \mathrm{~km}$ offshore (Simpson and Raman, 2006; note that this is rare, since typically land-sea breeze circulations are limited to within about $100 \mathrm{~km}$ of the coast). Simpson and Raman (2006) also found that this extreme horizontal extent was occasionally evident in the trajectories of the constant-level balloons (Appu et al., 2001; Ethé et al., 2002) shown earlier in Fig. 8. The convergence of the sea breeze with the NE monsoon winds results in strong upwelling in the boundary layer. Verma et al. (2006) computed that both the mean horizontal velocity of the sea breeze $(3.4 \mathrm{~m} / \mathrm{s})$ and the ascent rate are about twice as large in March as in February 1999. For March, the mean ascent rate computed with the global model is about $0.25 \mathrm{~Pa} / \mathrm{s}$, which is equivalent to about $12 \mathrm{~h}$ for transport from the surface to $1 \mathrm{~km}$ (about $100 \mathrm{hPa}$ pressure difference); interestingly, in some cases up to an order of magnitude more rapid ascent is computed with the mesoscale model, though the reasons for these differences (other than the higher resolution of the mesoscale model) are not known. These ascent rates are rapid enough to readily transport a substantial amount of aerosols and trace gases into the elevated layer each day, resulting in the elevated pollutant mixing ratios such as those shown in Figs. 17 and 18. 

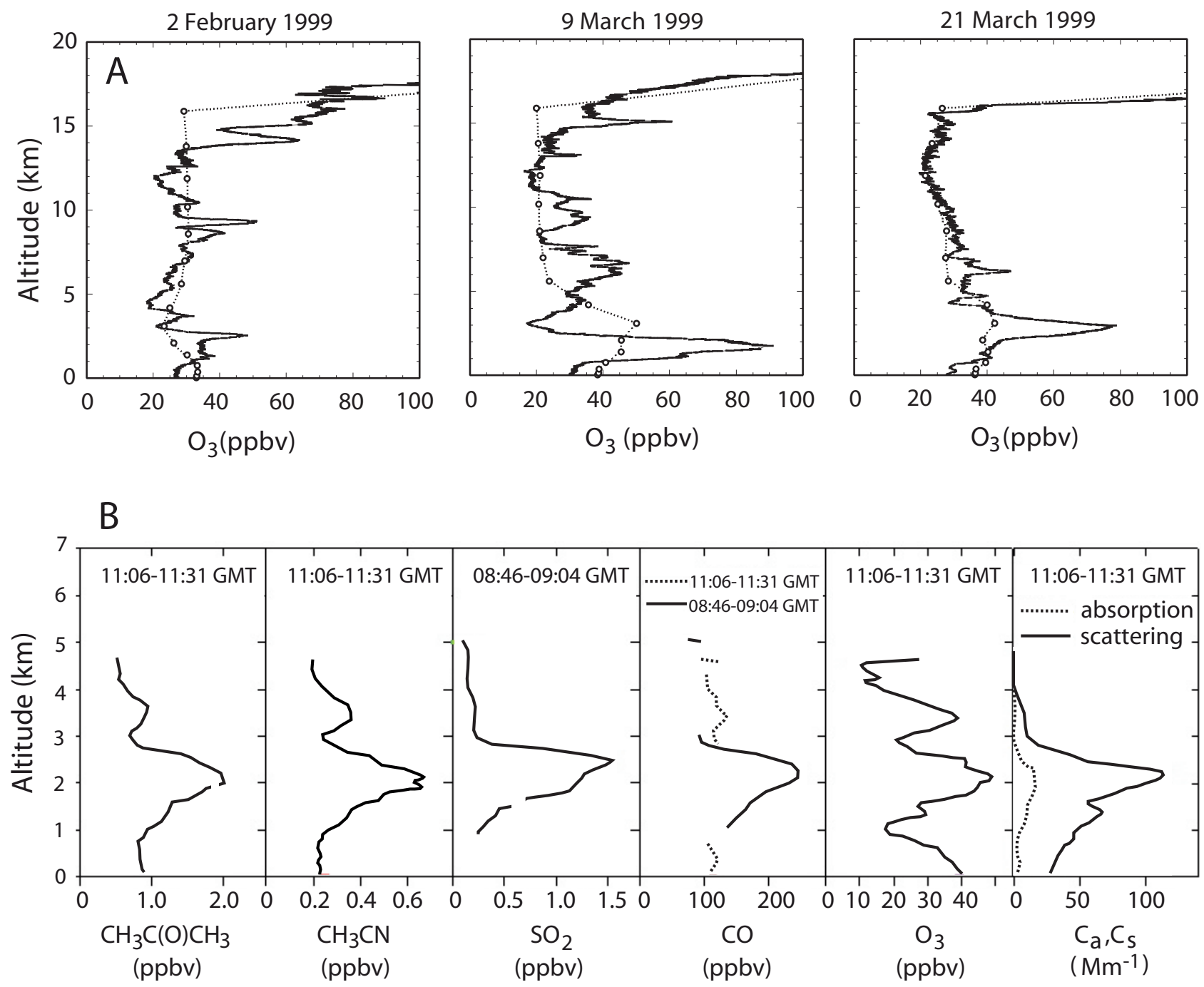

Fig. 19. Examples of the elevated layers observed for ozone and various other trace gases and aerosol properties during INDOEX: (A) $\mathrm{O}_{3}$ profiles over the Kaashidhoo Climate Observatory (KCO) from balloon sondes (solid line) and computed with the ECHAM model (dashed lines); (B) measurements of several trace gases and the aerosol absorption and scattering coefficients $\left(\mathrm{C}_{\mathrm{a}}\right.$ and $\mathrm{C}_{\mathrm{s}}$, respectively) at $7.5^{\circ} \mathrm{N}$, $72^{\circ} \mathrm{E}$, made on a flight of the NCAR C-130 aircraft on 13 March 1999 (note that this figure and several of the following figures taken from the published literature use the unit "ppbv" (parts per billion volume) for trace gas mixing ratios, which is equivalent to the SI unit nmol/mol used throughout the text; from Lelieveld et al., 2001, copyright 2001 by the American Academy for the Advancement of Science, reproduced with permission).

Though secondary to the elevated layer in terms of polluted airmasses, there is also a substantial outflow from the continent directly in the MBL. This can especially be anticipated, since the aerosols and shorter-lived trace gas pollutants over land are often most concentrated near the surface. Long-term measurements of aerosol profiles from 1989-1997 over Trivandrum in southern India show that on average during wintertime, the aerosol number density is roughly constant over a mixing height of about $400 \mathrm{~m}$, falling off above this with a scale height of 500 $1000 \mathrm{~m}$ (Parameswaran, 2001). An interesting feature of the pollutant outflow in the MBL was the appearance of very strong horizontal gradients in pollution levels, noted by Simpson and Raman (2005) based on aerosol measurements from the RV Sagar Kanya (Jayaraman et al., 2001) and $\mathrm{CO}$ measurements from RV Ronald H. Brown (Stehr et al., 2002). Simpson and Raman (2005) propose that this is caused by the transition from sea breeze to land breeze in the evening, as depicted in Fig. 20. During the daytime, the sea breeze effectively lofts pollutants into the elevated layer, and prevents a significant outflow directly in the MBL. In the evening, the transition to the land breeze allows a "pollution 


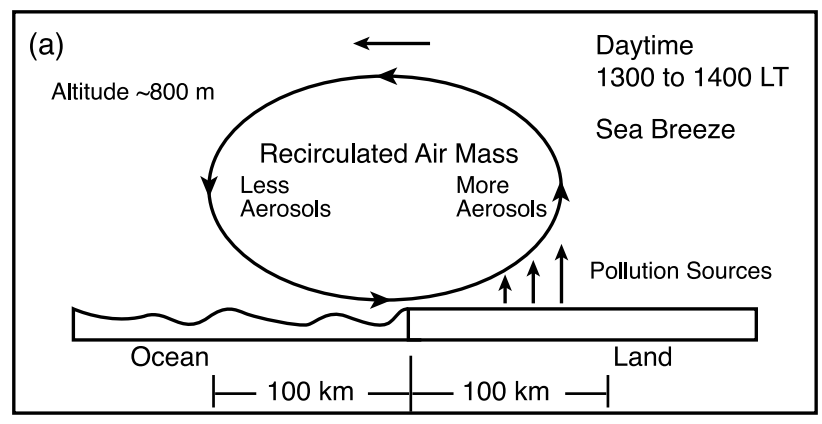

(b)
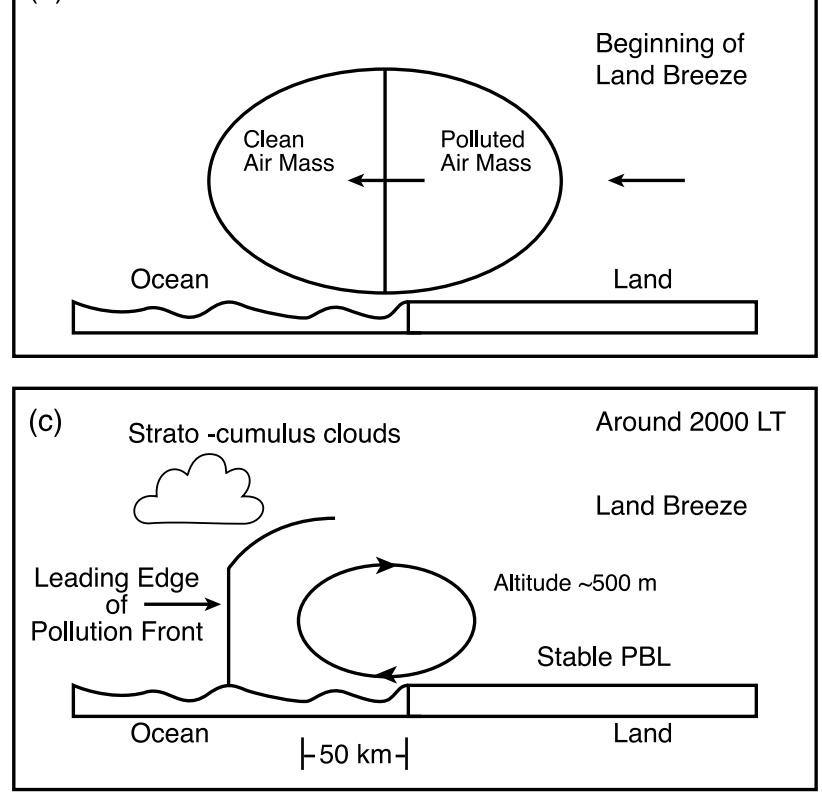

Fig. 20. Schematic of the mechanism leading to the strong pollution gradients in the MBL outflow: (a) the daytime situation, (b) evening transition, and (c) nighttime with the pollution front being advected offshore over the Indian Ocean (redrawn from Simpson and Raman, 2005, copyright 2005 by the Indian Academy of Sciences, reproduced with permission).

front" to be transported out over the ocean, and then carried further by the NE monsoon winds. In regions where the wind is relatively steady between the coast and the observations point, this results in diurnal cycles in the pollution (where the phase depends on the distance from the coast). These pollution fronts can also be observed as "stripes" of sharp gradients in infrared satellite images (Désalmand et al., 2003), where high aerosol concentrations block the IR radiation from the sea surface and lower the retrieved temperatures. The first evidence of this diurnal behavior was already gathered during the pre-INDOEX FFP campaign in 1998, when rapid increases of an order of magnitude in the aerosol concentrations in all size categories were seen corresponding with the onset of the land breeze in the evening in the coastal city of Trivandrum (Murugavel and Kamra,
1999). Similar to the daytime sea breeze effects, simulations with a mesoscale model (Simpson and Raman, 2005) reproduce this mechanism, and the basic features are also present in the zoom region of a global model (Verma et al., 2006), confirming this as an important mechanism in controlling the pollutant outflow in the regional MBL.

The split layers in the SAW-ABC will have important implications for the large scale effects, for instance due to differences in the impact of warming by absorbing aerosols located near the surface (which would tend to substantially increase atmospheric instability) compared to warming in the residual layer (which can strengthen the MBL inversion cap). Since the radiative forcing of aerosols depends on the reflectivity of the underlying surface, the presence of clouds below the inversion can have a strong impact on aerosols transported aloft (Haywood et al., 1997). Satellite measurements show that when aerosol layers are advected over a partly cloudy MBL, i.e. at a cloud coverage $>0.4$, the aerosol radiative forcing can even switch from a net cooling to a net warming effect (Chand et al., 2009). Furthermore, the split layers make long-term monitoring of the pollutant outflow more complicated, since island stations with only groundbased instruments may not be observing the most important part of the outflow, thus arguing for the need for regular balloon soundings and lidar measurements where possible - and perhaps in the future the implementation of routine AUAV (unmanned airborne vehicle) measurements at some of the remote $\mathrm{ABC}$ monitoring sites such as $\mathrm{MCOH}$.

Finally, in addition to the surface layer and the elevated pollution outflow layer discussed above, there is also evidence of several other layers higher up, which vary strongly from day to day, including:

- a layer at about 3-4 km altitude which carries pollution primarily from Southeast Asia, especially from biomass burning (Lelieveld et al., 2001; Chatfield et al., 2007),

- frequently observed free tropospheric layers, usually between 5 and $10 \mathrm{~km}$, with elevated mixing ratios of $\mathrm{O}_{3}$ and other pollutants; these were originally primarily attributed to long-range transport of polluted air masses from biomass burning in African (de Laat, 2002), although a recent, more detailed analysis (Chatfield et al., 2007) has shown that primary contributions come from stratospheric input of $\mathrm{O}_{3}$ and from convective lofting of pollutants out of the polluted MBL of the northern Indian Ocean;

- upper tropospheric pollution from southern Asia in the return flow of the Hadley Cell, after the polluted airmasses are lofted by convection in the ITCZ (de Laat et al., 2001b; Phadnis et al., 2002).

This "crossroads" of pollution above the Indian Ocean is reminiscent of the situation over the Mediterranean Sea (see Sect. 5), and has some important consequences for the 


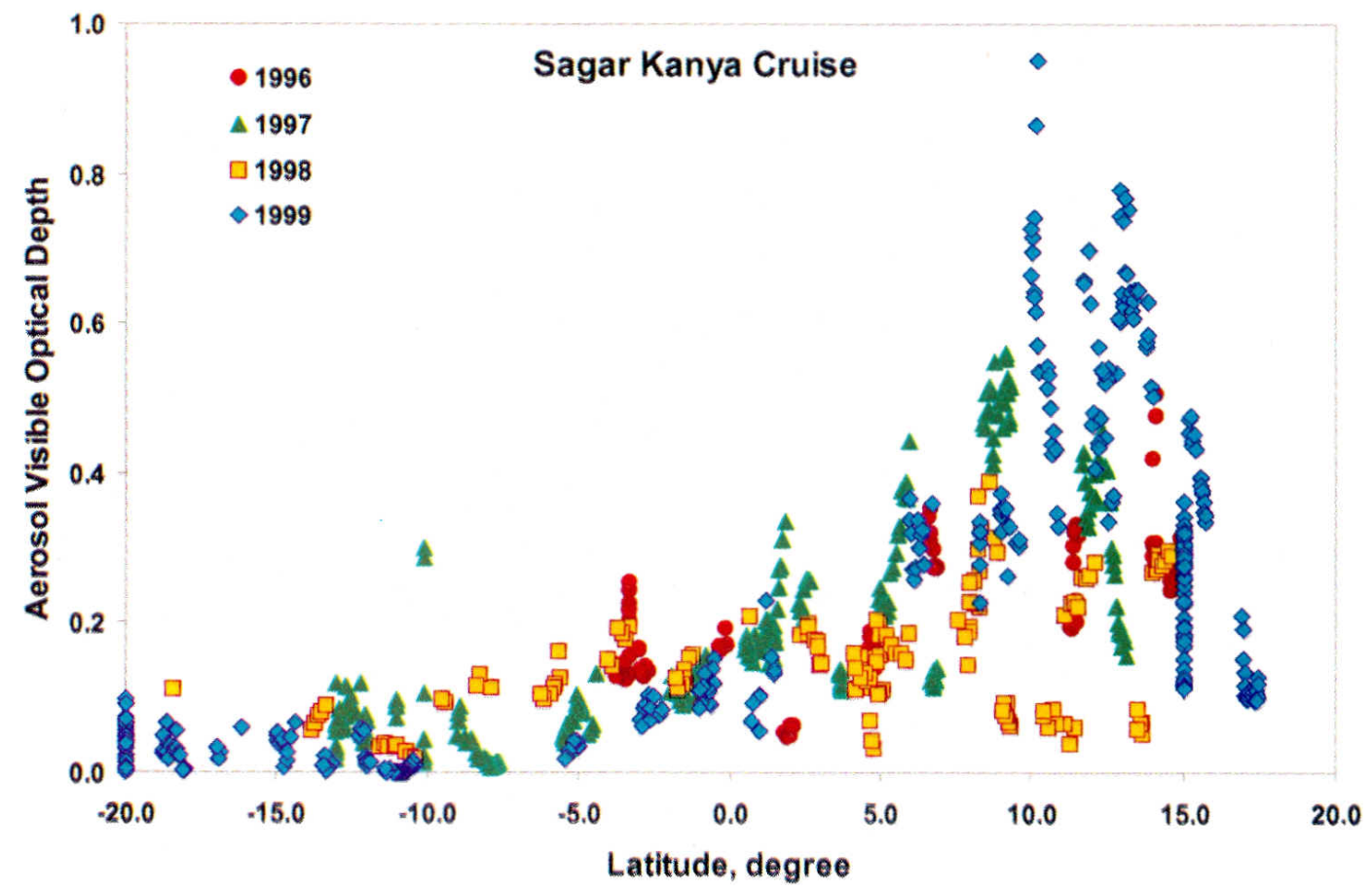

Fig. 21. Variation of Aerosol Optical Depth (AOD) as a function of latitude, based on measurements made during the four RV Sagar Kanya cruises during 1996-1999 (from Ramanathan et al., 2001, copyright 2001 by the American Geophysical Union, reproduced with permission).

analysis of the SAW-ABC, such as the differences in the anthropogenic contribution to the column-integrated AOD versus the surface layer aerosol concentrations, as discussed in Sect. 4.4.

\subsubsection{Transit times, lofting in the ITCZ and interhemispheric exchange}

After leaving the continent, pollutants in the SAW-ABC are transported over the ocean until they reach the ITCZ. The typical transit time from the southern coast of India to the ITCZ has been estimated to be about a week to ten days, based on constant-level balloons and trajectory calculations (Ethé et al., 2002) and on the ratios of the concentrations of pollutants with different chemical lifetimes (de Gouw et al., 2001). This transport time, combined with the effects of chemical processing, dilution, and surface deposition, results in substantial north-south gradients of various gases and aerosols, such as the example for AOD shown in Fig. 21. These strong gradients, including the sharp gradient across the ITCZ, were first noted in measurements made on the pre-INDOEX and INDOEX ship cruises (e.g., Rhoads et al., 1997; Moorthy et al., 1997; Jayaraman et al., 1998, 1999, 2001; Satheesh et al., 1998; Naja et al., 1999; Stehr et al., 2002; Quinn et al., 2002; Chand et al., 2001, 2003; Kamra et al., 2003; Norman et al., 2003; Nair et al., 2004; Naja et al., 2004), as well as in aircraft observations during INDOEX (e.g., Ramanathan et al., 2001; Reiner et al., 2001; Gabriel et al., 2002a; Pelon et al., 2002; de Reus et al., 2002), and shortly thereafter were corroborated to be a general feature of the broader region based on numerous pieces of evidence, including further in situ observations, satellite retrievals and model simulations (e.g., Rajeev et al., 2000, 2004; Rajeev and Ramanathan, 2001; Rasch et al., 2001; Collins et al., 2001, 2002; de Laat et al., 2001a, b; Lelieveld et al., 2001; Lawrence et al., 2003a; Minvielle et al., 2004a, b; Moorthy et al., 2005a; Satheesh et al., 2006a, b; Vinoj et al., 2007; Verma et al., 2008).

In addition to this generally strong gradient of pollutants in the SAW-ABC, these observations and modeling studies have also shown a very abrupt transition between the polluted $\mathrm{NH}$ air masses and more pristine $\mathrm{SH}$ air in the MBL at the ITCZ, which can be considered a "chemical ITCZ" (Lawrence et al., 2003a; it has also been termed the "chemical equator" by Hamilton et al., 2008, with respect to similar observations over the Pacific). The chemical ITCZ can be seen particularly well in surface-level $\mathrm{CO}$ and $\mathrm{O}_{3}$ observations; Fig. 22 shows an example in which the mixing ratios of both gases tripled within less than a day as the RV Ronald $\mathrm{H}$. Brown crossed the chemical ITCZ heading north in late February 1999. The ITCZ, and thus the chemical ITCZ, meanders to the north and south over a substantial latitude range during the winter monsoon; for instance, during a three-week period in 1999 , it was observed to migrate nearly 10 degrees southwards, from about $2^{\circ} \mathrm{S}$ to $11^{\circ} \mathrm{S}$, at an average rate of approximately $50 \mathrm{~km} /$ day (Lawrence et al., 2003a; note that 

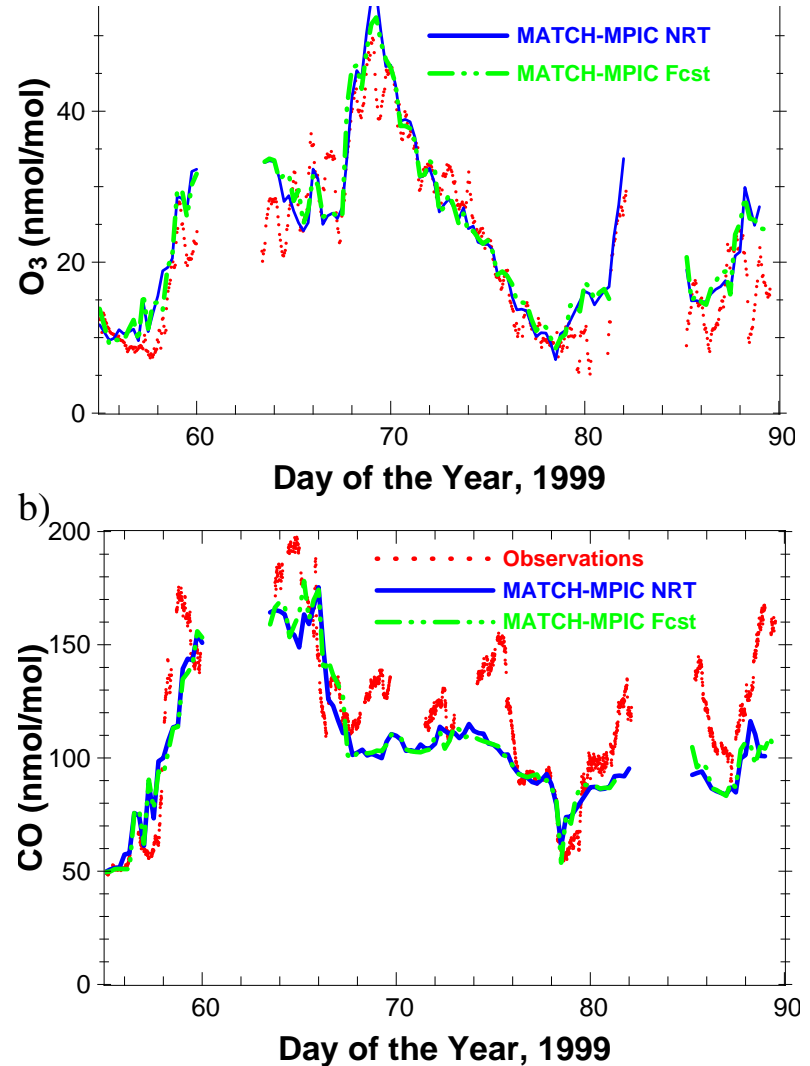

c)

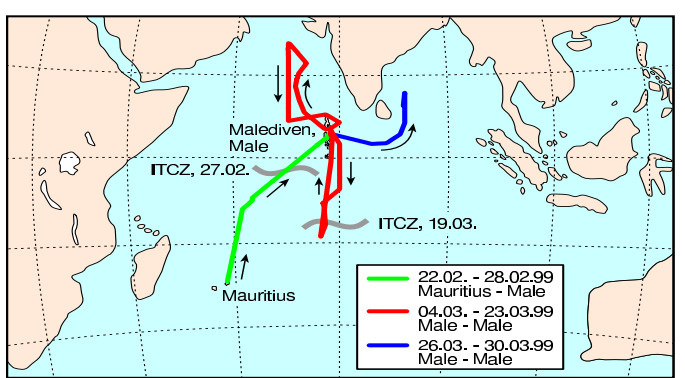

Fig. 22. Observations (dots) and modelled values (solid lines, from MATCH-MPIC) of (a) $\mathrm{O}_{3}$ and (b) $\mathrm{CO}$ during the $1999 \mathrm{RV}$ Ronald $\mathrm{H}$. Brown cruise; the cruise route is depicted in panel (c), with indicators for the two encounters with the ITCZ: the crossing on 27 February 1999 (Julian day 58), and the brief encounter on 19 March 1999 (Julian day 78) (from Lawrence et al., 2003a, copyright 2003 by the European Geophysical Union, reproduced with permission).

this is also consistent with the analysis of the wind fields in Verver et al., 2001). The position and movement of the chemical ITCZ was shown to be simulated and even forecasted well by a global chemistry-transport model at a standard contemporary horizontal resolution of about $2^{\circ}$ in the horizontal (see Fig. 22).

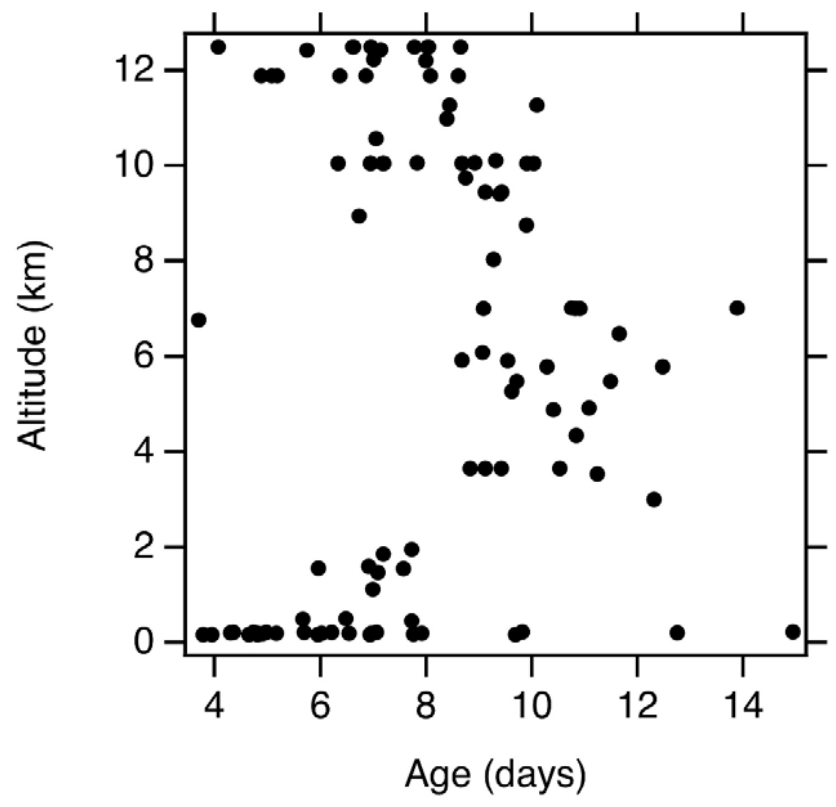

Fig. 23. Altitude profile of the estimated age of sampled pollution during INDOEX (from de Gouw et al., 2001, copyright 2001 by the American Geophysical Union, reproduced with permission).

Once airmasses reach the ITCZ, deep cumulus convection lifts trace gases and aerosols out of the MBL and deposits them into the MT and UT (middle and upper troposphere). Model simulations show that as a result of this, the main region in the UT in which tracers from India are concentrated is the equatorial central to western Indian Ocean (de Laat et al., 2001b; Phadnis et al., 2002). At the same time, some of the gases and aerosols are taken up in the condensate in the ITCZ convection, and depending on their degree of solubility or hygroscopicity, can be very efficiently removed from the atmosphere by precipitation (Andronache et al., 2002; Wilcox and Ramanathan, 2004). Deep convection characteristically transports air rapidly and directly from the BL to the UT, compensated by slower subsidence into the MT (for overviews of the general effects of deep convective transport on pollution tracers, see Lawrence et al., 2003b; Lawrence and Rasch, 2005; Lawrence and Salzmann, 2008; and references therein). These transport characteristics are reflected in the average ages of air masses sampled in this region (Fig. 23), which are about 4-8 days in the MBL, increasing rapidly to $10-14$ days in the MT (4-7 km), but then falling to 6-10 days in the UT (above $7 \mathrm{~km}$ ), with minimum values falling to 4 days in the outflow region around $12 \mathrm{~km}$ (de Gouw et al., 2001). This is also seen in the vertical profiles of $\mathrm{CO}$ and several other gases (e.g., propane), which frequently had UT mixing ratios which exceeded their MT values (de Gouw et al., 2001).

An important consequence of the ITCZ convection is that scavenging by precipitation in the convective cores significantly reduces the concentration of medium-sized and large 


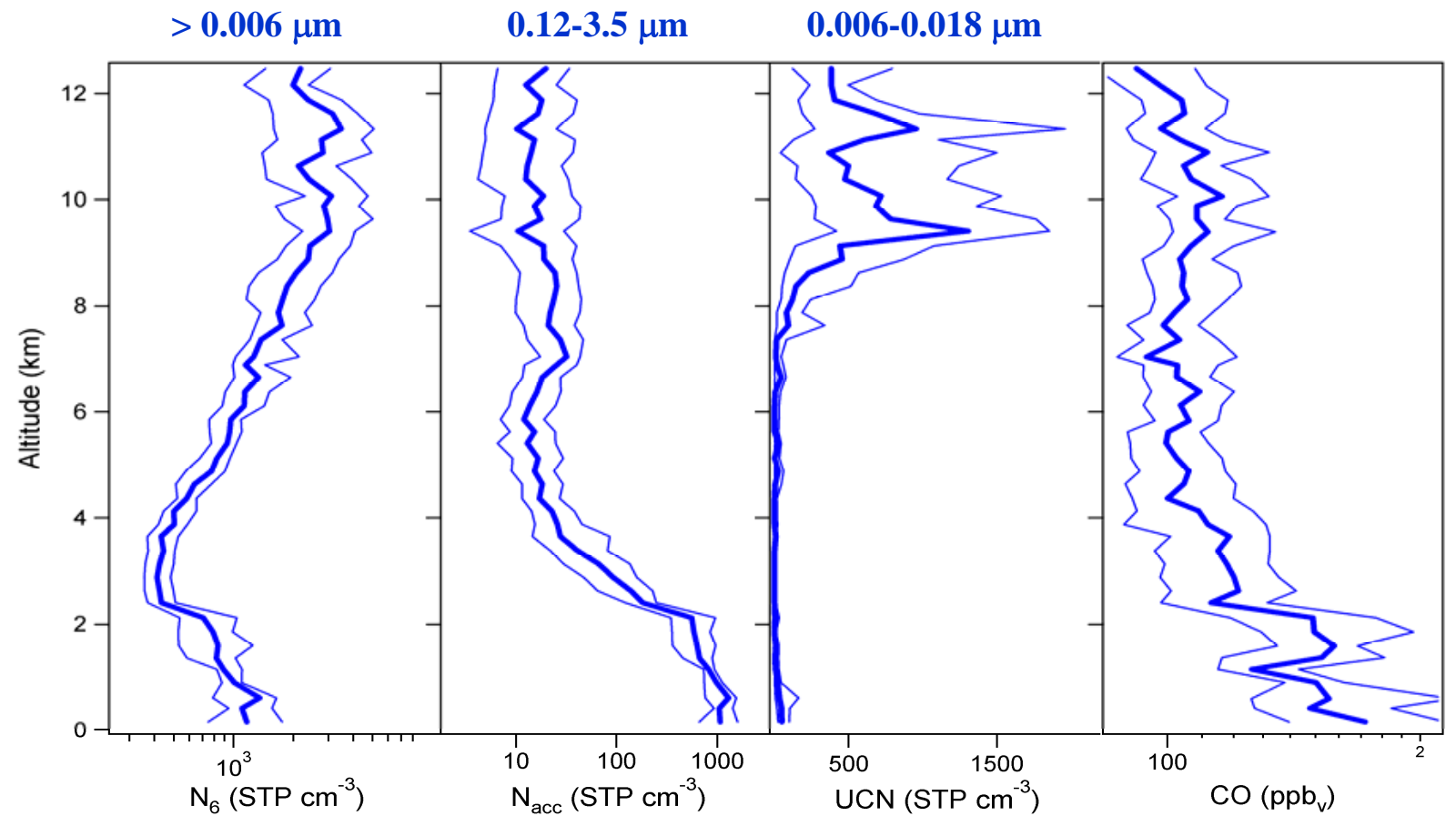

Fig. 24. Vertical profiles of particles of various size classes, along with CO, as measured during flights over the northern Indian Ocean during INDOEX (from de Reus et al., 2001, copyright 2001 by the American Geophysical Union, reproduced with permission).

aerosol particles reaching the convective outflow in the UT. This in turn reduces the surface area available onto which newly-formed particles would normally rapidly condense, thus making the UT outflow region very conducive to the nucleation of new particles (de Reus et al., 1998). Some of the slightly soluble pollution gases, including some organics, may survive the precipitation scavenging and, subsequent to their oxidation in the UT, contribute to the particle formation. Subsidence, combined with growth through coagulation and coalescence, then results in a source of small particles to the MT. This direct connection between deep convective outflow and new particle formation was first observed during INDOEX by de Reus et al. (2001), who found a substantial enhancement in ultrafine particles in the upper troposphere, as shown in Fig. 24, corresponding with a weaker enhancement in the mixing ratio of $\mathrm{CO}$ (a long-lived tracer of deep convective outflow). Based on further analysis of these observations, they concluded that this is the main source of ultrafine particles in the UT and submicron particles in the MT over the northern Indian Ocean during the winter monsoon, and hypothesized that this connection may be important in other convectively-active regions as well. The role of this process for the INDOEX region has since been corroborated by modeling studies (e.g., Engström et al., 2008), as well as by independent measurements made in the CARIBC project using commercial aircraft flying in the UT over the Arabian Sea (Weigelt et al., 2009). The CARIBIC data also show a similar relationship for flights over the Caribbean; however, for flights over southeastern Europe, the relationship was only observed for airmasses that had experienced very long contact times $(>4 \mathrm{~h})$ with clouds upwind of the observations, and for data from the Middle East and the midlatitude North Atlantic Ocean, no clear connection was observed. On the other hand, it has been clearly observed that such nucleation events occur over Brazil and Africa in the TROCCINOX and AMMA campaigns (Weigel et al., 2010). Thus it is clear that this occurs in other regions as well, but it not yet clear how significant this mechanism is on a global scale. One likely cause for regional variability is the dependence on the chemical nature of the mixture of aerosol precursor gases (Kulmala et al., 2006). It will also compete with other major source mechanisms, such as the formation of new particles along fronts and in midlatitude tropopause folds (de Reus et al., 2000; Young et al., 2007). Finally, an important issue for future research will be investigating how the potential for new particle formation relates to the dynamical characteristics of individual convective storms.

The ITCZ is the gateway for interhemispheric transport, which occurs via various mechanisms, such as outflow from deep convection and Rossby wave propagation (Hartley and Black, 1995; Lintner et al., 2004). The occurrence of interhemispheric transport during INDOEX was inferred by Williams et al. (2002) based on the observation that in the UT south of the ITCZ, the mixing ratios of CO $(>100 \mathrm{nmol} / \mathrm{mol})$ can exceed the typical SH MBL mixing ratios (about $50 \mathrm{nmol} / \mathrm{mol}$ ) by more than a factor of two, but are very consistent with the typical NH MBL mixing ratios in the inflow region of the ITCZ deep convection. The physical 
mechanisms controlling interhemispheric exchange in this region were examined by Zachariasse et al. (2001). Most of the exchange appears to take place in the MT and UT, especially from convective outflow, since the strong nearsurface convergence associated with the Hadley Cell makes the transport of air masses from one hemisphere deep into the other hemisphere directly in the MBL difficult. A preferred region for interhemispheric mixing in the UT was identified using back trajectories as the convergence region between two anticyclones, one in the SH over northern Australia and the other in the NH east of the Philippines, from which air then enters the Indian Ocean region, passing over the highly convective Indonesian region. There are several questions still open in understanding the interhemispheric transport, such as the degree of interannual variability, especially in connection with the ENSO, and whether the presence of the SAW-ABC and its influence on the regional climate and circulation have an influence on the ITCZ and interhemispheric transport.

Interhemispheric transport of the SAW-ABC pollutants appears to not only be important in the north-south direction, but also between the Eastern and Western Hemispheres. In particular, it has been hypothesized that the SAW-ABC may help to explain the "tropical Atlantic ozone paradox" (Thompson et al., 2000), in which it has been noted that a striking maximum in total column ozone occurs over the southern Atlantic at the same time as the maximum biomass burning is occurring over northern Africa, despite the previous assumption that lofting of African emissions would provide the primary and perhaps nearly exclusive source of pollutants for the Atlantic region. Chatfield et al. (2004) show that the SAW-ABC provides an episodic and significant source of ozone pollution to the Atlantic troposphere, via occasional convective lofting of the pollutants over the northern to central Indian Ocean, addition of $\mathrm{NO}_{\mathrm{x}}$ from convection (particularly over Africa), westward transport in the upper troposphere, and merging in of stratospheric $\mathrm{O}_{3}$ and ozone precursors from convective lofting over Africa, while subsidence over the Atlantic "tends to enhance the $\mathrm{O}_{3}$ column as high $\mathrm{O}_{3}$ fills in from above". Although the northern Indian Ocean tends to be relatively cloud-free during the winter monsoon, down to the ITCZ, occasional deep convection in mesoscale convective systems does occur (Roca et al., 2002), leading to the possibility of this long-range contribution to the tropical Atlantic ozone columns.

\subsection{Chemical characteristics and processing}

This section gives an overview of the chemical characteristics as well as the processing of trace gases and aerosols in the polluted airmasses of the SAW-ABC; aerosols are discussed first in the Sect. 4.3.1, followed by gases in Sect. 4.3.2.

\subsubsection{Aerosols}

The strong gradient in AOD from the southern Asian coastal regions down to the ITCZ was discussed in the previous section (Fig. 21). Despite this rapid decrease away from the coasts, the aerosol mass loading over much of the northern Indian Ocean is nevertheless substantial, even up to several hundred $\mathrm{km}$ downwind, e.g., at $\mathrm{KCO}$, where the mean aerosol dry mass density was measured using cascade impactors and filter samplers and found to be $17 \mu \mathrm{g} / \mathrm{m}^{3}$ for supermicron aerosols, and ranged from $19-22 \mu \mathrm{g} / \mathrm{m}^{3}$ for submicron aerosols in polluted, highly scattering airmasses, down to $\sim 8 \mu \mathrm{g} / \mathrm{m}^{3}$ in low scattering airmasses (based on the instrument intercomparison and aerosol properties analysis in Clarke et al., 2002, and on the overview of Lelieveld et al., 2001, which makes use of the measurements described in Chowdhury et al., 2001, and Eldering et al., 2002). The submicron aerosol lies between the mean values of $15 \mu \mathrm{g} / \mathrm{m}^{3}$ for suburban air pollution and $33 \mu \mathrm{g} / \mathrm{m}^{3}$ determined for urban pollution in North America and Europe (Heintzenberg, 1989; unfortunately, despite the vast wealth of observations - or perhaps due to it - there are no comprehensive overviews of regional mean aerosol mass densities following up on this study). Perhaps even more poignant is the comparison to recommended exposure limits: adding the submicron and supermicron aerosol masses observed at $\mathrm{KCO}$ together yields nearly $40 \mu \mathrm{g} / \mathrm{m}^{3}$, which exceeds the legally-binding limit value for $\mathrm{PM}_{10}$ mass concentrations in Europe (EC, 1999). On the other hand, these values are much lower than observed in major Indian cities, such as the measurements made during INDOEX in Mumbai (Venkataraman et al., 2002), which showed typical 24-h average $\mathrm{PM}_{10}$ values in the range of $120-180 \mu \mathrm{g} / \mathrm{m}^{3}$, and Goa (Alfaro et al., 2003), for which the mean total particulate matter densities were $\sim 60 \mu \mathrm{g} / \mathrm{m}^{3}$ and the mean $\mathrm{PM}_{1}$ values were $\sim 27 \mu \mathrm{g} / \mathrm{m}^{3}$ (note that different measurements techniques and cut-off sizes were used for the different measurements, e.g., $\mathrm{PM}_{10}$ will include all of the submicron and much, but not all of the supermicron component; thus, a direct quantitative comparison cannot be made, rather these give a qualitative indication of the differences and similarities of these regions).

Airborne measurements onboard the C130 (Gabriel et al., 2002a) over the Indian Ocean north of the ITCZ were comparable to KCO measurements, with submicron aerosol mass densities typically in the range of about $7-34 \mu \mathrm{g} / \mathrm{m}^{3}$ in the layer from the surface up to $3.5 \mathrm{~km}$, the highest densities typically being found in the elevated pollution layer. This range of aerosol mass densities is also reflected in more recent observations and in other parts of the northern Indian Ocean; for instance, an average aerosol mass density of $8.9 \mu \mathrm{g} / \mathrm{m}^{3}$, with a mean number density of $7 \pm 3 \mathrm{~cm}^{-3}$, was measured in the Bay of Bengal during the PESO cruise of January-March 2004 (Pant et al., 2009), and a range of about $5-50 \mu \mathrm{g} / \mathrm{m}^{3}$ in both the Arabian Sea and Bay of Bengal observed during ICARB (Kumar et al., 2008; George and 
Table 6. Mean fine and coarse mass fractions of aerosols collected on filters on board the NCAR C-130 aircraft in the boundary layer (34 samples) and at Kaashidhoo Climate Observatory (KCO) (24 samples). $D$ is diameter. MSA is methane sulfonic acid. "Rest" includes magnesium, calcium, oxalate, formate, and unidentified material (based on Lelieveld et al., 2001, copyright 2001 by the American Association for the Advancement of Science, reproduced with permission).

\begin{tabular}{lrrrr}
\hline Compound & $\begin{array}{c}D<1 \mu \mathrm{m} \\
\text { mass }\left(\mu \mathrm{g} / \mathrm{m}^{3}\right)\end{array}$ & $\begin{array}{c}D>1 \mu \mathrm{m} \\
(\%)\end{array}$ & $\begin{array}{c}\text { mass }\left(\mu \mathrm{g} / \mathrm{m}^{3}\right) \\
(\%)\end{array}$ \\
\hline Sulfate & 7.0 & 32 & 4.3 & 25 \\
Organics & 5.7 & 26 & 3.2 & 19 \\
Black carbon & 3.1 & 14 & 1.7 & 10 \\
Mineral dust & 2.2 & 10 & 1.9 & 11 \\
Ammonium & 1.8 & 8 & 1.9 & 11 \\
Fly ash & 1.1 & 5 & 1.0 & 6 \\
Potassium & 0.4 & 2 & 0.2 & 1 \\
Nitrate & 0.1 & $<1$ & 0.7 & 4 \\
Sea salt, MSA & 0.1 & $<1$ & 2.0 & 12 \\
Rest & 0.4 & 2 & 0.2 & 1 \\
Total & 22 & & 17 & \\
\hline
\end{tabular}

Nair, 2008). The effective particle radius was observed to be $0.20 \pm 0.08 \mu \mathrm{m}$ for particles in the elevated pollution layer above the nearby Hulule Island $\left(4.1^{\circ} \mathrm{N}, 73.3^{\circ} \mathrm{E}\right.$, at the Maldives airport) during the INDOEX IFP and in March 2000 (Müller et al., 2003). AODs over KCO and Hulule typically ranged from 0.15-0.4 (Welton et al., 2002; Lobert and Harris, 2002; Satheesh et al., 2002; Müller et al., 2003). Occasionally, maritime airmasses which were far removed from anthropogenic influence were sampled, in which case the AODs were typically less than about 0.05 . Generally observed AODs ranged from about $0.1-0.6$ over the Indian Ocean north of the ITCZ (see Fig. 21).

Several studies have indicated that the aerosol mass concentrations over the Bay of Bengal tend to be either comparable to or somewhat higher than over the Arabian Sea, and also that the relative contribution of anthropogenic versus natural sources to the AOD tends to be higher over the Bay of Bengal (e.g., Ramachandran and Jayaraman, 2003; Kedia and Ramachandran, 2008; Reddy et al., 2008; Kedia et al., 2010); a few exceptions to this have been observed, however, as can be anticipated, given the heterogeneous distribution of aerosols in the SAW-ABC outflow over both regions. Similarly for gases, $\mathrm{O}_{3}$ and $\mathrm{CO}$ have been observed to have higher mixing ratios over the Bay of Bengal than the Arabian Sea (Naja et al., 2004; Lal et al., 2006; Asatar and Nair, 2010). This also applies to airmasses sorted by their origins based on back trajectories, depending strongly on the platform and thus the sampled region, as shown by Clarke et al. (2002): data from the NCAR C-130 shows roughly equal aerosol properties for the two trajectory origins (with the notable exception of the mass concentration of nss- $\mathrm{SO}_{4}^{2-}$, which is about twice as high for airmasses from the Arabian Sea as for those from the Bay of Bengal), while the data from the RV Ronald H. Brown shows that the airmasses from the Bay of Bengal are much more polluted in several aspects, especially with respect to the $\mathrm{BC}$ loading.

In contrast to the polluted $\mathrm{NH}$ airmasses, immediately south of the ITCZ the MBL airmasses were observed to be much cleaner, with typical aerosol mass densities of $\sim 2 \mu \mathrm{g} / \mathrm{m}^{3}$ observed in the MBL during INDOEX (Gabriel et al., 2002a) and $3 \mu \mathrm{g} / \mathrm{m}^{3}$ at the surface during PESO (Pant et al., 2009), and AODs in clean airmasses of about $0.05 \pm 0.02$ (Welton et al., 2002). Further south of the ITCZ, the PESO measurements (Moorthy et al., 2005a; Pant et al., 2009) show that the aerosol loadings increase again, up to $8-10 \mu \mathrm{g} / \mathrm{m}^{3}$ in the Southern Ocean south of $30^{\circ} \mathrm{S}$, primarily due to the high sea-salt aerosol source resulting from the strong winds in the "roaring forties" (with correspondingly lower number densities, in the range of $\sim 4-6 \mathrm{~cm}^{-3}$, due to the larger particles, and very low fractional contributions of $\mathrm{BC}$ to the total aerosol). The contrast between the polluted $\mathrm{NH}$ and the clean SH just south of the ITCZ was used by Lelieveld et al. (2001) to infer a large (>85\%) human-produced contribution to the total SAW-ABC aerosol. The main exceptions to this are the contribution of DMS to sulfate, which was found by Norman et al. (2003) to be up to $40 \%$ in cleanest airmasses in the northern Indian Ocean (though less than $10 \%$ in polluted air), and mineral dust, although Lelieveld et al. (2001) argued that even for this component, a substantial (but difficult to quantify) contribution is likely due to road dust and agriculture. Subsequent analyses provide further support for this, for instance based on amounts and ratios of various aerosol constituents in the measurements made during ICARB (Kumar et al., 2008; Reddy et al., 2008).

The chemical composition of fine particles as observed during INDOEX at KCO and in the MBL during 34 C130 flights, which should be broadly representative of the SAW$\mathrm{ABC}$ in the northern Indian Ocean MBL, is summarized in Fig. 25 and Table 6. The aerosol composition measurements (Table 6) indicate that sulfate is the most abundant component, accounting for $1 / 4-1 / 3$ of the aerosol mass, followed by organic matter $(\sim 20-25 \%)$ and black carbon $(\sim 10-15 \%)$, soil dust and ammonium (both about $10 \%)$, and sea salt (10\% of the supermicron particles). Aerosol chemical composition observations on the RV Ronald H. Brown similarly showed the dominance of total carbonaceous particles for the submicron size range (Guazotti et al., 2001). Interestingly, with the exception of sea salt and nitrate, the composition of the submicron and supermicron aerosols are remarkably similar, with the contributions from sulfate and carbonaceous aerosols being slightly greater in the submicron aerosol, compensating for the missing contributions from seasalt and nitrate. Even the partitioning of carbonaceous aerosol is very similar, with about $2 / 3$ being OM (organic matter), the other $1 / 3 \mathrm{BC}$ for both size classes. The 


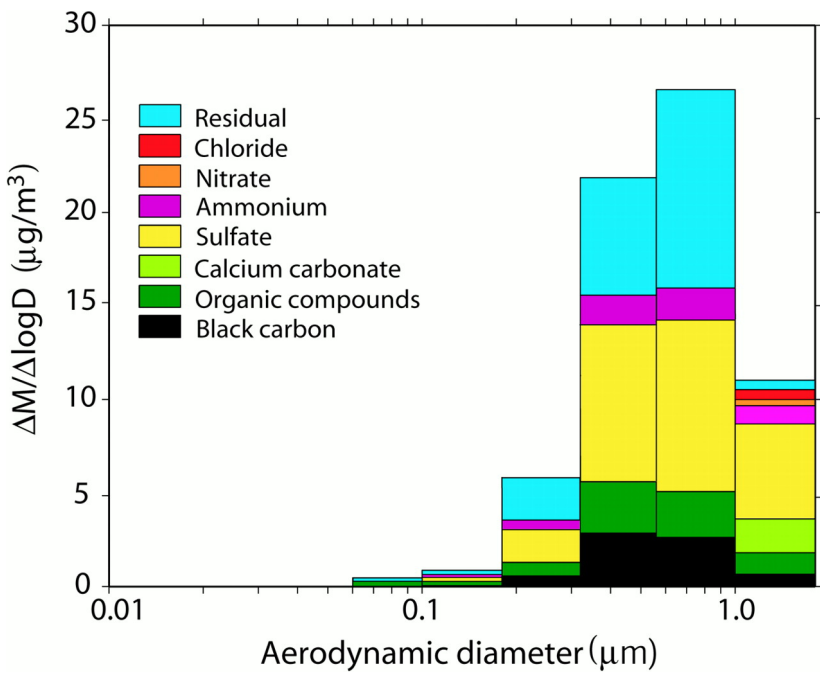

Fig. 25. Average mass $(M)$ composition of the aerosol observed at the Kaashidhoo Climate Observatory (KCO) during February 1999, as a function of the particle size. The residual includes mineral dust, fly ash, and unknown compounds (from Lelieveld et al., 2001, copyright 2001 by the American Association for the Advancement of Science, reproduced with permission).

relative contributions of $\mathrm{OM}$ and $\mathrm{BC}$ for the $\mathrm{C} 130$ flights alone (Gabriel et al., 2002a) were somewhat greater than the values listed in Table 6 , since the aircraft frequently sampled the elevated plume, with its stronger continental component, as discussed in the previous section. However, the differences between the chemical composition observed on the aircraft and the island (as well as shipboard) are not very large, and on the whole the aerosol composition over the northern Indian Ocean was found to be remarkably uniform (Lelieveld et al., 2001).

One of the most remarkable features of the aerosol chemical composition is the high mean black carbon concentration observed at $\mathrm{KCO}$ and over the northern Indian Ocean (Table 6), which is not much smaller than the $4.0 \pm 0.46 \mu \mathrm{g} / \mathrm{m}^{3}$ for $\mathrm{BC}$ in fine particles observed upwind in Goa (Alfaro et al., 2003). Furthermore, the $\mathrm{BC} / \mathrm{PM}_{1}$ ratios are nearly the same at the coast and in the outflow: $6-11 \%$ at $\mathrm{KCO}$ (Chowdhury et al., 2001) and $\sim 10 \%$ at Goa (Alfaro et al., 2003). Thus, despite the strong gradients away from the coasts, the relative $\mathrm{BC}$ contribution remains remarkably constant. This gives the aerosol a strong sunlight-absorbing character, with a mean single scattering albedo over $\mathrm{KCO}$ ranging from 0.91 at $440 \mathrm{~nm}$ to 0.83 at $1020 \mathrm{~nm}$, with a roughly linear wavelength dependence in this range (Eck et al., 2001), and a very comparable value of $0.90 \pm 0.06$ at $532 \mathrm{~nm}$ measured for the elevated plume above Hulule Island (Müller et al., 2003). These values are typical for much of the northern Indian Ocean and Arabian Sea, with mean values of $0.83 \pm 0.05$ based on retrievals from the lidar on the French M20 (and a similar value being inferred from Meteosat 5 satellite retrievals;
Léon et al., 2002), and values of $0.85 \pm 0.01$ observed on the RV Ronald H. Brown for airmasses directly influenced by low-level outflow from the Indian subcontinent (Quinn et al., 2002). The lowest values, around 0.8, were typically observed in airmasses originating from northern India (Müller et al., 2003). In the vertical, data over the Arabian Sea near the Indian west coast taken during the recent W_ICARB campaign (Babu et al., 2010) indicate that the SSA tends to decrease with altitude, being lower in the elevated pollution layers than directly at the surface.

Several studies have used aerosol model simulations to examine the spatial distributions of the various aerosol components (Rasch et al., 2001; Collins et al., 2001, 2002; Reddy et al., 2004; and Minvielle et al., 2004a, b). All of these result in a consistent picture of the regional distribution of the aerosol components and their contribution to the total concentration and AOD, with an example from Reddy et al. (2004) shown in Fig. 26. Several of these also include an evaluation of the models compared to the INDOEX and pre-INDOEX observations, all concluding that the models are able to represent the AOD sufficiently well to be used for subsequent analyses of the regional aerosol properties, though often with offsets, such as the tendency to underestimate high-pollution episodes noted in Reddy et al. (2004). One of the most interesting findings common to these studies is the overall complexity of the SAW-ABC: no individual component dominates the overall outflow. Instead, most of the individual components contribute significantly to the AOD throughout the region, and nearly every component provides the largest contribution to the AOD in at least one part of the Indian Ocean:

- sulfate over the eastern Arabian Sea, especially near the southwestern coast of India;

- organic matter (OM) over much of the Bay of Bengal, especially the eastern part;

- dust over the northwestern Arabian Sea; and

- seasalt over the central Indian Ocean.

The two exceptions to this are BC and fly ash; however, although $\mathrm{BC}$ does not dominate the AOD anywhere, it nevertheless plays an important role throughout the northern Indian Ocean due to its sunlight absorbing nature, as discussed above. It is worth noting that the model simulations may appear to contradict the indication noted above based on the aircraft, ship and island measurements, that the aerosol composition in the sampled region is "remarkably uniform" (Lelieveld et al., 2001). This uniformity refers to the large pollution plume that was tracked from the Indian coastal region, over the Maldives and the northern Indian Ocean, which does not necessarily represent the overall SAW-ABC. During INDOEX the measurements were focused mainly on the region to the north and south of the Maldives, where the 

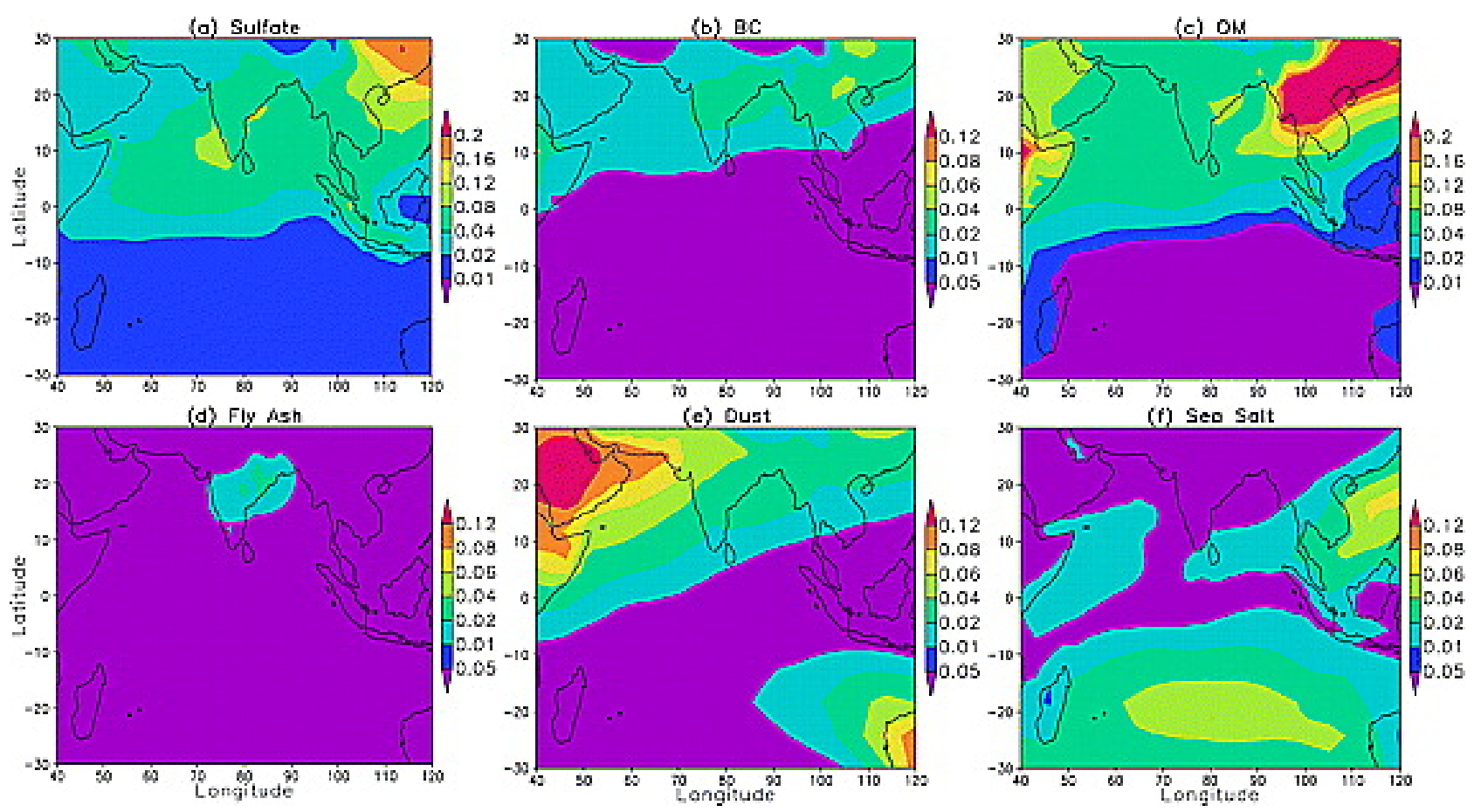

Fig. 26. AOD at $550 \mathrm{~nm}$ from different aerosol species: (a) sulfate, (b) black carbon (BC), (c) organic matter (OM), (d) fly ash, (e) dust, and (f) sea salt (from Reddy et al., 2004, copyright 2004 by the American Geophysical Union, reproduced with permission).

various aerosol components largely co-vary in their concentrations, maintaining relatively uniform ratios; the shifts in dominant aerosol species, according to the model simulations, are mostly farther away from this region (e.g., in the Bay of Bengal or northwestern Arabian Sea).

The relative constancy of the aerosol composition in the direct outflow of the Indian subcontinent, as measured during INDOEX, is largely due to the combination of steady, rapid monsoon winds together with the low cloud coverage and precipitation amounts. Wilcox and Ramanathan (2004) performed simulations with an aerosol model including and neglecting precipitation scavenging, and found the simulations with scavenging reduced the aerosol amounts over the Indian Ocean basin by only about $25 \%$ compared to the simulation neglecting scavenging. They also found that most of this scavenging occurs in regions of light precipitation; although rare, the precipitation events are still frequent and efficient enough to remove much of the aerosol already before the airmasses reach the heavy precipitation regions in the ITCZ, and even occasional deep convective systems form in the northern Indian Ocean during this period (Roca et al., 2002). Nevertheless, the overall dry nature of the monsoon outflow results in relatively long aerosol lifetimes, $\sim 7$ days for sulfate and $\sim 8$ days for carbonaceous aerosol particles, compared to the global average of $\sim 5$ days (Rasch et al., 2001). Recent work (Granat et al., 2010) indicates that this is even exacerbated for BC aerosol particles, which generally have a "washout ratio" (the rate of loss compared to non-scavenged insoluble compounds) which is only about one-third as large as that of sulfate (note that this only applies during the winter monsoon, whereas during the summer monsoon the washout ratios for $\mathrm{BC}$ and sulfate appear to be similar, indicating that $\mathrm{BC}$ is acting effectively as a cloud condensation nuclei under the conditions of the more vigorous summertime convection).

The long lifetimes prolong the time during which oxidation reactions can take place, which results in a greater "sulfate potential" (Rasch et al., 2001) for the $\mathrm{SO}_{2}$ emitted from southern Asia during the wintertime, partly compensating for the lower relative $\mathrm{SO}_{2}$ emissions for this region compared to most other parts of the world (see Table 2). Furthermore, the time during which aerosol-aerosol and aerosol-gas interactions can take place is prolonged in the SAW-ABC. Electron microscope analysis of the haze aerosol clearly shows that "internally mixed" aerosols containing sulfate, organic carbon and soot are present all the way down to the ITCZ (Ramanathan et al., 2001). In contrast, the models noted above generally treat the aerosols as separate, "externally mixed" components. A recent review by McFiggans et al. (2006) stresses that internal mixtures are the rule rather than the exception, apart from regions close to the aerosol sources. The mixing state of aerosols has important repercussions for their optical properties and regional radiative forcing. In the outflow from India natural dust aerosols typically mix with black carbon and other anthropogenic compounds, which can strongly enhance the 


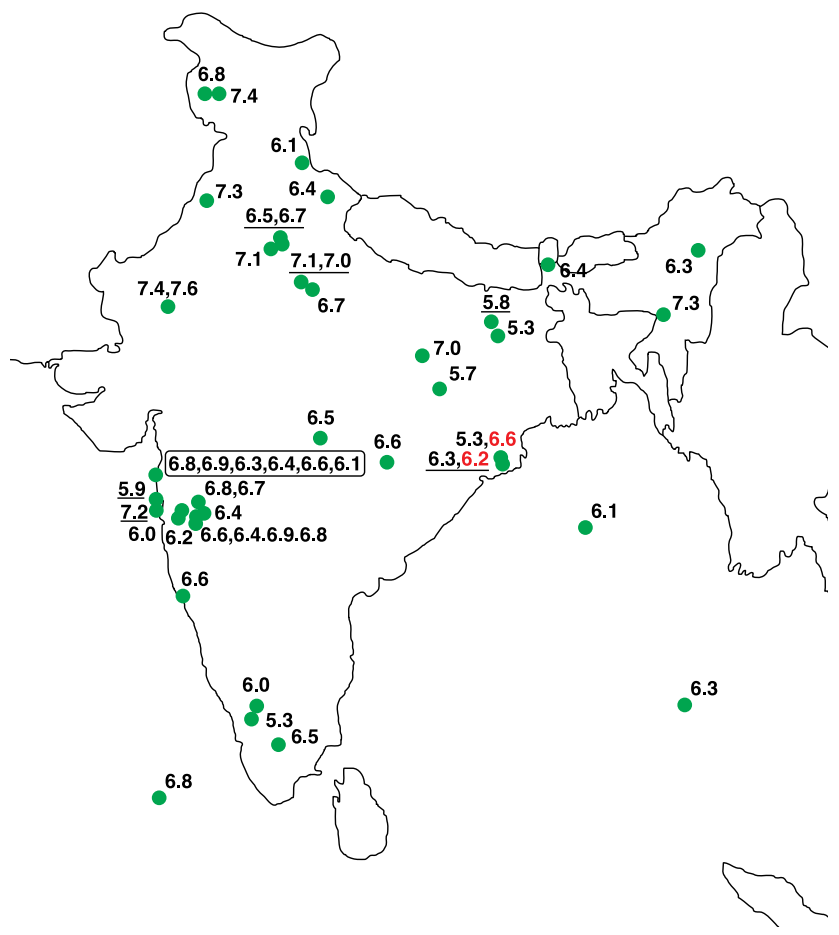

Fig. 27. Values of the $\mathrm{pH}$ of rain observed in various studies during the time period 1963-1999, at Indian Ocean sites and in India (both rural and suburban (underlined) sites), obtained using bulk (black) and wet only (red) collectors (redrawn from Kulshrestha et al., 2005, copyright 2005 by Elsevier, reproduced with permission).

radiative forcing compared to the single, i.e. externally mixed particulates (Jacobson, 2001; Satheesh et al., 2006a, b; Wang et al., 2009). Traditionally chemistry-climate models treat aerosols in categories according to their emission sources, such as dust, sea salt, sulfate, black carbon, organics, etc. (e.g., Stier et al., 2005). Since these components do not have a chemical identity, several aspects such as the mixing state, their chemical aging through oxidation processes, coating by strong acids and the hygroscopic growth properties must all be prescribed or parameterized, e.g., through look-up tables. Recently, global modeling has started to account for such processes in greater detail by more explicitly treating the individual reactive species and gas-aerosol partitioning, including the "processing" of particles by cloud condensation-evaporation cycles (Pringle et al., 2010). The continuation of these efforts will be critical to developing a deeper understanding of aerosol particles and their effects in this region.

Finally, not only are the aerosols affected by precipitation in the region, but in turn the chemical composition of the aerosols also has a notable impact on the precipitation chemistry. Numerous studies of precipitation and fog chemistry in continental India (e.g., Norman et al., 2001; Safai et al., 2004; Ali et al., 2004; plus a review paper by Kulshrestha et al., 2005) have shown a tendency for precipitation in this region to be neutral to alkaline, in contrast to the normally acidic precipitation throughout much of the rest of the world, especially near and over the continents; a depiction of the mean $\mathrm{pH}$ values measured over India and the surrounding oceans is shown in Fig. 27. This is due to the combination of $\mathrm{NH}_{4}^{+}$produced from human and animal excrement together with cations like $\mathrm{Ca}^{2+}$ and $\mathrm{Mg}^{2+}$ from the alkaline soils. A downward trend in $\mathrm{pH}$ has been determined from long-term measurements (Safai et al., 2004), due to increases in emissions of $\mathrm{N}$ - and S-containing compounds, and decreases of open soil regions due to urbanization, but this has not yet been sufficient to reverse the regional precipitation from alkaline to acidic. Over the ocean, rainwater samples collected in the SAW-ABC during the INDOEX IFP on the RV Ronald H. Brown and Sagar Kanya (Granat et al., 2002), as well as on the Sagar Kanya during ICARB (Reddy et al., 2008), clearly reflected the influence of anthropogenic and soil sources of (non-sea-salt) $\mathrm{SO}_{4}^{2-}, \mathrm{NO}_{3}^{-}$, $\mathrm{NH}_{4}^{+}, \mathrm{K}^{+}$and $\mathrm{Ca}^{2+}$, although the concentrations were typically a factor of $2-3$ lower than over land. The concentrations of cations like $\mathrm{Ca}^{2+}$ tended to decrease more rapidly away from the coasts than anions like $\mathrm{SO}_{4}^{2-}$, due to the differences in aerosol size (with the larger mineral dust aerosols being scavenged and sedimenting out more efficiently), so that the precipitation over the ocean, especially towards the ITCZ was generally more acidic than over land. The chemical composition of the deposited aerosols has far-reaching consequences, not only for the cloud microphysics, but also as an important source of nutrient input to the marine regions, especially in terms of the fixed nitrogen budget in the coastal waters around India (Church and Jickells, 2004).

\subsubsection{Gases}

Many of the studies of gas phase chemistry in the SAW$\mathrm{ABC}$ have focused on ozone, due to its role as both a greenhouse gas and an air pollutant with implications for health and agriculture, as well as its role as a driver for atmospheric chemistry, e.g., in the production of $\mathrm{OH}$ and the partitioning of $\mathrm{NO}$ and $\mathrm{NO}_{2}$, etc. Due to this, $\mathrm{O}_{3}$ was measured from nearly all platforms during the INDOEX IFP and pre-INDOEX campaigns, including at ground stations, onboard the ships, by balloon sondes, and on the aircraft (e.g., Rhoads et al., 1997; Mandal et al., 1999; Naja et al., 1999, 2004; Chand et al., 2001, 2003; Rao et al., 2001; Peshin et al., 2001; Lal and Lawrence, 2001; de Gouw et al., 2001; Williams et al., 2002; Stehr et al., 2002; Burkert et al., 2003; Ladstätter-Weissenmayer et al., 2007). Since then, data from satellite retrievals (e.g., Fishman et al., 2003; LadstätterWeissenmayer et al., 2007) and model simulations (de Laat et al, 2001a; de Laat, 2002; Saraf et al., 2003) focused on analyzing ozone in this region, as well as other cruises in the Indian Ocean (e.g., Lal et al., 2006, 2007), have added to this information base. 
The combination of high pollution levels in the SAW$\mathrm{ABC}$, the strong tropical solar radiation and the frequently cloud-free conditions results in substantial photochemical production of $\mathrm{O}_{3}$ in the outflow air masses directly off the coast of India, with relatively high ozone mixing ratios of $50-70 \mathrm{nmol} / \mathrm{mol}$ observed up to a few hundred $\mathrm{km}$ downwind (Lal and Lawrence, 2001; Stehr et al., 2002; Chand et al., 2003; Burkert et al., 2003). Similarly high maximum mixing ratios (up to slightly over $60 \mathrm{nmol} / \mathrm{mol}$ ) were observed in the outflow over the Bay of Bengal during the 2001 and 2003 Sagar Kanya cruises (Naja et al., 2004; Lal et al., 2006, 2007). Peak values in the residual layer were even observed to reach $80-100 \mathrm{nmol} / \mathrm{mol}$, as depicted in Fig. 19 (Lelieveld et al., 2001). Interestingly, Lal and Lawrence (2001) noted that the observations in major west coast Indian cities available up to that time showed much lower $\mathrm{O}_{3}$ mixing ratios, typically about $10-35 \mathrm{nmol} / \mathrm{mol}$ on average, ranging up to $\sim 50 \mathrm{nmol} / \mathrm{mol}$ maximum daytime peak values (e.g., Varshney and Aggarwal, 1992; Lal et al., 2000). Several studies since then have also measured similar ozone levels in other Indian coastal cities (e.g., Nair et al., 2002; Debaje and Kakade, 2009). Lal and Lawrence (2001) suggested this would imply that strong photochemical production of ozone was occurring in the outflow, whereas ozone was being titrated by reaction with NO in the Indian cities, though it was unclear at first whether this would really be the case, since the NO emissions in Indian cities are considerably less than in many other parts of the world (see Tables 12 and 3). One explanation of relatively strong photochemical ozone formation in some parts of the Indian Ocean is the rapid increase of $\mathrm{NO}_{\mathrm{x}}$ emissions from ship traffic, which is particularly dense in the congested track between Sri Lanka and Indonesia (Beirle et al., 2004).

Lal and Lawrence (2001) also suggested that the strong photochemical production in the urban outflow was likely to similarly be occurring over rural regions of India, although observations were not available at the time of INDOEX to examine this hypothesis. Following INDOEX, however, observations made downwind of the coastal city of Ahmedabad (Chand and Lal, 2004) showed that this strong photochemical $\mathrm{O}_{3}$ production does indeed occur in rural regions of India downwind of major cities, with maximum ozone levels exceeding $100 \mathrm{nmol} / \mathrm{mol}$. Further observations made at eight rural sites in eastern and central India during the first ISRO-GBP campaign in February 2004, clearly confirmed the widespread nature of elevated rural ozone mixing ratios in India, with average mixing ratios at the sites in the range of 60-90 nmol/mol (Lal et al., 2008b), high enough to have significant negative impacts on human health, natural ecosystems and agriculture. These indications of potential agriculture impacts are supported by simulations with a regional chemistry-transport model (Roy et al., 2008, 2009), which show that large areas of India are in exceedence of the recommended AOT40 threshold (AOT40 is the Accumulated exposure Over a Threshold of $40 \mathrm{nmol} / \mathrm{mol}$, which the UNECE (United Nations Economic Commission for Europe) and WHO (World Health Organization) have stipulated should not exceed $3000 \mathrm{nmol} / \mathrm{mol}-\mathrm{h}$ in a three month period). Regional monitoring will be important to establish in order to better characterize the ozone distribution over India and limit the social and economic consequences of ozone pollution.

As the polluted continental airmasses are transported farther away from the coast, $\mathrm{NO}_{\mathrm{x}}$ levels decline rapidly due to conversion to $\mathrm{HNO}_{3}$, and chemical ozone depletion takes over (e.g., Rhoads et al., 1997; Lal et al., 1998; Naja et al., 1999), with the lifetime of $\mathrm{O}_{3}$ falling to about 5 days (Chand et al., 2003). This corresponds to a loss of about $15 \%$ per day, and results in a decrease in ozone levels to about $10 \mathrm{nmol} / \mathrm{mol}$ near the ITCZ. The ozone depletion appears to be widespread over the northern Indian Ocean away from the coasts: based on observations of several trace gases and key photolysis rates, including the very low $\mathrm{NO}_{\mathrm{x}}$ levels, Burkert et al. (2003) determined that all airmasses sampled on the RV Ronald H. Brown were in the regime of rapid photochemical destruction.

The daytime photochemical loss of $\mathrm{O}_{3}$ in the marine environment is typically counterbalanced by advection of polluted upstream air masses at night, resulting in a diurnal cycle with minimum concentrations during the day and maximum at night (de Laat and Lelieveld, 2000). In regions remote from fresh pollution the $\mathrm{O}_{3}$ diurnal cycle is thus expected to be relatively small. These diurnal cycles are different than the "pollution fronts" that were found to be sometimes associated with diurnal cycles of less photochemicallydriven components of the SAW-ABC such as aerosols and $\mathrm{CO}$, as discussed in Sect. 4.2.1, occurring due to the transition from daytime sea breeze to nighttime land breeze. Ozone over the continent tends to be depleted at night, so that the airmasses that are transported more readily off the coast by the land breeze into the MBL at night will generally have low ozone mixing ratios. However, much of the depletion is due to reaction with $\mathrm{NO}$, so that there is an approximate conservation of oxidant $\mathrm{O}_{3}+\mathrm{NO}_{2}$; when the sun rises on the airmasses that are transported offshore, ozone is initially replenished by $\mathrm{NO}_{2}$ photolysis. Farther downwind, $\mathrm{NO}_{\mathrm{x}}$ is rapidly depleted by reaction with $\mathrm{OH}$, and photochemical loss of ozone takes over in determining its diurnal cycle, fitting with observations (which do not show the "pollution front" characteristics of a phase shift in the diurnal cycles depending on the distance from the shore). Chand et al. (2003) observed that the diurnal variations also persisted in regions where there were no horizontal gradients, concluding that downward mixing from the free troposphere can also contribute to producing the diurnal cycles, especially near the equator. Bremaud et al. (1998) observed a similar phenomenon on Reunion Island in the southwestern Indian Ocean, concluding from their data that the entrainment velocity would need to be an order of magnitude greater at night than during the day in order to match their observations; some of this difference was hypothesized to be due to 
the differences in turbulent sensible heating fluxes during day and night, although in their case, topographic influences from Reunion Island may have also played a role in producing the apparent differences in entrainment rates.

Interestingly, the observed magnitude of the diurnal cycle of $\mathrm{O}_{3}$ in the MBL far away from the shore was sometimes observed to be very large. During the 1995 RV Malcolm Baldrige cruise, Rhoads et al. (1997) found it to be 30-37\% (peak-to-peak) in tropical maritime airmasses, which they indicated implies an $\mathrm{O}_{3}$ loss rate which is considerably faster than can be explained with traditional $\mathrm{HO}_{\mathrm{x}}-\mathrm{NO}_{\mathrm{x}}$ photochemistry, and speculated that reactions with halogens (e.g., Vogt et al., 1996) might be involved. Chand et al. (2003) observed an even larger maximum diurnal cycle, with a relative amplitude of $54 \%$ in a band between $10-15^{\circ} \mathrm{S}$ during the 1999 INDOEX IFP; in all other regions, however, and during the 1998 INDOEX FFP, they observed a diurnal cycle of only about $20 \%$ or less. Stehr et al. (2002) observed diurnal cycles during the 1999 Ronald $\mathrm{H}$. Brown cruise typically around $20 \%$, ranging up to $27 \%$, and Naja et al. (2004) also noted diurnal cycles peak-to-peak magnitudes of generally around 20-30\% for the Sagar Kanya cruises from 1996-2001. During a summertime 2002 cruise of the RV Sagar Kanya in the Arabian Sea (as part of the Arabian Sea Monsoon Experiment - ARMEX), Ali et al. (2009) similarly observed very low levels of ozone, which could not be reproduced with a global chemistry-transport model, and likewise inferred that reactive halides might be contributing to ozone destruction in this region.

Following up on the initial suggestion by Rhoads et al. (1997) that halogen chemistry might play an important role in the Indian Ocean MBL, Dickerson et al. (1999) used a photochemical box model to demonstrate that catalytic destruction of $\mathrm{O}_{3}$ due to reactions with bromine-containing compounds could indeed be a viable mechanism for reproducing the large diurnal cycles. Evidence of bromide depletion in sea-salt aerosols, and thus in turn of reactive bromine release into the gas phase, has been observed during numerous campaigns over marine regions (Sander et al., 2003), including several over the Indian Ocean (Sadasivan, 1978, 1980; Johansen et al., 1999; Gabriel et al., 2002b). Furthermore, satellite retrievals for the INDOEX period (Ladstätter-Weissenmayer et al., 2007) showed evidence of about $4 \mathrm{pmol} / \mathrm{mol}$ of $\mathrm{BrO}$ in the MBL in the northern Indian Ocean, very close to the daytime average $\mathrm{BrO}$ mixing ratios of $4-5 \mathrm{pmol} / \mathrm{mol}$ computed in the simulations of Dickerson et al. (1999). The study of Burkert et al. (2003) also used a box model to simulate the MBL photochemistry, together with INDOEX observations of key gases and parameters for the ozone budget (e.g., $\mathrm{OH}, \mathrm{HO}_{2}$ and photolysis rates of $\mathrm{NO}_{2}$ and $\mathrm{O}_{3}$ ) and came to a similar conclusion about the role of halogens. Wagner et al. (2002) added a twist to this with further box model sensitivity simulations compared to their INDOEX observations, showing that high concentrations of reactive chlorine result in excessive amounts of
$\mathrm{CH}_{2} \mathrm{O}$ compared to the observations, while high concentrations of reactive bromine do not notably affect $\mathrm{CH}_{2} \mathrm{O}$. Recent observations over the Atlantic Ocean (Read et al., 2008) provide further strong support for the general role of halogens, especially bromine, in reducing ozone over marine regions. In the case of the Indian Ocean, quantification is still needed of the role of halogens, in particular in terms of the dependence of the effects on the details of pollution composition in the SAW-ABC outflow, together with the wind-speed-related source of sea-salt aerosols.

The rapid ozone depletion by photolysis and subsequent reaction of excited oxygen atoms $\left(\mathrm{O}\left({ }^{1} \mathrm{D}\right)\right)$ with water vapor in turn results in significant production of $\mathrm{OH}$. In lieu of direct $\mathrm{OH}$ measurements, De Gouw et al. (2001) used the ratios of various hydrocarbons in a "quasi-Lagrangian experiment" during INDOEX, in which the observations were targeted to sample roughly the same airmass in the outflow on two subsequent days, to estimate a 24-h average $\mathrm{OH}$ concentration in the Indian Ocean MBL of $3.7 \times 10^{6} \mathrm{molec} / \mathrm{cm}^{3}$, in approximate agreement with the output from two global models compared to in that study. This is higher than the estimated mean $\mathrm{OH}$ concentration in the southern Indian Ocean, which Warneke and de Gouw computed to be about $1.4( \pm 0.7) \times 10^{6} \mathrm{molec} / \mathrm{cm}^{3}$ based on the diurnal cycle of DMS. The northern Indian Ocean values is also several times higher than the global average $\mathrm{OH}$ concentration of about $1 \times 10^{6} \mathrm{molec} / \mathrm{cm}^{3}$ (Lawrence et al., 2001), sufficient to provide substantial breakdown rates of trace gases in the SAW-ABC, resulting for instance in a CO lifetime of only $\sim 15$ days near the surface, and a $\mathrm{NO}_{\mathrm{x}}$ lifetime of less than a day. The high oxidant levels in the haze are also important for chemical processing of aerosol precursors, such as the oxidation of $\mathrm{SO}_{2}$ to sulfate by reaction with $\mathrm{OH}$ in the gas phase, or by reaction with $\mathrm{H}_{2} \mathrm{O}_{2}, \mathrm{O}_{3}, \mathrm{HOCl}$ and $\mathrm{HOBr}$ (von Glasow et al., 2002) in cloud droplets and aerosols. Due to the rarity of clouds, oxidation by $\mathrm{OH}$ plays a disproportionately large role here compared to other cloudier regions (Rasch et al., 2001). This is reflected in a clear dependence which was observed for the $\mathrm{SO}_{2}$ concentration on the travel time since India (Norman et al., 2003). It can also be anticipated that the high $\mathrm{OH}$ levels will be important in the rapid oxidation of various hydrocarbons which have been observed to be present at significant levels in the SAW-ABC compared to rural continental observations, though much lower than observed in urban Indian regions (Mühle et al., 2002; Sahu et al., 2006; Lal et al., 2008b). Furthermore, rapid oxidation of SOA precursors may also lead to formation and growth of SOA, although we are unaware of any studies examining this issue specifically in the SAW-ABC.

\subsection{Origins of the SAW-ABC}

The chemical characteristics of the SAW-ABC are closely linked to its origins, which have been examined in several studies. These can be broadly sorted into two main classes: 

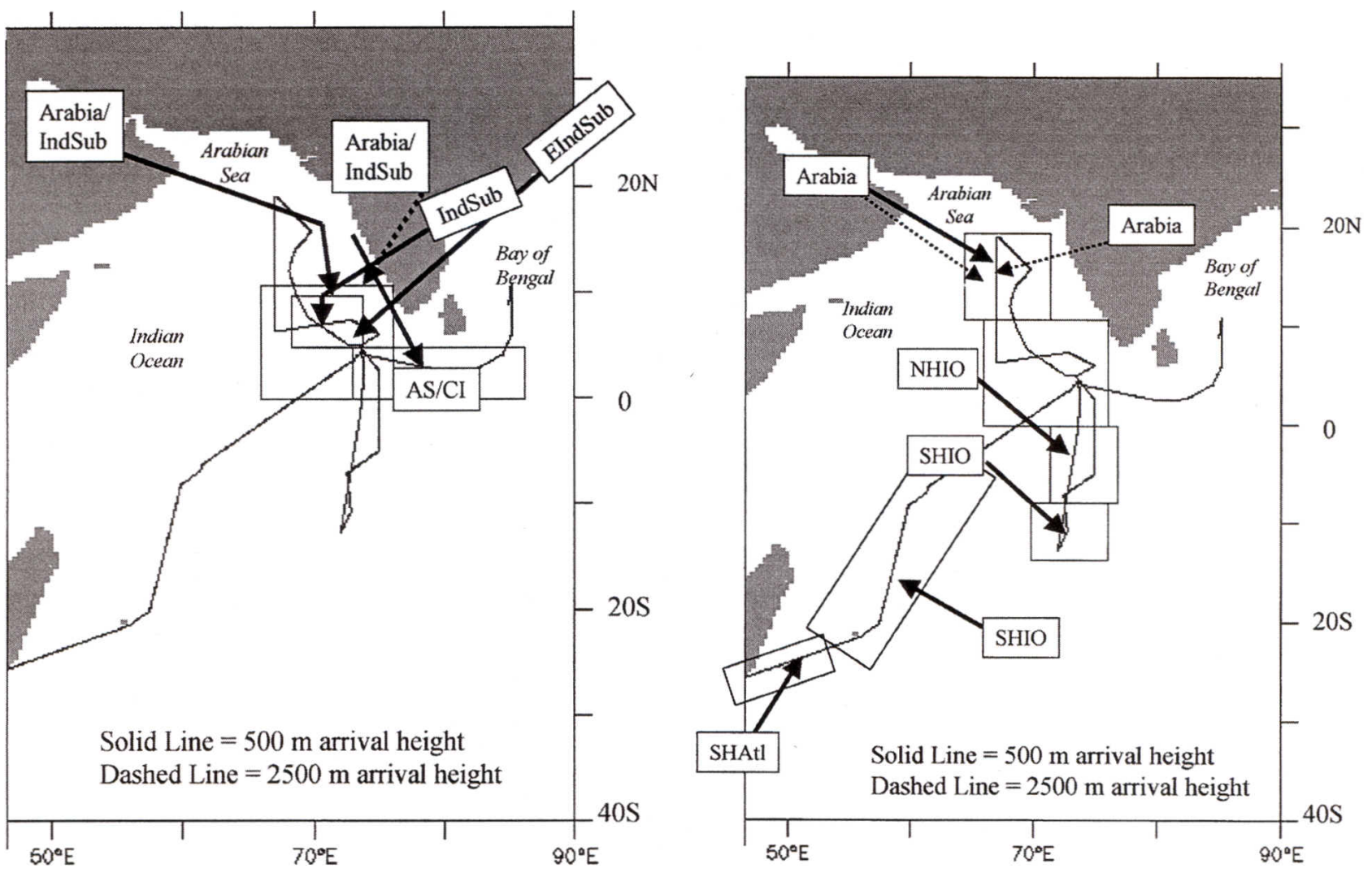

Fig. 28. Airmass origins along the RV Ronald H. Brown cruise track, with boxes indicating where air masses from the different source regions were encountered along the cruise track (see Table 7 for explanation of the source region abbreviations). Airflow is shown for $500 \mathrm{~m}$ arrival height trajectories (solid line), and also for $2500 \mathrm{~m}$ arrival height trajectories (dashed line) when they differed significantly (from Quinn et al., 2002, copyright 2002 by the American Geophysical Union, reproduced with permission).

Table 7. Air mass origins encountered during the pre-INDOEX and INDOEX cruises, characterized by broad regions, along with the more specific characterizations of Quinn et al. (2002); the abbreviations in square brackets refer to those used in Fig. 28.

\begin{tabular}{ll}
\hline $\begin{array}{l}\text { Broad } \\
\text { characterization }\end{array}$ & Specific origins \\
\hline SHmX & $\begin{array}{l}\text { SH Atlantic [SHAtl], SH Indian Ocean } \\
{[\text { SHIO }]^{1}}\end{array}$ \\
SHmT & SH Indian Ocean [SHIO] \\
NHmT & $\begin{array}{l}\text { Ar Indian Ocean [NHIO], } \\
\text { Arabian Sea/coastal India [AS/CI] }\end{array}$ \\
NHcT & $\begin{array}{l}\text { Indian subcontinent (western/central and } \\
\text { eastern) [IndSub, EIndSub] }\end{array}$ \\
NHcX & $\begin{array}{l}\text { Arabia } \\
\text { Arabia + India mixture }\end{array}$ \\
\hline
\end{tabular}

1 The SH Indian Ocean (SHIO) was not included for SHmX in the Quinn et al. (2002) summary; it is added here based on results from several of the other studies listed in the text.

${ }^{2}$ Added to the Quinn et al. (2002) summary based on Ball et al. (2003). those focused specifically on the origins of the pollution in airmasses which were sampled on various platforms during INDOEX and during the pre-INDOEX cruises; and those using 3-D models to consider the overall outflow of continental pollution over the various sub-regions of the Indian Ocean. These studies show that there is no single, well-defined origin for the SAW-ABC as a whole, but rather a mixture of regions and source processes from which the pollutants originate. The influence of continental emissions varies in time and space, depending on the regional meteorology, and also varies for different aerosols and gases, depending on their major source processes and their lifetimes due to chemical degradation, sedimentation, deposition and scavenging. However, several basic, overarching aspects of the origins of the SAW-ABC emerge from these studies, as discussed below.

Numerous analyses of the trace gas and aerosol measurements made during the pre-INDOEX and INDOEX cruises have employed back trajectories to classify the air mass origins into several basic regions. The earliest of these studies, by Rhoads et al. (1997) for the RV Malcolm Baldrige cruise in 1995, encountered air masses with four different origins: Southern Hemisphere maritime extratropical (SHmX), 
Southern Hemisphere maritime tropical (SHmT, also called SHmE in some studies, with "E" for "equatorial"), Northern Hemisphere maritime Tropical (NHmT, or NHmE), and Northern Hemisphere continental Tropical (NHcT). Several analyses of the $1999 \mathrm{RV}$ Ronald H. Brown cruise data (Mühle et al., 2002; Quinn et al., 2002; Stehr et al., 2002; Welton et al., 2002; Wisthaler et al., 2002; Ball et al., 2003; Burkert et al., 2003) build directly on this classification, and also show that the 1999 cruise encountered an additional air mass origin from the Northern Hemisphere continental extratropics (NHcX), and one further analysis of the RV Ronald H. Brown cruise (Ball et al., 2003) added the Northern Hemisphere continental (NHc) region, which was encountered in surface layer air along the west coast of India, where coastal mesoscale circulations mixed airmasses from India into the prevailing flow from Arabia. Generally the $\mathrm{SHmX}$ airmasses prevailed south of about $20^{\circ} \mathrm{S}$, the SHmT airmasses were encountered mostly from there up to the ITCZ, NHmT mainly up to about $0-5^{\circ} \mathrm{N}$, and the continental airmasses (NHcT and $\mathrm{NHcX}$ ) prevailed north of this. Quintessential to these analyses is the additional characterization provided by Quinn et al. (2002), in which these broad regions were associated with eight more specific regions, as listed in Table 7, and shown for the RV Ronald H. Brown cruise track in Fig. 28.

The analysis of the strong variability in the aerosol and trace gas measurements made during the RV Ronald $\mathrm{H}$. Brown cruises is facilitated in the studies noted above by decomposing the observations into their regions of origin, as classified in Table 7. The overall picture that emerges from these studies is:

- SHmX and SHmT airmasses are relatively uninfluenced by continental emissions (as hypothesized in planning INDOEX); these airmasses have the lowest aerosol optical depths observed during the campaign, dominated by the contribution from sea salt aerosols, very low $\mathrm{O}_{3}$ and $\mathrm{CO}$ mixing ratios, and generally properties similar to observations in the remote Pacific and Atlantic Ocean regions;

- North of the ITCZ, the lowest concentrations of aerosols and pollutant gases were observed in NHmT airmasses, although these already show a substantial influence of continental emissions, with e.g. nss-sulfate concentrations being more than five times higher and $\mathrm{O}_{3}$ and $\mathrm{CO}$ mixing ratios also several times higher than in the $\mathrm{SH}$ marine airmasses (note that these clean SH airmasses were rarely observed in the $\mathrm{NH}$, according to Gabriel et al. (2002a), due to the convergent flow in the winter monsoon towards the ITCZ);

- Even higher concentrations of nss-sulfate were observed in the NHcX airmasses, as well as high concentrations of particulate organic matter (POM) and inorganic oxidized material (IOM), and notable amounts of $\mathrm{BC}$ aerosols; chemical classification of the aerosols and trace gases showed that these pollutants mostly originated from fossil fuel burning and industrial processes, which led to the highest concentrations observed during the campaign of several gases such as ozone, methane, acetylene, ethane, and propane; the NHcX airmasses were also moderately absorbing, mainly due to the presence of mineral dust from the Arabian desert regions, with single scatter albedo values around 0.9;

- NHcT and NHc airmasses influenced by the Indian subcontinent generally had the highest concentrations of $\mathrm{BC}, \mathrm{POM}, \mathrm{IOM}$, and $\mathrm{SO}_{4}^{2-}$, as well as $\mathrm{CO}$, originating from a mixture of FFB and BMB + BFB sources; they also had the greatest degree of absorption of solar radiation, with a mean single scatter albedo of about 0.85 , primarily due to $\mathrm{BC}$.

Recently, a similar approach was applied to the 1998 and 1999 RV Sagar Kanya cruises (Verma et al., 2007; Norman et al., 2003), though using different classifications of the regions. Earlier analyses of the Sagar Kanya data (e.g., Parameswaran et al., 1999; Moorthy et al., 1999) mostly made use of trajectories or streamline data to more broadly demonstrate that the polluted airmasses in the north were consistent with a continental origin, and cleaner airmasses in the south with maritime origins. Analysis of the more recent ICARB 2006 Sagar Kanya cruise (Reddy et al., 2008) combined with back trajectories revealed a very similar overall picture to the analyses summarized above, in particular with the most polluted airmasses, especially in terms of sulfate aerosols, deriving from the Indian continental region.

A few studies have also examined the pollutant origins for the airmasses observed onboard the aircraft deployed during INDOEX. For instance, for the NCAR C-130 aircraft, Gabriel et al. (2002a) classified airmasses into their region of origin based on back trajectories, again with differences in the classification scheme compared to the studies discussed above, but with similar overall findings to the analyses of the $\mathrm{RV}$ Ronald H. Brown cruise data. A further example is the study of Forêt et al. (2006), who used regional 3-D model simulations of artificial tracers from Madras, Calcutta, Hyderabad and Mumbai to classify the pollutant origins for the LIDAR plume observations made during one flight with the French M20.

An alternate perspective is offered by the studies of Lobert and Harris (2002), Moorthy et al. (2003), and Beegum et al. (2008), who examined the origins of polluted airmasses arriving at three island locations in the northern Indian Ocean: the Kaashidhoo Climate Observatory (KCO) on the Maldives, Minicoy Island (about $500 \mathrm{~km}$ west of the southern tip of India), and Port Blair (the capital of the Andaman and Nicobar Islands) in the central Bay of Bengal. Lobert and Harris (2002) considered a time series of observations of $\mathrm{CO}$ and other gases at $\mathrm{KCO}$ in light of back trajectories arriving at $\mathrm{KCO}$. The trajectories were grouped into several 


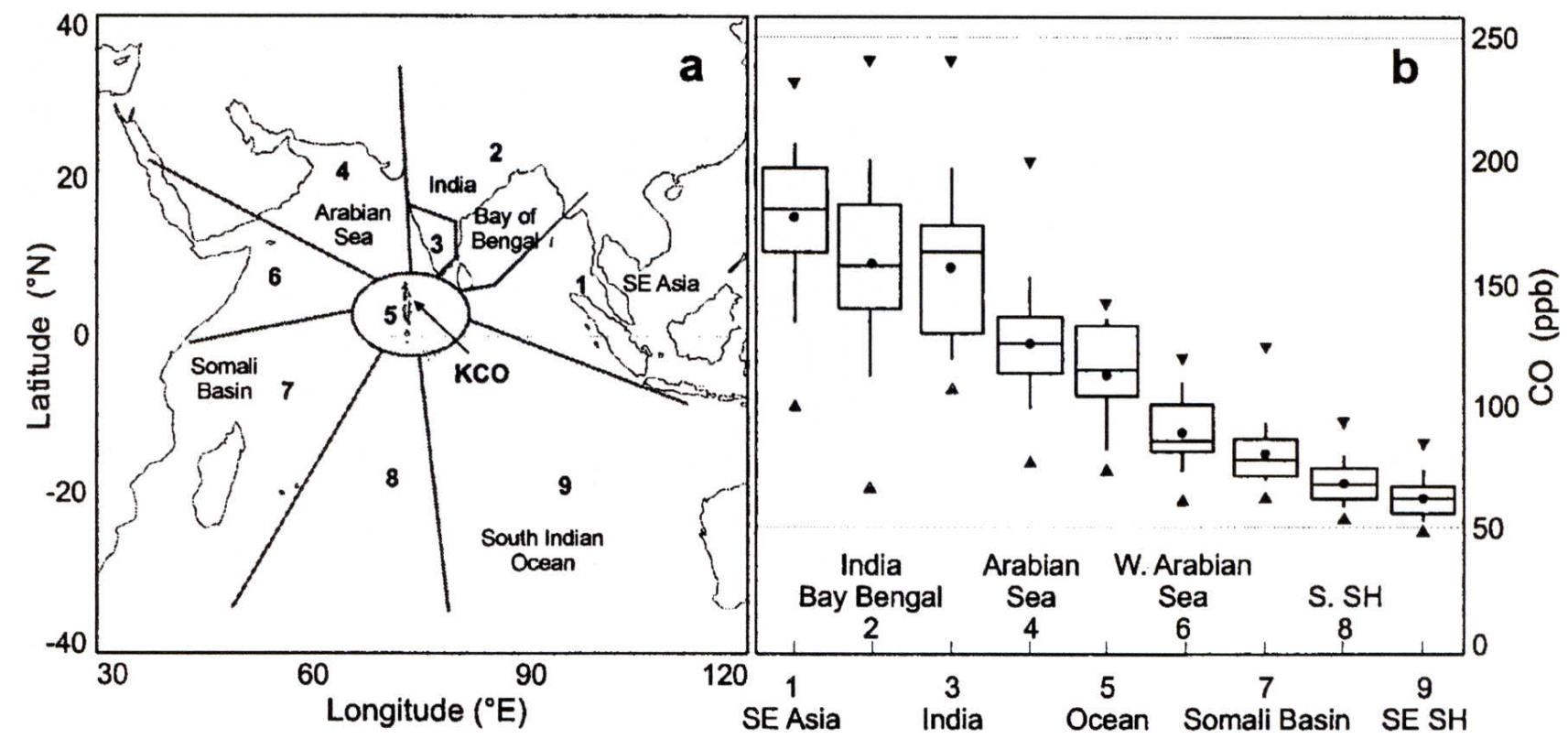

Fig. 29. (a) Key air mass flow bins for Kaashidhoo Climate Observatory (KCO) and (b) daily mean CO mixing ratios distributed over these nine air mass flow bins. The boxes describe the upper and lower quartile, the solid dot is the mean, and the bar is the median. The whiskers are the $10 \%$ and $90 \%$ quantiles, and the black triangles are minima and maxima (from Lobert and Harris, 2002, copyright 2002 by the American Geophysical Union, reproduced with permission).

main regions of origin using a clustering technique. Trajectories at 950,850 and $750 \mathrm{hPa}$ had broadly similar origins, as noted in Sect. 4.2.1, with the higher altitude trajectories tending towards a slightly more easterly origin than those at the surface. A strong interannual variability was found for the years analyzed (1998-2000), but generally there is a consistent shift in origin from east to west over the period of January to April, with:

- trajectories in January primarily originating from southern India, the Indo-Gangetic Plain (including Kolkata) by way of the Bay of Bengal, and southeastern Asia;

- February and March being a mix of about half of the airmasses having the same origins as in January, and the other half from Arabia via the Arabian Sea (with notable interannual exceptions, such as only $5 \%$ originating from Arabia in February 1999); and

- airmasses in April originating mostly from Arabia, the Arabian Sea and south-central India (again with exceptions such as April 1998, during which about half of the trajectories originated over southeastern Asia).

A very distinct gradient in $\mathrm{CO}$ as a function of the region of origin was found, as shown in Fig. 29, with the highest mixing ratios $(150-200 \mathrm{nmol} / \mathrm{mol})$ originating from SE Asia and the India/Bay of Bengal regions, and somewhat lower levels $(100-150 \mathrm{nmol} / \mathrm{mol})$ in air originating from Arabia and Europe, consistent with the differences in emissions characteristics in India and other regions discussed in Sect. 2. The
$\mathrm{CO}$ observations were found to also correlate very closely with several aerosol properties, such as the AOD and the absorption and scattering coefficients.

Figures 30 and 31 show summaries of the trajectory analysis of Beegum et al. (2008) for Minicoy Island and Port Blair. Minicoy Island shows generally similar characteristics for trajectory origins to $\mathrm{KCO}$, including the shift to more westerly origins between March and April, especially in the elevated pollution layer. At Port Blair the airmass trajectories originated mainly from Southeast Asia, the Indo-Gangetic Plain in northern India, and a small fraction $(\sim 10 \%)$ from Arabia, traversing over northern India. A clear shift towards a greater fraction of maritime origins is seen for both locations in May during the monsoon transition period (see Sect. 6). Interestingly, Moorthy et al. (2003) found for Port Blair that the airmasses originating from the east tended to have even higher values of AOD, as well as greater Angstrom exponents (indicating an abundance of fine particles), than those originating from the west, which will partly contribute to the observations (see Sect. 4.3.1) that the Bay of Bengal tends to be somewhat more polluted than the Arabian Sea.

In order to develop a broader classification of the origin of the gas and aerosol pollutants in the SAW-ABC, several studies have employed models, often in combination with in situ or satellite observations. The rest of this section will focus on studies which specifically examine the SAW-ABC, though it is worth noting that several other studies have been published using models to examine the overall source-receptor relations for various global regions, which have included the 


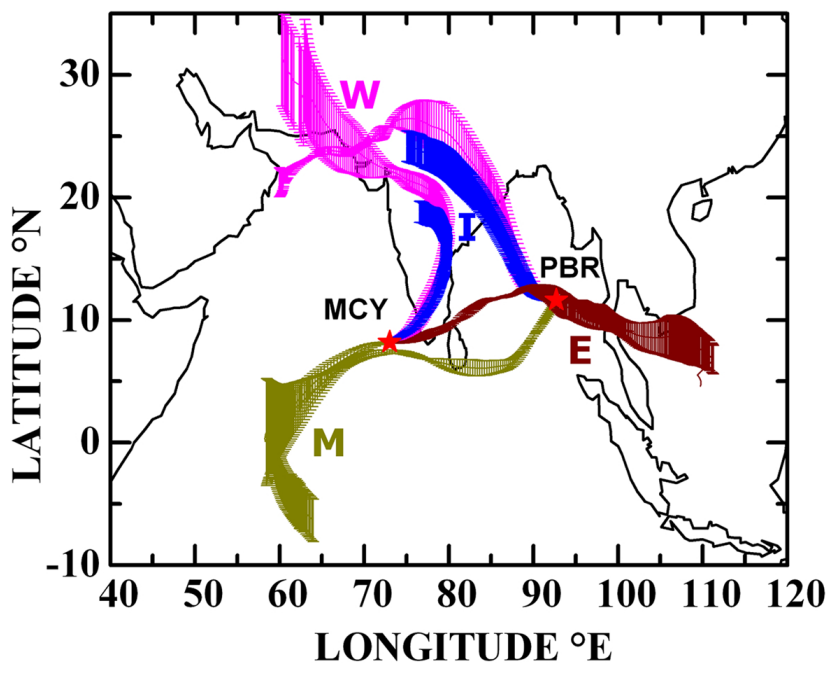

Fig. 30. Back trajectory groups arriving at $1800 \mathrm{~m}$ a.s.l. over Minicoy Island (MCY) and Port Blair (PBR) during April 2006. The vertical bars over the mean line show the spatial spread of each group. The regions of origin are: "E" - Eastern Asia; "I" - India; "W" - Western Asia and Arabia; "M" - marine (from Beegum et al., 2008, copyright 2008 by the Indian Academy of Sciences, reproduced with permission).

SAW-ABC in this context, both for aerosols (e.g., Koch et al., 2007) and for gases (e.g., Fiore et al., 2009).

Most of the aerosol modeling studies on this topic (Rasch et al., 2001; Collins et al., 2001, 2002; Reddy et al., 2004; Minvielle et al., 2004a, b) have focused on examining the distributions of the different aerosol components, and broadly linking these to the regions where sources of these components are known to be prominent (e.g., dust from the Arabian deserts, BC from biofuel burning in India and surrounding countries). The basic picture emerging from these studies has been discussed in Sect. 4.3.1. The study of Verma et al. (2008) takes these analyses a step further by examining the influence of individual regions and source processes on the distributions of the aerosol components over southern Asia and the Indian Ocean; an example of this is shown in Fig. 32 (note that the total sulfate and BC aerosol simulations are essentially the same as those from Reddy et al. (2004), shown earlier in Fig. 7). Table 8 presents a summary of the relative contributions of anthropogenic sources, as well as three major anthropogenic source categories, FFB, $\mathrm{BFB}$ and $\mathrm{BMB}$, to the surface aerosol density (in $\mu \mathrm{g} / \mathrm{m}^{3}$ ) and AOD in five subregions: the Indian subcontinent; the Arabian Sea (AS) and the Bay Of Bengal (BOB), both of which are assumed to extend down to $5^{\circ} \mathrm{N}$; and the western and eastern tropical Indian Ocean regions (WTIO and ETIO, respectively), both from $5^{\circ} \mathrm{N}-20^{\circ} \mathrm{S}$. On the whole, the anthropogenic contribution is computed to be generally larger for AOD than for surface concentrations, especially over the marine regions. This is largely due to two factors:
Table 8. Relative contributions of source processes to the surface aerosol density and AOD (in \%, all values rounded to the nearest integer) for the five subregions noted in the text: $\mathrm{AS}=$ Arabian Sea; $\mathrm{BOB}=$ Bay Of Bengal; WTIO = Western Tropical Indian Ocean; ETIO = Eastern Tropical Indian Ocean (based on data in Table 1 of Verma et al., 2008, copyright 2008 by the American Geophysical Union, adopted with permission).

\begin{tabular}{lrrrrr}
\hline & \multicolumn{5}{c}{ Emissions Source } \\
Anthropogenic \\
Region & Natural & Total & FFB & BFB & BMB \\
\hline \multicolumn{5}{c}{ Surface density } \\
India & 32 & 68 & 36 & 18 & 14 \\
AS & 76 & 24 & 15 & 1 & 8 \\
BOB & 69 & 31 & 18 & 4 & 9 \\
WTIO & 89 & 11 & 6 & 1 & 4 \\
ETIO & 94 & 6 & 3 & 1 & 2 \\
\hline & & AOD & & & \\
India & 12 & 88 & 44 & 14 & 30 \\
AS & 16 & 84 & 40 & 10 & 34 \\
BOB & 12 & 88 & 54 & 12 & 22 \\
WTIO & 40 & 60 & 35 & 7 & 18 \\
ETIO & 46 & 54 & 32 & 7 & 15 \\
\hline
\end{tabular}

first, in the MBL, sea salt aerosol densities are large and compete strongly with anthropogenic aerosols; and second, in the model simulations of Verma et al. (2008), some of the anthropogenic emissions such as $\mathrm{SO}_{2}$ from large industrial sources and aerosols from biomass burning are emitted into higher model levels (up to $1500 \mathrm{~m}$ above the ground, as described in Reddy et al., 2004). Thus, in the surface layer, there is a notably larger influence from anthropogenic emissions directly over India, a moderate influence (about 1/4 $1 / 3$ of the total aerosol) over the AS and BOB, and a small (order 10\%) influence over the WTIO and ETIO. In contrast, for the AOD there is a much larger influence of anthropogenic emissions everywhere, especially over the AS and $\mathrm{BOB}$, which have relative contributions comparable to that computed for the air column over India (exceeding 80\%), and even over the tropical Indian Ocean regions more than half of the AOD is due to anthropogenic emissions. Among the anthropogenic sources, FFB makes the largest contribution, about $1 / 2$ to $2 / 3$ of the anthropogenic surface density and $\mathrm{AOD}$, while $\mathrm{BFB}+\mathrm{BMB}$ contribute the other $1 / 3$ to $1 / 2$. Breaking these down into their chemical and regional origins, Verma et al. (2008) found the following (note that this goes beyond Table 8 , which shows only source types, not the details of regional tracer origin):

- the FFB contribution is mostly in the form of sulfate aerosols, but also contributes notably to $\mathrm{BC}$ and $\mathrm{OM}$; the largest contribution of sulfate (surface density and AOD) in most of the receptor regions is from India, though a substantial contribution (50-60\%) from the 

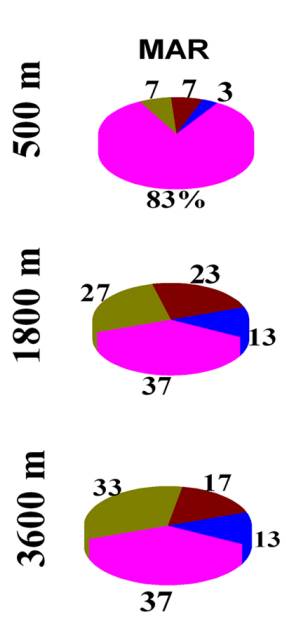
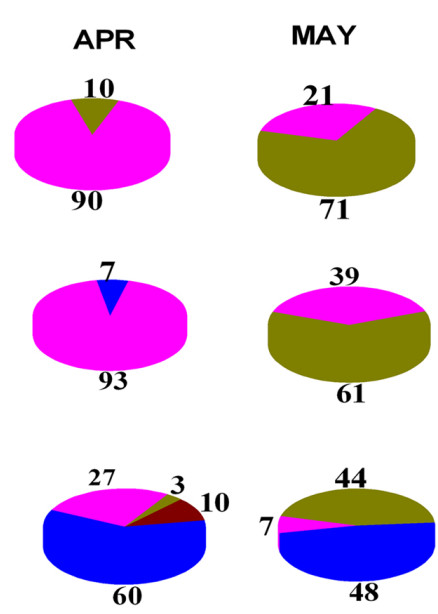

a
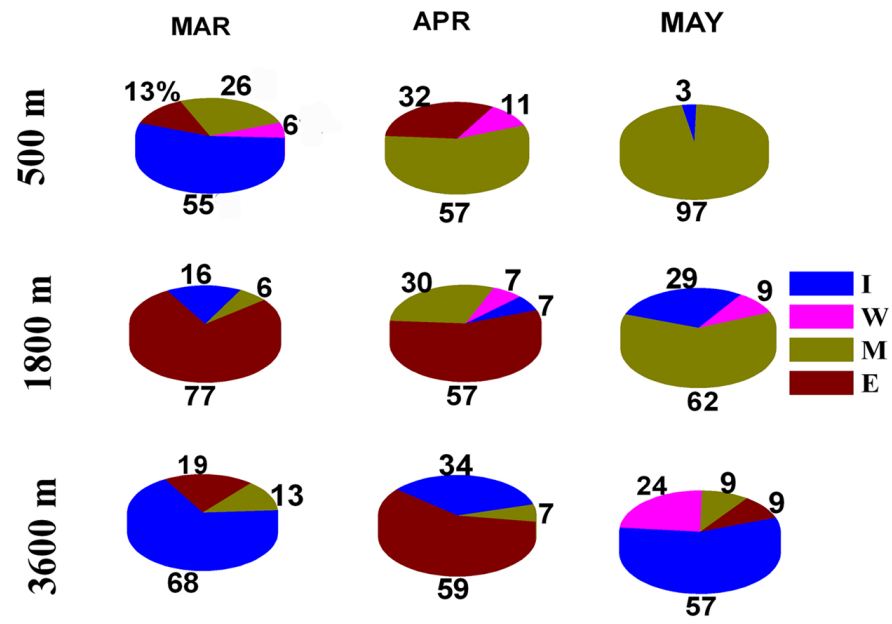

b

Fig. 31. Pie-chart representation of the percentage contribution from the different groups of trajectories depicted in Fig. 30, for three altitudes (500 m, $1800 \mathrm{~m}$ and $3600 \mathrm{~m}$ a.s.1.) for March, April and May over the two island stations of (a) Minicoy and (b) Port Blair (from Beegum et al., 2008, copyright 2008 by the Indian Academy of Sciences, reproduced with permission).

rest of the world is computed for the tropical Indian Ocean regions;

- BFB especially influences BC, particularly over India and the Bay of Bengal, with about $60-80 \%$ of BC in the surface layer coming from India, and the Indo-Gangetic Plain being the largest contributor amongst Indian subregions;

- BMB is especially important for OM, as well as contributing significantly to $\mathrm{BC}$, mostly coming from Africa and Arabia, with a notable influence throughout the domain, and a particularly large role in the aerosol composition over the Arabian Sea;

- Natural emissions are primarily in the form of sea salt in the MBL, and dust, mainly from Africa and Arabia, particularly in elevated aerosol layers.

Two caveats to these results are worth noting. First, the role of BFB + BMB is likely to be somewhat overestimated, since as discussed in Sect. 2 (Fig. 3), the new results of Gustafsson et al. (2009) show that the contribution to BC over the Indian Ocean is somewhat smaller than previously indicated in Reddy and Venkataraman (2002a, b), on which the emissions used in Verma et al. (2008) are based. Second, the aerosol parameterization used in the simulations of Verma et al. (2008) included a simplified aerosol microphysics and assumed external mixtures. This has on the one hand the advantage that the results of the simulations including only emissions from each region or source type under consideration will be linear, so that these simulations provide an exact source attribution for each region or process in the model (for more complex, non-linear aerosol parameterizations, this would not be the case). On the other hand, this introduces further uncertainties in the results compared to a model with a more complex aerosol representation. In both cases, however, we do not expect this to have a significant qualitative influence on the results discussed here.

Similar to the Verma et al. (2008) analysis of aerosols, a few studies have examined the broader features of the origins of gas phase tracers like radon, $\mathrm{CO}, \mathrm{NO}_{\mathrm{x}}, \mathrm{O}_{3}$, and polycyclic aromatic hydrocarbons (PAHs). Like for aerosols, some of these have included evaluations compared to the INDOEX observations, which generally show that the models are capable of simulating relatively well the large scale gradients and their changes over time, and thus presumably the gross influences of shifts in tracer origin, especially for $\mathrm{CO}$.

A good overall indicator of the connection between outflow patterns and pollutant origins is the radioactive tracer radon, which has an approximately uniform source over the continental regions, no source from the oceans, and a wellknown decay time (half-life of 3.8 days). Radon measurements were planned during INDOEX (Moore et al., 1999), but to the extent of our knowledge were never published. However, tagged radon tracer simulations for the region (Rasch et al., 2001) are useful in examining airmass origins; like for the aerosol tracers, the Indian contribution is found to dominate throughout much of the region, with significant additional contributions from Arabia and Africa, especially in the elevated pollutant layers discussed above.

Carbon monoxide, also valuable as a pollution tracer, has a much longer lifetime than radon or aerosols, and thus is more strongly influenced by long-distance transport sources. Nevertheless, the southern and southeastern Asian contributions to $\mathrm{CO}$ in the SAW-ABC are still very apparent, with 

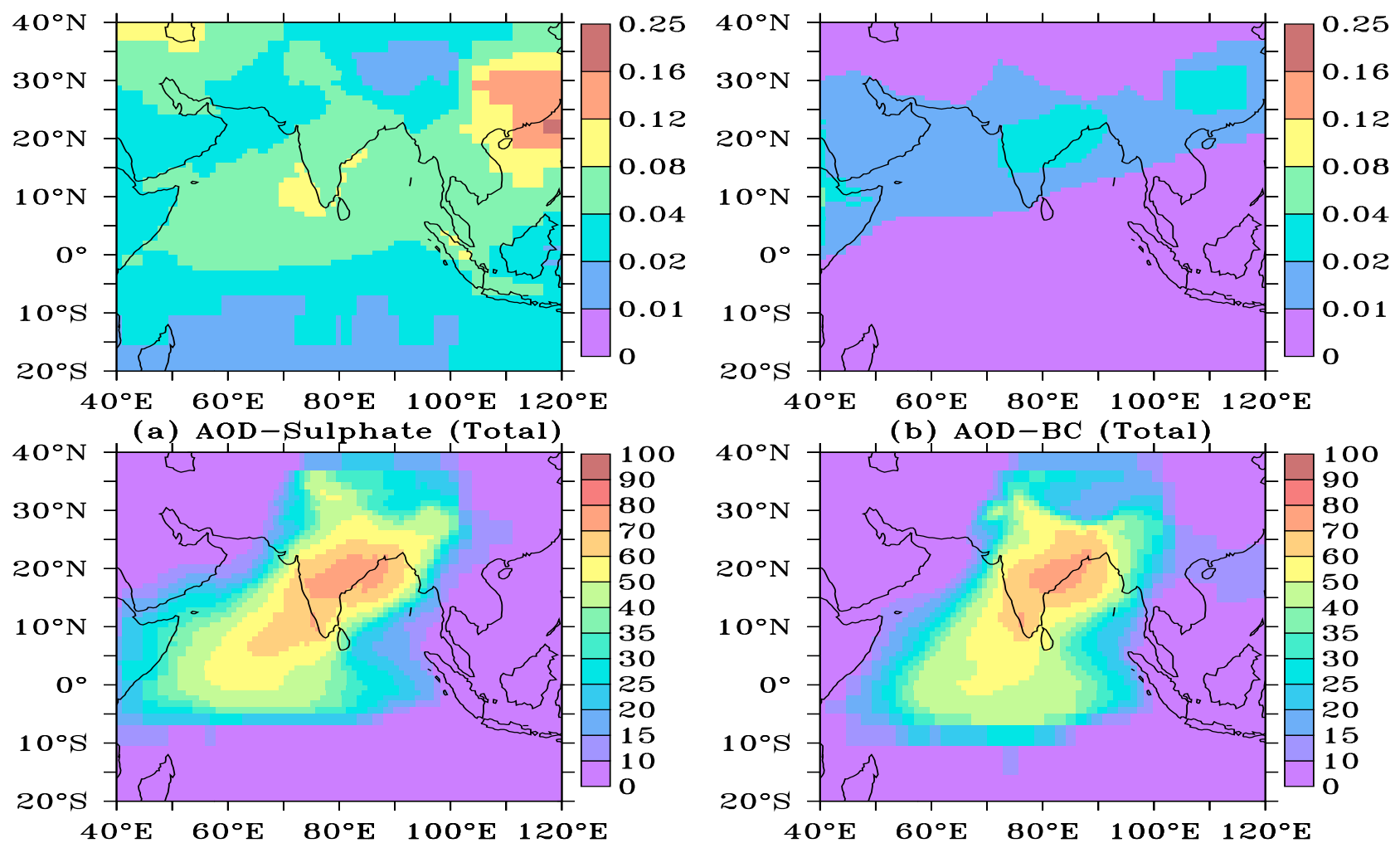

(c) AOD-Sulphate (India)

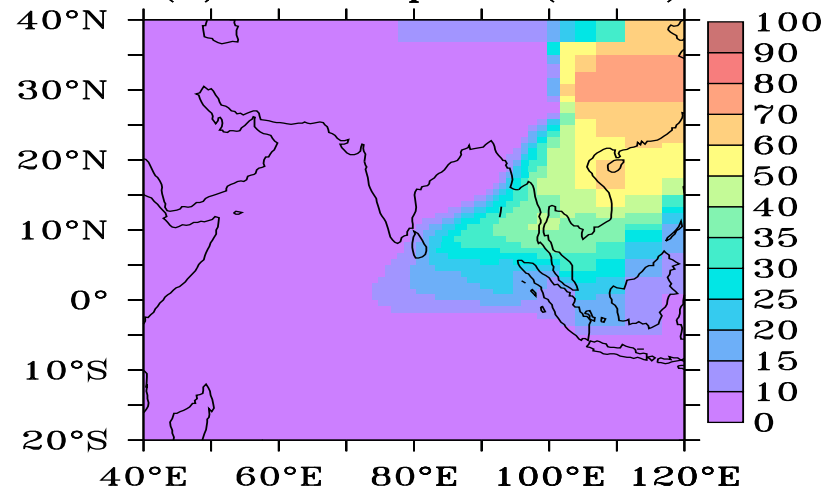

(d) AOD-BC (India)
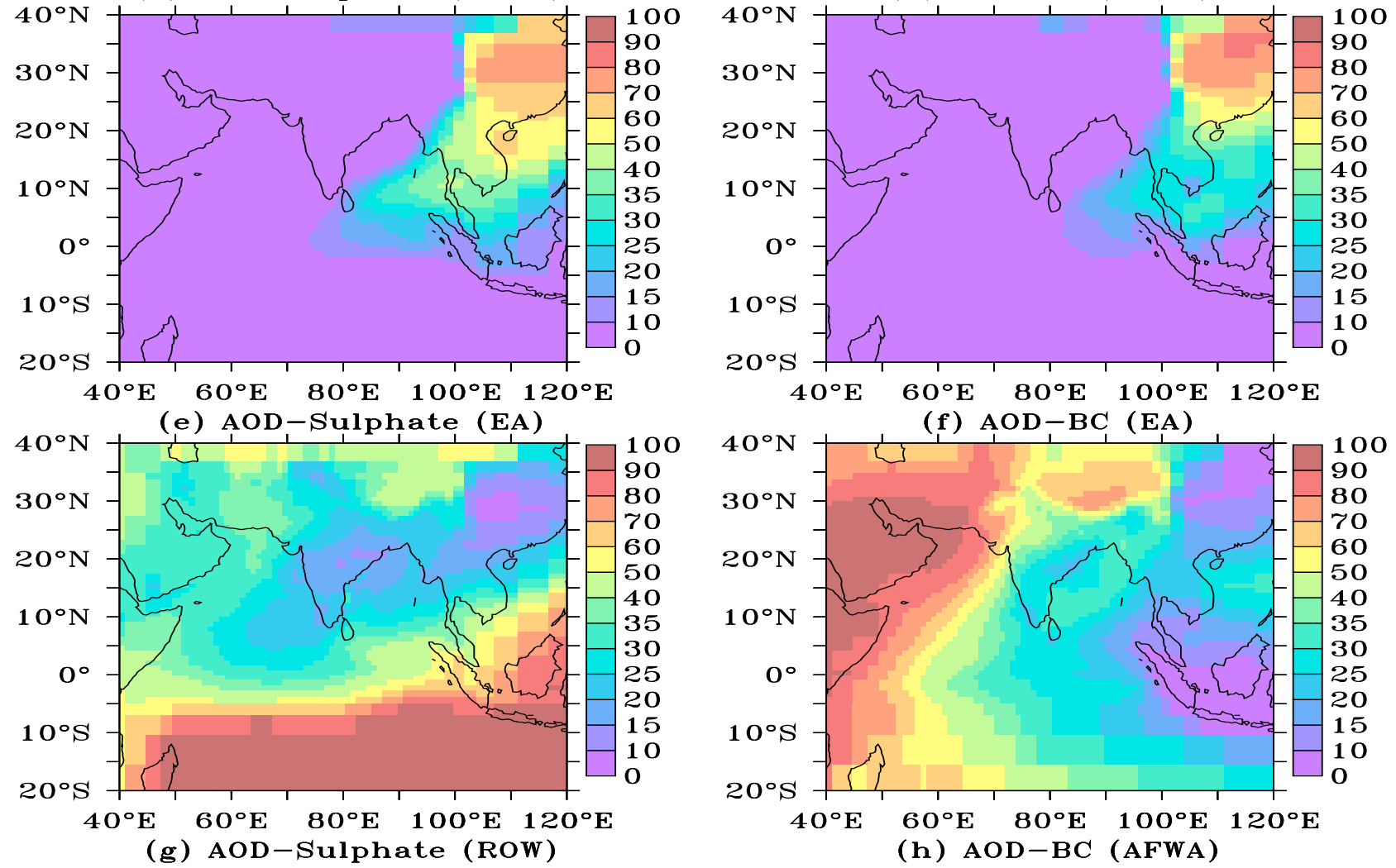

Fig. 32. Aerosol optical depth (AOD) at $550 \mathrm{~nm}$ simulated with the LMD-ZT GCM for sulphate and BC aerosols: (a) and (b) total; (c) and (d) from India; (e) and (f) from East Asia; (g) sulphate from the rest off the world (not including Africa); (h) BC from Africa and Arabia (from Verma et al., 2008, copyright 2008 by the American Geophysical Union, reproduced with permission). 
about $30-40 \%$ of the CO throughout most of the Arabian Sea MBL coming from India, and 20-30\% over most of the Bay of Bengal coming from SE Asia (de Laat et al., 2001b; Phadnis et al., 2002). Even down to the equator, generally $>20 \%$ of the MBL CO is simulated to be from India (in the west) or SE Asia (in the east).

For $\mathrm{NO}_{\mathrm{x}}$, which has significant chemical feedbacks, it is more difficult to determine an exact attribution. An alternate approach, used by Kunhikrishnan and Lawrence (2004), is to determine the "small perturbation tendency", or firstorder sensitivity to changes in the emissions, which is done by reducing the $\mathrm{NO}_{\mathrm{x}}$ emissions in a region by a small fraction (e.g., 10\%), then comparing the relative change in the $\mathrm{NO}_{\mathrm{x}}$ mixing ratio in the outflow regions to the relative reduction in the emissions. Doing this, the sensitivity of the SAW-ABC to the $\mathrm{NO}_{\mathrm{x}}$ emissions from India is computed to be about 20-30\% near the surface over the Arabian Sea and $30-40 \%$ over the Bay of Bengal, with a similar sensitivity to SE Asian emissions over the Bay of Bengal. Over the central Indian Ocean, due to its short lifetime (of the order of 1 day), $\mathrm{NO}_{\mathrm{x}}$ is relatively insensitive to any continental emissions, with the largest sensitivities being to SE Asia (5-10\%) and to India (3-5\%).

The photochemical production of $\mathrm{O}_{3}$ in the lower tropospheric SAW-ABC outflow from southern Asia, resulting in relatively high mixing ratios (exceeding $50 \mathrm{nmol} / \mathrm{mol}$ ) for several hundred $\mathrm{km}$ off the coast of India, was discussed above (Sect. 4.3.2). Several studies have also examined various aspects of layers of $\mathrm{O}_{3}$ pollution observed higher up in the free troposphere. The most comprehensive of these, by Chatfield et al. (2007), points towards two primary origins of ozone in the layers above 3-4 km altitude: stratospheric injection (Zachariasse et al., 2000, 2001), which provides an additional $\sim 40-50 \mathrm{nmol} / \mathrm{mol}$ of $\mathrm{O}_{3}$ when this mechanism is active, and convective injection of ozone and its precursors from the low-level SAW-ABC outflow into the middle troposphere over the northern Indian Ocean, which provides an additional $\sim 20-30 \mathrm{nmol} / \mathrm{mol}$. The analysis of de Laat (2002) provides an alternate explanation for these ozone layers, suggesting, based on model simulations in comparison with ozone soundings, that they originate mainly from convective lofting of biomass burning emissions over Africa. However, two particular criticisms of de Laat (2002) were raised by Mandal (2002): the assumption of an African BMB source is not consistent with the dataset south of the ITCZ, where similar ozone layers were encountered in the UT, but no biomass burning source should be available from Africa (i.e., stratospheric injection must be playing a significant role there); and only a subset (about half) of the available ozone soundings were selected for the analysis, possibly missing important signals in the remaining data. Chatfield et al. (2007) also state that though some of their trajectories do originate from the region west of North Africa, none come "close to either lightning or the potential venting of biomass burning." Sorting out this disagreement definitively will make an interesting future topic of research in this area of the field.

Finally, the origins of PAHs, another pollution tracer with important health implications, were investigated by Crimmins et al. (2004). They compared their data on the RV Ronald H. Brown during the INDOEX leg of the cruise to data with the same instrument on the AEROSOLS 99 leg, which traversed the Atlantic Ocean prior to INDOEX. Generally, the PAH concentrations over the northern Indian Ocean were found to be much larger (by approximately an order of magnitude) than those over the northern Atlantic Ocean. Comparison with other pollutants suggested that the main source is from fossil fuel combustion, with a smaller contribution from biomass burning. Interestingly, they found that although the total rate of fossil fuel burning in southern Asia is much smaller than that in Europe or the United States (see Tables 2 and 3), the larger amounts of inefficient combustion and fewer emissions controls in southern Asia results in notably greater PAH levels above the northern Indian Ocean than over the northern Atlantic.

Two final points are worth noting. First, many of these studies were conducted for one or two specific years (mostly 1999, plus some also for 1998), so that no clear sense can be given of the interannual variability in the details of the pollution origins as discussed above. However, some studies have examined the general impact of interannual variability on the pollution over the Indian Ocean, as discussed below in Sect. 4.5. Second, the degree of connection between the pollution origins and the resulting pollution levels in the SAW-ABC depends strongly on the chemical processing and aerosol aging which occurs within the outflow, as discussed previously in Sect. 4.3.

\subsection{Trends and interannual variability}

Concurrent with the increase in pollutant emissions discussed in Sect. 2, one would expect a long-term trend in the SAW-ABC pollution levels. This has been clearly observed over Trivandrum, a city on the southwest coast of India, for which consistent AOD measurements have been made over an extended period (Parameswaran et al., 1998). The time series was analyzed after INDOEX by Satheesh et al. (2002), and shows a gradual increase in AOD (at $500 \mathrm{~nm}$ wavelength), doubling in value from $\sim 0.2$ in 1986 to $\sim 0.4$ in 1999 (see Fig. 33). Ozone has also shown a long-term increase based on measurements of the total column over 23-45 years at several locations (Chakrabarty et al., 1998), and based on surface-level measurements made in the Indian west-coast city of Ahmedabad; peak afternoon values increased from about $25 \mathrm{nmol} / \mathrm{mol}$ in the mid-1950s to over $50 \mathrm{nmol} / \mathrm{mol}$ in the early 1990s (Naja and Lal, 1996). Similarly, recent measurements of $\mathrm{CO}$ over the Bay of Bengal made during the W_ICARB cruise of December 2008January 2009 show notably higher mixing ratios than observed during previous campaigns (including INDOEX) in 


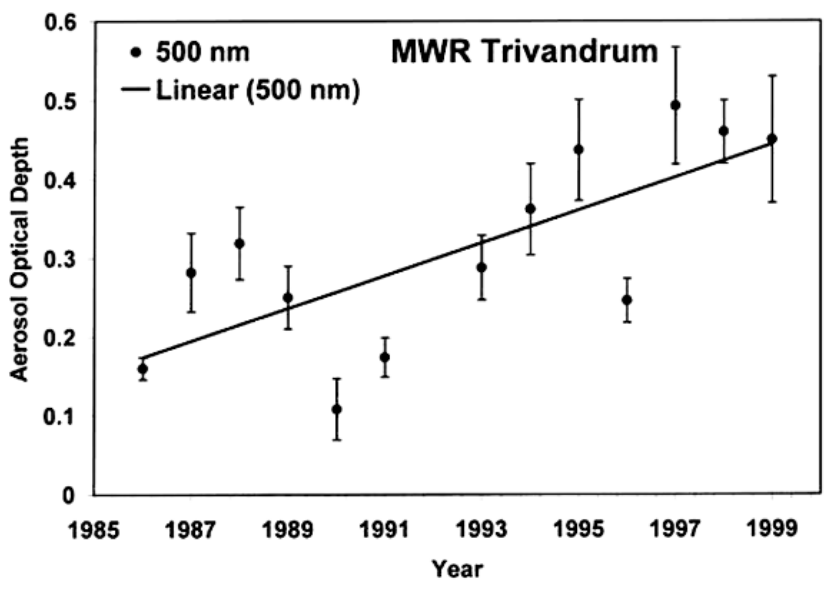

Fig. 33. Long-term variations in aerosol optical depth from 1986 to 1999 measured above Trivandrum; plotted are annual mean values with standard deviations determined from the monthly means (from Satheesh et al., 2002, copyright 2002 by the American Geophysical Union, reproduced with permission).

1999, 2001 and 2002 (Asatar and Nair, 2010), although the time period is too short and the data too sparse to establish a robust trend for $\mathrm{CO}$.

Superimposed on these trends is a strong interannual variability, which can be seen in Fig. 33, as well as in the earlier example depicted in Fig. 21. This was particularly noticed during and immediately after INDOEX, when observed AOD (Ramanathan et al., 2002) in the $1000 \times 1000 \mathrm{~km}$ region surrounding KCO was found to be up to twice as high in 1999 as in 1998. Similar large differences were also noted for gases such as CO (Lobert and Harris, 2002).

This large interannual variability led to the suggestion that the INDOEX results could be biased towards more polluted conditions than normal, since "the intensity of the haze happened to be a maximum in 1999 when the INDOEX observations were made" (Srinivasan and Gadgil, 2002; a response to this was given by Ramanathan et al., 2002, indicating in particular that the UNEP/ABC report, which was the focus of the commentary by Srinivasan and Gadgil, 2002, was based on a broad set of measurements and model simulations, not only the 1999 INDOEX data). A considerable debate evolved to determine the causes of the interannual variability, which included a special session on this issue at the first INDOEX science workshop in Utrecht, the Netherlands, in September 1999, with 15 presentations on various aspects of the contrast between 1998 and 1999. Since then, several publications have analyzed various aspects of this. For instance, Norman et al. (2003) examined aerosol observations from the 1998 and 1999 Sagar Kanya cruises and from the 1999 Ron Brown cruise, finding that the higher aerosol concentrations in 1999 compared to 1998 were associated with much shorter trajectory transport times since the last contact with the Indian subcontinent $(\sim 50 \mathrm{~h}$ for the 1999 Ron Brown cruise and $\sim 60 \mathrm{~h}$ for the 1999 Sagar Kanya cruise, compared to $\sim 110$ h for the 1998 Sagar Kanya cruise), resulting in a much greater potential for deposition loss in 1998. The reason for the shorter transport times in 1999 was a particularly strong northeasterly flow, transporting airmasses rapidly from the Indian subcontinent (also discussed in the meteorological overview by Verver et al., 2001).

A broader analysis of the interannual differences was provided by de Laat and Lelieveld (2002), who showed that the differences between 1999 and the previous years 1996-1998, as depicted in Fig. 34, can be ascribed to two main factors acting together. First, early 1999 was a La Niña period, during which the high pressure system which normally resides over southern Asia was stronger than normal, enhancing the pressure gradient between the Indian subcontinent and the northern Indian Ocean and strengthening the continental outflow. Second, during this period (especially February 1999) the convection in the ITCZ was considerably weaker than normal, associated with a passive phase of the Madden-Julian Oscillation (MJO), resulting in less effective ventilation of the pollutants out of the continental outflow, and thus in a buildup of trace gas and aerosol levels in the lower troposphere (LT) in the INDOEX measurements region. These two factors can also generally be used to explain most of the variations on a monthly-average basis which were observed throughout the INDOEX and pre-INDOEX campaigns (de Laat and Lelieveld, 2002).

Despite these large interannual differences, particularly seen in the region surrounding the Maldives, which was intensely sampled during INDOEX, it appears that there is much less interannual variability in the aerosol optical depths over the larger region covering most of the Arabian Sea and northwestern Indian Ocean. This was shown by Ramanathan et al. (2002), based on data from Li and Ramanathan (2002) and Tahnk and Coakley (2002), as depicted in Fig. 35; the wintertime AOD only varies by about $\pm 15 \%$ from year to year, with the AOD for 1999 being only slightly above the average from 1995 to 2001. An open question is whether this apparent stability is due to the relative interannual constancy of the largely anthropogenic emissions in the regions surrounding the Arabian Sea and northern Indian Ocean, or whether it is more of a balance - perhaps coincidental during the period analyzed by Ramanathan et al. (2002) - between processes leading to higher AODs in some parts of the region and lower AODs elsewhere.

\subsection{Regional climate effects}

The large scale effects of the SAW-ABC include in particular the radiative and cloud-modifying properties of aerosols and the resulting perturbations to the regional atmospheric and oceanic energy balance and climate. These effects depend on both the amount of aerosol present and the aerosol composition, and thus in turn on the emissions and chemical 
1999

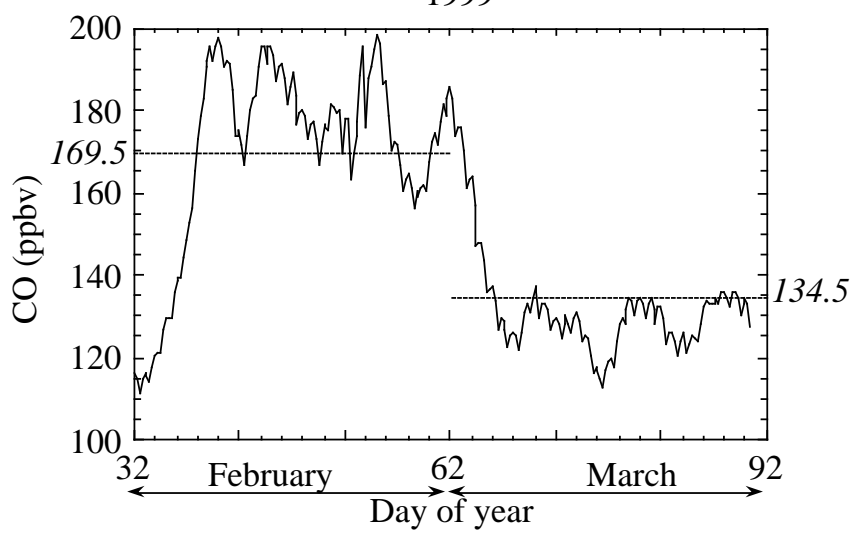

1997

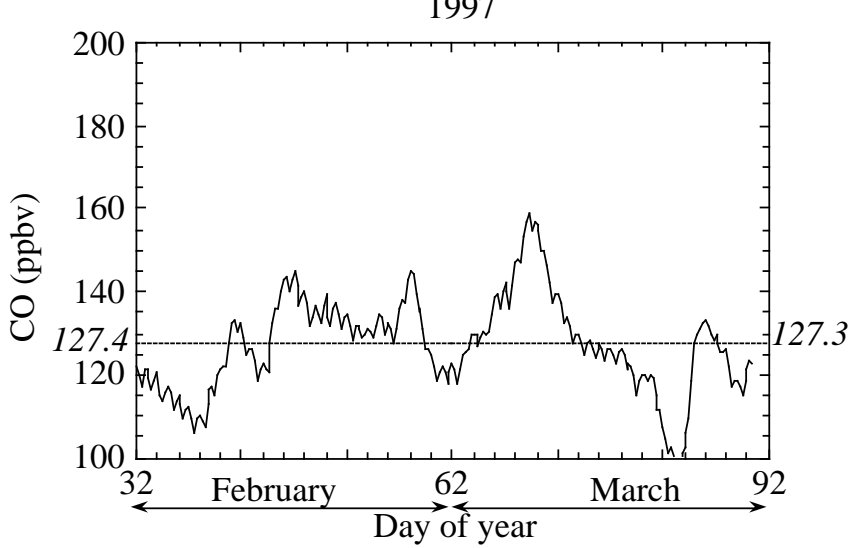

1998

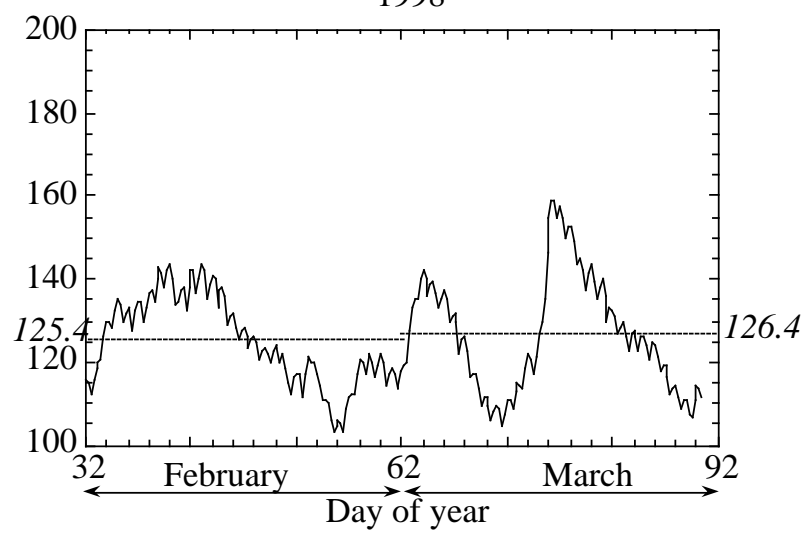

1996

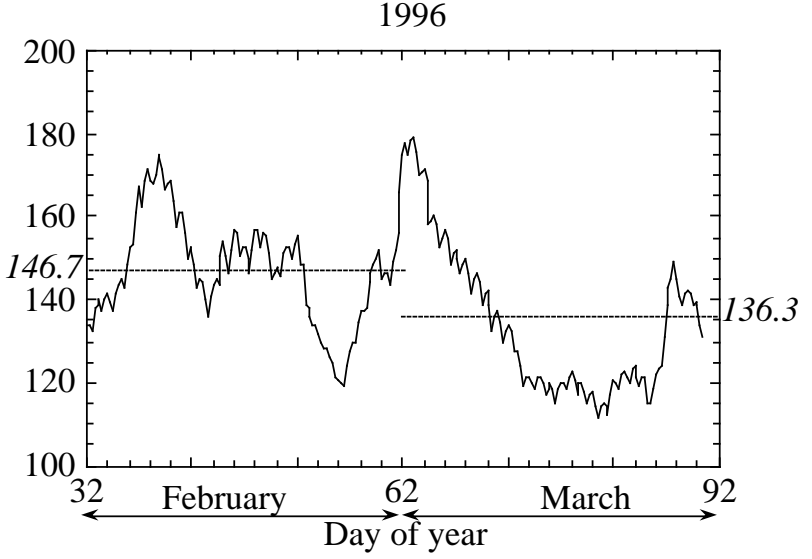

Fig. 34. Surface CO mixing ratio (ppbv) south of India at $5.5^{\circ} \mathrm{N}, 77^{\circ} \mathrm{E}$, for February and March 1999, 1998, 1997, and 1996, calculated with the ECHAM4 chemistry-general circulation model. The straight lines represent the monthly averaged modelled CO mixing ratios (from de Laat and Lelieveld, 2002, copyright 2002 by the American Geophysical Union, reproduced with permission).

processing, with the uncertainties and heterogeneities noted above. Despite these uncertainties, one message has become clear: the aerosol forcing is large, and the particles are highly effective in absorbing solar radiation. There are many different possible impacts of the SAW-ABC on regional climate. An summary of several of the main possible climate effects is presented in Table 9. This section gives an overview of the current state of knowledge about these regional climate impacts.

\subsubsection{Radiative forcing and atmospheric heating}

As discussed in Sect. 4.3.1, the SSA of aerosol mixtures observed over the Indian Ocean is typically $\sim 0.9$, computed from several independent methods based on observations, and it plays a key role in the radiative forcing of climate (Ramanathan et al., 2001). Model simulations indicate particularly low values $(\mathrm{SSA}<0.8)$ over continental northern India, Southeast Asia, and the northern Bay of Bengal (Collins et al., 2002). Black carbon is largely responsible for the absorption of solar radiation by the aerosols, and is nearly ubiquitously present in the pollution plumes (Lelieveld et al., 2001;
Satheesh, 2002; Satheesh et al., 2002; Vinoj et al., 2004). In the pollution source regions within the Indo-Gangetic plains the black carbon component is typically $10 \%$ or higher $(\mathrm{Ni}-$ ranjan et al., 2006; Ganguly et al., 2009), and although the aerosol mass concentrations decrease by dry deposition during transport, this fraction stays approximately constant during transport over the Indian Ocean (Ramanathan et al., 2001). Recently, it was shown that Asian air pollution also contains substantial quantities of "brown" carbonaceous compounds in amorphous spherules, which adds to the climate effects of the black carbon (Alexander et al., 2008). The absorbing and scattering properties of these spherules show a complex dependence on wavelength and diameter, as shown in Fig. 36. This of course adds a considerable complexity to an accurate representation of these effects in model simulations.

The radiative forcing efficiency, defined as the mean forcing per unit of AOD, depends on the aerosol mixing state. The absorption of sunlight can be non-linearly enhanced in a thick and well-mixed (internally mixed) aerosol haze due to the increased reflections and extinction efficiency, as well as gaseous absorption, notably by water vapor (Podgorny 
Table 9. Climate impacts of the SAW-ABC.

\begin{tabular}{ll}
\hline Impact & Level of understanding \\
\hline Aerosol forcing & Strong observational support \\
Solar dimming & Supported by observations (available since 1960) \\
Surface cooling effect & Supported by observed temperature trends \\
Reduction of surface evaporation & Consistent with observations over land (no ocean data available) \\
Weakening of latitudinal SST gradients & Robust model result, some observational support \\
Doubling of boundary layer heating rate & Robust model result, supported by measurement campaigns \\
Stabilization of lower troposphere & Consistent with satellite observations (available since 1979) \\
Deceleration of monsoon circulation & Consistent with meteorological analyses (unknown reliability) \\
Decrease in monsoon rainfall & Consistent with observed rainfall trends and variability \\
Retreat of Himalayan glaciers & Consistent with satellite observations (available since 1962) \\
ABC-induced droughts & Consistent with observed number of droughts/decade \\
\hline
\end{tabular}

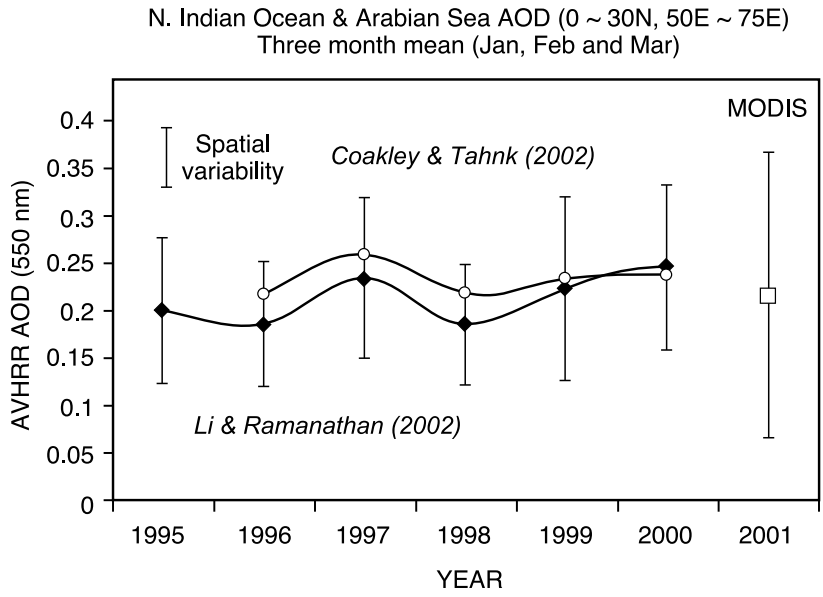

Fig. 35. Interannual variability of the mean satellite-observed aerosol optical depth (AOD) averaged over the northern Indian Ocean and the Arabian Sea; closed symbols are from Li and Ramanathan (2002), open symbols from Tahnk and Coakley (2002) (from Ramanathan et al., 2002, copyright 2002 by the Indian Academy of Sciences, reproduced with permission).

et al., 2000; Jacobson, 2001; Chandra et al., 2004). For the INDOEX plume it was shown that the top of the atmosphere (TOA) forcing was relatively modest, $-7 \mathrm{~W} \mathrm{~m}^{-2}$ for clear sky conditions and $-2 \mathrm{~W} \mathrm{~m}^{-2}$ by also accounting for the presence of clouds. However, this is deceptive because the effects of scattering and absorption counterbalance, which cannot be distinguished at the TOA. The uncertainty associated with the aerosol mixing appears to be limited because the INDOEX observations indicate an internal mixture, which is commonplace for particulates at some distance from the sources (McFiggans et al., 2006). Importantly, the observed surface forcing was much stronger than at the TOA, and the large difference between these terms implies substantial solar radiation absorption within the aerosol layer. Recent modeling results by Chung et
Table 10. Aerosol Radiative Forcing $\left(\mathrm{W} \mathrm{m}^{-2}\right)$ : North Indian Ocean, January-March 1999; 0-20 $\mathrm{N}, \tau_{\mathrm{a}}=0.3$ (based on plate 13 of Ramanathan et al., 2001, copyright 2001 by the American Geophysical Union, adopted with permission).

\begin{tabular}{lrrr}
\hline & $\begin{array}{r}\text { Direct } \\
(\text { Clear Sky })\end{array}$ & $\begin{array}{r}\text { Direct } \\
(\text { Cloudy Sky) }\end{array}$ & First Indirect \\
\hline TOA & $-7.0 \pm 1$ & $-2.0 \pm 2$ & $-5 \pm 2.5$ \\
Atmosphere & $+16.0 \pm 2$ & $+18.0 \pm 3$ & $+1 \pm 0.5$ \\
Surface & $-23 \pm 2$ & $-20 \pm 3$ & $-6 \pm 3$ \\
\hline
\end{tabular}

al. (2010) emphasize the regional and seasonal differences between different parts of Asia: in southern Asia the aerosol surface forcing is much larger in the dry season than in the wet season, whereas this is the reverse in eastern Asia.

The AOD over land during INDOEX was very high, about 0.5 , and remained high in the outflow, with values of up to 0.2 near the equator. Combined with the low SSA values, this yields a direct aerosol forcing of $-23( \pm 2) \mathrm{W} \mathrm{m}^{-2}$ (see Table 10) at the surface averaged over the northern Indian Ocean and the southern tip of India, which is about $15 \%$ of the solar heating of the northern Indian Ocean, and is over half as large as the net downward energy flux into the ocean, which is estimated at $30-50 \mathrm{~W} \mathrm{~m}^{-2}$ (Ramanathan et al., 2001). Only about $1 / 3$ of this surface forcing is due to the backscattering of sunlight; the other $2 / 3$ is due to the absorption of solar radiation by aerosols in the troposphere. This energetic input to the LT (lower troposphere) amounts to a heating rate perturbation of $0.5 \mathrm{~K} /$ day for the layer from the surface to $3 \mathrm{~km}$, which accounts for about half of the climatological solar heating of the LT in this region (Ramanathan et al., 2001; Satheesh, 2002; Satheesh et al., 2002, 2006a, b; Vinoj et al., 2004). The presence of clouds modifies the direct aerosol forcing slightly, but the qualitative distribution and magnitude of the forcing remains very similar. Several 
A

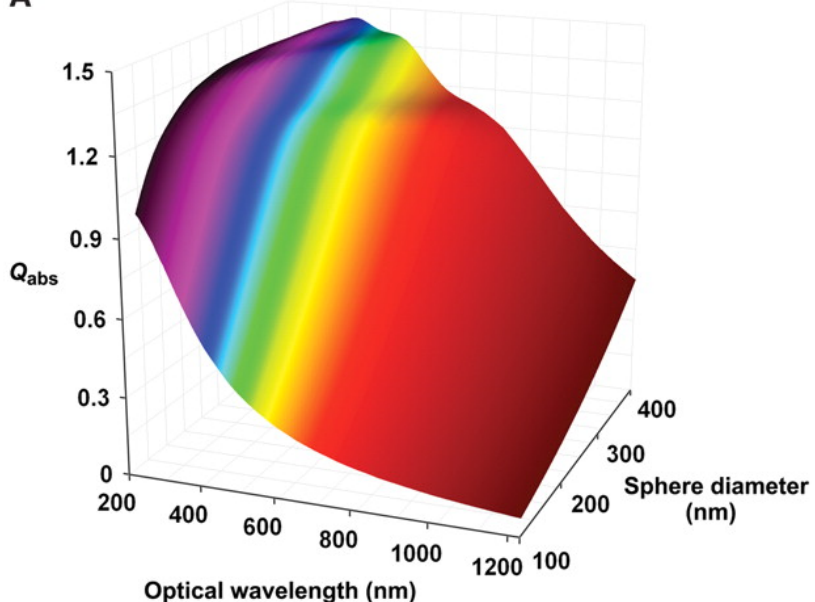

B

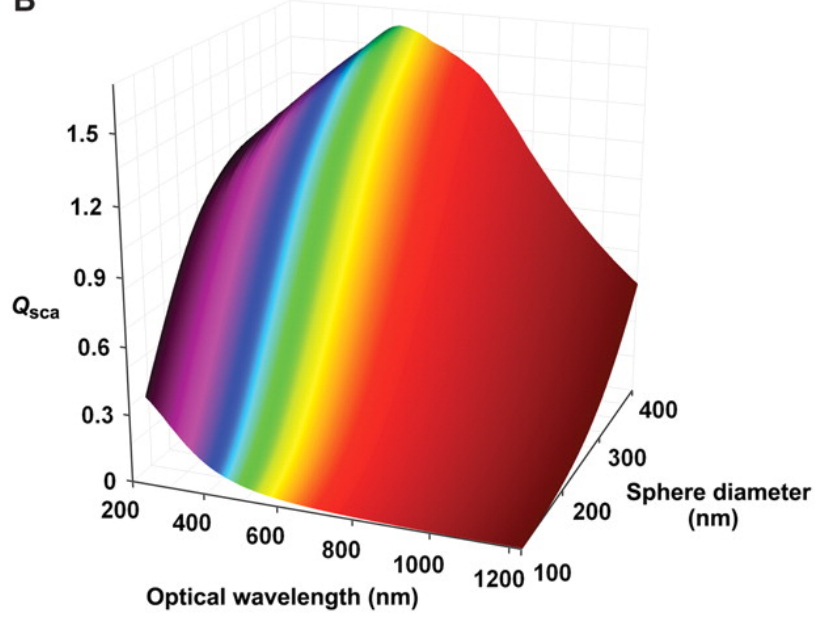

Fig. 36. Diameter and optical wavelength dependence of the light absorbing and scattering efficiencies, $Q_{\text {abs }}(\mathbf{A})$ and $Q_{\text {sca }}(\mathbf{B})$, of the carbon spheres observed by Alexander et al. (2008). The plots are colored to match the colors of the optical wavelengths; darkening of the red at high wavelengths and of the violet at low wavelengths represent infrared and ultraviolet, respectively (from Alexander et al., 2008, copyright 2008 by the American Association for the Advancement of Science, reproduced with permission).

studies reiterate the importance of realistically accounting for the full mixture of natural and anthropogenic aerosol compounds, in particular because the solar absorption by dust particles contributes to the heating of the lower atmosphere (Gautam et al., 2009; Wang et al., 2009). It is furthermore important to account for the aerosol layering as observed in the Indian outflow during the dry season in INDOEX and during the pre-monsoon season during ICARB. Much of the pollution can actually be transported above the boundary layer $(>2 \mathrm{~km})$, and often the extinction of solar radiation in these elevated layers is enhanced by clouds that form within the boundary layer (Satheesh et al., 2008). Such enhancements may reach up to a factor of three, and in particular the absorption-induced warming can be several degrees compared to that near the surface.

A complicating factor in calculating aerosol heating rate perturbations is that the AOD is wavelength dependent, as a result of the wavelength dependence of aerosol absorption and scattering properties (see Fig. 36). Meywerk and Ramanathan (2002) found that the Southern Asian aerosol haze reduces the solar irradiance at the surface per unit AOD by $25 \%$ at $350 \mathrm{~nm}$ wavelength, but only $10 \%$ in the nearinfrared. In addition, mid- and far-infrared effects need to be accounted for. A typical SAW-ABC with an AOD of 0.3 decreases the downwelling longwave radiation flux at the surface by $7.7 \mathrm{~W} \mathrm{~m}^{-2}$ while decreasing the upwelling flux by $1.3 \mathrm{~W} \mathrm{~m}^{-2}$, thus partly offsetting the aerosol related shortwave cooling forcing (Lubin et al., 2002). These calculations were performed for an externally mixed aerosol, whereas it is expected that the effects for internally mixed particles can be larger by up to a factor of two. Again the composition and mixing state of the pollution haze are important, and they also influence the aerosol hygroscopic growth and thus the particle size and wavelength dependent forcing.

An interesting feedback is that the latitude dependent radiative forcing over the Indian Ocean affects the regional heating gradients and consequently the wind speed. It is expected that the north-south gradients are reduced by the shortwave forcing of the SAW-ABC (Chung and Ramanathan, 2006). As a consequence the winds may weaken, and less sea salt would be emitted. The sea salt particles are generally large and effectively contribute to the longwave forcing (Satheesh and Lubin, 2003). Although not yet studied in sufficient detail, the expected consequence of the reduced sea salt abundance is that the net radiative forcing will increase. It will be important that climate models account for such feedbacks.

The net cooling forcing at the surface can have a major influence on the hydrological cycle, in particular over water surfaces (e.g., Roeckner et al., 1999). Over the tropical oceans about $70-80 \%$ of the absorbed solar energy is balanced by evaporation, so that the pollution aerosols reduce the water vapor flux to the atmosphere (Podgorny and Ramanathan, 2001). On the other hand, the solar heating of the LT can lead to the dissipation of trade cumulus clouds as they are sensitive to solar absorption, which enhances the solar radiation penetration to the surface (Ackerman et al., 2000). When clouds are present the vertical distribution of the aerosols is of key importance, in particular when the pollution is located above the clouds, which can cause the net aerosol cooling to change sign (Haywood and Shine, 1997; Satheesh et al., 2008). Thus, it is not so much the TOA forcing by anthropogenic aerosols which is most relevant but rather the redistribution of solar energy within the 

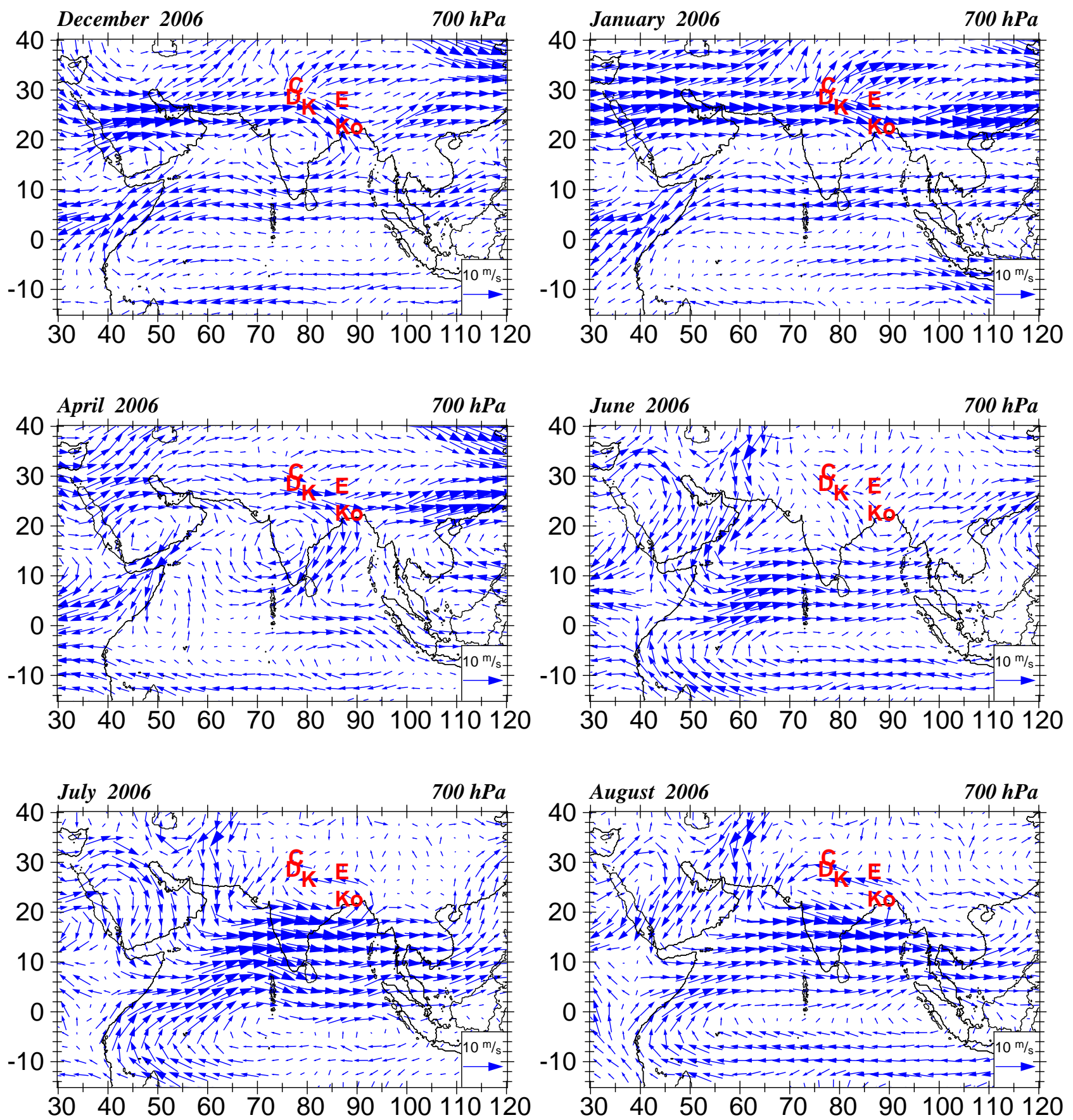

Fig. 37. Wind vector fields over southern Asia at $700 \mathrm{hPa}$ for selected months in 2006, based on NCEP-GFS data, focusing particularly on the flow to the Himalayas, marked by "E" for Mt. Everest. Labeled cities in the Indo-Gangetic Plain are: C - Chandigarh; D - Delhi; K Kanpur; Ko - Kolkata (Calcutta).

atmosphere-surface system, which can exert strong climate influences.

The surface albedo is another important factor. Land surfaces tend to be more reflective than the ocean, with the consequence that the TOA forcing by the aerosols can change drastically, e.g. turning from negative over the ocean into positive over land, all other conditions being equal (Satheesh et al., 2002). Since the surface forcing deviates less strongly, the net effect is that the atmospheric heating perturbation over land can be much larger than over the ocean. An observational study near Bangalore indicates an atmospheric heating rate perturbation of $\sim 0.8 \mathrm{~K} /$ day for an AOD of 0.24 and of $\sim 1.5 \mathrm{~K} /$ day for an AOD of 0.45 (Babu et al., 2002). The expected trend in surface cooling by increasing aerosol 
pollution over continental India since about 1960 is about $0.1 \mathrm{~K} / \mathrm{decade}$, supported by the analysis of historical meteorological data (Krishnan and Ramanathan, 2002). This study compared the temperature trend during the relatively polluted dry season with the monsoon period when the aerosols are more efficiently removed by precipitation. Unfortunately, for the ocean such data are lacking.

\subsubsection{Impacts on mountain cryospheric reservoirs}

The SAW-ABC and its climate effects extend into the Himalayan and Tibetan Plateau region. Though in principle this could still be considered part of southern Asia, this is an important example of the outflow of highly polluted air into an otherwise largely pristine region. Observations in Nepal, combined with satellite data, show elevated typical wintertime AODs of 0.2 to 0.34 in the entire region, with an SSA near the surface of $0.7-0.9$, indicating a highly absorbing aerosol layer (Ramana et al., 2004; Dumka et al., 2006). The consequent mean seasonal solar radiation reduction at the surface is about $25 \mathrm{~W} \mathrm{~m}^{-2}$, with some $4-20 \mathrm{~W} \mathrm{~m}^{-2}$ of this being due to absorption by $\mathrm{BC}$ in the lower atmosphere (Marcq et al., 2010). This results in a heating rate anomaly in the lower two kilometers of $\sim 1 \mathrm{~K} /$ day; depending on where this heating occurs in the vertical, and the large-scale atmospheric characteristics, this can either stabilize the LT by strengthening the temperature inversion, which would tend to increase the aerosol residence time (a positive feedback), or it could destabilize the near-surface atmosphere, providing potential energy for development of deep cumulus convection. The aerosol induced heating anomalies in the Himalayan region, in addition to the direct solar radiation absorption by black carbon deposited on the ice surface, have been proposed to lead to changes in the southern Asian monsoon dynamics, as well as to contribute to the observed strong decrease of glacier area in this region (Kulkarni et al., 2007; Ramanathan et al., 2007b; Xu et al., 2009; Menon et al., 2010).

One of the difficult issues has been sorting out the relative impacts on the snowpack runoff and glacier melt due to:

- increasing greenhouse gas levels;

- aerosols in the atmosphere (which tend to warm the air due to the large absorbing fraction, but reduce the solar flux reaching the surface); and

- decreases in snow and ice albedo due to deposition of aerosol particles, especially BC and dust, which requires a complex chain of modelling considerations, including emissions, atmospheric transport, aerosol deposition, and detailed snow surface dynamics.

The general potential for a substantial transport of aerosol pollution to the Himalayas, especially as part of the SAW$\mathrm{ABC}$, is indicated in Fig. 37, which shows the regional transport pattern at $700 \mathrm{hPa}$ based on wind fields from the NCEPGFS data (these are complementary to the surface data in
Fig. 6). The Indo-Gangetic Plain is situated diagonally, running from the northwest to the south of the Himalayas (Mt. Everest is marked with an "E", while the other markings are major cities of the Indo-Gangetic Plain, see caption for details). During the long period from December to April there appears to be an effective pathway for transport of pollution, especially in the elevated layers discussed in the previous sections, from the Indo-Gangetic Plain to the Himalayas (the wind patterns are very similar at 800 and $600 \mathrm{hPa}$, with generally increasing wind speeds at higher altitudes). During May-June, as well as September-November, this pathway becomes less distinct, though still present. Interestingly, during the main summer monsoon period (July and August) the possibility of transport of airmasses from central India out over the Bay of Bengal, then northwards over Bangladesh and up into the Himalayas is evident; it can be expected, however, that substantial scavenging of aerosols and soluble gases would occur via this pathway. During the wintertime, the wind fields also suggest the possibility of transport of Arabian desert dust and pollution aerosols (especially from oil drilling and processing), and possibly even of pollution from Europe. There is some interannual variability in these transport patterns, though the seasonal variations are similar for other years that we have examined, with the main exception that the recirculation pattern during the summer monsoon appears to have been particularly strong in 2006 .

Indeed, strong evidence for transport of pollution to the Himalayas has been provided by ice core observations at 5 locations (Xu et al., 2009), which showed high BC levels during the period 1950-1970 in several of the ice cores, especially those further to the west (attributed by $\mathrm{Xu}$ et al. (2009) to strong European pollution during that period), and growing BC levels since about 1980 in most of the ice cores, especially those further to the south (attributed to increasing Asian pollution). Further support has been provided by recent observations at the Nepal Climate ObservatoryPyramid (NCO-P), located at $5079 \mathrm{~m}$ a.s.l. on the southern foothills of Mt. Everest (a joint venture of the UNEP/ABC and the Italian SHARE-Ev-K2-CNR projects). Regular observations have been made there since March, 2006, showing that pollution from the Indo-Gangetic Plains can be transported in a "direct channel" up the Himalayan foothills and have a substantial impact on the air quality of the region, especially in the southern Himalayas (Bonasoni et al., 2010). The pollution levels are astonishing: peak mass densities of $\mathrm{BC}$ of up to $5 \mu \mathrm{g} \mathrm{m}^{-3}$ - characteristic of a typical polluted urban center - are observed during several days each year (Marinoni et al., 2010). The pollution impact has a large seasonal cycle, as shown in Fig. 38, being largest directly before the summer monsoon (mainly March-May), minimum during the summer monsoon, and moderate in the post-monsoon and winter monsoon periods (Bonasoni et al., 2010; Marinoni et al., 2010; Decesari et al., 2010). The seasonality does not fit exactly to the indication from the large scale wind patterns (Fig. 37), which is indicative of the complex 

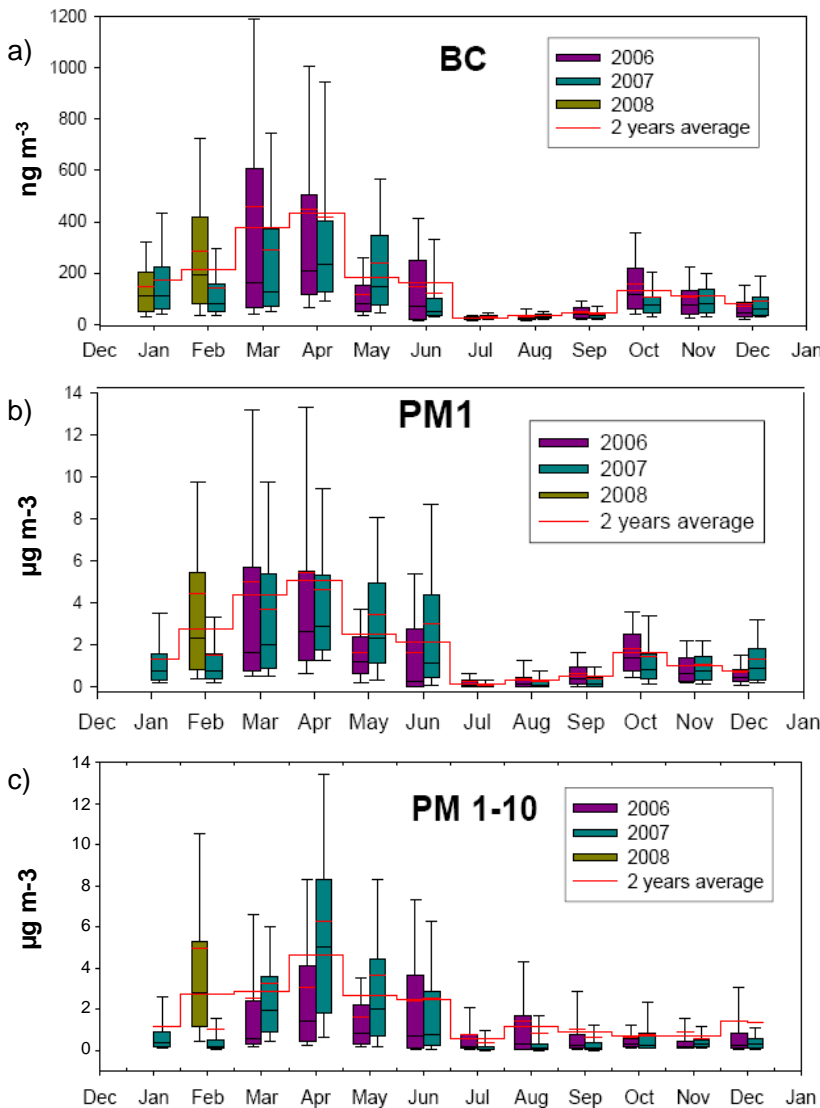

Fig. 38. Observations at the Nepal Climate Observatory-Pyramids of (a) BC, (b) PM1, (c) PM1-10; the 30-min measurements are presented as monthly averages (black line within the boxes), medians (red line within the boxes) and percentiles (10-25-75-90, boxes and whiskers), with the continuous red lines representing the 2 year averaged monthly data. (from Marinoni et al., 2010, copyright 2010 by the European Geophysical Union, reproduced with permission).

chain of processes from emissions to deposition and interaction with the snow, as noted above, in particular the importance of small-scale meteorological features in the difficult Himalayan terrain.

A first attempt to quantify the origins of the $\mathrm{BC}$ being deposited in the snow in this region has been made by Kopacz et al. (2010), employing an adjunct version of the GEOSChem global chemistry-transport model to perform a formal inversion for five different locations spread out over the Himalayas and Tibetan Plateau. This in principle allows an exact determination of the mixture of sources from different locations which contribute to the BC pollution in the Himalayan and Tibetan Plateau region. However, at present, the precision of such results will be substantially limited due to the large uncertainties in modelling the processes involved, especially with the coarse resolution of current global models; in this case, the GEOS-Chem model is run at a resolution of $2^{\circ} \times 2.5^{\circ}$. The difficulty in simulations of the $\mathrm{BC}$ deposition in snow is evident in the comparison with available observations which Kopacz et al. (2010) present, which show differences of more than a factor of two at 11 out of 17 sites (both over- and under-estimates, with no recognizable systematic biases). Nevertheless, the model is within the right order of magnitude, and is able to reproduce some of the seasonal and spatial variations in the concentrations, and thus can be considered a valuable step forward in providing a first rough quantification of the source regions for the $\mathrm{BC}$ deposited in snow here. An example of the results is in Fig. 39, which shows the BC origins for the model grid cell containing the Mt. Everest station. The results are generally similar to what was expected based on Fig. 37, which is not surprising, since the large scale winds will be one of the dominant factors determining the $\mathrm{BC}$ transport in global models like GEOS-Chem. The Indo-Gangetic Plain is the primary source region in January, as well as in October, and the anticipated recycling through the Bay of Bengal in July is also seen in these results. Long range transport is also evident, particularly from Arabia and Africa in January and from China in July. Interestingly, the GEOS-Chem results show a strong transport from throughout India during April. There are differences in the $\mathrm{BC}$ origins for the other target locations examined by Kopacz et al. (2010), in particular with the European contribution becoming significant for the sites farther north over the Tibetan Plateau. Further refinement of these results using more highly-resolved regional models will be an important step in furture studies of this issue.

Based on their simulation results, Kopacz et al. (2010) also estimate the radiative forcing by the $\mathrm{BC}$ in air and deposited in snow, with the snow-albedo effect being in the range of $4-16 \mathrm{~W} \mathrm{~m}^{-2}$, and the direct atmospheric effect being about a factor of five smaller. Based directly on atmospheric observations, Yasunari et al. (2010) have made similar estimates; taking this one step farther down the chain of processes, they compute that the deposition of $\mathrm{BC}$ on the snow here should result in a reduction of the albedo by $2.0-5.2 \%$, which would in turn increase the runoff by about $10-30 \%$. However, Qian et al. (2010) have pointed out that there are substantial uncertainties in the processes involved, and that any "more quantitative assessment of this effect will require improved models and/or higher grid resolution to better simulate snow and aerosol deposition on the TP [Tibetan Plateau]." Qian et al. (2010) used a climate model coupled with a snow and ice radiation model (Flanner et al., 2007, 2009) to more broadly examine the relative roles of the three processes noted above. While greenhouse warming leads to a substantial increase in glacier melt rates, their simulations indicate that under present conditions, the impact from decreased albedo due to aerosol particle deposition on the snow is computed to be even larger (although they point out that their modelling approach may lead to an overestimate of the effects of aerosol deposition on snow, so that it would be most fitting to say that the greenhouse warming and aerosol deposition effects appear to be roughly comparable). 

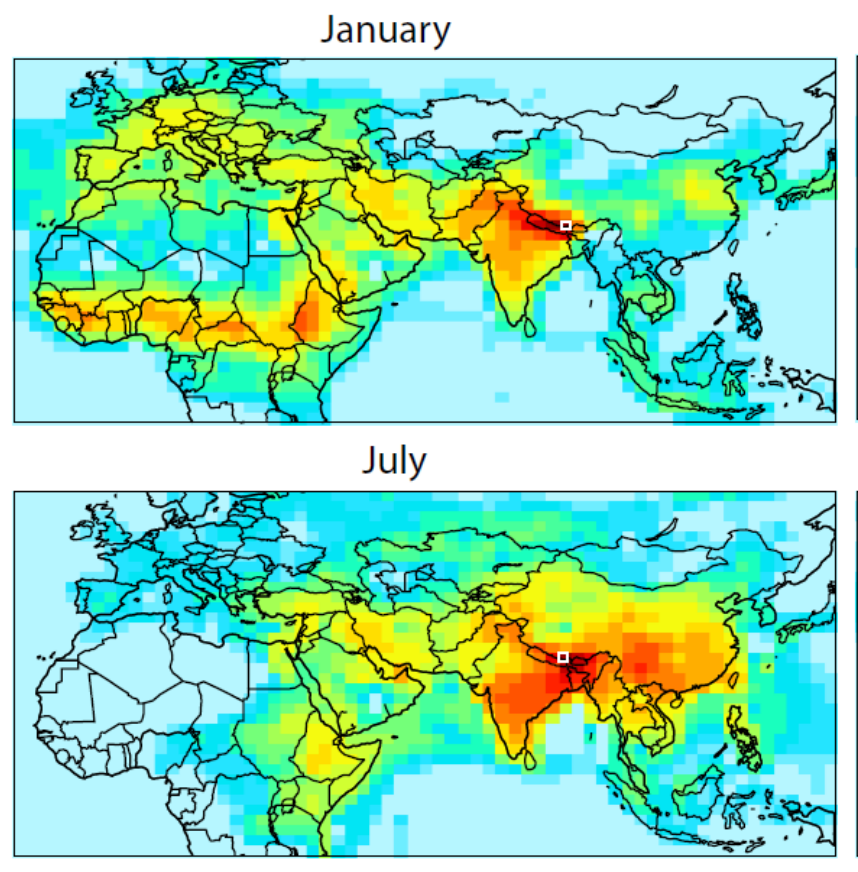

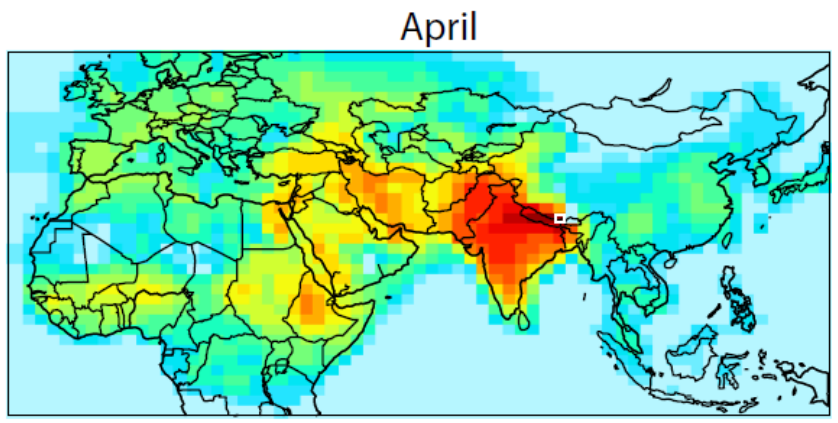

October

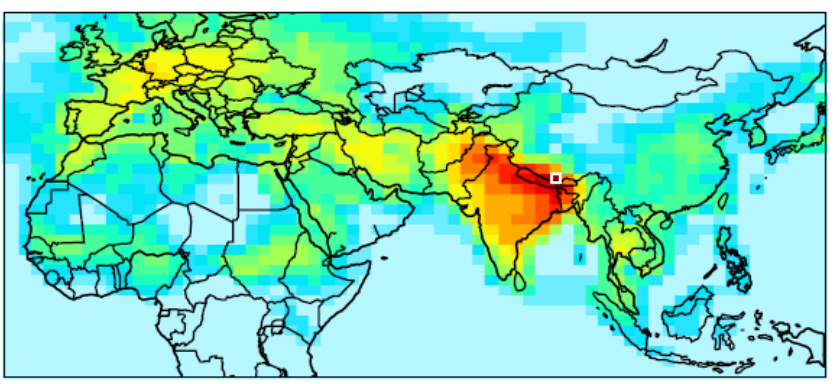

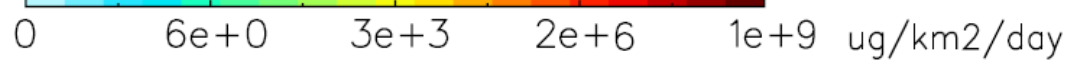

Fig. 39. Origin of black carbon by season (January, April, July, October) at Mt. Everest, as simulated with the GEOS-Chem model; the target grid box is outlined in white, and the quantity of BC deposited in the glacier grid box originating from every other grid box in the domain is indicated in color (from Kopacz et al., 2010, copyright 2010 by the European Geophysical Union, reproduced with permission).

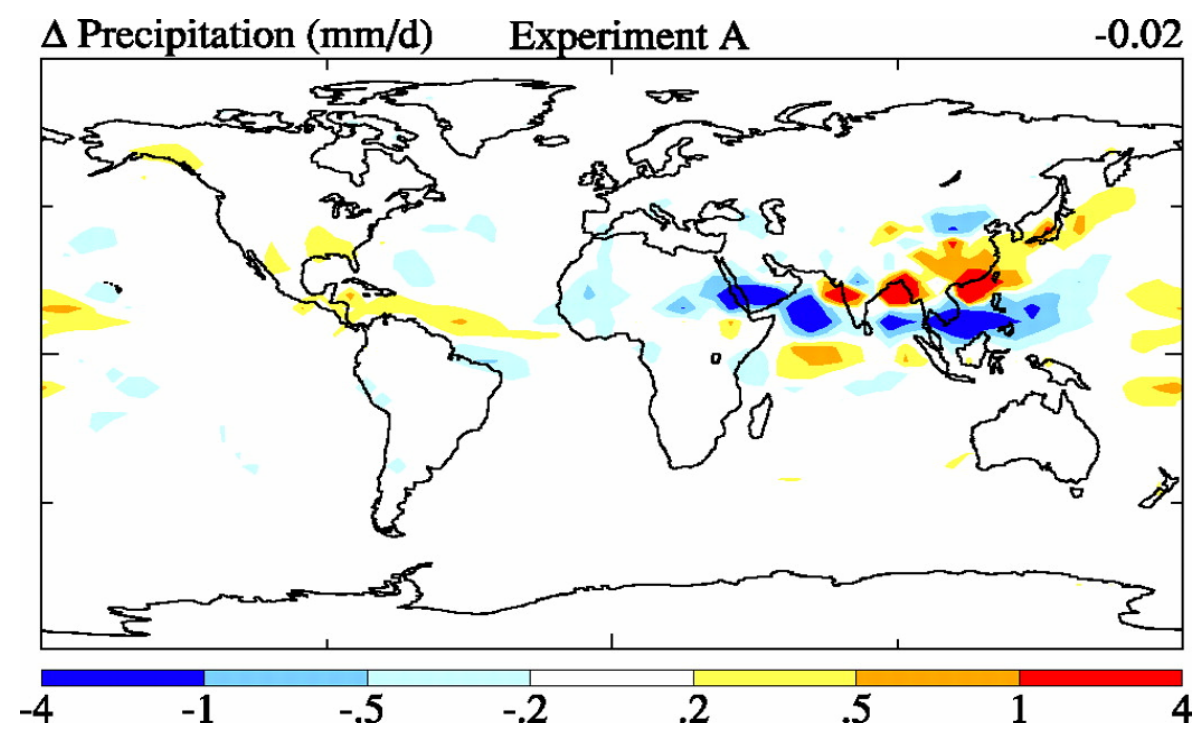

Fig. 40. Simulated JJA surface precipitation changes for an experiment including a mixture of sulfate and BC, yielding absorbing aerosol particles with ssa $=0.85$, minus a reference simulation without aerosol forcing (from Menon et al., 2002, copyright 2002 by the American Association for the Advancement of Science, reproduced with permission).

In particular they note that the "snowmelt efficiency", which they define as the amount of snowpack reduction per unit degree of warming induced by either of the two forcing agents, may be up to 4 times larger for the aerosol deposition in snow than for greenhouse warming. Furthermore, though their sensitivity simulations show that the aerosols in the atmosphere result in a cooling at the surface, this effect is overwhelmed by the combined warming effects of greenhouse 
gases and reduced albedo from aerosol deposition. The climate model of Qian et al. (2010) shows that these combined effects, for the Himalayas and the broader Tibetan Plateau, lead to substantial perturbations of the regional hydrological cycle as well as the Asian monsoon circulation. Given these potential impacts, and their implications for the vast regional population, further studies with ongoing observations and improved models are crucially needed.

\subsubsection{Regional climate changes due to aerosol direct and indirect effects}

The first attempts to simulate the regional climate effects of the SAW-ABC in terms of its impact on the overall regional circulation have been made by including the aerosol radiative forcing terms in global general circulation models (Chung et al., 2002; Chung and Ramanathan, 2003; Menon et al., 2002). The absorbing nature of the haze results in a stabilization of the BL and a reduction of surface energy fluxes (latent and sensible heating). Dynamically, the models respond with a northward shift in the ITCZ and an increase in precipitation (by up to 20\%) over the haze regions, especially directly in the outflow regions of the Arabian Sea and Bay of Bengal, accompanied by a decrease in precipitation over the Indonesian and Pacific warm pool regions, as shown in Fig. 40 (Menon et al., 2002; Chung et al., 2002; Chung and Ramanathan et al., 2003). The simulated changes in precipitation and temperature are similar to observations of a small cooling trend in China and India, contrasted with the warming trend throughout most of the rest of the world (Menon et al., 2002). A preliminary link has been made to changes in the Indian summer monsoon rainfall patterns (Chung et al., 2002) and to the El Niño Southern Oscillation (Chung and Ramanathan, 2003). Beyond these modeling studies, Bhawar and Devara (2010) have presented circumstantial observational evidence of a link between aerosol levels and the monsoon. Based on measurements of aerosol index (AI) above Pune, they found that the "bad monsoon" year of $2002 \mathrm{had}$ elevated AI levels lasting over a much longer period (100 versus 50 days) compared to the normal monsoon year of 2001.

While the early climate modeling studies were based on sensitivity simulations (time slice runs), Ramanathan et al. (2005) performed transient simulations for the 20th century since 1930 with a coupled atmosphere-ocean climate model, confirming that the regional climate impacts are substantial (see Fig. 41). For example, the increase in LT stability suppresses convection, which inhibits vertical transport of moisture and trace species, and leads to a moistening of the boundary layer and drying aloft. The model results suggest that this is accompanied by a meridional circulation change, with increased rising motion south of the equator over the Indian Ocean and increased downward motion over India during the summer monsoon. An important implication is that the monsoon rainfall decreases, on which the South Asian fresh water supply and agriculture are critically dependent.
Actually, the suppression of summer precipitation may be a combined consequence of aerosol and greenhouse gas forcings (Ashfaq et al., 2009). During the dry season the reverse occurs due to the enhanced boundary layer heating by the black carbon. Furthermore, the heating by absorbing aerosol pollution over Tibet may act as an "elevated heat pump", which carries moist air into the region and can persist into the pre-monsoon period (Lau et al., 2006; Satheesh et al., 2008). It appears that precipitation over land is relatively sensitive to changes in SST gradients (Rotstayn and Lohmann, 2002; Chung and Ramanathan, 2007). This is underscored by an apparent increase in the frequency of droughts in India, defined as years during which a decrease of monsoon precipitation exceeds $10 \%$ compared to the climatological average; 9 such years were experienced from 1871-1930, and 12 drought years from 1931-1990 (Sikka, 2003; Ramanathan et al., 2005).

Finally, the aerosols can modify cloud properties via the "first indirect" effect (Twomey, 1974, 1977) for which some of the first clear observational evidence was gathered during INDOEX. Two early studies (Heymsfield and McFarquhar, 2001; Liu et al., 2003a) have shown that the NH clouds that are affected by the haze have both aerosol and cloud droplet number concentrations which are much higher than in SH clouds with background aerosol levels, while the condensed water content is nearly the same for clouds in both regions. This basic effect has been reproduced in simulations with a cloud resolving model for the INDOEX conditions (Andronache et al., 2002). This results in effective droplet radii that are $\sim 20 \%$ smaller in the polluted clouds. These data were used in Ramanathan et al. (2001) along with a radiative transfer model to estimate the impact on solar forcing to be $-6 \pm 3 \mathrm{~W} \mathrm{~m}^{-2}$ at the surface $\left(-5 \pm 3 \mathrm{~W} \mathrm{~m}^{-2}\right.$ at the top of the atmosphere; see Table 10). The combined forcing from the direct aerosol effect and the first indirect effect varies as a function of latitude, from about $-5 \mathrm{~W} \mathrm{~m}^{-2}$ south of the ITCZ to over $-30 \mathrm{~W} \mathrm{~m}^{-2}$ north of about $10^{\circ} \mathrm{N}$. Two other indirect effects, namely the reduction of drizzle due to smaller droplets ("second indirect") and the reduction of trade cumuli due to warming in the residual layer ("semi-direct") have also been postulated for the region (Ackerman et al., 2000). These effects will have opposite signs (the second indirect effect cools while the semi-direct effect warms), and have been estimated to be much smaller, of the order of 2 $5 \mathrm{~W} \mathrm{~m}^{-2}$ with an uncertainty exceeding $50 \%$ (Ramanathan et al., 2001). Yet another highly uncertain possible impact of pollution aerosol on clouds is that the smaller drops or ice crystals, resulting due to more condensation nuclei, are likely to be lofted higher by the updrafts in deep cumulus convective clouds, resulting in deeper clouds (greater cloud top heights) on average; Padma Kumari and Goswami (2010) speculate that this may contribute partly to the trend towards ongoing solar dimming observed over southern Asia, which is associated with increasing cumulus cloud depths. 


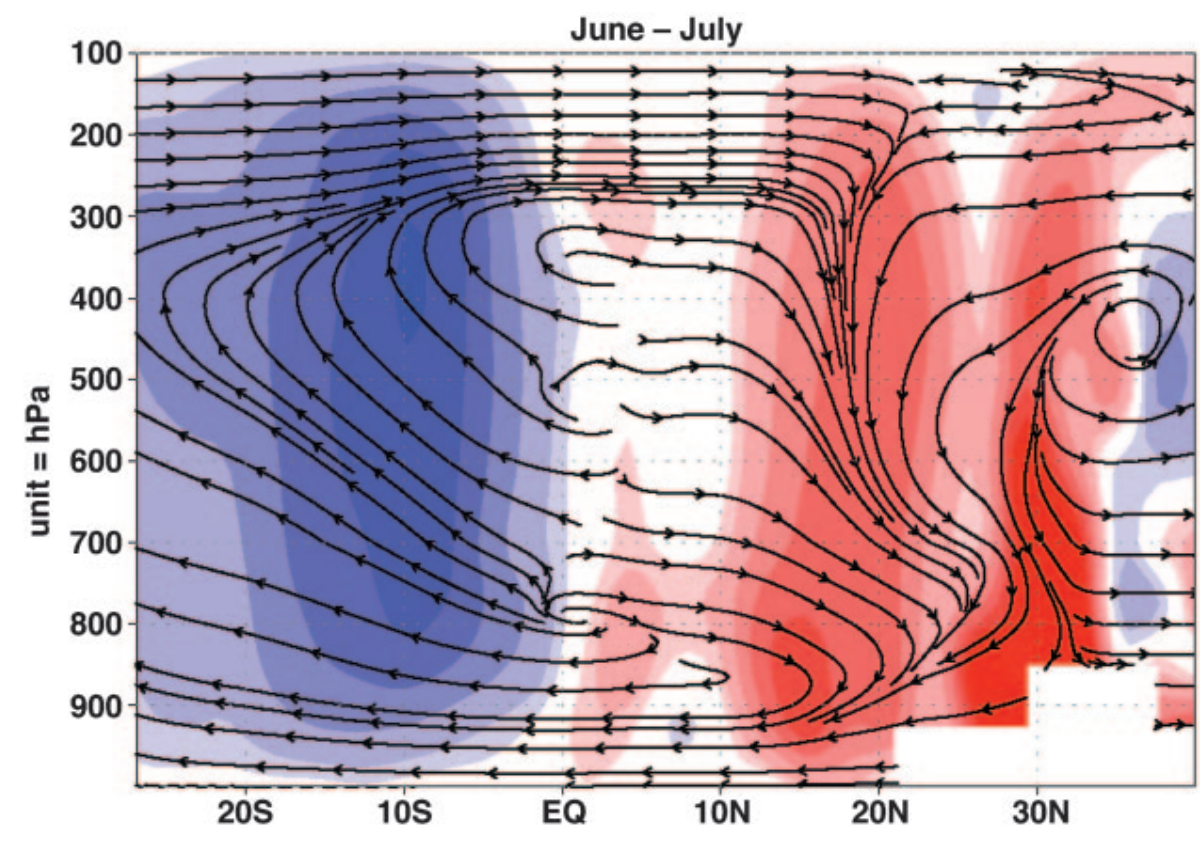

Fig. 41. Simulated changes in the meridional circulation due to the effects of the Asian-ABC for June and July 1985-2000, averaged over $60^{\circ} \mathrm{E}-100^{\circ} \mathrm{E}$; red indicates increased sinking motions, blue increased rising motions (from Ramanathan et al., 2005, copyright 2005 by the National Academy of Sciences, USA, reproduced with permission).

The enhancement of cloud albedo by increased aerosol concentrations has been directly measured by multiple unmanned aerial vehicles, suggesting a relatively high sensitivity of trade cumuli (Roberts et al., 2008). Chylek et al. (2006) analyzed satellite measurements over the seas adjacent to the Indian subcontinent, providing support for the first indirect aerosol effect on liquid water clouds. Interestingly, they found the reverse for ice crystals in cold clouds during the winter season. This "inverted" indirect effect may be related to the enhanced presence of ice nuclei, which are usually hydrophilic particles such as black carbon that initiate ice nucleation at temperatures above those of homogeneous nucleation. Additional satellite-based support for the first indirect aerosol effect was obtained by Jones et al. (2009). They found a relatively strong response over the Arabian Sea during summer, when the area is impacted by both desert dust and pollution haze, whereas over the Bay of Bengal the effect seems negligible.

Meanwhile, the analyses of satellite data (Kaufman et al., 2005; Myhre et al., 2007) and modeling studies (Lohmann et al., 2007) have confirmed the direct relationship between aerosols and clouds. However, the mechanisms of this relationship, basic to the theories about aerosol indirect effects on climate, remain controversial (Stevens and Feingold, 2009). It has recently been proposed that at least part of the aerosol "indirect" effects may actually be "direct", related to the strong swelling of hydrophyllic particles at high relative humidity, especially in the vicinity of clouds (Koren et al., 2007; Ma et al., 2010; Quaas et al., 2010). It will be a major challenge to accurately represent the aerosol hygroscopic growth and $\mathrm{CCN}$ activation in chemistry-climate models.

The aerosol impacts on precipitation formation are ambiguous, though first efforts have been undertaken to account for cloud microphysical properties that influence the conversion of cloud into rain water in climate models (Lohmann et al., 2007). Nevertheless, climate models may be expected to simulate dynamical effects realistically. For example, Krishnamurti et al. (2009) combined satellite data with model based analyses and found that aerosol pollution can enhance rain over the Arabian Sea in winter, associated with divergence in the upper troposphere, which in turn induces subsidence over the Bay of Bengal and a precipitation reduction over southeast India. Furthermore, the analysis of extreme rain events over India in the second half of the 20th century suggests that the frequency of torrential monsoon rains has increased at the expense of moderate events (Goswami et al., 2006). However, the attribution of extreme weather to $\mathrm{ABCs}$ and/or greenhouse warming with climate models is still in its infancy, hampered by the limited capability to realistically simulate distinct storm events.

\section{The southern Asian summer monsoon plume}

As discussed in Sect. 3 (Fig. 5), during the summertime the ITCZ moves north over the Indian subcontinent. The intense monsoon rains effectively remove soluble gases and hygroscopic aerosols from the atmosphere. As a result, the 


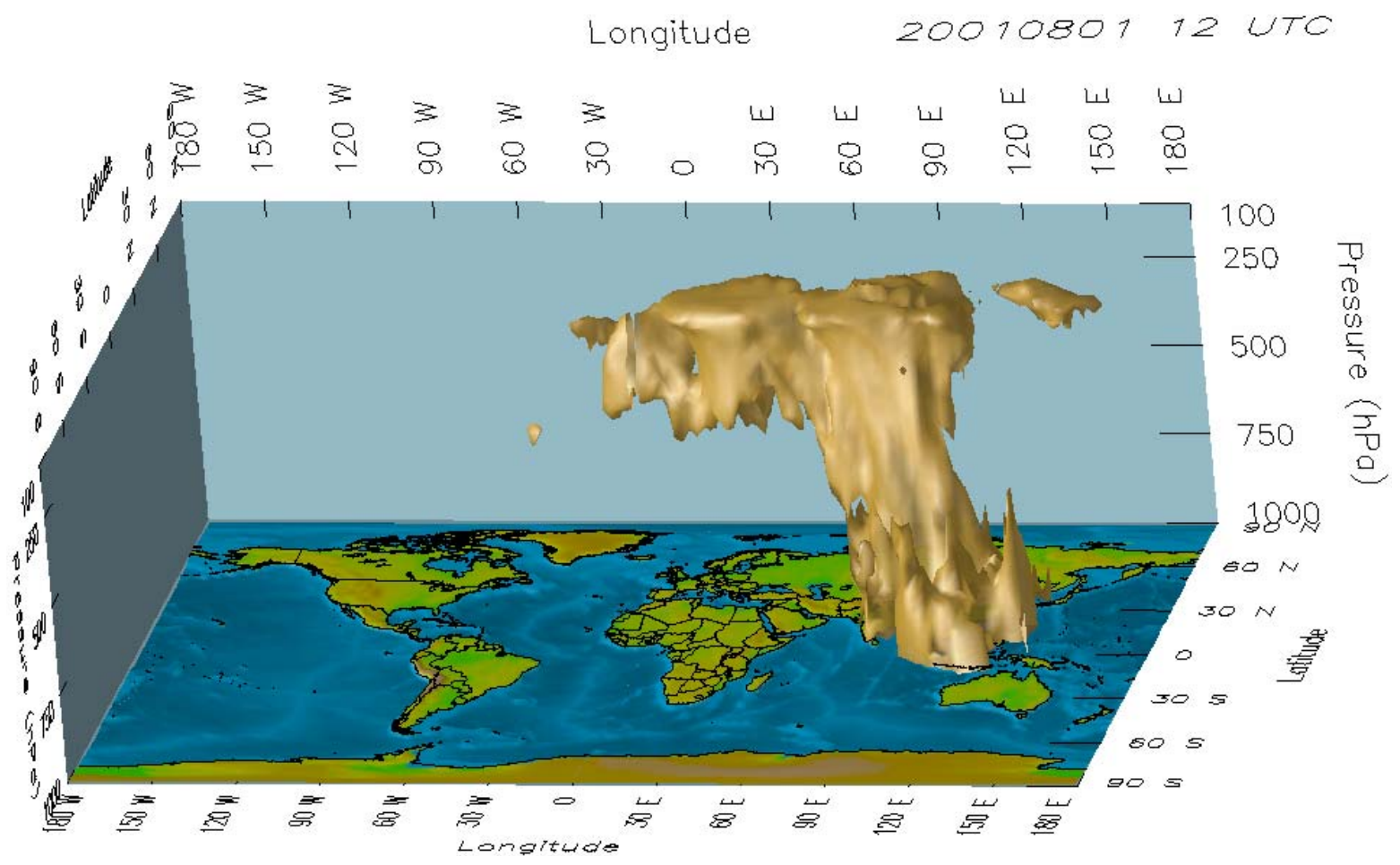

Fig. 42. Simulated 3-D structure of the Asian monsoon plume on 1 August 2001, based on simulation of a southern Asian CO tracer with the global chemistry transport model MATCH-MPIC; the shaded region depicts mixing ratios above $25 \mathrm{nmol} / \mathrm{mol}$ (from Lawrence et al., $2003 \mathrm{a}$, copyright 2003 by the European Geophysical Union, reproduced with permission).

air quality in southern Asia is generally improved compared to the dry season. Interestingly though, the low level convergence of moist air over the Bay of Bengal is associated with pollution transport from southern India and Sri Lanka toward the northern Bay of Bengal and the coastal regions of Bangladesh and eastern India. We note that this pollution transport regime has thus far received little attention, and could well be associated with pollutant ozone buildup during transport over the Bay of Bengal, an issue which deserves more research. Furthermore, the updrafts of the summer monsoon deep convection can effectively transport insoluble pollutants from the surface to the upper troposphere. A modeling study by Metzger et al. (2002), for example, predicts that the deep convection south of the Himalayas provides an effective mechanism to transport ammonia into the UT, which subsequently reacts with nitric acid and thus forms a global UT hot spot of ammonium nitrate. Recent work (A. Panday, personal communication, 2010) also shows that substantial lofting of polluted airmasses all the way into the upper troposphere may be associated with up-slope flow transporting pollutants from the Indo-Gangetic plain on the south side of the Himalayas (note that this lofting appears to occur during the winter monsoon as well, though little has been done yet to investigate the lofting during that period). Once these polluted airmasses reach the upper troposphere, they can then be effectively transported over large distances by the rapid upper tropospheric winds. This long-range pollution transport has been examined in several studies, which are discussed in this section.

Figure 42 gives a basic idea of the overall form of the southern Asian summer monsoon outflow plume, based on a model simulation of a southern Asian CO tracer. As can be seen in the figure, the transport is predominately towards the west. However, a fraction of the pollution is also transported towards the east, and a few studies have highlighted this eastward transport of southern Asian pollution, especially from biomass burning in southeastern Asia (e.g., Liu et al., 2003b; Liang et al., 2007). Stohl et al. (2007) have demonstrated a very poignant example of the outflow of southern Asian pollution towards the east, in which a plume of $\mathrm{CO}, \mathrm{NO}_{\mathrm{y}}, \mathrm{O}_{3}$ and aerosols was tracked all the way to Europe by satellite observations and model simulations, and intercepted by research aircraft flights over the North Atlantic west of Spain and a day later over Spain; the primary origins of the pollution could be shown to be from several locations in Asia, including Bangladesh in southern Asia, as well as eastern Asian locations such as the Szechuan Basin and Hong Kong. Nevertheless, as shown in Fig. 43, the absolute amount of southern Asian pollution exported eastwards is on average much smaller than that transported towards the west, and also pales in comparison to the outflow of pollution towards the east from northern and eastern Asian, which was brought to mainstream attention by a series of seminal papers by Berntsen et al. (1999), Jaffe et al. (1999), and Jacob et al. (1999), which 
have been followed up by numerous studies (for overviews of studies on this issue, see Wuebbles et al., 2007, and Zhang et al., 2008).

Here we will be focusing on the dominant outflow channel for southern Asian pollution, towards the west. In the next section we discuss the key meteorological features which control this outflow. Following that, we discuss the pollutant transport into the upper troposphere and towards the west: first the buildup of pollution in the Tibetan anticyclone, then the export over Africa, the Mediterranean, Europe and the Middle East. Finally, we consider some of the chemical and climate impacts of this pollutant outflow, especially the transport into the stratosphere.

\subsection{Meteorological elements}

Three key meteorological elements contribute to the upper tropospheric southern Asian summer monsoon pollutant outflow plume towards the west:

- the southern Asian summer monsoon,

- the Tibetan High, and

- the tropical easterly jet stream.

The monsoon convection is associated with the northward movement of the ITCZ, as already discussed above. Very deep convection over southern Asia results in UT outflow that in turn leads to a persistent high pressure system, known as the Tibetan High. The resulting upper tropospheric anticyclonic flow can effectively trap pollutants which are transported upwards in the summer monsoon convection, as discussed in the next section.

In recent years the role of the Tibetan Plateau in the UT meteorology and tracer transport has received growing attention. Conventional wisdom holds that the strong elevated surface heating over Tibet causes an unstable stratification and intense convective activity, which promotes the abrupt seasonal change and also the maintenance of the Asian monsoon (e.g., Ye and Wu, 1998). Furthermore, as noted in Sect. 4.6, it has been hypothesized that enhanced heating of lower tropospheric air masses above the Tibetan Plateau could lead to a strengthened monsoon circulation (Lau et al., 2006). Interestingly, three recent studies offer evidence against both of these hypotheses. First, Kuhlmann and Quaas (2010) analyze vertically resolved satellite data from the CALIPSO instrument for the region, finding that the aerosol concentrations are greatest below $5 \mathrm{~km}$ altitude (a.s.1.), and that only small amounts reach the Tibetan Plateau, arguing against the hypothesized elevated heat pump effect of aerosol pollution. Second, Devasthale and Fueglistaler (2010) have reassessed satellite data from the AVHRR and MODIS instruments and have determined that the strongest convection in the Asian summer monsoon is south of the Himalayas, particularly over the Bay of Bengal, and that there is relatively little intense, very deep convection over the Tibetan Plateau. And third, it has been found in GCM simulations that the thin band of very high peaks in the Himalayas appears to play a larger role in determining the exceptional strength of the Asian summer monsoon than the broad Tibetan Plateau (Boos and Kuang, 2010). This may lead to a substantial rethinking of the regional southern Asian meteorology. However, Boos and Kuang (2010) leave open the possibility that even though the Himalayas appear to play the dominant role in the monsoon forcing in their simulations, changes over the Tibetan Plateau, such as increased black carbon aerosol loads, may still result in non-negligible changes in the monsoon circulation. Regardless of the key causes of the strong monsoon circulation, it is clear that the UT anticyclone located over the Tibetan Plateau and northern India is moistened by the deep penetration of cumulonimbus clouds. Part of the humidified UT air moves southward along isentropic surfaces, where it can enter the tropical tropopause layer over the western Pacific Ocean (Bannister et al., 2004; Fueglistaler et al., 2004), and can be further transported into the lower stratosphere.

On the southern flank of the anticyclonic circulation of the Tibetan High is the tropical easterly jet stream (TEJ), a belt of strong easterly winds centered at about $200 \mathrm{hPa}$ which stretches from central southern Asia to central northern Africa, counter to the westerly jets normally found in the subtropical upper troposphere. The TEJ is extended by the flow on the southern side of another persistent upper tropospheric anticyclone, located over the Arabian Peninsula. A typical snapshot of these two adjacent anticyclones was shown earlier in Fig. 7a, along with the mean anticyclonic circulation covering most of southern Asia and the Middle East in Fig. 7b. Following transport along the TEJ, the southerly transport on the western flank of the Arabian anticyclone brings the pollution into the Mediterranean and Middle Eastern regions, as discussed in the following section.

\subsection{Transport towards the west in the upper troposphere}

\subsubsection{Pollution in the Tibetan anticyclone}

The first step in the westward outflow of pollution from southern Asia during the summer monsoon is the transport into the upper troposphere. As noted above, this can be due to deep convective updrafts, as well as a possible contribution from upslope lofting along the southern side of the Himalayas (A. Panday, personal communication, 2010). Once in the upper troposphere, the anticyclonic flow of the Tibetan High tends to trap a fraction of the lofted airmasses, with their elevated levels of pollutants such as $\mathrm{CO}$ and aerosols. This was first noted by Kar et al. (2004), Park et al. (2004) and $\mathrm{Li}$ et al. (2005) in analyses of observations from the MOPITT (Measurements Of Pollution In The Troposphere) and the MLS (Microwave Limb Sounder) instruments, along 


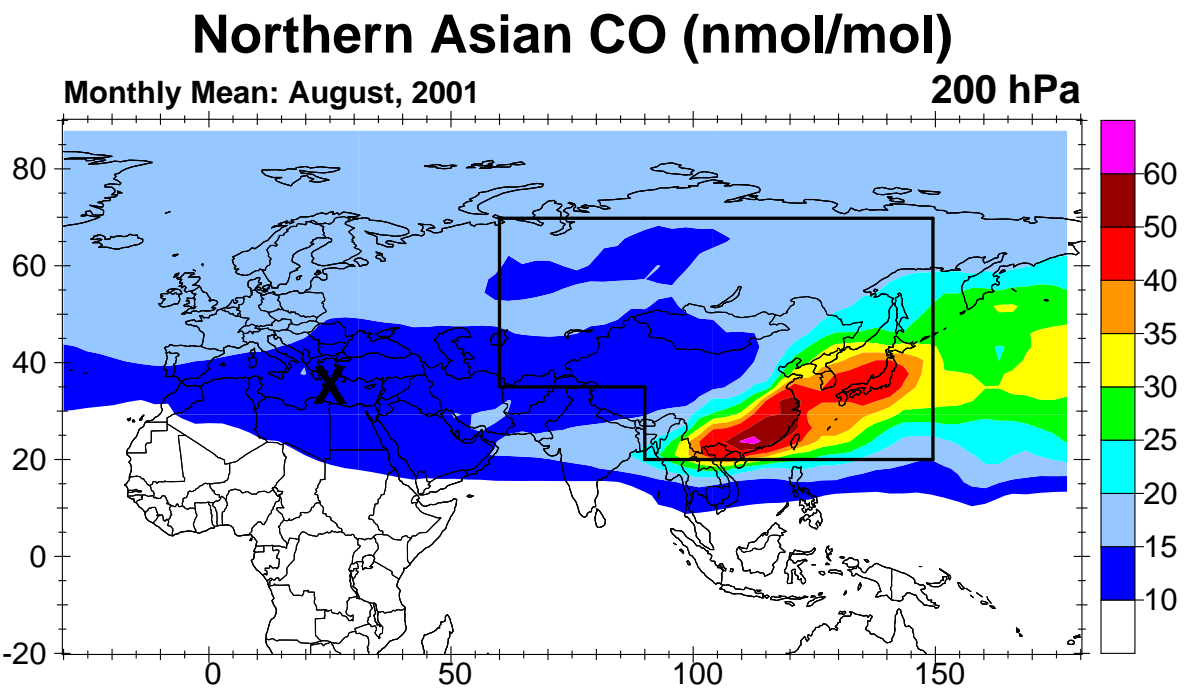

\section{Southern Asian $\mathrm{CO}(\mathrm{nmol} / \mathrm{mol})$}

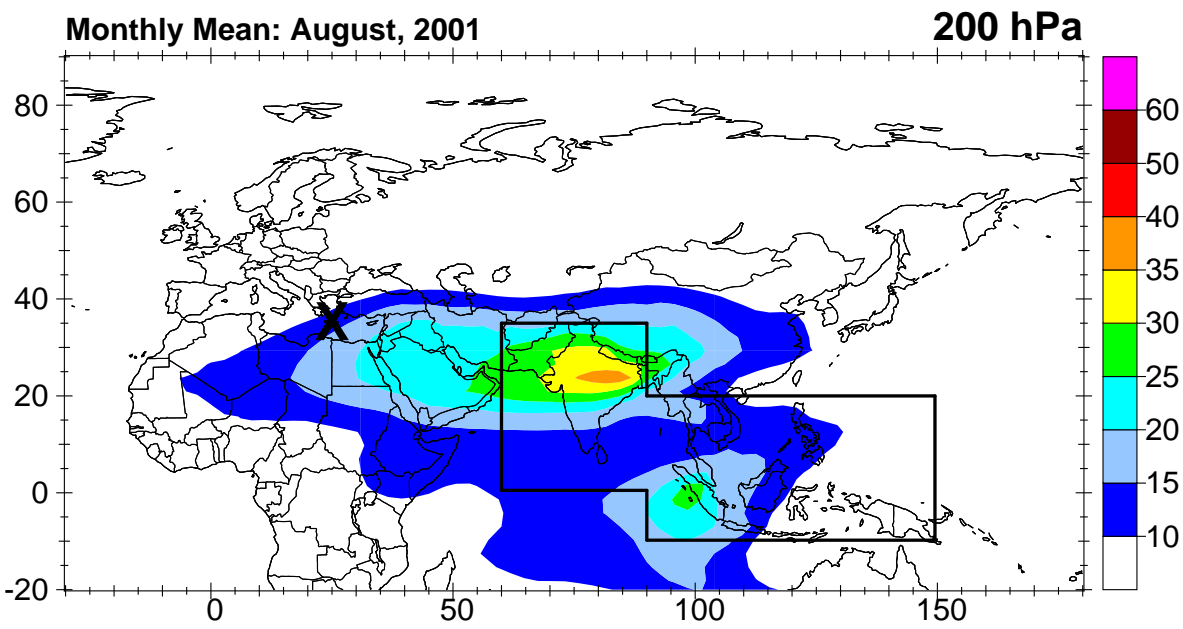

Fig. 43. Mean simulated distributions of a northern Asian and a southern Asian CO tracer at $200 \mathrm{hPa}$ averaged over August 2001; the heavy black lines indicate the boundaries of where emissions are included for each of the two tracers (based on Lawrence et al., 2003a, copyright 2003 by the European Geophysical Union, modified with permission; an animation of the outflow is available in the supplementary material of Lawrence et al., 2003a, http://www.copernicus.org/EGU/acp/acp/3/267/acp-3-267_supp.zip).

with simulations with the chemistry-transport model GEOSCHEM, which is able to reproduce the observed pollutant maximum well. The pollutant maximum, depicted in Fig. 44 based on the satellite observations, is primarily at very high altitudes, around $150 \mathrm{hPa}$, whereas the dominant outflow reaching the Mediterranean tends to be at lower altitudes, as discussed below. Fu et al. (2006) suggested that the high altitude of the pollutant maximum could be associated with extremely deep convection over the Tibetan Plateau, which is suggested to detrain even more water vapor, carbon monoxide and possibly other pollutants at the tropopause than the monsoon area itself. However, this seems unlikely, given that the main sources of pollutants are not located on the Tibetan Plateau, and several analyses (Randel and Park, 2006; Park et al., 2007, 2008, 2009; Xiong et al., 2009), using satellite observations and model simulations, have indeed shown that the primary source for the $\mathrm{CO}$ and $\mathrm{CH}_{4}$ maxima in the Tibetan anticyclone is vertical transport of emissions from India and Southeast Asia in the summer monsoon convection, followed by large-scale vertical advection from the main convective detrainment level (around $12 \mathrm{~km}$ ) to altitudes near the tropopause $(\sim 15-16 \mathrm{~km})$, then trapping within the anticyclone. 

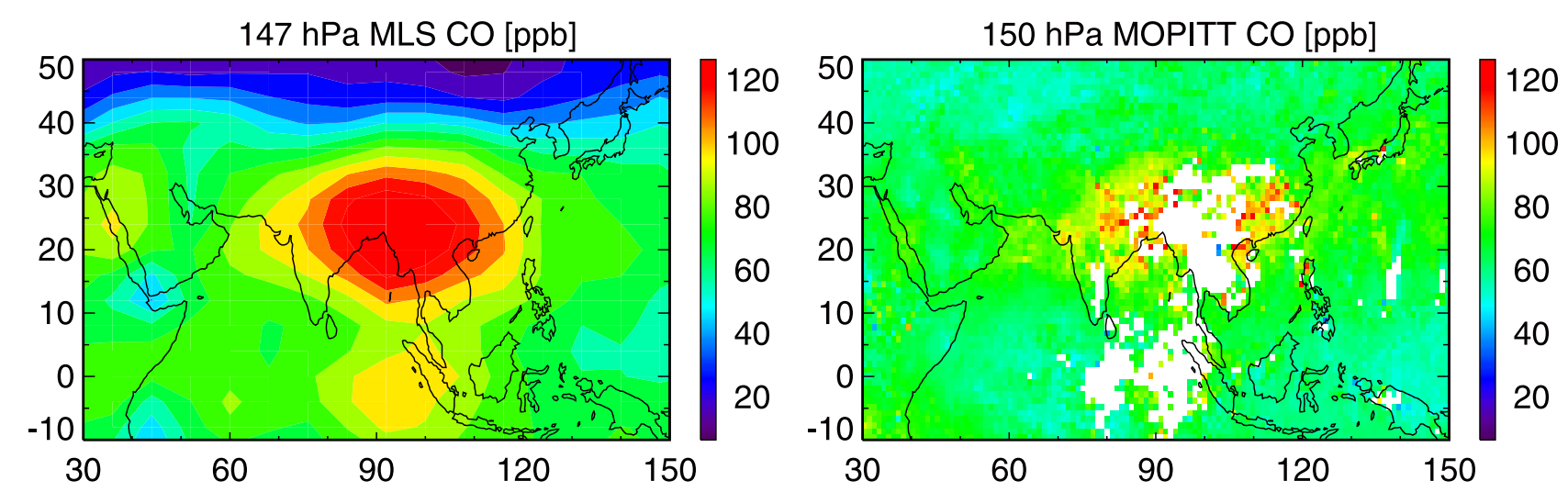

Fig. 44. Satellite observations of the mixing ratios of $\mathrm{CO}$ at $147 \mathrm{hPa}$ from the MLS satellite instrument and at $150 \mathrm{hPa}$ from the MOPITT satellite instrument (averages of both for the ten days that MLS measurements were available, on 25-27, 29-31 August and 3-6 September 2004); white areas indicate missing data (from Li et al., 2005, copyright 2005 by the American Geophysical Union, reproduced with permission).

\subsubsection{Transport of the plume away from southern Asia}

At slightly lower altitudes than the pollution trapped in the Tibetan anticyclone, the pollution plume is predominantly transported towards the west in the tropical easterly jet. Important contributions to understanding various aspects of the plume during this transport are coming from the project CARIBIC (Civil Aircraft for Regular Investigation of the atmosphere Based on an Instrument Container; Brenninkmeijer et al., 2007), in which a cargo container implemented with trace gas measurements instruments flies regularly in a Lufthansa passenger aircraft. A first analysis of several medium- to long-lived tracers $\left(\mathrm{CH}_{4}, \mathrm{~N}_{2} \mathrm{O}, \mathrm{SF}_{6}\right.$, $\mathrm{CO}_{2}, \mathrm{CO}, \mathrm{O}_{3}$, and $\mathrm{H}_{2} \mathrm{O}$ ) has been provided by Schuck et al. (2010), showing that the plume and several characteristics of its structure and evolution are apparent in 16 flights between Frankfurt and India during April-December 2008. The flights are generally in the $8-12.5 \mathrm{~km}$ altitude range, which makes them very appropriate for observing the outflow plume. During May-September, the observations show a substantial enhancement in the mixing ratios of $\mathrm{CH}_{4}, \mathrm{CO}$, $\mathrm{N}_{2} \mathrm{O}$, and $\mathrm{SF}_{6}$ in the region $50-80^{\circ} \mathrm{E}$, south of $40^{\circ} \mathrm{N}$, with the largest enhancements generally in August (except for CO, which peaks in June), as shown in Fig. 45a. The latitude at which the peak enhancement is observed moves north and south with the ITCZ and the monsoon convection, also peaking in August at around $25-30^{\circ} \mathrm{N}$ for all gases (Fig. 45b). CARIBIC observations also show that several NMVOCs (including ethane, propane, butane, pentane, acetylene, and benzene) were substantially enhanced in the plume (Baker et al., 2010). Most of these were well-correlated with CO, indicative of their anthropogenic origins. In addition, several halogenated tracers of marine origin (e.g., $\mathrm{CH}_{3} \mathrm{Br}, \mathrm{CH}_{2} \mathrm{Br}_{2}$, and $\mathrm{CH}_{3} \mathrm{I}$ ) were present at elevated mixing ratios, indicating the contribution from convective transport over the marine regions (especially the Bay of Bengal).
Ozone behaves notably differently in the outflow plume than the other pollutants discussed above. On the one hand, Schuck et al. (2010) observed that $\mathrm{O}_{3}$ mixing ratios were reduced in the central plume, defined as where the $\mathrm{H}_{2} \mathrm{O}$ mixing ratios are relatively high due to the convective outflow, and where the winds were predominately easterly. On the other hand, $\mathrm{O}_{3}$ is enhanced further to north, where $\mathrm{H}_{2} \mathrm{O}$ is reduced and the winds turn to being westerly. This results in an anticorrelation between $\mathrm{O}_{3}$ and $\mathrm{H}_{2} \mathrm{O}$ when they are plotted as a function of latitude, with a relatively sharp transition around $25^{\circ} \mathrm{N}$, consistent with the mean wind fields seen earlier in Fig. 7. Baker et al. (2010) showed that this coincides with differences in $\mathrm{O}_{3}$ production in the airmasses, and that the airmass ages (based on "photochemical clocks" using ratios between different NMVOCs) were about 3-6 days in the southern part of the plume and 10-15 days in the north. Together, this indicates that the lower $\mathrm{O}_{3}$ levels observed in the south are $\mathrm{O}_{3}$-depleted airmasses transported directly from the polluted regions of India, for which not enough time has been available for significant photochemical production to take place, whereas the $\mathrm{O}_{3}$-rich airmasses in the north have been recirculated around the Arabian anticyclone, allowing significant $\mathrm{O}_{3}$ production to take place underway. This contributes to solving a long-standing mystery (Lawrence, 2004) about conflicting evidence of elevated and surpressed $\mathrm{O}_{3}$ levels in this region, and help generally to explain the observed Arabian $\mathrm{O}_{3}$ maximum, which is discussed further below (Sect. 5.2.4).

Trajectory calculations in Schuck et al. (2010) clearly demonstrate that the origin of the pollution plume is largely from India and other countries around the Bay of Bengal (note that these ECMWF-based trajectories are without an explicit representation of deep convection; however, as pointed out by Lawrence and Salzmann (2008), since much of the convective upwelling in this region is connected to large scale circulations, the trajectories should be reasonably 

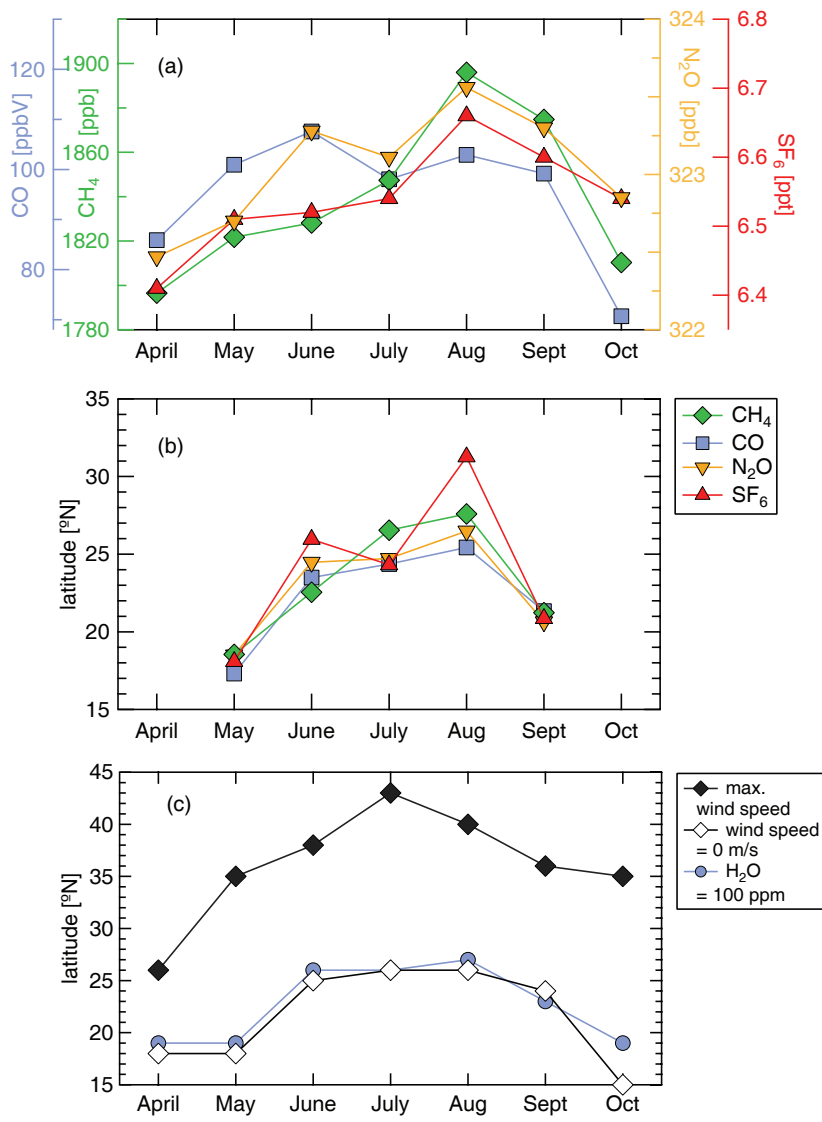

Fig. 45. Observations of the southern Asian summer monsoon plume from the CARIBIC project: (a) Maximum mixing ratios of $\mathrm{CH}_{4}, \mathrm{CO}, \mathrm{N}_{2} \mathrm{O}$, and $\mathrm{SF}_{6}$ observed in summer 2008 south of $40^{\circ} \mathrm{N}$, showing the plume enhancements from May-September (monthly mean values are shown for April and October); (b) Latitudinal position at which the maximum mixing ratios of $\mathrm{CH}_{4}, \mathrm{CO}, \mathrm{N}_{2} \mathrm{O}$, and $\mathrm{SF}_{6}$ were observed. (c) Latitudinal position of the maximum wind speed in the westerly jet (on the northern side of the regional mean anticyclone), and the latitude where the zonal wind speed is $0 \mathrm{~m} / \mathrm{s}$, together indicating the latitudinal position of the regional anticyclone. All measurements were in the altitude range $8-12.5 \mathrm{~km}$. The latitude where the $\mathrm{H}_{2} \mathrm{O}$ mixing ratio exceeds $100 \mathrm{ppmv}$ (equivalent to $100 \mu \mathrm{mol} / \mathrm{mol}$ ) is also shown, indicating the northern extension of the strong monsoon convection (from Schuck et al., 2010, copyright 2010 by the European Geophysical Union, reproduced with permission).

representative of the actual vertical and long-range transport for long-lived tracers). Finally, Schuck et al. (2010) used fits to the enhancements in the trace gas mixing ratios to obtain estimates of the regional emissions, and compared these to values from the EDGAR database (for $\mathrm{CO}$, the comparison was to the same version of EDGAR as used in Table 2, while for the greenhouse gases a newer version was available for the comparison). Interestingly, all gases except $\mathrm{CO}$ were in relatively good agreement with EDGAR; the estimated $\mathrm{CO}$ emissions based on the CARIBIC observations were found to be much lower than in the EDGAR database. The reason for this is unclear at present; given its long lifetime compared to the transport timescale, it would not be expected that much $\mathrm{CO}$ should be lost to photochemical oxidation during the transport. It is also not expected that the emissions from this region have decreased drastically over the 8 years from when the EDGAR data is valid (2000) to when the measurements were made (2008). Thus, this remains an open, interesting issue for future work. Another issue to clarify would be the vertical extent and layering of the plume, which may extend above the maximum altitude of the CARIBIC observations.

The further transport of pollution over Africa has been examined by Barret et al. (2008), who make use of CO observations from in situ aircraft in the MOZAIC (Measurements of OZone, water vapour, carbon monoxide and nitrogen oxides by in-service AIrbus airCraft) program, along with $\mathrm{CO}$ data from the MLS satellite instrument assimilated into a chemistry-transport model, to investigate the transport pathways of $\mathrm{CO}$ over Africa and how they are also influenced by the western African monsoon. Their results indicate a broad $\mathrm{CO}$ maximum in the upper troposphere over Central Africa. Here, however, in contrast to the observations of CARIBIC, the deep convection over Africa has a significant direct effect on the lower part of the upper troposphere (pressures $>150 \mathrm{hPa}$ ), and only the highest altitude layers (pressures $<150 \mathrm{hPa}$ ) are dominantly influenced by transport from Asia through the tropical easterly jet.

\subsubsection{The southern Asian summer monsoon plume over the Mediterranean}

Often the polluted airmasses are caught in the southerly flow on the western flank of the Arabian anticyclone, bypassing most of northern Africa and being transported northwards over the eastern Mediterranean Sea. Observing the plume over the Mediterranean was one of the objectives of the field campaign MINOS (Mediterranean Intensive Oxidants Study), which also investigated the European pollutant outflow into the Mediterranean region (mainly in the lower troposphere), as well as the import of pollution from North America into the region (Lelieveld et al., 2002). During MINOS, global chemical weather forecasts were employed to determine when and where the plume was likely to be sampled; these were similar to the forecasts first developed for INDOEX, though in this case using two models in tandem (MATCH-MPIC and ECHAM5). Unlike the relatively simple outflow structure of the SAW-ABC, a much longer chain of conditions and processes determines the exact extent and intensity of the southern Asian summer monsoon plume, including:

- the geographical distribution of emissions over southern Asia, 
- the geographical distribution of deep cumulus convection (in relation to the emissions and the tropical easterly jet),

- the frequency of convection and the stability of the boundary layer (determining the buildup of pollutants prior to the lofting of airmasses into the UT),

- the intensity and location of the Tibetan and Arabian UT anticyclones (Fig. 7),

- the chemical processing in the plume during transport, and

- dilution due to mixing with other UT air masses.

Despite this complexity, it was possible to target the first three research flights of MINOS to intercept the Asian summer monsoon plume. The anticipated plume distribution in terms of simulated upper tropospheric $\mathrm{CO}$ during these times is depicted in Fig. 46. According to analysis of the observations, as well as further model simulations, it appears that the measurement flights were successful in sampling the polluted Asian airmasses. As far as we are aware, and according to a recent review (Mihalopoulos, 2007), these are the only in situ measurements so far of the plume over the eastern Mediterranean.

The median of the observed profiles for several gases measured on the three MINOS flights compared to the profiles averaged over the entire campaign are shown in Fig. 47. In the UT numerous gases such as $\mathrm{CO}, \mathrm{CH}_{4}, \mathrm{CH}_{3} \mathrm{OH}, \mathrm{CH}_{2} \mathrm{O}$, $\mathrm{C}_{2} \mathrm{H}_{6}$, and $\mathrm{CH}_{3} \mathrm{Cl}$ were substantially enhanced above the average levels during these flights (shown by the red, dashed lines), in some cases by considerably more than one standard deviation. On the other hand, $\mathrm{O}_{3}, \mathrm{NO}$ and $\mathrm{NO}_{\mathrm{y}}$ were significantly below the average UT levels. The upper-altitude peak shows several characteristics which give experimental evidence for the Asian origin of this pollution, including:

- high levels of indicator gases for biomass burning and biofuel use, in particular $\mathrm{CH}_{3} \mathrm{Cl}, \mathrm{C}_{2} \mathrm{H}_{2}$, and $\mathrm{CH}_{3} \mathrm{CN}$ (Scheeren et al., 2003);

- low levels of the new air conditioning agent HFC-134a in comparison to air masses at lower altitudes of North American origin (Scheeren et al., 2003; not shown in Fig. 47);

- high levels of $\mathrm{CH}_{4}$, likely from rice fields (Lelieveld et al., 2002), as also noted above to have been seen in the plume closer to Asia in the observations of the CARIBIC project (Schuck et al., 2010); and

- low levels of $\mathrm{O}_{3}$ and $\mathrm{NO}_{\mathrm{x}}$, consistent with the tendency towards more inefficient burning processes in southern Asia (see Tables 2 and 3 ) and the concomitant $\mathrm{NO}_{\mathrm{x}}$ limitation of $\mathrm{O}_{3}$ production.
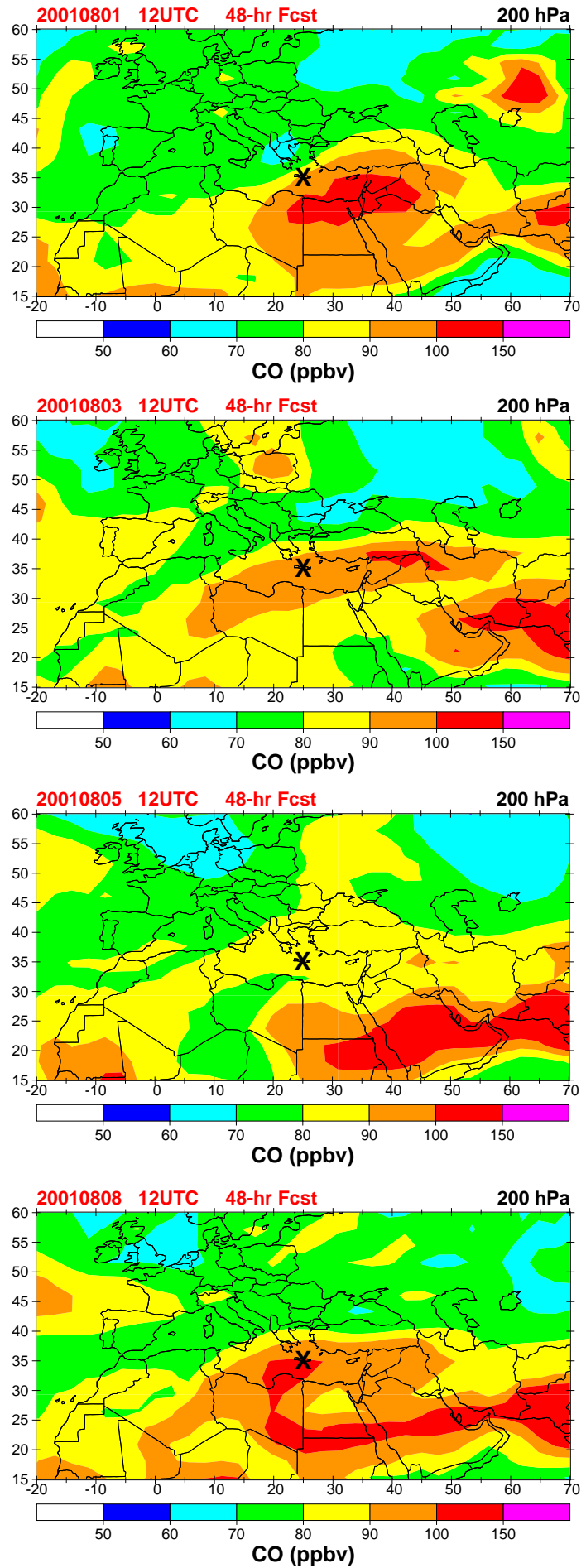

Fig. 46. Forecasts of the southern Asian summer monsoon plume distribution at different times during the MINOS campaign in early August 2001, from the MATCH-MPIC model for the days of the first three flights (1, 3 and 8 August), along with the forecast for 5 August showing the contrast when a strong plume is not present over the eastern Mediterranean (from Lawrence et al., 2003a, copyright 2003 by the European Geophysical Union, modified with permission). 

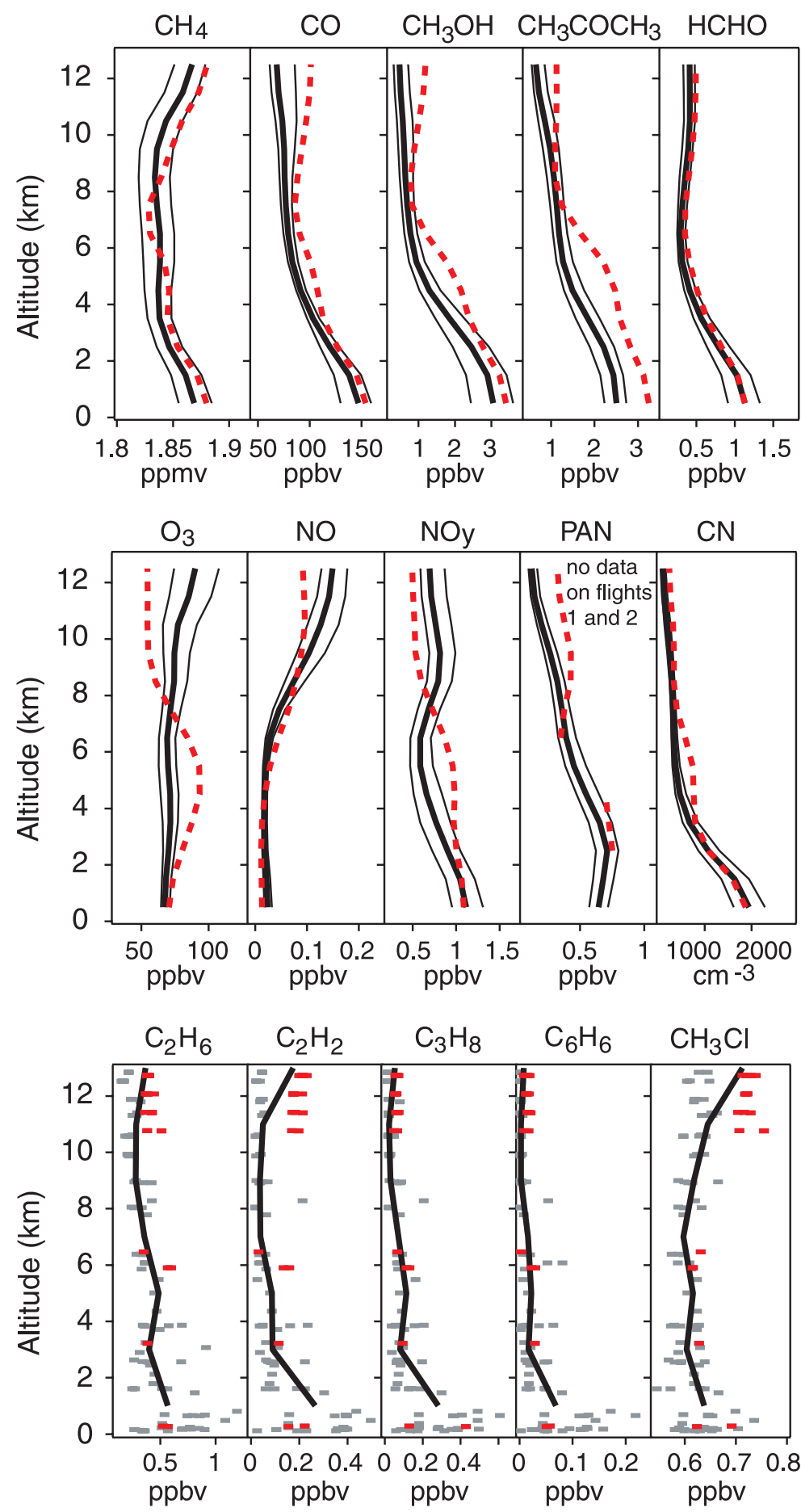

Fig. 47. Vertical profiles of trace gases measured during the 14 MINOS flights in August 2001. Thick solid lines are median values, thin solid lines are $\pm 1 \sigma$, dashed lines are the median values for only the first three flights (which sampled the Asian summer monsoon plume), and small boxes (bottom row) are individual canister samples (from Lelieveld et al., 2002, copyright 2002 by the American Association for the Advancement of Science, reproduced with permission).

Further evidence of the Asian origin comes from 10-day back-trajectories used to determine the longitude of origin of each of the air samples (Scheeren et al., 2003), and from global model simulations (Lawrence et al., 2003a; Roelofs et al., 2003). The model simulations were found to generally correlate well with the MINOS measurements in the UT 
during the three flights into the plume (e.g., $r=0.59$ for $\mathrm{CO}$ from MATCH-MPIC; Lawrence et al., 2003a). Particularly relevant is that global models are able to reproduce the variation in $\mathrm{CO}$ and $\mathrm{O}_{3}$ levels as a function of source longitude (Roelofs et al., 2003; Scheeren et al., 2003). On the other hand, the models have difficulties with the absolute levels of several gases, for example underestimating $\mathrm{NO}_{\mathrm{y}}$ and various NMVOCs, such as C2-C5 alkanes, both in the southern Asian monsoon plume as well as near the surface in the European outflow (Scheeren et al., 2003; Roelofs et al., 2003; Lawrence et al., 2003a; Salisbury et al., 2003; Gros et al., 2004). Several VOCs show relatively constant offsets, accompanied by good correlations with the observations, which suggests discrepancies in the emissions factors, rather than the geographical source distributions or the simulated meteorology.

The age of the Asian air masses by the time they reach the Mediterranean can be estimated based on the ratios of certain gases along with knowledge about their ratios at the source and their chemical lifetimes. This method was applied by Scheeren et al. (2003), based on the measured ratios of $\mathrm{CH}_{3} \mathrm{Cl}, \mathrm{C}_{2} \mathrm{H}_{2}, \mathrm{CH}_{3} \mathrm{CN}$, and $\mathrm{C}_{6} \mathrm{H}_{6}$ to $\mathrm{CO}$ in the Asian outflow during MINOS, and the assumption that the initial ratios could be taken from the INDOEX outflow measurements near the Indian coast (Scheeren et al., 2002; de Gouw et al., 2001), with the exception of $\mathrm{C}_{2} \mathrm{H}_{2}$, for which the emission ratio to $\mathrm{CO}$ measured for fresh biomass burning was used. A chemical age of about 1-2 weeks is inferred from the measured ratios of both $\mathrm{CH}_{3} \mathrm{Cl}$ and $\mathrm{C}_{6} \mathrm{H}_{6}$ to $\mathrm{CO}$, and of 2-3 weeks based on $\mathrm{C}_{2} \mathrm{H}_{2}$ and $\mathrm{CH}_{3} \mathrm{CN}$, respectively. A trajectory analysis (Traub et al., 2003) is consistent with this, indicating a typical transit time from southern Asia to the Mediterranean UT of about 10-15 days, with air masses first residing in the BL over India for a few days on average before they are rapidly transported to the UT in convective updrafts, fitting with the episodic nature of deep convection during the summer monsoon (e.g., Gadgil, 2003). Two notes are worth making with regards to this analysis. First, these estimated transit times are broadly consistent, though somewhat longer than those computed by Baker et al. (2010) using photochemical clock information based on NMVOC observations (see Sect. 5.2.2). Second, similar to the point made above in Sect. 5.2.2, the ECMWF-based trajectories of Traub et al. (2003) are without an explicit representation of deep convection, which would lead one to expect an overestimate of the actual mean transit times; however, here again, since much of the convective upwelling in this region is connected to large scale circulations, the computed transit times should only differ slightly from reality, as appears to be the case in the comparison to Baker et al. (2010).

A considerable short-term variability in the pollution plume over the Mediterranean can be expected, due to the long sequence of processes controlling the outflow plume, as seen in the examples in Fig. 46. This short-term variability has been analyzed in terms of the frequency of occurrence of simulated strong plumes over the eastern Mediterranean (Lawrence et al., 2003a), showing that during 2001 a strong plume was present above Crete about a quarter of the time (between $12 \%$ and $40 \%$, depending on the threshold value chosen for the Asian CO), while it is considerably more prevalent (about 1.5 times as frequent) to the south and east of Crete, and it is relatively rare $(<10 \%$ of the time) that the plume extends over the Mediterranean much past Crete (due to the curvature on the western side of the Arabian anticyclone). Nevertheless, even though such distinct plumes from the southern Asian summer monsoon outflow are rare over mainland Europe, analyses of the origins of $\mathrm{O}_{3}$ (Auvray and Bey, 2005) and CO (Fischer et al., 2006) show that long-range transport of Asian emissions (from both southern and eastern Asia), mostly via westerlies (across the Pacific and Atlantic Oceans), with a small contribution from transport in the tropical easterly jet, provides the strongest regional source of $\mathrm{CO}$ to the upper troposphere over Europe, as well as a substantial contribution to the total tropospheric $\mathrm{O}_{3}$ (comparable to the sources from N. America and Europe).

\subsubsection{The Middle Eastern summertime ozone maximum}

Finally, an interesting set of observations and model simulation results have recently emerged (Li et al., 2001; Liu et al., 2006, 2009; Worden et al., 2009) showing evidence of a broad summertime ozone maximum in the middle to upper troposphere (around 400-500 hPa) over the Middle East and Northern Africa, as depicted in Fig. 48. This is in addition to the strong surface-level ozone pollution, in particular near the Persian Gulf, which has recently been shown to be prominent in this region (Lelieveld et al., 2009). The mid-tropospheric ozone maximum is in contrast to the ozonedepleted Asian airmasses observed in the upper troposphere during MINOS (Fig. 47), and is not always observed in satellite retrievals (e.g., Fishman et al., 2003; Liu et al., 2006). Although the cause for this difference is not yet resolved, it has been suggested to possibly be due to the instrument resolution (Liu et al., 2009). The mid-tropospheric peak in $\mathrm{O}_{3}$ over the Middle East, in the most recent study in which it has been observed, appears to be attributed to a combination of several factors (Liu et al., 2009), with transport from Asia and in situ production making comparable contributions (about 30-35\% each), where the in situ production is strongly influenced by lightning $\mathrm{NO}_{\mathrm{x}}$. This seems to be consistent with the CARIBIC observations, discussed above, which showed a strong south-to-north gradient in $\mathrm{O}_{3}$ (Schuck et al., 2010), with the higher mixing ratios north of about $25^{\circ} \mathrm{N}$ being associated with greater ozone production potentials, and with westerly winds (e.g., Fig. 7), indicating that the same airmasses as observed in the southern Asian summer monsoon outflow plume are being swept around the Arabian anticyclone and subsiding into the middle troposphere. This long range transport phenomenon, and its potential implications for regional radiative transfer due to the enhanced 
(a) Ozone, TES, 2005 July, $464 \mathrm{hPa}$

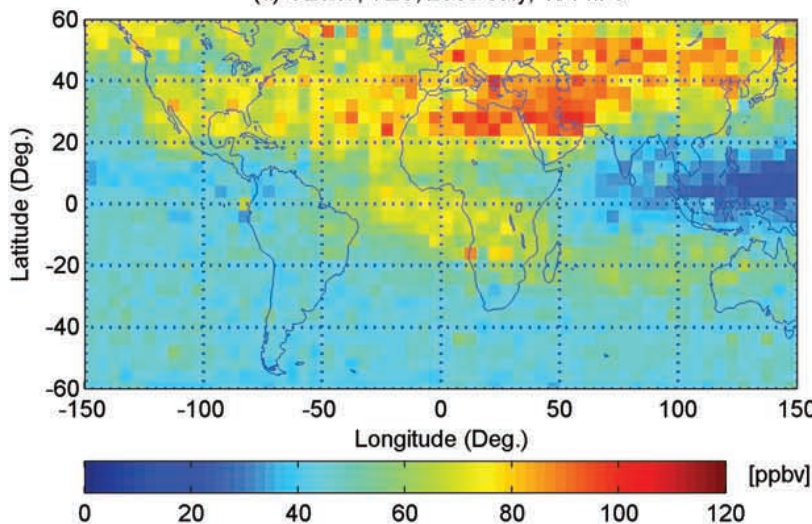

(b) Ozone, GEOS-Chem, 2005 July, $464 \mathrm{hPa}$

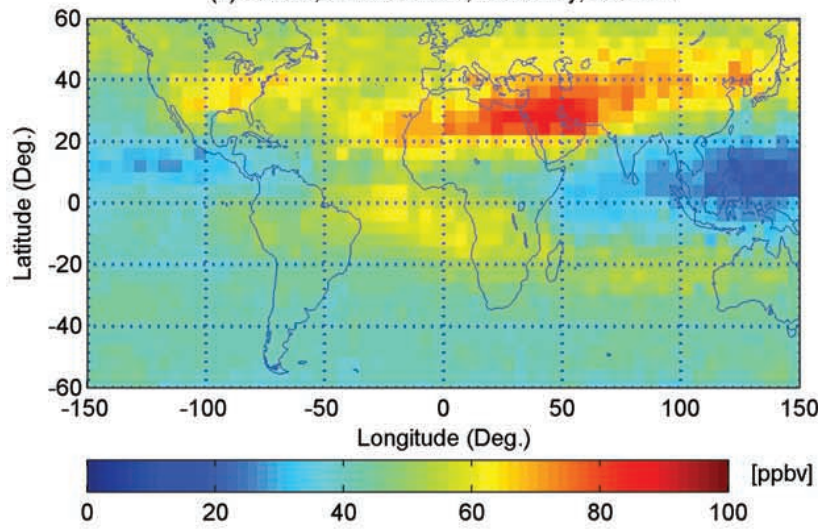

Fig. 48. Monthly mean ozone mixing ratio in July 2005 at $464 \mathrm{hPa}$ from (a) the TES satellite instrument, and (b) GEOS-Chem model simulation output, smoothed with the local TES averaging kernels; note the difference in scales (from Liu et al., 2009, copyright 2009 by the American Geophysical Union, reproduced with permission).

ozone levels, would be interesting to examine in a future dedicated field campaign.

\subsection{Chemistry and climate impacts}

\subsubsection{Future ozone enhancements}

One possible consequence of the Asian summer monsoon outflow is an enhancement of the tropospheric $\mathrm{O}_{3}$ column over Northern Africa, Europe and the Middle East, and associated effects on climate and oxidant chemistry if Asian $\mathrm{NO}_{\mathrm{x}}$ emissions increase in the future (Lelieveld et al., 2002). Based on sensitivity simulations with a chemistry-general circulation model, it has been estimated that the southern Asian emissions contribute about $20-25 \%$ of the $\mathrm{O}_{3}$ in the UT during summer when the Asian plume is present over the eastern Mediterranean (Roelofs et al., 2003). A scenario simulation for the year 2025 emissions shows a $14 \%$ increase of $\mathrm{O}_{3}$ in the plume, and also indicates that the $\mathrm{O}_{3}$ formation in the plume is $\mathrm{NO}_{\mathrm{x}}$-limited. Given that $\mathrm{NO}_{\mathrm{x}}$ emissions rates from southern Asia are relatively low compared to more industrialized regions (Table 3), one might expect significant increases in $\mathrm{NO}_{\mathrm{x}}$ emissions and consequently $\mathrm{O}_{3}$ production in the outflow plume as the region becomes more industrially developed during the next few decades; the actual extent of this will depend strongly on which emissions controls are implemented, especially in the transport sector.

\subsubsection{Effects on cirrus clouds}

There is circumstantial evidence that some aerosol components are effectively transported to the UT in the southern Asian summer monsoon plume, and may in turn have effects on cirrus cloud properties. The model simulations of $\mathrm{Li}$ et al. (2005), which agree well with satellite observations of the trapping of $\mathrm{CO}$ in the Tibetan anticyclone, also indicate a significant coincident transport of aerosol particles, corroborating the model results of Metzger et al. (2002). It has been conjectured (Lohmann, 2002) that in particular BC aerosols might influence the formation and in turn radiative transfer properties of cirrus clouds. If so, then given the remarkable emissions of BC aerosols from India found during INDOEX and other studies of the SAW-ABC (see Sect. 4), it is feasible that a substantial amount of hygroscopic $\mathrm{BC}$ aerosol is being transported to the UT through the summer monsoon convection (or lofted orographically along the Himalayas), which may in turn have consequences for the climate. An assessment of this would require in situ measurements of $\mathrm{BC}$ and other aerosols in the UT at various locations in the summer monsoon outflow, as well as improvements in model simulations, in particular knowledge of the scavenging efficiency of deep convective clouds for these aerosols, which is presently poorly understood.

\subsubsection{Transport into the stratosphere}

A final important effect of the Asian summer monsoon outflow is the transport of trace constituents into the stratosphere. This can occur via two distinct mechanisms:

- isentropic transport in northward flow, which can cross the tropopause due to its steep slope from about $15 \mathrm{~km}$ altitude over northern Africa down to about $11 \mathrm{~km}$ over Europe;

- large scale ascent through the tropical tropopause layer (TTL) of airmasses trapped in the Tibetan anticyclone. These two mechanisms are discussed below for the transport of pollutants, as well as for water vapor (which has been studied more extensively thus far).

Chen (1995) and Dunkerton (1995) were the first to notice that during summer the monsoon circulations in various regions influence the lower stratosphere. Using rawinsonde data and a transport model based on ECMWF meteorological analyses they showed that monsoons, and in particular the Asian monsoon, are displaced sufficiently far from the 
equator to affect meridional air mass transports. Around the combined Asian-Arabian UT anticyclone (see Fig. 7b), the relatively rapid meridional advection is poleward at the western flank and equatorward at the eastern flank and leaves a clear signal in lower stratospheric water vapor, which can be observed by satellites. Particularly in summer, due to a relatively weak potential vorticity gradient the cross-tropopause exchange across the subtropical jet stream can take place more easily than in winter, so that the upper tropospheric monsoon circulation has the potential to effectively penetrate into the stratosphere (Dethof et al., 2000). An important consequence of this circulation mechanism is that it allows moist air to bypass the cold equatorial tropopause and contribute a significant input (up to $75 \%$ of the total) of water into the extratropical stratosphere during summertime (Gettelman et al., 2004).

Traub and Lelieveld (2003) investigated the poleward pathway that tracks over the eastern Mediterranean region and the neighboring countries up to the Black Sea. It appears that the convergence of the anticyclonic flow with the polar front jet at $40-45^{\circ} \mathrm{N}$ increases the wind shear and creates a jet streak, which gives rise to clear air turbulence that mixes air pollutants across the tropopause (note that qualitative confirmation of this phenomenon is provided by the fact that passengers of aircraft are usually requested to tighten their safety belts prior to passing through this region). After crossing the tropopause the transport is vertically shallow and much of the pollution is mixed back into the troposphere within weeks by stratosphere-troposphere exchange events over the Pacific and Atlantic Oceans. Hence this circulation system constitutes an efficient mechanism for hemispheric transport of Asian air pollution. Observational evidence of this was obtained on one flight during MINOS, on which enhanced levels of $\mathrm{CO}$, VOCs, and $\mathrm{CH}_{3} \mathrm{Cl}$ were encountered, with chemical characteristics similar to those of the air masses measured directly within the South Asian outflow plume in the UT (Scheeren et al., 2003). (It is worth noting that this is distinct from the observations made by Fischer et al., 2003, of a highly polluted airmass in the lower stratosphere, which was attributed to direct convective injection of European airmasses.) During the subsequent transport of the Asian outflow airmasses in the lower stratosphere there may be various chemical consequences, including increased $\mathrm{O}_{3}$ loss due to the release of halogens from $\mathrm{CH}_{3} \mathrm{Cl}$ and other short-lived halocarbons.

The second mechanism takes place near convective regions in cloud-free air, where infrared radiative heating by ozone and water vapor accelerates the ascent of air masses into the stratosphere. This phenomenon contributes to the moist phase of the so-called tape recorder signal in water vapor observed by satellite instruments, in which the seasonal dehydration at the cold tropical tropopause plays a key role (Mote et al., 1996; Randel et al., 2001). Lelieveld et al. (2007) used the chemistry-general circulation model
EMAC (Jöckel et al., 2006) to investigate the source of water to the stratosphere. As an illustration of the vertical transport pathways, Fig. 49 shows the summertime water mass fluxes across the 340 and $380 \mathrm{~K}$ isentropic surfaces. The model calculations indicate that the water transport across $340 \mathrm{~K}(\sim 200 \mathrm{hPa})$ is even larger over southeastern Asia than over the western Pacific warm pool, owing to the exceptional altitude attained by the Asian convection, in particular over Tibet. Further, transport across the tropopause at $380 \mathrm{~K}(\sim 100 \mathrm{hPa})$ in the equatorial zone is rather weak (and can even be downward), whereas the upward fluxes are much larger over the Asian monsoon region. The diabatic transport (i.e. across isentropic surfaces, as shown in Fig. 49) into the tropical tropopause layer at $340 \mathrm{~K}$ is dominated by convection (i.e. latent heating), while the ascent into the stratosphere at $380 \mathrm{~K}$ is controlled by the stratospheric BrewerDobson circulation, being enhanced by localized net radiative heating.

Two recent findings provide strong evidence of the transport of southern Asian pollutants to the stratosphere via this pathway. First, in the tropical lower stratosphere, a tape recorder signal can be detected for CO (Schoeberl et al., 2006), similar to that noted above for water vapor. The semiannual cycle of $\mathrm{CO}$ can be explained by the seasonal variations in deep convection and biomass burning (Liu et al., 2007). Since the chemical lifetime of CO is relatively short in the stratosphere (several months), the observable signal does not extend above $20 \mathrm{~km}$ altitude, in contrast to that of $\mathrm{H}_{2} \mathrm{O}$, which can reach up to $35 \mathrm{~km}$. In retrospect, aircraft measurements of $\mathrm{CO}_{2}$ at about $20 \mathrm{~km}$ altitude also appear to be consistent with a tape recorder transport mechanism (Andrews et al., 1999). The other finding (Randel et al., 2010) is that satellite observations and model simulations of $\mathrm{HCN}$, a biomass and biofuel burning product, show a pronounced maximum in its mixing ratio in the TTL above the Tibetan anticyclone, where the air is largely originating from southern Asia. In contrast, $\mathrm{HCN}$ is effectively removed on the ocean surface, so that regions of strong, deep upwards transport of less polluted air, such as the Pacific warm pool, are tagged with very low HCN mixing ratios. Future observations of other trace gases may help to elucidate the role of southern Asian emissions compared to other regions contributing to this input pathway for the lower stratosphere.

In summary, if air pollution is mixed into the extratropical stratosphere through the western UT route over the eastern Mediterranean, much of it will ultimately be mixed back into the midlatitude troposphere. On the other hand, if the pollution gets trapped into the UT anticyclone over Tibet, it may be transported into the tropical tropopause layer and subsequently lofted into the stratosphere. There will clearly be an influence on the stratosphere due to trace gas transport by both of these mechanisms, although the quantitative elucidation of pollution transport pathways from Asia into the stratosphere and their chemical and climate effects will require considerable additional research. 


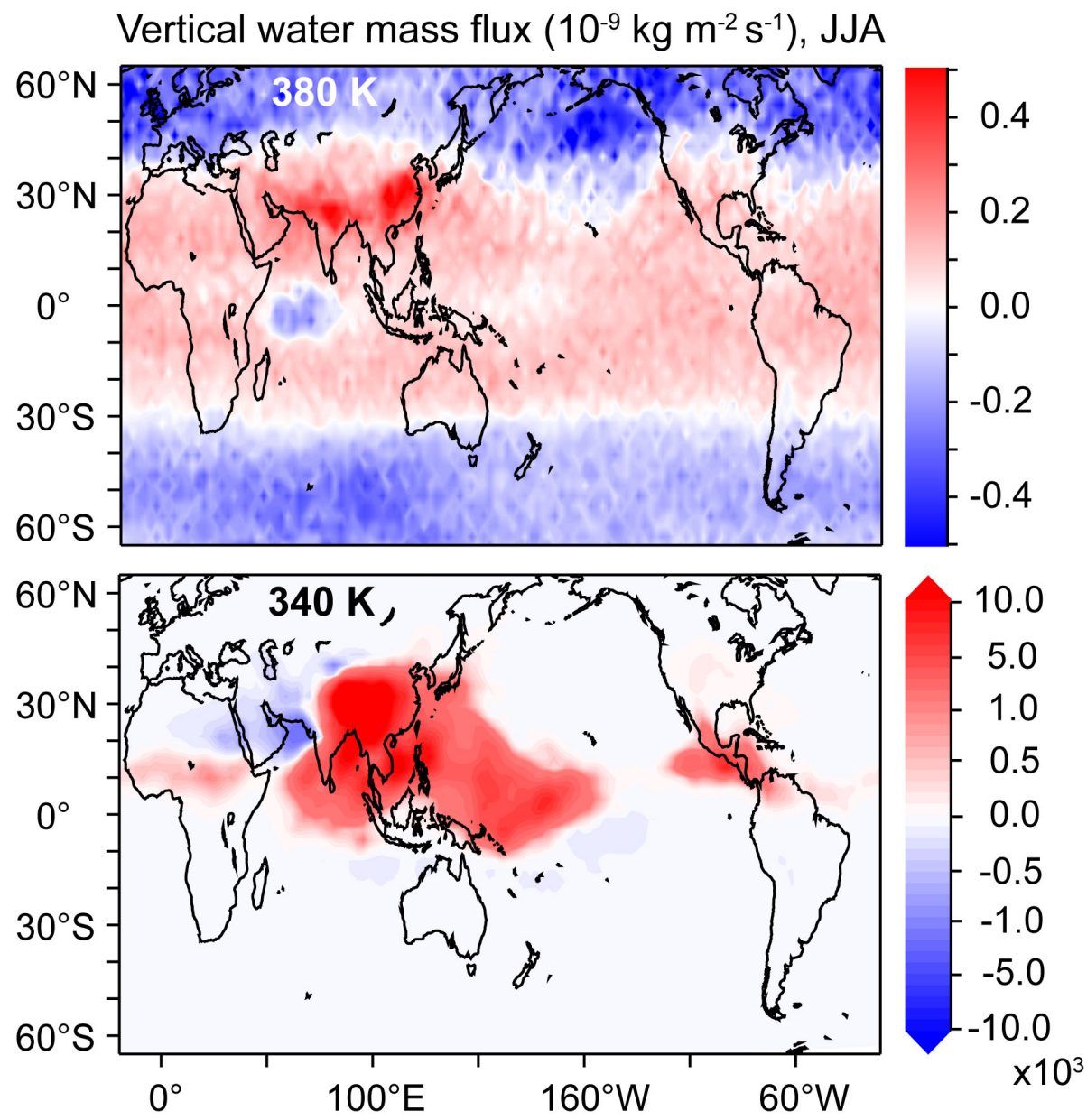

Fig. 49. Model calculated water mass fluxes (in all phases) across the 340 and $380 \mathrm{~K}$ isentropes, averaged for the periods June-August 2002 and 2003; red is upward; note that the scale changes between the lower and upper panel (from Lelieveld et al., 2007, copyright 2007 by the European Geophysical Union, modified with permission).

\section{The monsoon transition period plumes}

Between the summer and winter monsoons are the "Monsoon Transition Periods" (MTPs), during which the ITCZ migrates north or south, the meridional winds weaken, and zonal trade winds become strong across the Indian Ocean. These periods are referred to by various names, for example the "pre" and "post-monsoon transition periods" (indicating before and after the summer monsoon, respectively); here we will use the terminology "onset-MTP" and "withdrawal-MTP". Thus far the atmospheric chemistry of these periods has received much less attention than the summer and in particular the winter monsoon periods, though there have been several recent studies based on campaigns since INDOEX, especially ICARB, the latter part of which extended into the pre-monsoon transition period (see Sect. 4.1). This section gives a brief overview of what is known about the southern Asian pollution outflow during this period.
The shifts in mean wind directions during the two MTPs were depicted earlier in Sect. 3 for 2006 (Fig. 6). The firsts signs of the shift in winds for the onset-MTP can already be seen in March, when the outflow from India into the Arabian Sea and from Southeast Asia into the Bay of Bengal begins to weaken. In April the equatorial westerlies move north to crossing Sri Lanka, and there is otherwise little offshore flow from either the Indian subcontinent or Southeast Asia. By May the winds have largely taken on the character of the summer monsoon (though with much lower wind speeds), with the strong westerlies extending up to about $20^{\circ} \mathrm{N}$, crossing India and providing a strong, lowlevel outflow into the Bay of Bengal. The winds then basically maintain the same appearance from June until September, intensifying until August and weakening thereafter. The withdrawal-MTP shift occurs fairly rapidly in late September or during October, and by November the wind fields are nearly the same as during the rest of the winter monsoon, with offshore flow towards the southwest from India 
and southern Asia. The winds in October (withdrawal-MTP) are notably different from those in April-May (onset-MTP), with weaker westerlies and offshore flow mainly towards the Arabian Sea (rather than towards the Bay of Bengal).

These seasonally varying transport patterns are reflected in observations of trace gases and aerosols during the MTPs. Onshore, the winds suggest the possibility of transport from northern India and Bangledesh towards Eastern Asia (Myanmar and western China). Though not many observations are available from this region, evidence of significant pollutant transport has been presented by Chan et al. (2006), based on surface-level measurements of pollutants made on the southeastern Tibetan Plateau during a field campaign in AprilMay 2004. Their analysis shows that about $20-25 \%$ of the trajectories originated from the west (India, Nepal and Bangledesh), and tended to be the most polluted airmasses, with mixing ratios of $\mathrm{O}_{3}, \mathrm{CO}, \mathrm{NO}_{\mathrm{y}}$ and mass densities of $\mathrm{PM}_{10}$ and $\mathrm{PM}_{2.5}$ exceeding those in airmasses from the south or east. While this may be important in the less populated and less industrialized regions of western China, further to the east one would expect any import of polluted airmasses from southern Asia to be dwarfed by local emissions.

Offshore, where more observations are available, the weaker winds from the continent lead to generally lower aerosol mass concentrations and trace gas mixing ratios during the MTPs compared to the SAW-ABC (e.g., Moorthy et al., 2008; Nair et al., 2008), as well as weaker northsouth gradients for $\mathrm{O}_{3}$ and $\mathrm{CO}$ (Sahu et al., 2006). The earliest known chemical observations during the MTPs date back to three cruises in 1995, the pre-INDOEX cruise of the American RV Malcolm Baldrige (Rhoads et al., 1997), which lasted into late April (Table 4), and another independent pair of cruises in the Arabian Sea with the German RV Meteor during May and July/August 1995 (Johansen et al., 1999). The latter study could contrast the onset-MTP with the summer monsoon period, and showed that the anthropogenic component of sulfate aerosol was still relatively high $(65 \%)$ during the onset-MTP, falling rapidly to only $25 \%$ during the summer monsoon. A similar transition was seen during two cruises in the Arabian Sea with the RV Sagar Kanya during March-June 2003 (Babu et al., 2004, 2008; Moorthy et al., 2005a), with a rapid decrease in BC mass fraction from $\sim 2.5 \%$ in March to $0.5 \%$ in June, and similar decreases in the anthropogenic influence over the Arabian Sea during the onset-MTP were seen during the ICARB cruise (Moorthy et al., 2008). ICARB observations of AOD and the Angstrom exponent (the wavelength dependence of the extinction of shortwave radiation by the aerosols) by Kaskaoutis et al. (2010) and Kalapureddy et al. (2009) indicated a very strong spatial heterogeneity in the Arabian Sea during this period. Highly polluted airmasses containing small urban particles were still observed near the coasts like in the winter monsoon; relatively high AOD values were also observed in the northern Arabian Sea, associated mainly with mineral dust. On the other hand, very low values of
AOD were observed in the central and western Arabian Sea, associated with the anticyclonic center seen in April in Fig. 6, along with transport from the central Indian Ocean that takes over in May.

During the onset-MTP over the Bay of Bengal, one could expect a decrease in pollutant levels and in indicators like the AOD, which has been confirmed by observations at the island station of Port Blair (Beegum et al., 2008). During this period, the $\mathrm{BC}$ fraction of the total aerosol over the Bay of Bengal has been found to be very sensitive to the transition (Babu et al., 2004, 2008; Sumanth et al., 2004; Moorthy et al., 2005a; Satheesh et al., 2006b). In late April and early May, the BC mass fraction peaks at about $6 \%$, due to the shift to westerly offshore flow and little pre-monsoon precipitation, so that a substantial amount of the anthropogenic continental aerosol survives the transport over the Bay. Further evidence of this long survival of anthropogenic pollution comes from the study of Nair et al. (2010), in which ICARB observations are analyzed to determine the anthropogenic contribution as a function of geographic location. They find that the TOA radiative forcing by anthropogenic aerosols is nearly constant at -3.3 to $-3.6 \mathrm{~W} \mathrm{~m}^{-2}$ from north to south within the sampled area, suggesting relatively little loss of anthropogenic aerosols during the transport away from the coastal source regions. However, very interestingly, they also find that the anthropogenic fraction increases substantially away from the coast: in other words, near the outflow from the highly-polluted Indo-Gangetic Plain, the anthropogenic aerosols only contribute about $25 \%$ of the total AOD, whereas over the southern Bay of Bengal the fractional contribution increases to about $50 \%$. Though this surprising result needs further investigation to be corroborated and explained, the authors offer a sensible hypothesis: large amounts of dust particles accompany the pollution near the coast, but due to their larger sizes they sediment out much more rapidly than the anthropogenic aerosol particles, leaving anthropogenic aerosols like BC to make a larger relative contribution farther away from land.

In contrast, during the withdrawal-MTP in October the BC mass fraction generally falls to about half as much as during the onset MTP ( $\sim 3 \%$, with an SSA of 0.94$)$, due to the nondescript outflow from both India and southeastern Asia. On the other side of India, observations in the Arabian Sea during the withdrawal-MTP show clear anthropogenic fingerprints reappearing during October (Spencer et al., 2008): at $\mathrm{MCOH}$, high-BC episodes occur during which over $70 \%$ of the particles show characteristics of originating from BMB + BFB, and most of the aerosol samples are also mixed with notable amounts of sulfate due to secondary processing during transport. Further observations made during the withdrawal MTP over both the Arabian Sea and the Bay of Bengal have shown similar trends towards reduced pollution levels with the shifts in the wind direction (e.g., Mandal et al., 2006; Sahu et al., 2006). 


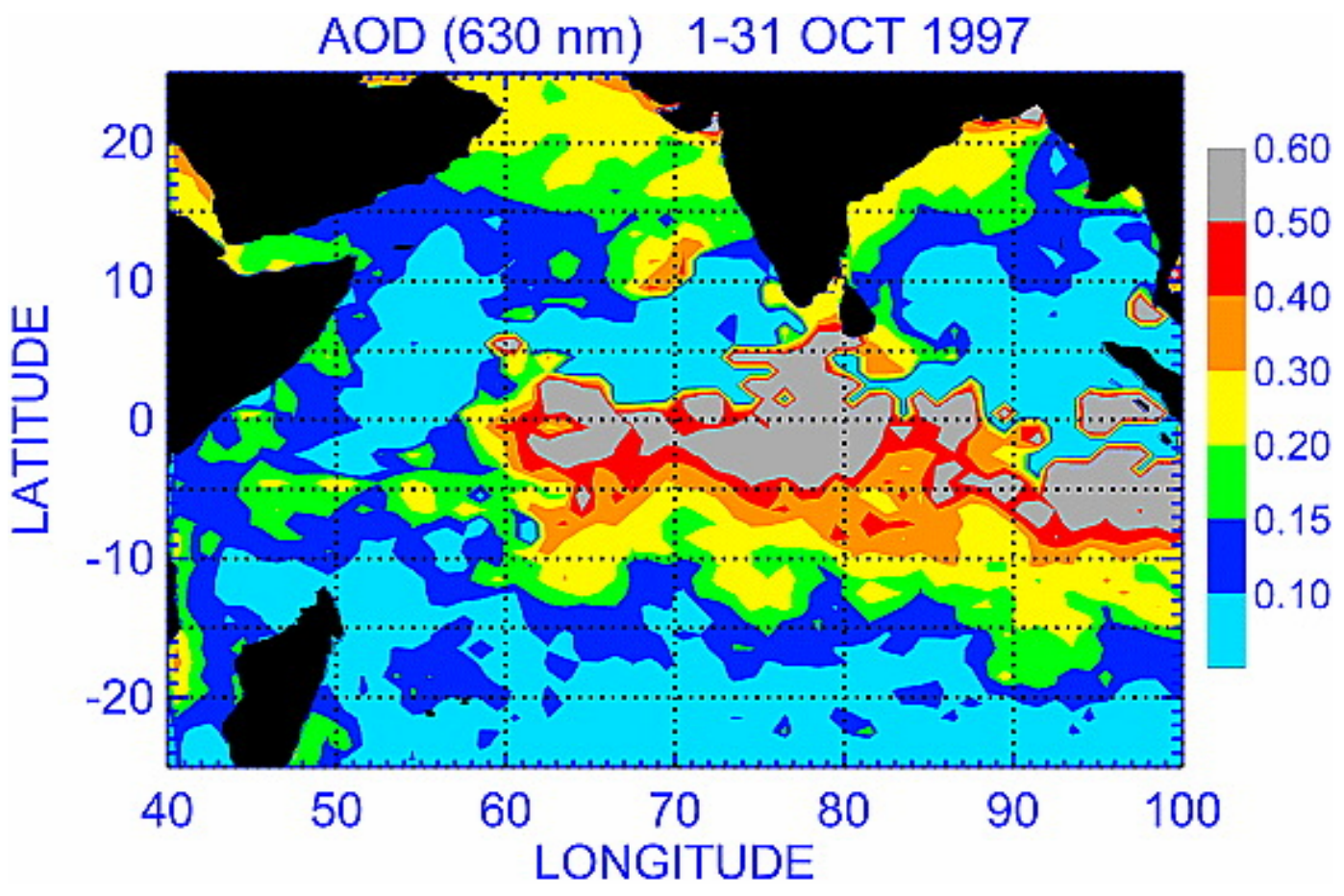

Fig. 50. Satellite retrieval of the aerosol optical depth (AOD) during October 1997, showing the strong plume from the Indonesian forest fires (from Li and Ramanathan, 2002, copyright 2002 by the American Geophysical Union, reproduced with permission).

One of the particularly interesting observations during the MTPs is the occasional, extremely strong influence of biomass burning in Indonesia on the eastern equatorial Indian Ocean during El Niño periods (Heil and Goldammer, 2001). The most poignant example was during the 1997 El Niño, when tremendous fires during September-November 1997 resulted in a massive aerosol plume with an AOD $>1.0$ (Fig. 50). Aerosol concentrations reached up to $4 \mathrm{mg} \mathrm{m}^{-3}$, while several hundred $\mu \mathrm{g} \mathrm{m}^{-3}$ were observed over extended areas and periods, with severe regional air quality and climate consequences, such as a regional reduction of solar radiation reaching the equatorial Indian Ocean of 15-25\% (Heil and Goldammer, 2001; Li and Ramanathan, 2002; Podgorny et al., 2003; Rajeev et al., 2004). An additional strong plume during the $2006 \mathrm{El}$ Nino (October/November) was examined by Thampi et al. (2009), employing the CALIPSO satellite instrument to allow an analysis of the vertical structure; the plume was found to be mostly confined to below $3 \mathrm{~km}$, with the highest concentrations between $0.6-$ $2.0 \mathrm{~km}$. The plume was noted to also be very clearly visible in satellite-derived CO columns (Gloudemans et al., 2009). Finally, Kunhikrishnan et al. (2004b) found that while strong pollution plumes are clearly most pronounced during the special El Niño conditions, they are recurrent phenomena, particularly for $\mathrm{NO}_{\mathrm{x}}$, which can be seen during most transition periods (especially the withdrawal-MTP), as shown in Fig. 51. These plumes can be seen in satellite retrievals of $\mathrm{NO}_{2}$ from the GOME (Global Ozone Monitoring
Experiment) and SCIAMACHY (Scanning Imaging Absorption Spectrometer for Atmospheric CHartographY) instruments. They are transported across the Indian Ocean near the equator mostly in the middle troposphere (around $700 \mathrm{hPa}$ ), originating primarily from biomass burning in southeast Asia (especially Indonesia), as well as having a strong (and sometimes dominant) contribution from Africa. This finding has the interesting implication that the central and southern Indian Ocean is not always as pristine as found during INDOEX in the winter monsoon; in particular, during the monsoon transition periods, pollution levels are even greater south of $10^{\circ} \mathrm{S}$ than over the northern Indian Ocean, the opposite of the winter monsoon situation encountered during INDOEX (Fig. 52).

\section{Conclusions and outlook}

This article has given an overview of the key aspects of the outflow of pollutants from southern Asia during the monsoon and transition seasons, with an emphasis on the dry winter monsoon, for which both the transport potential and the body of literature are largest. While an immense amount has been learned about these issues over the last decades, there are still many unanswered questions. Foremost in many readers' minds may not be the impact of southern Asian emissions on the rest of the world, which has been the focus of this review, but instead the impact of southern Asian emissions plus 


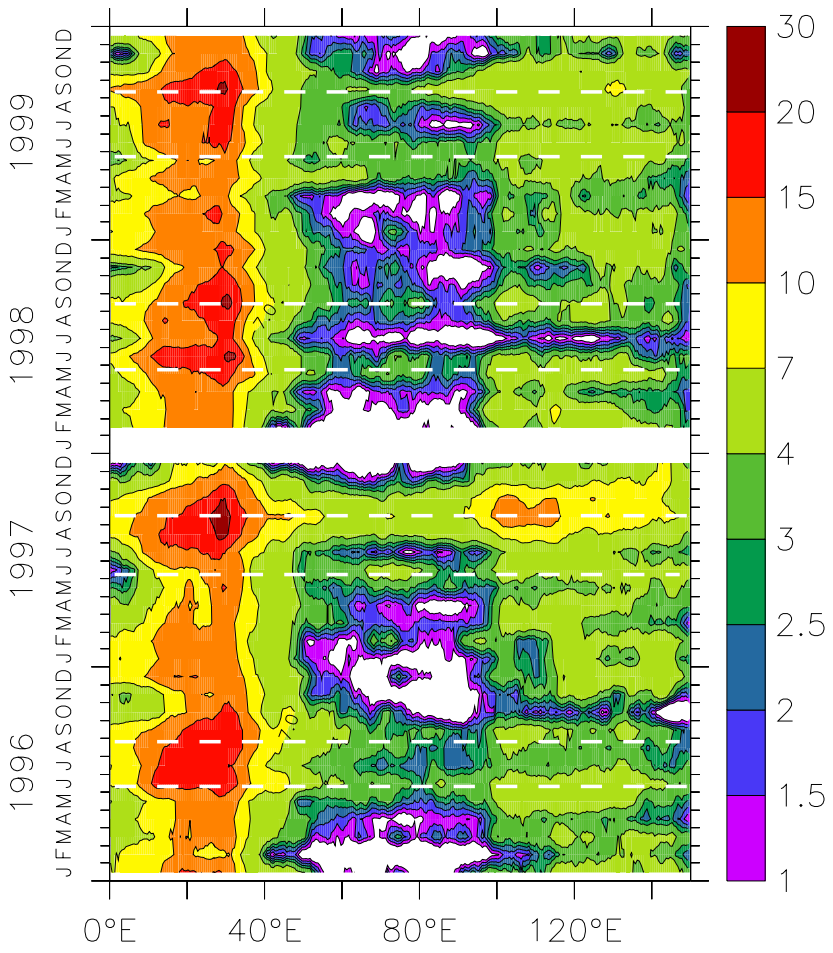

Fig. 51. Tropospheric $\mathrm{NO}_{2}$ column (in $10^{14}$ molecules $/ \mathrm{cm}^{2}$ ) averaged for $5^{\circ} \mathrm{N}-30^{\circ} \mathrm{S}$ during 1996-1999 from the GOME satellite instrument (from Kunhikrishnan et al., 2004, copyright 2004 by the American Geophysical Union, reproduced with permission).

the emissions from the rest of the world on southern Asia itself. It is clear that long-lived greenhouse gases from Europe and North America have global effects, and certainly other gases with intermediate lifetimes such as $\mathrm{CO}$ and $\mathrm{O}_{3}$ may also be strongly affected by trans-boundary transport, particularly between various parts of Asia. This is not limited to anthropogenic emissions, but also includes natural sources of gases and aerosols, in particular dust, which can be transported over long distances, for instance from the Arabian deserts, to have a significant short-term influence on the AOD over India and other parts of southern Asia (e.g., Badarinath et al., 2010). Considerable work is needed to deepen our scientific understanding of atmospheric tele-connections and to develop effective strategies for dealing with the air pollution problems facing the local populations, which will almost inevitably help alleviate many of the superregional pollution problems discussed here.

In addition to the emissions from biomass, biofuel and fossil fuel burning in southern Asia, another major problem facing the region is the intermittent severe biomass burning (forest fires) on the Southeast Asian islands (especially Indonesia), particularly in connection with El Niño. These fires can lead to very large amounts of trace gas and aerosol emissions on short time scales in a region which is one of the most convectively active worldwide.
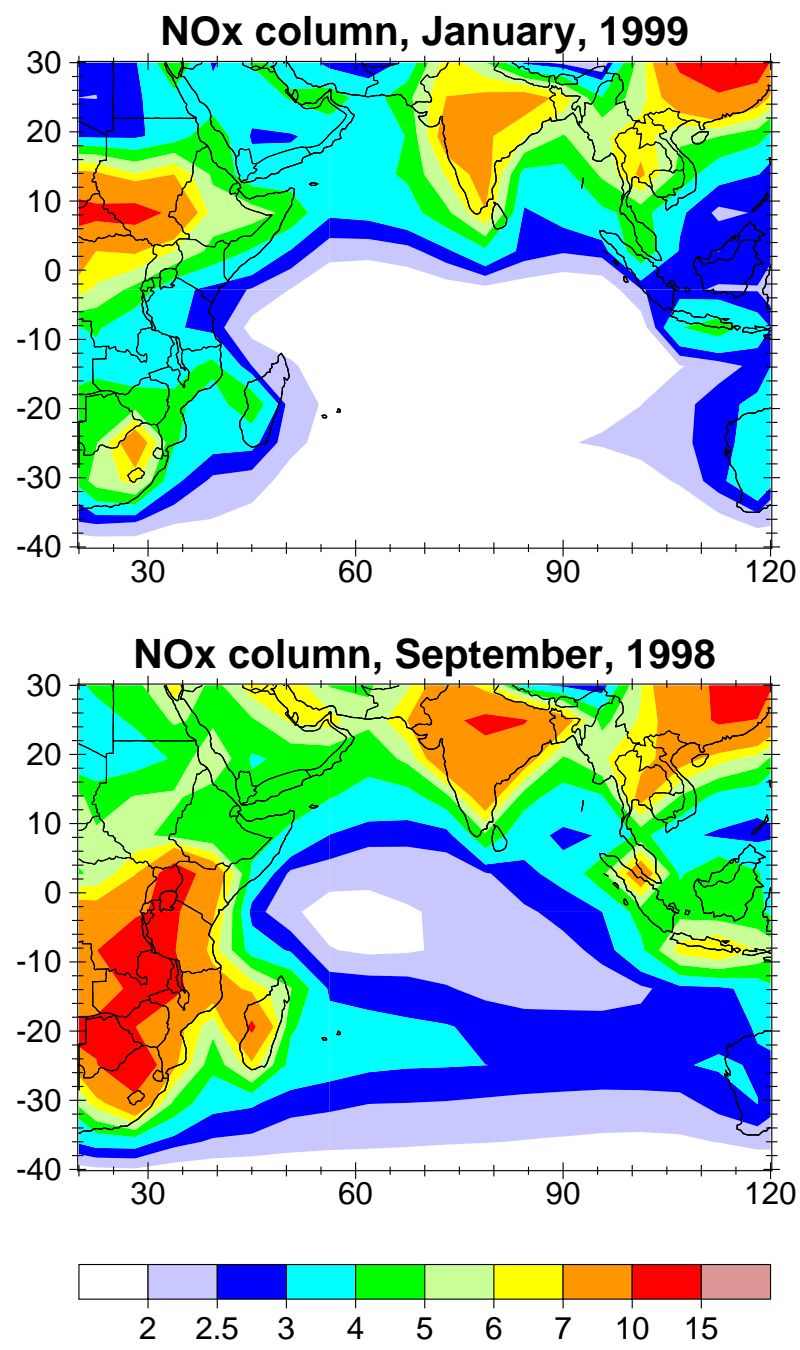

Fig. 52. Horizontal structure of the tropospheric $\mathrm{NO}_{\mathrm{x}}$ column (in $10^{14}$ molecules $/ \mathrm{cm}^{2}$ ) from the MATCH-MPIC model. Top: January 1999, during INDOEX; bottom: September 1998, during the monsoon transition period (based on data from simulations discussed in Kunhikrishnan et al., 2004).

The next decade of research on this subject will be driven by a number of key questions, many of which have been brought up already in the above discussions:

Open issues - SAW-ABC:

- How much of the pollution over various parts of the Indian Ocean is from southern Asia versus other regions (especially China, Africa, the Middle East and Europe)? Can we link atmospheric chemistry measurements in the pollution source regions with those over the Indian Ocean to learn more about the transport potential?

- How do the gaseous and particulate pollutants over the ocean interact, including emissions from international shipping, sea spray and wind-blown desert dust, which can be important in specific geographical regions and 
periods? How do aerosols in the SAW-ABC age? For instance, how do the properties of $\mathrm{BC}$ change from hydrophobic into hydrophyllic, over what time scales?

- To what extent do mesoscale meteorological patterns, for example land-sea breeze circulations, orographic flows and cloud-enhanced mixing between the boundary layer and free troposphere influence the pollution transport potential?

- How large is the regional source of $\mathrm{BC}$ and what are the relative roles of biomass, biofuel and fossil fuel burning (i.e., can the discrepancies between top down versus bottom up estimates be finally resolved), how large is the radiative forcing from $\mathrm{BC}$ in the haze, and how does this affect boundary layer and lower tropospheric dynamics?

- What are the effects of the pollution haze on: clouds and deep convection in the ITCZ; the monsoon transition periods; the summer monsoon onset and intensity; and tropospheric chemistry? What are the key factors that need to be focused on to reduce the uncertainty in simulating these effects with chemistry-climate models?

- How much pollution in general (e.g., as a function of lifetime) makes it into the ITCZ? What are the details of the convective and large-scale transport in the ITCZ, such as the amount of interhemispheric exchange which occurs, and the fraction of gases and aerosols that are washed out during the transport?

- In addition to vertical transport in the ITCZ, can there also be significant lofting of pollutants during this period along the southern edge of Himalayas? How much pollution in general makes it into the Himalayas and the Tibetan Plateau region, during the winter monsoon as well as the rest of the year, and what effects do these pollutants have on the cryospheric reservoirs and the monsoon circulation?

\section{Open issues - Asian summer monsoon outflow:}

- What quantities of various trace species in the Asian monsoon plumes are actually transported into the tropical tropopause layer and subsequently into the lower stratosphere?

- How much of the immense amount of carbonaceous aerosol which is produced in southern Asia (evidenced by the SAW-ABC) is able to survive transport to the UT through summertime deep convective clouds? What happens to the aerosols once they are in the UT in terms of aging, coating, and primary loss mechanisms, and how do they affect radiation processes and possibly cirrus cloud properties?
- Is $\mathrm{O}_{3}$ generally enhanced or depleted in the Asian summer monsoon plumes, and how does this vary spatially and temporally within the outflow?

- What is the role of breaks in the monsoon in allowing pollution buildup and transformations (especially photochemical $\mathrm{O}_{3}$ formation and aerosol aging) prior to the convection (i.e., how different do things look in years when the convection is more even versus years when there are lots of breaks between intense rainy spells)?

- How significant is the eastward component of the monsoon outflow, in part through the lower stratosphere? Can it also be observed (in situ or by satellites)? Does it join up with the outflow from eastern and northern Asia and head across the Pacific towards North America, and if so, does it represent a non-negligible additional source for any particular gases or aerosols?

- How does pollution transport from southern India and Sri Lanka toward the northern Bay of Bengal and the coastal regions of Bangladesh and eastern India contribute to pollutant ozone buildup over the Bay of Bengal?

\section{Open issues - monsoon transition periods:}

- Do further measurements during this period support the first impressions from the sparse measurements, along with satellite and modeling studies, which have been made so far?

- Is this a particularly sensitive period for effects of aerosols on the monsoon onset and withdrawal? If so, how large is the natural interannual variability of this (due mainly to ENSO), and how will the anthropogenic component of the influence change in the future?

- Are the pollutant outflow and the resulting radiative effects during this period of global significance compared to the longer summer and winter monsoon periods?

Open issues - general:

- How do we go about improving emissions estimates and their future projections? The emissions from this populous region grow so rapidly that results from bottom-up methods are predestined to be outdated upon their availability for the modeling community. Can combinations of bottom-up and top-down satellite-based approaches lead to major advances in the near future? The development of emission scenarios will be associated with large uncertainties and needs intensified cooperation between policy makers and environmental scientists.

- How do the emissions from southern Asia influence global mean $\mathrm{OH}$ levels and the tropospheric oxidizing efficiency? What are the effects on global tropospheric 
$\mathrm{O}_{3}$, particularly on surface $\mathrm{O}_{3}$ over the US and Europe, which is predicted to increase notably in the future due to the impact of Asian emissions on the hemispheric background $\mathrm{O}_{3}$ levels?

- Finally, a major set of questions involves the effects of air pollutants on the atmospheric energy and water budgets. Although field observations have provided clear indications of the influence of aerosol particles on atmospheric heating rates, as well as the surface energy budget and water fluxes, the representation of these processes as well as the indirect effects of aerosols on clouds in climate models are in their infancy.

It is important to consider how future research will be organized, and who will lead it, so that it will most effectively address the issues that are most important for the populations of southern Asia, as well as those that are critical to the rest of the world. A major step towards developing such a focused international and interdisciplinary research initiative is the UNEP-sponsored ABC (Atmospheric Brown Clouds) project, with an initial focus on Asia, in which several measurement stations have been established, which are important for monitoring, model testing and providing an indispensable reference point for future measurement campaigns. ABCAsia also plays a key role in the international organization of modeling exercises, field campaigns and their coordination with satellite observations. Future work sponsored by ABCAsia and other programs will hopefully be able to make substantial progress towards answering many of the questions posed above.

Acknowledgements. Our appreciation goes to the many colleagues who have shared their curiosity and wisdom with us during the course of INDOEX, MINOS, and other studies of the Asian pollutant outflow, and to those who have provided comments and helpful information for this manuscript during its development. Among these are Paul Crutzen, V. Ramanathan, the late A. P. Mitra, Shyam Lal, A. Jayaraman, Tuhin K. Mandal, D. R. Sikka, Arnico Panday, S. K. Satheesh, Phil Rasch, Horst Fischer, Jonathan Williams, Russ Dickerson, Henning Rodhe, Nikos Mihalopoulos, Sethu Raman, Shubha Verma, T. Kunhikrishnan, Rolf Sander, Tanja Schuck, Angela Baker, and numerous others. We thank Sarah Alznauer, Claudia Keller and the MPIC graphics department for help with references and figures.

The service charges for this open access publication have been covered by the Max Planck Society.

Edited by: O. Cooper

\section{References}

Ackerman, A. S., Toon, O. B., Stevens, D. E., Heymsfield, A. J., Ramanathan, V., and Welton, E. J.: Reduction of tropical cloudiness by soot, Science, 288, 1042-1047, 2000.

Akimoto, H.: Global air quality and pollution, Science, 302, 17161719, 2003.

Akimoto, H., Ohara, T., Kurokawa, J., and Horii, N.: Verification of energy consumption in China during 1996-2003 by using satellite observational data, Atmos. Environ., 40, 7663-7667, 2006.

Alexander, D. T. L., Crozier, P. A., and Anderson, J. R.: Brown Carbon Spheres in East Asian Outflow and Their Optical Properties, Science, 321, 833-836, 2008.

Alfaro, S. C., Gaudichet, A., Rajot, J. L., Gomes, L., Maillé, M., and Cachier, H.: Variability of aerosol-resolved composition at an Indian coastal site during the Indian Ocean Experiment (INDOEX) intensive field phase, J. Geophys. Res., 108, 4235, doi:10.1029/2002JD002645, 2003.

Ali, K., Momin, G. A., Tiwari, S., Safai, P. D., Chate, D. M., and Rao, P. S. P.: Fog and precipitation chemistry at Delhi, North India, Atmos. Environ., 38, 4215-4222, 2004.

Ali, K., Beig, G., Chate, D. M., Momin, G. A., Sahu, S. K., and Safai, P. D.: Sink mechanism for significantly low level of ozone over the Arabian Sea during monsoon, J. Geophys. Res., 114, D17306, doi:10.1029/2008JD011256, 2009.

Aloysius, M., Mohan, M., Babu, S. S., Nair, V. S., Parameswaran, K., and Moorthy, K. K.: Influence of circulation parameters on the AOD variations over the Bay of Bengal during ICARB, J. Earth Syst. Sci., 117, 353-360, 2008.

Anderson, R. C.: Do dragonflies migrate across the western Indian Ocean?, J. Trop. Ecol., 25, 347-358, 2009.

Andrews, A. E., Boering, K. A., Daube, B. C., Wofsy, S. C., Hintsha, E. J., Weinstock, E. M., and Bui, T. P.: Empirical age spectra for the lower tropical stratosphere from in sitiu observations of $\mathrm{CO}_{2}$ : implications for stratospheric transport, J. Geophys. Res., 104, 26581-26596, 1999.

Andronache, C., Donner, L. J., Seman, C. J., and Hemler, R. S.: A study of the impact of the Intertropical Convergence Zone on aerosols during INDOEX, J. Geophys. Res., 107, 8027, doi:10.1029/2001JD900248, 2002.

Appu, K. S., Nair, S. M., Kunhikrishnan, P. K., Moorthy, K. K., Sarode, P. R., Rao, L. V., Bajpai, S. R., Prakash, L. H., Viswanathan, G., Mitra, A. P., Sadoumy, R., Basdevant, C., Ethe, C., Ovarlez, H., Chapuis, R., Dartigudongue, B., and Vianeys, P.: Spatial distribution of meteorological parameters around $900 \mathrm{hPa}$ level over the Arabian Sea and Indian Ocean regions during the IFP-99 of the INDOEX programme as revealed from the constant altitude balloon experiments conducted from Goa, Curr. Sci. India, 80, 89-96, 2001.

Ashfaq, M., Shi, Y., Tung, W., Trapp, R. J., Gao, X., Pal, J. S., and Diffenbaugh, N. S.: Suppression of south Asian summer monsoon precipitation in the 21st century, Geophys. Res. Lett., 36, L01704, doi:10.1029/2008GL036500, 2009.

Asatar, G. I. and Nair., P. R.: Spatial distribution of near-surface CO over Bay of Bengal during winter: role of transport, J. Atmos. Sol.-Terr. Phy., 72, 1241-1250, doi:10.1016/j.jastp.2010.07.025, 2010.

Auvray, M. and Bey, I.: Long-range transport to Europe: Seasonal variations and implications for the European ozone budget, J. Geophys. Res., 110, D11303, doi:10.1029/2004JD005503, 2005. 
Babu, S. S., Satheesh, S. K., and Moorthy, K. K.: Aerosol radiative forcing due to enhanced black carbon at an urban site in India, Geophys. Res. Lett., 29, 1880, doi:10.1029/2002GL015826, 2002.

Babu, S. S., Moorthy, K. K., and Satheesh, S. K.: Aerosol black carbon over Arabian Sea during intermonsoon and summer monsoon seasons, Geophys. Res. Lett., 31, L06104, doi:10.1029/2003GL018716, 2004.

Babu, S. S., Satheesh, S. K., Moorhty, K. K., Dutt, C. B. S., Nair, V. S., Alappattu, D. P., and Kunhikrishnan, P. K.: Aircraft measurements of aerosol black carbon from a coastal location in the north-east part of peninsular India during ICARB, J. Earth Syst. Sci., 117, 263-271, 2008.

Babu, S. S., Sreekanth, V., Nair, V. S., Satheesh, S. K., and Moorthy, K. K.: Vertical profile of aerosol single scattering albedo over west coast of India during W_ICARB, J. Atmos. Sol.-Terr. Phy., 72, 876-882, doi:10.1016/j.jastp.2010.04.013, 2010.

Badarinath, K. V. S., Kumar Kharol, S., Kaskaoutis, D. G., Sharma, A. R., Ramaswamy, V., and Kambezidis, H. D.: Long-range transport of dust aerosols over the Arabian Sea and Indian region - A case study using satellite data and ground-based measurements, Glob. Plan. Change, 72, 164-181, doi:10.1016/j.gloplacha.2010.02.003, 2010.

Badarinath, K. V. S. and Kumar Kharol, S.: Studies on aerosol properties during ICARB-2006 campaign period at Hyderabad, India using ground-based measurements and satellite data, J. Earth Syst. Sci., 117, 413-420, 2008

Baker, A. K., Schuck, T. J., Slemr, F., van Velthoven, P., Zahn, A., and Brenninkmeijer, C. A. M.: Characterization of non-methane hydrocarbons in Asian summer monsoon outflow observed by the CARIBIC aircraft, Atmos. Chem. Phys. Discuss., 10, 1810118138, doi:10.5194/acpd-10-18101-2010, 2010.

Ball, W. P., Dickerson, R. R., Doddridge, B. G., Stehr, J. W., Miller, T. L., Savoie, D. L., and Carsey, T. P.: Bulk and size-segregated aerosol composition observed during INDOEX 1999: overview of meteorology and continental impacts, J. Geophys. Res., 108, 8001, doi:10.1029/2002JD002467, 2003.

Bannister, R. N., O’Neill, A., Gregory, A. R., and Nissen, K. M.: The role of the south-east Asian monsoon and other seasonal features in creating the "tape-recorder" signal in the Unified Model, Q. J. Roy. Meteor. Soc., 130, 1531-1554, 2004.

Barret, B., Ricaud, P., Mari, C., Attié, J.-L., Bousserez, N., Josse, B., Le Flochmoën, E., Livesey, N. J., Massart, S., Peuch, V.H., Piacentini, A., Sauvage, B., Thouret, V., and Cammas, J.P.: Transport pathways of $\mathrm{CO}$ in the African upper troposphere during the monsoon season: a study based upon the assimilation of spaceborne observations, Atmos. Chem. Phys., 8, 3231-3246, doi:10.5194/acp-8-3231-2008, 2008.

Beegum, S. N., Moorthy, K. K., Nair, V. S., Babu, S. S., Satheesh, S. K., Vinoj, V., Ramakrishna Reddy, R., Rama Gopal, K., Badarinath, K. V. S., Niranjan, K., Kumar Pandey, S., Behera, M., Jeyaram, A., Bhuyan, P. K., Gogoi, M. M., Singh, S., Pant, P., Dumka, U. C., Kant, Y., Kuniyal, J. C., and Singh, D.: Characteristics of spectral aerosol optical dephts over India during ICARB, J. Earth Syst. Sci., 117, 303-313, 2008.

Beirle, S., Platt, U., von Glasow, R., Wenig, M., and Wagner, T.: Estimate of nitrogen oxide emissions from shipping by satellite remote sensing, Geophys. Res. Lett., 31, L18102, doi:10.1029/2004GL020312, 2004.
Berntsen, T. K., Karlsdòttir, S., and Jaffe, D. A.: Influence of Asian emissions on the composition of air reaching the North Western United States, Geophys. Res. Lett., 26, 2171-2174, 1999.

Bhawar, R. L. and Devara, P. C. S.: Study of successive contrasting monsoons (2001-2002) in terms of aerosol variability over a tropical station Pune, India, Atmos. Chem. Phys., 10, 29-37, doi:10.5194/acp-10-29-2010, 2010.

Bonasoni, P., Laj, P., Marinoni, A., Sprenger, M., Angelini, F., Arduini, J., Bonafè, U., Calzolari, F., Colombo, T., Decesari, S., Di Biagio, C., di Sarra, A. G., Evangelisti, F., Duchi, R., Facchini, MC., Fuzzi, S., Gobbi, G. P., Maione, M., Panday, A., Roccato, F., Sellegri, K., Venzac, H., Verza, GP., Villani, P., Vuillermoz, E., and Cristofanelli, P.: Atmospheric Brown Clouds in the Himalayas: first two years of continuous observations at the Nepal Climate Observatory-Pyramid (5079 m), Atmos. Chem. Phys., 10, 7515-7531, doi:10.5194/acp-10-7515-2010, 2010.

Bond, T. C., Streets, D. G., Yarber, K. F., Nelson, S. M., Woo, J.H., and Klimont, Z.: A technology-based global inventory of black and organic carbon emissions from combustion, J. Geophys. Res., 109, D14203, doi:10.1029/2003JD003697, 2004.

Boos, W. R. and Kuang, Z.: Dominant control of the South Asian monsoon by orographic insulation versus plateau heating, Nature, 463, 218-222, 2010.

Bremaud, P. J., Taupin, F., Thompson, A. M., and Chaumerliac, N.: Ozone nighttime recovery in the marine boundary layer: Measurement andn simulation of the ozone diurnal cycle at Reunion Island, J. Geophys. Res., 103, 3463-3473, 1998.

Brenninkmeijer, C. A. M., Crutzen, P., Boumard, F., Dauer, T., Dix, B., Ebinghaus, R., Filippi, D., Fischer, H., Franke, H., Frieß, U., Heintzenberg, J., Helleis, F., Hermann, M., Kock, H. H., Koeppel, C., Lelieveld, J., Leuenberger, M., Martinsson, B. G., Miemczyk, S., Moret, H. P., Nguyen, H. N., Nyfeler, P., Oram, D., O'Sullivan, D., Penkett, S., Platt, U., Pupek, M., Ramonet, M., Randa, B., Reichelt, M., Rhee, T. S., Rohwer, J., Rosenfeld, K., Scharffe, D., Schlager, H., Schumann, U., Slemr, F., Sprung, D., Stock, P., Thaler, R., Valentino, F., van Velthoven, P., Waibel, A., Wandel, A., Waschitschek, K., Wiedensohler, A., Xueref-Remy, I., Zahn, A., Zech, U., and Ziereis, H.: Civil Aircraft for the regular investigation of the atmosphere based on an instrumented container: The new CARIBIC system, Atmos. Chem. Phys., 7, 4953-4976, doi:10.5194/acp-7-4953-2007, 2007.

Burkert, J., Andrés-Hernández, M. D., Reichert, L., Meyer-Arnek, J., Doddridge, B., Dickerson, R. R., Mühle, J., Zahn, A., Carsey, T., and Burrows, J. P.: Trace gas radical diurnal behavior in the marine boundary layer during INDOEX 1999, J. Geophys. Res., 108, 8000, doi:10.1029/2002JD002790, 2003.

Butler, T. M., Lawrence, M. G., Gurjar, B. R., van Aardenne, J., Schultz, M., and Lelieveld, J.: The representation of emissions from megacities in global emission inventories, Atmos. Environ., 42, 703-719, 2008.

Chakrabarty, D. K., Peshin, S. K., Pandya, K. V., and Shah, N. C.: Long-term trend of ozone column over the Indian region, J. Geophys. Res., 103, 19245-19251, 1998.

Chan, C. Y., Wong, K. H., Li, Y. S., Chan, L. Y., and Zheng, X. D.: The effects of Southeast Asia fire activities on tropospheric ozone, trace gases, and aerosols at a remote site over the Tibetan Plateau of Southwest China, Tellus, 58B, 310-318, 2006. 
Chand, D. and Lal, S.: High ozone at rural sites in India, Atmos. Chem. Phys. Discuss., 4, 3359-3380, doi:10.5194/acpd-4-33592004, 2004.

Chand, D., Modh, K. S., Naja, M., Venkataramani, S., and Lal, S.: Latitudinal trends in $\mathrm{O}_{3}, \mathrm{CO}, \mathrm{CH}_{4}$ and $\mathrm{SF}_{6}$ over the Indian Ocean during the INDOEX IFP-1999 ship cruise, Curr. Sci. India, 80, 100-104, 2001.

Chand, D., Lal, S., and Naja, M.: Variations of ozone in the marine boundary layer over the Arabian Sea and the Indian Ocean during the 1998 and 1999 INDOEX campaigns, J. Geophys. Res., 108, 4190, doi:10.1029/2001JD001589, 2003.

Chand, D., Wood, R., Anderson, T. L., Satheesh, S. K., and Charlson, R. J.: Satellite-derived direct radiative effect of aerosols dependent on cloud cover, Nat. Geosci., 2, 181-184, 2009.

Chandra, S., Satheesh, S. K., and Srinivasan, J.: Can the state of mixing of black carbon aerosols explain the mystery of "excess" atmospheric absorption?, Geophys. Res. Lett., 31, L19109, doi:10.1029/2004GL020662, 2004.

Chatfield, R. B., Guan, H., Thompson, A. M., and Witte, J. C.: Convective lofting links Indian Ocean air pollution to paradoxical South Atlantic ozone maxima, Geophys. Res. Lett., 31, L06103, doi:10.1029/2003GL018866, 2004.

Chatfield, R. B., Guan, H., Thompson, A. M., and Smit, H. G. J.: Mechanisms for the intraseasonal variability of tropospheric ozone over the Indian Ocean during the winter monsoon, J. Geophys. Res., 112, D10303, doi:10.1029/2006JD007347, 2007.

Chazette, P.: The monsoon aerosol extinction properties at Goa during INDOEX as measured with lidar, J. Geophys. Res., 108, 4187, doi:10.1029/2002JD002074, 2003.

Chen, P.: Isentropic cross-tropopause mass exchange in the extratropics, J. Geophys. Res., 100, 16661-16673, 1995.

Chowdhury, Z., Hughes, L. S., Salmon, L. G., and Cass, G. R.: Atmospheric particle size and composition measurements to support light extinction calculations over the Indian Ocean, J. Geophys. Res., 106, 28597-28605, 2001.

Chung, C. and Ramanathan, V.: Weakening of N. Indian SST gradients and the monsoon rainfall in India and the Sahel, J. Climate, 19, 2036-2045, 2006.

Chung, C. E. and Ramanathan, V.: South Asian haze forcing: Remote impacts with implications to ENSO and AO, J. Climate, 16, 1791-1806, 2003.

Chung, C. E. and Ramanathan, V.: Relationship between trends in land precipitation and tropical SST gradient, Geophys. Res. Lett., 34, L16809, doi:10.1029/2007GL030491, 2007.

Chung, C. E., Ramanathan, V., and Kiehl, J. T.: Effects of the South Asian Absorbing Haze on the Northeast Monsoon Surface-Air Heat Exchange, J. Climate, 15, 2462-2476, 2002.

Chung, C. E., Ramanathan, V., Carmichael, G., Kulkarni, S., Tang, Y., Adhikary, B., Leung, L. R., and Qian, Y.: Anthropogenic aerosol radiative forcing in Asia derived from regional models with atmospheric and aerosol data assimilation, Atmos. Chem. Phys., 10, 6007-6024, doi:10.5194/acp-10-6007-2010, 2010.

Church, T. M. and Jickells, T. D.: Atmospheric chemistry in the coastal ocean: A synopsis of processing, scavenging and inputs, Indian J. Mar. Sci., 33, 71-76, 2004.

Chylek, P., Dubey, M. K., Lohmann, U., Ramanathan, V., Kaufman, Y. J., Lesins, G., Hudson, J., Altmann, G., and Olsen, S.: Aerosol indirect effect over the Indian Ocean, Geophys. Res. Lett., 33, L06806, doi:10.1029/2005GL025397, 2006.
Clarke, A. D., Howell, S., Quinn, P. K., Bates, T. S., Ogren, J. A., Andrews, E., Jefferson, A., Massling, A., Mayol-Bracero, O., Maring, H., Savoie, D., and Cass, G.: INDOEX aerosol: a comparison and summary of chemical, microphysical, and optical properties observed from land, ship, and aircraft, J. Geophys. Res., 107, 8033, doi:10.1029/2001JD000572, 2002.

Cofala, J., Amann, M., Klimont, Z., Kupiainen, K., and HöglundIsaksson, L.: Scenarios of global anthropogenic emissions of air pollutants and methane until 2030, Atmos. Environ., 41, 84868499, 2007.

Collins, W. D., Rasch, P. J., Eaton, B. E., Khattatov, B. V., Lamarque, J., and Zender, C. S.: Simulating aerosols using a chemical transport model with assimilation of satellite aerosol retrievals: Methodology for INDOEX, J. Geophys. Res., 106, 7313-7336, 2001.

Collins, W. D., Rasch, P. J., Eaton, B. E., Fillmore, D. W., Kiehl, J. T., Beck, C. T., and Zender, C. S.: Simulation of aerosol distributions and radiative forcing for INDOEX: Regional climate impacts, J. Geophys. Res., 107, 8028, doi:10.1029/2000JD000032, 2002.

Corrigan, C. E., Roberts, G. C., Ramana, M. V., Kim, D., and Ramanathan, V.: Capturing vertical profiles of aerosols and black carbon over the Indian Ocean using autonomous unmanned aerial vehicles, Atmos. Chem. Phys., 8, 737-747, doi:10.5194/acp-8-737-2008, 2008.

Crimmins, B. S., Dickerson, R. R., Doddridge, B. G., and Baker, J. E.: Particulate polycyclic aromatic hydrocarbons in the Atlantic and Indian Ocean atmospheres during the Indian Ocean Experiment and Aerosols99: Continental sources to the marine atmosphere, J. Geophys. Res., 109, D05308, doi:10.1029/2003JD004192, 2004.

Decesari, S., Facchini, M. C., Carbone, C., Giulianelli, L., Rinaldi, M., Finessi, E., Fuzzi, S., Marinoni, A., Cristofanelli, P., Duchi, R., Bonasoni, P., Vuillermoz, E., Cozic, J., Jaffrezo, J. L., and Laj, P.: Chemical composition of PM10 and PM1 at the highaltitude Himalayan station Nepal Climate Observatory-Pyramid (NCO-P) (5079 m a.s.1.), Atmos. Chem. Phys., 10, 4583-4596, doi:10.5194/acp-10-4583-2010, 2010.

de Gouw, J. A., Warneke, C., Scheeren, H. A., van der Veen, C., Bolder, M., Scheele, M. P., Williams, J., Wong, S., Lange, L., Fischer, H., and Lelieveld, J.: Overview of the trace gas measurements on board the Citation aircraft during the intensive field phase of INDOEX, J. Geophys. Res., 106, 28453-28467, 2001.

de Laat, A. T. J.: On the origin of tropospheric $\mathrm{O}_{3}$ over the Indian Ocean during the winter monsoon: African biomass burning vs. stratosphere-troposphere exchange, Atmos. Chem. Phys., 2, 325-341, doi:10.5194/acp-2-325-2002, 2002.

de Laat, A. T. J. and Lelieveld, J.: Diurnal ozone cycle in the tropical and subtropical marine boundary layer, J. Geophys. Res., 105, 11547-11559, 2000.

de Laat, A. T. J. and Lelieveld, J.: Interannual variability of the Indian winter monsoon circulation and consequences for pollution levels, J. Geophys. Res., 107, 4739, doi:10.1029/2001JD001483, 2002.

de Laat, A. T. J., de Gouw, J. A., and Lelieveld, J.: Model analysis of trace gas measurements and pollution impact during INDOEX, J. Geophys. Res., 106, 28469-28480, 2001 a. 
de Laat, A. T. J., Lelieveld, J., Roelofs, G. J., Dickerson, R. R., and Lobert, J. M.: Source analysis of carbon monoxide pollution during INDOEX 1999, J. Geophys. Res., 106, 28481-28495, 2001 b.

de Reus, M., Ström, J., Kulmala, M., Pirjola, L., Lelieveld, J., Schiller, C., and Zöger, M.: Airborne aerosol measurements in the tropopause region and the dependence of new particle formation on pre-existing particle number concentration, J. Geophys. Res., 103, 31255-31263, 1998

de Reus, M., Ström, J., Curtius, J., Pirjola, L., Vignati, E., Arnold, F., Hansson, H. C., Kulmala, M., Lelieveld, J., and Raes, F.: Aerosol production and growth in the upper free troposphere, $\mathrm{J}$. Geophys. Res., 105, 24751-24762, 2000.

de Reus, M., Krejci, R., Williams, J., Fischer, H., Scheele, R., and Ström, J.: Vertical and horizontal distributions of the aerosol number concentration and size distribution over the northern Indian Ocean, J. Geophys. Res., 106, 28629-28641, 2001.

de Reus, M., Formenti, P., Ström, J., Krejci, R., Müller, D., Andreae, M. O., and Lelieveld, J.: Airborne observations of dry particle absorption and scattering properties over the northern Indian Ocean, J. Geophys. Res., 107, 8002, doi:10.1029/2002JD002304, 2002.

Debaje, S. B. and Kakade, A. D.: Surface ozone variability over western Maharashtra, India, J. Hazard. Mater., 161, 686-700, 2009.

Désalmand, F., Szantai, A., Picon, L., and Desbois, M.: Systematic observation of westward propagating cloud bands over the Arabian Sea during Indian Ocean Experiment INDOEX, J. Geophys. Res., 108, 8004, doi:10.1029/2002JD002934, 2003.

Dethof, A., O'Neil, A., and Slingo, J.: Quantification of the isentropic mass transport across the dynamical tropopause, J. Geophys. Res., 105, 12279-12293, 2000.

Devasthale, A. and Fueglistaler, S.: A climatological perspective of deep convection penetrating the TTL during the Indian summer monsoon from the AVHRR and MODIS instruments, Atmos. Chem. Phys., 10, 4573-4582, doi:10.5194/acp-10-45732010, 2010.

Dey, S. and Tripathi, S. N.: Estimation of aerosol optical properties and radiative effects in the Ganga basin, northern India, during the wintertime, J. Geophys. Res., 112, D03203, doi:10.1029/2006JD007267, 2007.

Dickerson, R. R., Rhoads, K. P., Carsey, T. P., Oltmans, S. J., Burrows, J. P., and Crutzen, P. J.: Ozone in the remote marine boundary layer: A possible role for halogens, J. Geophys. Res., 104, 21385-21395, 1999.

Dickerson, R. R., Andreae, M. O., Campos, T., Mayol-Bracero, O. L., Neusuess, C., and Streets, D. G.: Analysis of black carbon and carbon monoxide observed over the Indian Ocean: Implications for emissions and photochemistry, J. Geophys. Res., 107, 8017, doi:10.1029/2001JD000446, 2002.

Dumka, U. C., Satheesh, S. K., Pant, P., Hegde, P., and Moorthy, K. K.: Surface changes in solar irradiance due to aerosols over central Himalayas, Geophys. Res. Lett., 33, L20809, doi:10.1029/2006GL027814, 2006.

Dumka, U. C., Moorthy, K. K., Pant, P., Hegde, P., Sagar, R., and Pandey, K.: Physical and optical characteristics of atmospheric aerosols during ICARB at Manora Peak, Nainital: A sparsely inhabited, high-altitude location in the Himalayas, J. Earth Syst. Sci., 117, 399-405, 2008.
Dunkerton, T. J.: Evidence of meridional motion in the summer lower stratosphere adjacent to monsoon regions, J. Geophys. Res., 100, 16675-16688, 1995.

EC: First Daughter Directive, Council Directive 1999/30/EC relating to limit values for sulphur dioxide, nitrogen dioxide and oxides of nitrogen, particulate matter, and lead in ambient, Oj 1 163, EC, 1999.

Eck, T. F., Holben, B. N., Dubovik, O., Smirnov, A., Slutsker, I., Lobert, J. M., and Ramanathan, V.: Column-integrated aerosol optical properties over the Maldives during the northeast monsoon for 1998-2000, J. Geophys. Res., 106, 28555-28566, 2001.

Eldering, A., Ogren, J. A., Chowdhury, Z., Hughes, L. S., and Cass, G. R.: Aerosol optical properties during INDOEX based on measured aerosol particle size and composition, J. Geophys. Res., 107, 8001, doi:10.1029/2001JD001572, 2002.

Engström, A., Ekman, A. M. L., Krejci, R., Ström, J., de Reus, M., and Wang, C.: Observational and modelling evidence of tropical deep convective clouds as a source of mid-tropospheric accumulation mode aerosols, Geophys. Res. Lett., 35, L23813, doi:10.1029/2008GL035817, 2008.

Ethé, C., Basdevant, C., Sadourny, R., Appu, K. S., Harenduprakash, L., Sarode, P. R., and Viswanathan, G.: Air mass motion, temperature, and humidity over the Arabian Sea and western Indian Ocean during the INDOEX intensive phase, as obtained from a set of superpressure drifting balloons, J. Geophys. Res., 107, 8023, doi:10.1029/2001JD001120, 2002.

Fiore, A. M., Dentener, F. J., Wild, O., et al.: Multimodel estimates of intercontinental source-receptor relationships for ozone pollution, J. Geophys. Res., 114, D04301, doi:10.1029/2008JD010816, 2009.

Fischer, H., de Reus, M., Traub, M., Williams, J., Lelieveld, J., de Gouw, J., Warneke, C., Schlager, H., Minikin, A., Scheele, R., and Siegmund, P.: Deep convective injection of boundary layer air into the lowermost stratosphere at midlatitudes, Atmos. Chem. Phys., 3, 739-745, doi:10.5194/acp-3-739-2003, 2003.

Fischer, H., Lawrence, M., Gurk, Ch., Hoor, P., Lelieveld, J., Hegglin, M. I., Brunner, D., and Schiller, C.: Model simulations and aircraft measurements of vertical, seasonal and latitudinal $\mathrm{O}_{3}$ and CO distributions over Europe, Atmos. Chem. Phys., 6, 339-348, doi:10.5194/acp-6-339-2006, 2006.

Fishman, J., Wozniak, A. E., and Creilson, J. K.: Global distribution of tropospheric ozone from satellite measurements using the empirically corrected tropospheric ozone residual technique: Identification of the regional aspects of air pollution, Atmos. Chem. Phys., 3, 893-907, doi:10.5194/acp-3-893-2003, 2003.

Flanner, M. G., Zender, C. S., Randerson, J. T., and Rasch, P. J.: Present-day climate forcing and response from black carbon in snow, J. Geophys. Res., 112, D11202, doi:10.1029/2006JD008003, 2007.

Flanner, M. G., Zender, C. S., Hess, P. G., Mahowald, N. M., Painter, T. H., Ramanathan, V., and Rasch, P. J.: Springtime warming and reduced snow cover from carbonaceous particles, Atmos. Chem. Phys., 9, 2481-2497, doi:10.5194/acp-9-24812009, 2009.

Forêt, G., Flamant, C., Cautenet, S., Pelon, J., Minvielle, F., Taghavi, M., and Chazette, P.: The structure of the haze plume over the Indian Ocean during INDOEX: tracer simulations and LIDAR observations, Atmos. Chem. Phys., 6, 907-923, doi:10.5194/acp-6-907-2006, 2006. 
Franke, K., Ansmann, A., Müller, D., Althausen, D., Venkataraman, C., Reddy, M. S., Wagner, F., and Scheele, R.: Optical properties of the Indo-Asian haze layer over the tropical Indian Ocean, J. Geophys. Res., 108, 4059, doi:10.109/2002JD002473, 2003.

Fu, R., Hu, Y., Wright, J. S., Jiang, J. S., Dickinson, R. E., Chen, M., Filipiak, M., Read, W. G., Waters, J. W., and Wu, D. L.: Short circuit of water vapor and polluted air to the global stratosphere by convective transport over the Tibetan Plateau, P. Natl. Acad. Sci. USA, 103, 5664-5669, 2006.

Fueglistaler, S., Wernli, H., and Peter, T.: Tropical troposphereto-stratosphere transport inferred from trajectory calculations, J. Geophys. Res., 109, D03108, doi:10.1029/2003JD004069, 2004.

Gabriel, R., Mayol-Bracero, O. L., and Andreae, M. O.: Chemical characterization of submicron aerosol particles collected over the Indian Ocean, J. Geophys. Res., 107, 8005, doi:10.1029/2000JD000034, 2002a.

Gabriel, R., von Glasow, R., Sander, R., Andreae, M. O., and Crutzen, P. J.: Bromide content of sea-salt aerosol particles collected over the Indian Ocean during INDOEX 1999, J. Geophys. Res., 107, 8032, doi:10.1029/2001JD001133, 2002b.

Gadgil, S.: The Indian monsoon and its variability, Annu. Rev. Earth Pl. Sc., 31, 429-467, 2003.

Ganguly, D., Jayaraman, A., Rajesh, T. A., and Gadhavi, H.: Wintertime aerosol properties during foggy and nonfoggy days over urban center Delhi and their implications for shortwave radiative forcing, J. Geophys. Res., 111, D15217, doi:10.1029/2005JD007029, 2006.

Ganguly, D., Ginoux, P., Ramaswamy, V., Winker, D. M., Holben, B. N., and Tripathi, S. N.: Retrieving the composition and concentration of aerosols over the Indo-Gangetic basin using CALIOP and AERONET data, Geophys. Res. Lett., 36, L13806, doi:10.1029/2009GL038315, 2009.

Gautam, R., Hsu, N. C., Lau, K., Tsay, S.-C., and Kafatos, M.: Enhanced pre-monsoon warming over the Himalayan-Gangetic region from 1979 to 2007, Geophys. Res. Lett., 36, L07704, doi:10.1029/2009GL037641, 2009.

George, S. K. and Nair, P. R.: Aerosol mass loading over the marine environment of Arabian Sea during ICARB: Sea-salt and nonsea-salt components, J. Earth Syst. Sci., 117, 333-344, 2008.

Gettelman, A., Kinnison, D. E., Dunkerton, T. J., and Brasseur, G. P.: Impact of monsoon circulations on the upper troposphere and lower stratosphere, J. Geophys. Res., 109, D22101, doi:10.1029/2004JD004878, 2004.

Zhang, Y., Dubey, M. K., Olsen, S. C., Zheng, J., and Zhang, R.: Comparisons of WRF/Chem simulations in Mexico City with ground-based RAMA measurements during the 2006-MILAGRO, Atmos. Chem. Phys., 9, 3777-3798, doi:10.5194/acp-9-3777-2009, 2009.

Goswami, B. N., Venugopal, V., Sengupta, D., Madhusoodanan, M. S., and Xavier, P. K.: Increasing Trend of Extreme Rain Events Over India in a Warming Environment, Science, 314, 1442-1445, 2006.

Granat, L., Norman, M., Leck, C., Kulshrestha, U. C., and Rodhe, $\mathrm{H}$.: Wet scavenging of sulfur compound and other constituents during the Indian Ocean Experiment (INDOEX), J. Geophys. Res., 107, 8025, doi:10.1029/2001JD000499, 2002.

Granat, L., Engström, J. E., Praveen, S., and Rodhe, H.: Light absorbing material (soot) in rainwater and in aerosol particles in the Maldives, J. Geophys. Res., 115, D16307,
doi:10.1029/2009JD013768, 2010.

Gros, V., Williams, J., Lawrence, M. G., von Kuhlmann, R., van Aardenne, J. A., Atlas, E., Chuck, A., Edwards, D. P., Stroud, V., and Krol, M.: Tracing the origin and ages of interlaced atmospheric pollution events over the tropical Atlantic Ocean with in-situ measurements, satellites, trajectories, emission inventories and global models, J. Geophys. Res., 109, D22306, doi:10.1029/2004JD004846, 2004.

Guazotti, S. A., Coffee, K. R., and Prather, K. A.: Continuous measurements of size-resolved particle chemistry during INDOEXIntensive Field Phase 99, J. Geophys. Res., 106, 28607-28627, 2001.

Guazzotti, S. A., Suess, D. T., Coffee, K. R., Quinn, P. K., Bates, T. S., Wisthaler, A., Hansel, A., Ball, W. P., Dickerson, R. R., and Neusüß, C.: Characterization of carbonaceous aerosols outflow from India and Arabia: Biomass/biofuel burning and fossil fuel combustion, J. Geophys. Res., 108, 4485, doi:10.1029/2002JD003277, 2003.

Gustafsson, Ö., Krusa, M., Zencak, Z., Sheesley, R. J., Granat, L., Engström, E., Praveen, P. S., Rao, P. S. P., Leck, C., and Rodhe, H.: Brown Clouds over South Asia: Biomass or Fossil Fuel Combustion?, Science, 323, 495-498, 2009.

Hamilton, J. F., Allen, G., Watson, N. M., et al.: Observations of an atmospheric chemical equator and its implications for the tropical warm pool region, J. Geophys. Res., 113, D20313, doi:10.1029/2008JD009940, 2008.

Hartley, D. E. and Black, R. X.: Mechanistic analysis of interhemispheric transport, Geophys. Res. Lett., 22, 2945-2948, 1995.

Haywood, J. M. and Shine, K. P.: Multi-spectral calculations of the direct radiative forcing of tropospheric sulphate and soot aerosols using a column model, Q. J. Roy. Meteor. Soc., 123, 1907-1930, 1997.

Haywood, J. M., Ramaswamy, V., and Donner, L. J.: A limitedarea-model case study of the effects of sub-grid scale variations in relative humidity and cloud upon the direct radiative forcing of sulfate aerosol, Geophys. Res. Lett., 24, 143-146, 1997.

Heil, A. and Goldammer, J. G.: Smoke-haze pollution: a review of the 1997 episode in Southeast Asia, Reg. Environ. Change, 2, 24-37, 2001.

Heintzenberg, J.: Fine particles in the global troposphere, Tellus, 41, 149-160, 1989.

Heymsfield, A. J. and McFarquhar, G. M.: Microphysics of INDOEX clean and polluted trade cumulus clouds, J. Geophys. Res., 106, 28653-28673, 2001.

Jacob, D. J., Logan, J. A., and Murti, P. P.: Effect of rising Asian emissions on surface ozone in the United States, Geophys. Res. Lett., 26, 2175-2178, 1999.

Jacobson, M. Z.: Strong radiative heating due to the mixing state of black carbon in atmospheric aerosols, Nature, 409, 695-697, 2001.

Jaffe, D., Anderson, T., Covert, D., Kotchenruther, R., Trost, B., Danielson, J., Simpson, W., Berntsen, T., Karlsdottir, S., Blake, D., Harris, J., Carmichael, G., and Uno, I.: Transport of Asian air pollution to North America, Geophys. Res. Lett., 26, 711714, 1999.

Jayaraman, A.: Results on direct radiative forcing of aerosols obtained over the tropical Indian Ocean, Curr. Sci. India, 76, 924 930, 1999. 
Jayaraman, A., Lubin, D., Ramachandran, S., Ramanathan, V., Woodbridge, E., Collins, W. D., and Zalpuri, K. S.: Direct observations of aerosol radiative forcing over the tropical Indian Ocean during the January-February 1996 pre-INDOEX cruise, J. Geophys. Res., 103, 13827-13836, 1998.

Jayaraman, A., Satheesh, S. K., Mitra, A. P., and Ramanathan, V.: Latitude gradient in aerosol properties across the Inter Tropical Convergence Zone: Results from the joint Indo-US study onboard Sagar Kanya, Curr. Sci. India, 80, 128-137, 2001.

Jayaraman, A., Gadhavi, H., Ganguly, D., Misra, A., Ramachandran, S., and Rajesh, T.: Spatial variations in aerosol characteristics and regional radiative forcing over India: Measurements and modeling of 2004 road campaign experiment, Atmos. Environ., 40, 6504-6515, doi:10.1016/j.atmosenv.2006.01.034, 2006.

Jöckel, P., Tost, H., Pozzer, A., Brhl, C., Buchholz, J., Ganzeveld, L., Hoor, P., Kerkweg, A., Lawrence, M. G., Sander, R., Steil, B., Stiller, G., Tanarhte, M., Taraborrelli, D., van Aardenne, J., and Lelieveld, J.: The atmospheric chemistry general circulation model ECHAM5/MESSy1: consistent simulation of ozone from the surface to the mesosphere, Atmos. Chem. Phys., 6, 50675104, doi:10.5194/acp-6-5067-2006, 2006

Johansen, A. M., Siefert, R. L., and Hoffmann, M. R.: Chemical characterization of ambient aerosol collected during the southwest monsoon and intermonsoon seasons over the Arabian Sea: Anions and cations, J. Geophys. Res., 104, 26325-26347, 1999.

Jones, T. A., Christopher, S. A., and Quaas, J.: A six year satellitebased assessment of the regional variations in aerosol indirect effects, Atmos. Chem. Phys., 9, 4091-4114, doi:10.5194/acp-94091-2009, 2009.

Kalapureddy, M. C. R., Kaskaoutis, D. G., Raj, P. E., Devara, P. C. S., Kambezidis, H. D., Kosmopoulos, P. G., and Nastos, P. T.: Identification of aerosol type over the Arabian Sea in the premonsoon season during the Integrated Campaign for Aerosols, Gases and Radiation Budget (ICARB), J. Geophys. Res., 114, D17203, doi:10.1029/2009JD011826, 2009.

Kamra, A. K., Murugavel, P., and Pawar, S. D.: Measured size distributions of aerosols over the Indian Ocean during INDOEX, J. Geophys. Res., 108, 8000, doi:10.1029/2002JD002200, 2003.

Kar, J., Bremer, H., Drummand, J. R., Rochon, Y. J., Jones, D. B. A., Nichitiu, F., Zou, J., Liu, J., Gille, J. C., Edwards, D. P., Deeter, M. N., Francis, G., Ziskin, D., and Warner, J.: Evidence of vertical transport of carbon monoxide by Measurements of Pollution in the Troposphere (MOPITT), Geophys. Res. Lett., 31, L23105, doi:10.1029/2004GL021128, 2004.

Kasibhatla, P., Arellano, A., Logan, J. A., Palmer, P. I., and Novelli, P.: Top-down estimate of a large source of atmospheric carbon monoxide associated with fuel combustion in Asia, Geophys. Res. Lett., 29, 1900, doi:10.1029/2002GL015561, 2002.

Kaskaoutis, D. G., Kalapureddy, M. C. R., Krishna Moorthy, K., Devara, P. C. S., Nastos, P. T., Kosmopoulos, P. G., and Kambezidis, H. D.: Heterogeneity in pre-monsoon aerosol types over the Arabian Sea deduced from ship-borne measurements of spectral AODs, Atmos. Chem. Phys., 10, 4893-4908, doi:10.5194/acp-10-4893-2010, 2010.

Kaufman, Y. J., Koren, I., Remer, L. A., and Rudich, Y.: The effect of smoke, dust, and pollution aerosol on shallow cloud development over the Atlantic Ocean, Proc. Natl. Acad. Sci., 102, 11207-11212, 2005.
Kedia, S. and Ramachandran, S.: Latitudinal and longitudinal variation in aerosol characteristics from Sun photometer and MODIS over the Bay of Bengal and Arabian Sea during ICARB, J. Earth Syst. Sci., 117, 375-387, 2008.

Kedia, S., Ramachandran, S., Kumar, A., and Sarin, M. M.: Spatiotemporal gradients in aerosol radiative forcing and heating rate over Bay of Bengal and Arabian Sea derived on the basis of optical, physical, and chemical properties, J. Geophys. Res., 115, D07205, doi:10.1029/2009JD013136, 2010.

Koch, D., Bond, T. C., Streets, D., Unger, N., and van der Werf, G. R.: Global impacts of aerosols from particular source regions and sectors, J. Geophys. Res., 112, D02205, doi:10.1029/2005JD007024, 2007.

Kopacz, M., Mauzerall, D. L., Wang, J., Leibensperger, E. M., Henze, D. K., and Singh, K.: Origin and radiative forcing of black carbon transported to the Himalayas and Tibetan Plateau, Atmos. Chem. Phys. Discuss., 10, 21615-21651, doi:10.5194/acpd-10-21615-2010, 2010.

Koren, I., Remer, L. A., Kaufman, Y. J., Rudich, Y., and Martins, J. V. : On the twilight zone between clouds and aerosols, Geophys. Res. Lett., 34, L08805, doi:10.1029/2007GL029253, 2007.

Krishnamurti, T. N., Jha, B., Rasch, P. J., and Ramanathan, V.: A high resolution global reanalysis highlighting the winter monsoon, Part I, Reanalysis fields, Met. Atmos. Phys., 64, 123-150, 1997a.

Krishnamurti, T. N., Jha, B., Rasch, P. J., and Ramanathan, V.: A high resolution global reanalysis highlighting the winter monsoon, Part II, transients and passive tracer transports, Met. Atmos. Phys., 64, 151-171, $1997 \mathrm{~b}$.

Krishnamurti, T. N., Chakraborty, A., Martin, A., Lau, W. K., Kim, K.-M., Sud, Y., and Walker, G.: Impact of Arabian Sea pollution on the Bay of Bengal winter monsoon rains, J. Geophys. Res., 114, D06213, doi:10.1029/2008JD010679, 2009.

Krishnan, R. and Ramanathan, V.: Evidence of surface cooling from absorbing aerosols, Geophys. Res. Lett., 29, 1340, doi:10.1029/2002GL014687, 2002.

Kuhlmann, J. and Quaas, J.: How can aerosols affect the Asian summer monsoon? Assessment during three consecutive premonsoon seasons from CALIPSO satellite data, Atmos. Chem. Phys., 10, 4673-4688, doi:10.5194/acp-10-4673-2010, 2010.

Kulkarni, A. V., Bahuguna, I. M., Rathore, B. P., Singh, S. K., Randhawa, S. S., Sood, R. K., and Dhar, S.: Glacial retreat in Himalaya using Indian Remote Sensing satellite data, Curr. Sci. India, 92, 69-74, 2007.

Kulmala, M., Reissell, A., Sipilä, M., Bonn, B., Ruuskanen, T. M., Lehtinen, K. E. J., Kerminen, V., and Ström, J.: Deep convective clouds as aerosol production engines: Role of insoluble organics, J. Geophys. Res., 111, D17202, doi:10.1029/2005JD006963, 2006.

Kulshrestha, U. C., Granat, L., Engardt, M., and Rodhe, H.: Review of precipitation monitoring studies in India - a search for regional patterns, Atmos. Environ., 39, 7403-7419, 2005.

Kumar, A., Sudheer, A. K., and Sarin, M. M.: Chemical characteristics of aerosols in MABL of Bay of Bengal and Arabian Sea during spring inter-monsoon: A comparative study, J. Earth Syst. Sci., 117, 325-332, 2008.

Kunhikrishnan, T. and Lawrence, M. G.: Sensitivity of $\mathrm{NO}_{2}$ over the Indian Ocean to emissions from the surrounding continents and nonlinearities in atmospheric chemistry responses, Geophys. 
Res. Lett., 31, L15109, doi:10.1029/2003GL020210, 2004.

Kunhikrishnan, T., Lawrence, M. G., von Kuhlmann, R., Richter, A., Ladstätter, A., and Burrows, J. P.: Analysis of tropospheric $\mathrm{NO}_{\mathrm{x}}$ over Asia using the Model of Atmospheric Transport and Chemistry (MATCH-MPIC) and GOME-satellite observations, Atmos. Environ., 38, 581-596, 2004a.

Kunhikrishnan, T., Lawrence, M. G., von Kuhlmann, R., Richter, A., Ladstätter, A., and Burrows, J. P.: Semiannual $\mathrm{NO}_{2}$ Plumes during the Monsoon Transition periods over Central Indian Ocean, Geophys. Res. Lett., 31, L08110, doi:10.1029/2003GL019269, 2004b.

Ladstätter-Weißenmayer, A., Altmeyer, H., Bruns, M., Richter, A., Rozanov, A., Rozanov, V., Wittrock, F., and Burrows, J. P.: Measurements of $\mathrm{O}_{3}, \mathrm{NO}_{2}$ and $\mathrm{BrO}$ during the INDOEX campaign using ground based DOAS and GOME satellite data, Atmos. Chem. Phys., 7, 283-291, doi:10.5194/acp-7-283-2007, 2007.

Lal, S. and Lawrence, M. G.: Elevated mixing ratios of surface ozone over the Arabian Sea, Geophys. Res. Lett., 28, 1487-1490, 2001.

Lal, S., Naja, M., and Jayaraman, A.: Ozone in the marine boundary layer over the tropical Indian Ocean, J. Geophys. Res., 103, 18907-18917, 1998.

Lal, S., Naja, M., and Subbaraya, B. H.: Seasonal variations in surface ozone and its precursors over an urban site in India, Atmos. Environ., 34, 2713-2724, 2000.

Lal, S., Chand, D., Sahu, L. K., Venkataramani, S., Brasseur, G., and Schultz, M. G.: High levels of ozone and related gases over the Bay of Bengal during winter and early spring of 2001, Atmos. Environ., 40, 1633-1644, 2006.

Lal, S., Sahu, L. K., and Venkataramani, S.: Impact of transport from the surrounding continental regions on the distributions of ozone and related trace gases over the Bay of Bengal during February 2003, J. Geophys. Res., 112, L14302, doi:10.1029/2006JD008023, 2007.

Lal, S., Sahu, L. K., Gupta, S., Srivastava, S., Modh, K. S., Venkataramani, S., and Rajesh, T. A.: Emission characteristic of ozone related trace gases at a semi-urban site in the IndoGangetic plain using inter-correlations, J. Atmos. Chem., 60, 189-204, 2008a.

Lal, S., Sahu, L. K., Venkataramani, S., Rajesh, T. A., and Modh, K. S.: Distributions of $\mathrm{O}_{3}, \mathrm{CO}$ and NMHCs over the rural sites in central India, J. Atmos. Chem., 61, 73-84, 2008 b.

Lau, K. M., Kim, M. K., and Kim, K. M.: Asian summer monsoon anomalies induced by aerosol direct forcing: the role of the Tibetan Plateau, Clim. Dynam., 26, 855-864, 2006.

Lawrence, M. G., Jöckel, P., and von Kuhlmann, R.: What does the global mean $\mathrm{OH}$ concentration tell us?, Atmos. Chem. Phys., 1, 37-49, doi:10.5194/acp-1-37-2001, 2001.

Lawrence, M. G.: Export of air pollution from southern Asia and its large-scale effects, Springer, 131-172, 2004.

Lawrence, M. G. and Rasch, P. J.: Tracer transport in deep convective updrafts: plume ensemble versus bulk formulations, J. Atmos. Sci., 62, 2880-2894, 2005.

Lawrence, M. G. and Salzmann, M.: On interpreting studies of tracer transport by deep cumulus convection and its effects on atmospheric chemistry, Atmos. Chem. Phys., 8, 6037-6050, doi:10.5194/acp-8-6037-2008, 2008.

Lawrence, M. G., Rasch, P. J., von Kuhlmann, R., Williams, J., Fischer, H., de Reus, M., Lelieveld, J., Crutzen, P. J., Schultz, M.,
Stier, P., Huntrieser, H., Heland, J., Stohl, A., Forster, C., Elbern, H., Jakobs, H., and Dickerson, R. R.: Global chemical weather forecasts for field campaign planning: predictions and observations of large-scale features during MINOS, CONTRACE, and INDOEX, Atmos. Chem. Phys., 3, 267-289, doi:10.5194/acp-3267-2003, 2003a.

Lawrence, M. G., von Kuhlmann, R., Salzmann, M., and Rasch, P. J.: The balance of effects of deep convective mixing on tropospheric ozone, Geophys. Res. Lett., 30, 1940, doi:10.1029/2003GL017644, 2003b.

Lawrence, M. G., Hov, O., Beekmann, M., Brandt, J., Elbern, H., Eskes, H., Feichter, H., and Takigawa, M.: The chemical weather, Environ. Chem., 2, 6-8, 2005.

Lelieveld, J. and Dentener, F.: What controls tropospheric ozone?, J. Geophys. Res., 105, 3531-3551, 2000.

Lelieveld, J., Ramanathan, V., and Crutzen, P. J.: The global effects of Asian haze, IEEE Spectrum, 36, 50-54, 1999.

Lelieveld, J., Crutzen, P. J., Ramanathan, V., Andreae, M. O., Brenninkmeijer, C. A. M., Campos, T., Cass, G. R., Dickerson, R. R., Fischer, H., de Gouw, J. A., Hansel, A., Jefferson, A., Kley, D., de Laat, A. T. J., Lal, S., Lawrence, M. G., Lobert, J. M., MayolBracero, O. L., Mitra, A. P., Novakov, T., Oltmans, S. J., Prather, K. A., Reiner, T., Rodhe, H., Scheeren, H. A., Sikka, D., and Williams, J.: The Indian Ocean Experiment: Widespread Air Pollution from South and Southeast Asia, Science, 291, 10311036, 2001.

Lelieveld, J., Berresheim, H., Borrmann, S., Crutzen, P. J., Dentener, F. J., Fischer, H., de Gouw, J., Feichter, J., Flatau, P., Heland, J., Holzinger, R., Korrmann, R., Lawrence, M., Levin, Z., Markowicz, K., Mihalopoulos, N., Minikin, A., Ramanathan, V., de Reus, M., Roelofs, G.-J., Scheeren, H. A., Sciare, J., Schlager, H., Schultz, M., Siegmund, P., Steil, B., Stephanou, E., Stier, P., Traub, M., Williams, J., and Ziereis, H.: Global air pollution crossroads over the Mediterranean, Science, 298, 794-799, 2002.

Lelieveld, J., Brühl, C., Jöckel, P., Steil, B., Crutzen, P. J., Fischer, H., Giorgetta, M. A., Hoor, P., Lawrence, M. G., Sausen, R., and Tost, H.: Stratospheric dryness: model simulations and satellite observations, Atmos. Chem. Phys., 7, 1313-1332, doi:10.5194/acp-7-1313-2007, 2007.

Lelieveld, J., Hoor, P., Jöckel, P., Pozzer, A., Hadjinicolaou, P., Cammas, J.-P., and Beirle, S.: Severe ozone air pollution in the Persian Gulf region, Atmos. Chem. Phys., 9, 1393-1406, doi:10.5194/acp-9-1393-2009, 2009.

Léon, J., Chazette, P., Pelon, J., Dulac, F., and Randriamiarisoa, H.: Aerosol direct radiative impact over the INDOEX area based on passive and active remote sensing, J. Geophys. Res., 107, 8006, doi:10.1029/2000JD000116, 2002.

Léon, J.-F., Chazette, P., Dulac, F., Pelon, J., Flamant, C., Bonazzola, M., Forêt, G., Alfaro, S. C., Cachier, H., Cautenet, S., Hamounou, E., Gaudichet, A., Gomes, L., Rajot, J.-L., Lavenu, F., Inamdar, S. R., Sarode, P. R., and Kadadevarmath, J. S.: Large-scale advection of continental aerosols during INDOEX, J. Geophys. Res., 106, 28427-28439, 2001.

Li, F. and Ramanathan, V.: Winter to summer monsoon variation of aerosol optical depth over the tropical Indian Ocean, J. Geophys. Res., 107, 4284, doi:10.1029/2001JD000949, 2002.

Li, Q., Jacob, D. J., Logan, J. A., Bey, I., Yantosca, R. M., Liu, H., Martin, R. V., Fiore, A. M., and Duncan, B. N.: A tropospheric 
ozone maximum over the Middle East, Geophys. Res. Lett., 28, 3235-3238, 2001.

Li, Q., Jiang, J. H., Wu, D. L., Read, W. G., Livesey, N. J., Waters, J. W., Zhang, Y., Wang, B., Filipiak, M. J., Davis, C. P., Turquety, S., Wu, S., Park, R. J., Yantosca, R. M., and Jacob, D. J.: Convective outflow of South Asian pollution: a global CTM simulation compared with EOS MLS observations, Geophys. Res. Lett., 32, L14826, doi:10.1029/2005GL022762, 2005.

Liang, Q., Jaeglé, L., Hudman, R. C., Turquety, S., Jacob, D. J., Avery, M. A., Browell, E. V., Sachse, G. W., Blake, D. R., Brune, W., Ren, X., Cohen, R. C., Dibb, J. E., Fried, A., Fuelberg, H., Porter, M., Heikes, B. G., Huey, G., Singh, H. B., and Wennberg, P. O.: Summertime influence of Asian pollution in the free troposphere over North America, J. Geophys. Res., 112, D12S11, doi:10.1029/2006JD007919, 2007.

Lintner, B. R., Gilliland, A. B., and Fung, I. Y.: Mechanisms of convection-induced modulation of passive tracer interhemispheric transport interannual variability, J. Geophys. Res., 109, D13102, doi:10.1029/2003JD004306, 2004.

Liu, C., Zipser, E., Garrett, T., Jiang, J. H., and Su, H.: How does the water vapor and carbon monoxide "tape recorders" start near the tropical tropopause?, Geophys. Res. Lett., 34, L09804, doi:10.129/2006GL029234, 2007.

Liu, G., Shao, H., Coakley Jr., J. A., Curry, J. A., Haggerty, J. A., and Tschudi, M. A.: Retrieval of cloud droplet size from visible and microwave radiometric measurements during INDOEX: implication to aerosols' indirect radiative effect, J. Geophys. Res., 108, 4006, doi:10.1029/2001JD001395, 2003a.

Liu, H., Jacob, D. J., Bey, I., Yantosca, R. M., Duncan, B. N., and Sachse, G. W.: Transport pathways for Asian pollution outflow over the Pacific: Interannual and seasonal variations, J. Geophys. Res., 108, 8786, doi:10.1029/2002JD003102, 2003 b.

Liu, J. J., Jones, D. B. A., Worden, J. R., Noone, D., Parrington, M., and Kar, J.: Analysis of the summertime buildup of tropospheric ozone abundances over the Middle East and North Africa as observed by the Tropospheric Emission Spectrometer instrument, J. Geophys. Res., 114, D05304, doi:10.1029/2008JD010993, 2009.

Liu, X., Chance, K., Sioris, C. E., Kurosu, T. P., Spurr, R. J. D., Martin, R. V., Fu, T., Logan, J. A., Jacob, D. J., Palmer, P. I., Newchurch, M. J., Megretskaia, I. A., and Chatfield, R. B.: First directly retrieved global distribution of tropospheric column ozone from GOME: Comparison with the GEOS-CHEM model, J. Geophys. Res., 111, D02308, doi:10.1029/2005JD006564, 2006.

Lobert, J. M. and Harris, J. M.: Trace gases and air mass origin at Kaashidhoo, Indian Ocean, J. Geophys. Res., 107, 8013, doi:10.1029/2001JD000731, 2002.

Lohmann, U.: A glaciation indirect aerosol effect caused by soot aerosols, Geophys. Res. Lett., 29, 1052, doi:10.1029/2001GL014357, 2002.

Lohmann, U., Stier, P., Hoose, C., Ferrachat, S., Kloster, S., Roeckner, E., and Zhang, J.: Cloud microphysics and aerosol indirect effects in the global climate model ECHAM5-HAM, Atmos. Chem. Phys., 7, 3425-3446, doi:10.5194/acp-7-3425-2007, 2007.

Lubin, D., Satheesh, S. K., McFarquar, G., and Heymsfield, A. J.: Longwave radiative forcing of Indian Ocean tropospheric aerosol, J. Geophys. Res., 107, 8004, doi:10.1029/2001JD001183, 2002.
Ma, J., Chen, Y., Wang, W., Yan, P., Liu, H., Yang, S., Hu, Z., and Lelieveld, J.: Strong air pollution causes widespread haze-clouds over China, J. Geophys. Res., 115, D18204, doi:10.1029/2009JD013065, 2010.

Mandal, T.: Interactive comment on "On the origin of tropospheric $\mathrm{O}_{3}$ over the Indian Ocean during the winter monsoon: African biomass burning vs. stratosphere-troposphere exchange" by A. T. J. de Laat, Atmos. Chem. Phys. Discuss., 2, S358-S361, 2002.

Mandal, T. K., Kley, D., Smit, H. G. J., Srivastava, S. K., Peshin, S. K., and Mitra, A. P.: Vertical distribution of ozone over the Indian Ocean $\left(15^{\circ} \mathrm{N}-20^{\circ} \mathrm{S}\right)$ during First Field Phase INDOEX1998, Curr. Sci. India, 76, 938-943, 1999.

Mandal, T. K., Khan, A., Ahammed, Y. N., Tanwar, R. S., Parmar, R. S., Zalpuri, K. S., Gupta, P. K., Jain, S. L., Singh, R., Mitra, A. P., Garg, S. C., Suryanarayana, A., Murty, V. S. N., Kumar, M. D., and Shepherd, A. J.: Observations of trace gases and aerosols over the Indian Ocean during the monsoon transition period, J. Earth Syst. Sci., 115, 473-484, 2006.

Manghnani, V., Raman, S., Niyogi, D. S., Parameswara, V., Morrison, J. M., Ramana, S. V., and Raju, J. V. S. S.: Marine boundarylayer variability over the Indian Ocean during INDOEX (1998), Bound. Lay. Meteorol., 97, 411-430, 2000.

Marcq, S., Laj, P., Roger, J. C., Villani, P., Sellegri, K., Bonasoni, P., Marinoni, A., Cristofanelli, P., Verza, G. P., and Bergin, M.: Aerosol optical properties and radiative forcing in the high Himalaya based on measurements at the Nepal Climate Observatory-Pyramid site (5079 m a.s.1.), Atmos. Chem. Phys., 10, 5859-5872, doi:10.5194/acp-10-5859-2010, 2010.

Marinoni, A., Cristofanelli, P., Laj, P., Duchi, R., Calzolari, F., Decesari, S., Sellegri, K., Vuillermoz, E., Verza, G. P., Villani, P., and Bonasoni, P.: Aerosol mass and black carbon concentrations, a two year record at NCO-P (5079 m, Southern Himalayas), Atmos. Chem. Phys., 10, 8551-8562, doi:10.5194/acp-10-85512010, 2010.

Mayol-Bracero, O. L., Gabriel, R., Andreae, M. O., Kirchstetter, T. W., Novakov, T., Ogren, J., Sheridan, P., and Streets, D. G.: Carbonaceous aerosols over the Indian Ocean during the Indian Ocean Experiment (INDOEX): Chemical characterization, optical properties, and probable sources, J. Geophys. Res., 107, 8030, doi:10.1029/2001JD000039, 2002.

McFiggans, G., Artaxo, P., Baltensperger, U., Coe, H., Facchini, M. C., Feingold, G., Fuzzi, S., Gysel, M., Laaksonen, A., Lohmann, U., Mentel, T. F., Murphy, D. M., O’Dowd, C. D., Snider, J. R., and Weingartner, E.: The effect of physical and chemical aerosol properties on warm cloud droplet activation, Atmos. Chem. Phys., 6, 2593-2649, doi:10.5194/acp-6-2593-2006, 2006.

Menon, S., Hansen, J., Nazarenko, L., and Luo, Y.: Climate Effects of Black Carbon Aerosols in China and India, Science, 297, 2250-2253, 2002.

Menon, S., Koch, D., Beig, G., Sahu, S., Fasullo, J., and Orlikowski, D.: Black carbon aerosols and the third polar ice cap, Atmos. Chem. Phys., 10, 4559-4571, doi:10.5194/acp-10-4559-2010, 2010.

Metzger, S., Dentener, F., Krol, M., Jeuken, A., and Lelieveld, J.: Gas/aerosol partitioning: 2. Global modeling results, J. Geophys Res., 107, 4313, doi:10.1029/2001JD001103, 2002.

Meywerk, J. and Ramanathan, V.: Influence of anthropogenic aerosols on the total and spectral irradiance at the sea surface 
during the Indian Ocean Experiment (INDOEX) 1999, J. Geophys. Res., 107, 8018, doi:10.1029/2000JD000022, 2002.

Mihalopoulos, N.: Long-range transport of pollutants above the eastern Mediterranean: Implications for air quality and regional climate, in: Regional Climate Variability and its Impacts in the Mediterranean Area, edited by: Mellouki, A. and Ravishankara, A. R., Springer-Verlag, 1-13, 2007.

Miller, S. T. K., Keim, B. D., Talbot, R. W., and Mao, H.: Sea breeze: Structure, forecasting, and impacts, Rev. Geophys., 41, 1011, doi:10.1029/2003RG000124, 2003.

Minvielle, F., Cautenet, G., Andreae, M. O., Lasserre, F., Forêt, G., Cautenet, S., Léon, J. F., Mayol-Bracero, O. L., Gabriel, R., Chazette, P., and Roca, R.: Modelling the transport of aerosols during INDOEX 1999 and comparison with experimental data-1: carbonaceous aerosol distribution, Atmos. Environ., 38, 18111822, 2004a.

Minvielle, F., Cautenet, G., Lasserre, F., Forêt, G., Cautenet, S., Léon, J. F., Andreae, M. O., Mayol-Bracero, O. L., Gabriel, R., Chazette, P., and Roca, R.: Modelling the transport of aerosols during INDOEX 1999 and comparison with experimental data, Part 2: Continental aerosols and their optical depth, Atmos. Environ., 38, 1823-1837, 2004b.

Mitra, A. P.: INDOEX (India): Introductory note, Curr. Sci. India, 76, 886-889, 1999.

Mitra, A. P.: Introductory note, Curr. Sci. India, 80, 3-6, 2001.

Mitra, A. P.: Indian Ocean Experiment (INDOEX): An overview, Indian J. Mar. Sci., 33, 30-39, 2004.

Mohanty, U. C., Niyogi, D. S., Raman, S., and Sarkar, A.: Numerical study of the role of land-air-sea interactions for the northeasterly monsoon circulations over Indian Ocean during INDOEX, Curr. Sci. India, 80, 60-68, 2001.

Moore, J., Dulac, F., Vishwanathan, V., and Lawrence, M. G.: INDOEX operations plan, Tech. rep., Joint Office for Science Support, UCAR, Boulder, CO, USA, 1999.

Moorthy, K. K. and Satheesh, S. K.: Characteristics of aerosols over a remote island, Minicoy in the Arabian Sea: Optical properties and retrieved size characteristics, Q. J. Roy. Meteor. Soc., 126, 81-109, 2000.

Moorthy, K. K., Satheesh, S. K., and Murthy, B. V. K.: Investigations of marine aerosols over the tropical Indian Ocean, J. Geophys. Res., 102, 18827-18842, 1997.

Moorthy, K. K., Pillai, P. S., Saha, A., and Niranjan, K.: Aerosol size characteristics over the Arabian Sea and Indian Ocean, Curr. Sci. India, 76, 961-967, 1999.

Moorthy, K. K., Suresh Babu, S., and Satheesh, S. K.: Aerosol spectral optical dephts over the Bay of Bengal: Role of transport, Geophys. Res. Lett., 30, 1249, doi:10.1029/2002GL016520, 2003.

Moorthy, K. K., Satheesh, S. K., Babu, S. S., and Saha, A.: Large latitudinal gradients and temporal heterogeneity in aerosol black carbon and its mass mixing ratio over southern and northern oceans observed during a trans-continental cruise experiment, Geophys. Res. Lett., 32, L14818, doi:10.1029/2005GL023267, 2005a.

Moorthy, K. K., Sunilkumar, S. V., Pillai, P. S., Parameswaran, K., Nair, P. R., Ahmed, Y. N., Ramgopal, K., Narasimhulu, K., Reddy, R. R., Vinoj, V., Satheesh, S. K., Niranjan, K., Rao, B. M., Brahmanandam, P. S., Saha, A., Badarinath, K. V. S., Kiranchand, T. R., and Latha, K. M.: Wintertime spatial characteristics of boundary layer aerosols over peninsular India, J. Geophys. Res., 110, D08207, doi:10.1029/2004JD005520, 2005 b.

Moorthy, K. K., Satheesh, S. K., Babu, S. S., and Dutt, C. B. S.: Integrated Campaign for Aerosols, gases and Radiation Budget (ICARB): An overview, J. Earth Syst. Sci., 117, 243-262, 2008.

Mote, P. W., Rosenlof, K. H., McIntyre, M. E., Carr, E. S., Gille, J. C., Holton, J. R., Kinnersley, J. S., Pumfrey, H. C., Russel III, J. M., and Waters, J. W.: An atmospheric tape-recorder: the imprint of tropical tropopause temperatures on stratospheric water vapor, J. Geophys. Res., 101, 3989-4006, 1996.

Mühle, J., Zahn, A., Brenninkmeijer, C. A. M., Gros, V., and Crutzen, P. J.: Air mass classification during the INDOEX R/V Ronald Brown cruise using measurements of nonmethane hydrocarbons, $\mathrm{CH}_{4}, \mathrm{CO}_{2}, \mathrm{CO}$, and delta- ${ }^{18} \mathrm{O}(\mathrm{CO})$, J. Geophys. Res., 107, 8021, doi:10.1029/2001JD000730, 2002.

Müller, D., Franke, K., Wagner, F., Althausen, D., Ansmann, A., and Heintzenberg, J.: Vertical profiling of optical and physical particle properties over the tropical Indian Ocean with sixwavelength lidar 1. Seasonal cycle, J. Geophys. Res., 106, 28567-28575, 2001a.

Müller, D., Franke, K., Wagner, F., Althausen, D., Ansmann, A., Heintzenberg, J., and Verver, G.: Vertical profiling of optical and physical particle properties over the tropical Indian Ocean with six-wavelength lidar 2. Case studies, J. Geophys. Res., 106, 28577-28595, 2001b.

Müller, D., Franke, K., Ansmann, A., Althausen, D., and Wagner, F.: Indio-Asian pollution during INDOEX: Microphysical particle properties and single-scattering albedo inferred from multiwavelength lidar observations, J. Geophys. Res., 108, 4600, doi:10.1029/2003JD003538, 2003.

Murugavel, P. and Kamra, A. K.: Changes in the concentration and size-distribution of the sub-micron particles associated with the sea- and land-breezes at a coastal station, Curr. Sci. India, 76, 994-997, 1999.

Murugavel, P., Gopalakrishnan, V., Pant, V., and Kamra, A. K.: Airborne measurements of submicron aerosols across the coastline at Bhubaneswar during ICARB, J. Earth Syst. Sci., 117, 273280, 2008.

Myhre, G., Stordal, F., Johnsrud, M., Kaufman, Y. J., Rosenfeld, D., Storelvmo, T., Kristjansson, J. E., Berntsen, T. K., Myhre, A., and Isaksen, I. S. A.: Aerosol-cloud interaction inferred from MODIS satellite data and global aerosol models, Atmos. Chem. Phys., 7, 3081-3101, doi:10.5194/acp-7-3081-2007, 2007.

Nair, P. R., Chand, D., Lal, S., Modh, K. S., Naja, M., Parameswaran, K., Ravindran, S., and Venkataramani, S.: Temporal variations in surface ozone at Thumba $\left(8.6^{\circ} \mathrm{N}, 77^{\circ} \mathrm{E}\right)-$ a tropical coastal site in India, Atmos. Environ., 36, 603-610, 2002.

Nair, P. R., Parameswaran, K., Kumar, S. V. S., and Rajan, R.: Continental influence on the spatial distribution of particulate loading over the Indian Ocean during winter season, J. Atmos. Sol.-Terr. Phy., 66, 27-38, 2004.

Nair, P. R., George, S. K., Sunilkumar, S., Parameswaran, K., Jacob, S., and Abraham, A.: Chemical composition of aerosols over peninsular India during winter, Atmos. Environ., 40, 6477-6493, doi:10.1016/j.atmosenv.2006.02.031, 2006.

Nair, V. S., Moorthy, K. K., Alappattu, D. P., Kunhikrishnan, P. K., George, S., Nair, P. R., Babu, S. S., Abish, B., Satheesh, S. K., 
Tripathi, S. N., Niranjan, K., Madhavan, B. L., Srikant, V., Dutt, C. B. S., Badarinath, K. V. S., and Reddy, R. R.: Wintertime aerosol characteristics over the Indo-Gangetic Plain (IGP): Impacts of local boundary layer processes and long-range transport, J. Geophys. Res., 112, D13205, doi:10.1029/2006JD008099, 2007.

Nair, V. S., Moorthy, K. K., Babu, S. S., Narasimhulu, K., Sankara Reddy, L. S., Ramakrishna Reddy, R., Rama Gopal, K., Sreekanth, V., Madhavan, B. L., and Niranjan, K.: Size segregated aerosol mass concentration measurements over the Arabian Sea during ICARB, J. Earth Syst. Sci., 117, 315-323, 2008.

Nair, V. S., Satheesh, S. K., Moorthy, K. K., Babu, S. S., Nair, P. R., and George, S. K.: Surprising observation of large anthropogenic aerosol fraction over the "near-pristine" Southern Bay of Bengal: Climate implications, J. Geophys. Res., 115, D21201, doi:10.1029/2010JD013954, 2010.

Naja, M. and Lal, S.: Changes in surface ozone amount and its diurnal and seasonal patterns, from 1954-55 to 1991-93, measured at Ahmedabad (23 N), India, Geophys. Res. Lett., 23, 81-84, 1996.

Naja, M., Lal, S., Venkataramani, S., Modh, K. S., and Chand, D.: Variabilities in $\mathrm{O}_{3}, \mathrm{NO}$ and $\mathrm{CH}_{4}$ over the Indian Ocean during winter, Curr. Sci. India, 76, 931-937, 1999.

Naja, M., Chand, D., Sahu, L., and Lal, S.: Trace gases over marine regions around India, Indian J. Mar. Sci., 33, 95-106, 2004.

Niranjan, K., Melleswara Rao, B., Brahmanandam, P. S., Madhavan, B. L., Sreekanth, V., and Krishna Moorthy, K.: Spatial characteristics of aerosol physical properties over the northeastern parts of peninsular India, Ann. Geophys., 23, 3219-3227, 2005, http://www.ann-geophys.net/23/3219/2005/.

Niranjan, K., Sreekanth, V., Madhavan, B. L., and Moorthy, K. K.: Wintertime aerosol characteristics at a north Indian site Kharagpur in the Indo-Gangetic plains located at the outflow region into Bay of Bengal, J. Geophys. Res., 111, D24209, doi:10.1029/2006JD007635, 2006.

Niranjan, K., Sreekanth, V., Madhavan, B. L., Devi, T. A., and Spandana, B.: Temporal characteristics of aerosol physical properties at Visakhapatnam on the east coast of India during ICARB - Signatures of transport onto Bay of Bengal, J. Earth Syst. Sci., 117, 421-427, 2008.

Norman, M., Das, S. N., Pillai, A. G., Granat, L., and Rodhe, H.: Influence of air mass trajectories on the chemical composition of precipitation in India, Atmos. Environ., 35, 4223-4235, 2001.

Norman, M., Leck, C., and Rodhe, H.: Differences across the ITCZ in the chemical characteristics of the Indian Ocean MBL aerosol during INDOEX, Atmos. Chem. Phys., 3, 563-579, doi:10.5194/acp-3-563-2003, 2003.

Novakov, T., Andreae, M. O., Gabriel, R., Kirchstetter, T. W., Mayol-Bracero, O. L., and Ramanathan, V.: Origin of carbonaceous aerosols over the tropical Indian Ocean: Biomass burning or fossil fuels?, Geophys. Res. Lett., 27, 4061-4064, 2000.

Ohara, T., Akimoto, H., Kurokawa, J., Horii, N., Yamaji, K., Yan, X., and Hayasaka, T.: An Asian emission inventory of anthropogenic emission sources for the period 1980-2020, Atmos. Chem. Phys., 7, 4419-4444, doi:10.5194/acp-7-4419-2007, 2007

Olivier, J. G. J., Aardenne, J. A. V., Dentener, F., Ganzeveld, L., and Peters, J.: Recent trends in global greenhouse gas emissions: regional trends and spatial distribution of key sources, in: Non$\mathrm{CO}_{2}$ Greenhouse Gases (NCGG ${ }^{-4}$ ), edited by van Amstel, A.,
Millpress, Rotterdam, ISBN 905966043 9, 325-330, 2005.

Padma Kumari, B. and Goswami, B. N., Seminal role of clouds on solar dimming over the Indian monsoon region, Geophys. Res. Lett., 37, L06703, doi:10.1029/2009GL042133, 2010.

Pant, V., Deshpande, C. G., and Kamra, A. K.: The concentration and number size distribution measurements of the Marine Boundary Layer aerosols over the Indian Ocean, Atmos. Res., 92, 381-393, 2009.

Parameswaran, K.: Influence of micrometeorological features on coastal boundary layer aerosol characteristics at the tropical station, Trivandrum, J. Earth Syst. Sci., 110, 247-265, 2001.

Parameswaran, K., Rajan, R., Vijayakumar, G., Rajeev, K., Moorthy, K. K., Nair, P. R., and Satheesh, S. K.: Seasonal and long term variations in aerosol content in the atmospheric mixing region at a tropical station in the Arabian Sea coast, J. Atmos. Sol.Terr. Phy., 60, 17-25, 1998.

Parameswaran, K., Nair, P. R., Rajan, R., and Raman, M. V.: Aerosol loading in coastal and marine environments in the Indian Ocean region during winter season, Curr. Sci. India, 76, 947-955, 1999.

Parashar, D. C., Gadi, R., Mandal, T. K., and Mitra, A. P.: Carbonaceous aerosol emissions from India, Atmos. Environ., 39, 7861-7871, 2005.

Park, M., Randel, W. J., Kinnison, D. E., Garcia, R. R., and Choi, W.: Seasonal variation of methane, water vapor, and nitrogen oxides near the tropopause: Satellite observations and model simulations, J. Geophys. Res., 109, D03302, doi:10.1029/2003JD003706, 2004.

Park, M., Randel, W. J., Gettelman, A., Massie, S. T., and Jiang, J. H.: Transport above the Asian summer monsoon anticyclone inferred from Aura Microwave Limb Sounder tracers, J. Geophys. Res., 112, D16309, doi:10.1029/2006JD008294, 2007.

Park, M., Randel, W. J., Emmons, L. K., Bernath, P. F., Walker, K. A., and Boone, C. D.: Chemical isolation in the Asian monsoon anticyclone observed in Atmospheric Chemistry Experiment (ACE-FTS) data, Atmos. Chem. Phys., 8, 757-764, doi:10.5194/acp-8-757-2008, 2008.

Park, M., Randel, W. J., Emmons, L. K., and Livesey, N. J.: Transport pathways of carbon monoxide in the Asian summer monsoon diagnosed from Model of Ozone and Related Tracers (MOZART), J. Geophys. Res., 114, D08303, doi: 10.1029/2008JD010621, 2009.

Pelon, J., Chazette, P., Léon, J., Tanre, D., Sicard, M., and Satheesh, S. K.: Characterization of aerosol spatial distribution and optical properties over the Indian Ocean from airborne LIDAR and radiometry during INDOEX'99, J. Geophys. Res., 107, 8029, doi:10.1029/2001JD000402, 2002.

Peshin, S. K., Mandal, T. K., Smit, H. G. J., Srivastava, S. K., and Mitra, A. P.: Observations of vertical distribution of tropospheric ozone over Indian Ocean and its comparison with continental profiles during INDOEX FFP-1998 and IFP-1999, Curr. Sci. India, 80, 197-208, 2001.

Phadnis, M. J., Levy II, H., and Moxim, W. J.: On the evolution of pollution from South and Southeast Asia during the winter-spring monsoon, J. Geophys. Res., 107, 4790, doi:10.1029/2002JD002190, 2002.

Podgorny, I. A. and Ramanathan, V.: A modeling study of the direct effect of aerosols over the tropical Indian Ocean, J. Geophys. Res., 106, 24097-24105, 2001. 
Podgorny, I. A., Conant, W., Ramanathan, V., and Satheesh, S. K.: Aerosol modulation of atmospheric and surface solar heating over the tropical Indian Ocean, Tellus, 52, 947-958, 2000.

Podgorny, I. A., Li, F., and Ramanathan, V.: Large Aerosol Radiative Forcing due to the 1997 Indonesian Forest Fire, Geophys. Res. Lett., 30, 1028, doi:10.1029/2002GL015979, 2003.

Pringle, K. J., Tost, H., Metzger, S., Steil, B., Giannadaki, D., Nenes, A., Fountoukis, C., Steir, P., Vignati, E., and Lelieveld, J.: Description and evaluation of GMXe: a new aerosol submodel for global simulations (v1), Geosci. Model Develop., 3, 391-412, 2010.

Qian, Y., Flanner, M. G., Leung, L. R., and Wang, W.: Sensitivity studies on the impacts of Tibetan Plateau snowpack pollution on the Asian hydrological cycle and monsoon climate, Atmos. Chem. Phys. Discuss., 10, 22855-22903, doi:10.5194/acpd-1022855-2010, 2010.

Quaas, J., Stevens, B., Stier, P., and Lohmann, U.: Interpreting the cloud cover -aerosol optical depth relationship found in satellite data using a general circulation model, Atmos. Chem. Phys., 10, 6129-6135, doi:10.5194/acp-10-6129-2010, 2010.

Quinn, P. K., Coffman, D. J., Bates, T. S., Miller, T. L., Johnson, J. E., Welton, E. J., Neusüss, C., Miller, M., and Sheridan, P. J.: Aerosol optical properties during INDOEX 1999: Means, variability, and controlling factors, J. Geophys. Res., 107, 8020, doi:10.1029/2000JD000037, 2002.

Raj, P. E., Saha, S. K., Sonbawne, S. M., Deshpande, S. M., Devara, P. C. S., Rao, Y. J., Dani, K. K., and Pandithurai, G.: Lidar observation of aerosol stratification in the lower troposphere over Pune during pre-monsoon season of 2006, J. Earth Syst. Sci., 117, 293-302, 2008.

Rajeev, K. and Ramanathan, V.: Direct observations of clear-sky aerosol radiative forcing from space during the Indian Ocean Experiment, J. Geophys. Res., 106, 17221-17235, 2001.

Rajeev, K., Ramanathan, V., and Meywerk, J.: Regional aerosol distribution and its long-range transport over the Indian Ocean, J. Geophys. Res., 105, 2029-2043, 2000.

Rajeev, K., Nair, S. K., Parameswaran, K., and Suresh Raju, C.: Satellite observations of the regional aerosol distribution and transport over the Arabian Sea, Bay of Bengal and Indian Ocean, Indian J. Mar. Sci., 33, 11-29, 2004.

Ramachandran, S. and Jayaraman, A.: Spectral aerosol optical dephts over Bay of Bengal and Chennai: II-sources, anthropogenic influence and model estimates, Atmos. Environ., 37, 1951-1962, 2003.

Ramachandran, S., Rengarajan, R., Jayaraman, A., Sarin, M. M., and Das, S. K.: Aerosol radiative forcing during clear, hazy, and foggy conditions over a continental polluted location in north India, J. Geophys. Res., 111, D20214, doi:10.1029/2006JD007142, 2006.

Raman, S., Niyogi, D. S., Simpson, M., and Pelon, J.: Dynamics of the elevated land plume over the Arabian Sea and the Northern Indian Ocean during northeasterly monsoons and during the Indian Ocean experiment (INDOEX), Geophys. Res. Lett., 29, 1817, doi:10.1029/2001GL014193, 2002.

Ramana, M. V., Ramanathan, V., Podgorny, I. A., Pradhan, B. B., and Shrestha, B.: The direct observations of large aerosol radiative forcing in the Himalayan region, Geophys. Res. Lett., 31, L05111, doi:10.1029/2003GL018824, 2004.
Ramana, M. V., Ramanathan, V., Kim, D., Roberts, G. C., and Corrigan, C. E.: Albedo, atmospheric solar absorption and heating rate measurements with stacked UAVs, Q. J. Roy. Meteor. Soc., 133, 1913-1931, 2007.

Ramanathan, V. and Crutzen, P. J.: New Directions: Atmospheric Brown "Clouds", Atmos. Environ., 37, 4033-4035, 2003.

Ramanathan, V. and Carmichael, G.: Global and regional climate changes due to black carbon, Nat. Geosci., 1, 221-227, 2008.

Ramanathan, V., Crutzen, P. J., Lelieveld, J., Mitra, A. P., A1thausen, D., Anderson, J., Andreae, M. O., Cantrell, W., Cass, G. R., Chung, C. E., Clarke, A. D., Coakley, J. A., Collins, W. D., Conant, W. C., Dulac, F., Heintzenberg, J., Heymsfield, A. J., Holben, B., Howell, S., Hudson, J., Jayaraman, A., Kiehl, J. T., Krishnamurti, T. N., Lubin, D., McFarquhar, G., Novakov, T., Ogren, J. A., Podgorny, I. A., Prather, K., Priestley, K., Prospero, J. M., Quinn, P. K., Rajeev, K., Rasch, P., Rupert, S., Sadourny, R., Satheesh, S. K., Shaw, G. E., Sheridan, P., and Valero, F. P. J.: Indian Ocean Experiment: An integrated analysis of the climate forcing and effects of the great Indio-Asian haze, J. Geophys. Res., 106, 28371-28398, 2001.

Ramanathan, V., Crutzen, P. J., Mitra, A. P., and Sikka, D.: The Indian Ocean Experiment and the Asian Brown Cloud, Curr. Sci. India, 83, 947-955, 2002.

Ramanathan, V., Chung, C., Kim, D., Bettge, T., Buja, L., Kiehl, J. T., Fu, W. M. W. Q., Sikka, D. R., and Wild, M.: Atmospheric brown clouds: Impacts on South Asian climate and hydrological cycle, P. Natl. Acad. Sci. USA, 102, 5326-5333, 2005.

Ramanathan, V., Li, F., Ramana, M. V., Praveen, P. S., Kim, D., Corrigan, C. E., Nguyen, H., Stone, E. A., Schauer, J. J., Carmichael, G. R., Adhikary, B., and Yoon, S. C.: Atmospheric brown clouds: Hemispherical and regional variations in longrange transport, absorption, and radiative forcing, J. Geophys. Res., 112, D22S21, doi:10.1029/2006JD008124, 2007a.

Ramanathan, V., Ramana, M. V., Roberts, G., Kim, D., Corrigan, C. E., Chung, C. E., and Winker, D.: Warming trends in Asia amplified by brown cloud solar absorption, Nature, 448, 575578, 2007b.

Randel, W. J. and Park, M.: Deep convective influence on the Asian summer monsoon anticyclone and associated tracer variability observed with Atmospheric Infrared Sounder (AIRS), J. Geophys. Res., 111, D12314, doi:10.1029/2005JD006490, 2006.

Randel, W. J., Wu, F., Getteman, A., Russel III, J. M., Zawodny, J. M., and Oltmans, S. J.: Seasonal variation of water vapor in the lower stratosphere observed in the Halogen Occultation Experiment data, J. Geophys. Res., 106, 14313-14325, 2001.

Randel, W. J., Park, M., Emmons, L., Kinnison, D., Bernath, P., Walker, K. A., Boone, C., and Pumphrey, H.: Asian monsoon transport of pollution to the stratosphere, Science, 328, 611-613, doi:10.1126/science.1182274, 2010.

Rao, P. S. P., Momin, G. A., Safai, P. D., Ali, K., Naik, M. S., and Pillai, A. G.: Aerosol and trace gas studies at Pune during INDOEX IFP-99, Curr. Sci. India, 80, 105-109, 2001.

Rasch, P. J., Collins, W. D., and Eaton, B. E.: Understanding the Indian Ocean Experiment (INDOEX) aerosol distributions with an aerosol assimilation, J. Geophys. Res., 106, 7337-7355, 2001.

Read, K. A., Mahajan, A. S., Carpenter, L. J., Evans, M. J., Faria, B. V. E., Heard, D. E., Lee, J. R. H. J. D., Moller, S. J., Lewis, A. C., McQuaid, L. M. J. B., Oetjen, H., Saiz-Lopez, A., Pilling, M. J., and Plane, J. M. C.: Extensive halogen-mediated ozone 
destruction over the tropical Atlantic Ocean, Nature, 453, 7035, doi:10.1038/nature07035, 2008.

Reddy, L. A. K., Kulshrestha, U. C., Satyanarayana, J., Kulshrestha, M. J., and Moorthy, K. K.: Chemical characteristics of $\mathrm{PM}_{10}$ aerosols and airmass trajectories over Bay of Bengal and Arabian Sea during ICARB, J. Earth Syst. Sci., 117, 345-352, 2008.

Reddy, M. S. and Venkataraman, C.: Inventory of aerosol and sulphur dioxide emissions form India: I - Fossil fuel combustion, Atmos. Environ., 36, 677-697, 2002a.

Reddy, M. S. and Venkataraman, C.: Inventory of aerosol and sulphur dioxide emissions from India, Part II - biomass combustion, Atmos. Environ., 36, 699-712, 2002b.

Reddy, M. S., Boucher, O., Venkataraman, C., Verma, S., Léon, J., Bellouin, N., and Pham, M.: General circulation model estimates of aerosol transport and radiative forcing during the Indian Ocean Experiment, J. Geophys. Res., 109, D16205, doi:10.1029/2004JD004557, 2004.

Reiner, T., Sprung, D., Jost, C., Gabriel, R., Mayol-Bracero, O. L., Andreae, M. O., Campos, T. L., and Shelter, R. E.: Chemical characterization of pollution layers over the tropical Indian Ocean, J. Geophys. Res., 106, 28497-28510, 2001.

Rhoads, K. P., Kelley, P., Dickerson, R. R., Carsey, T. P., Farmer, M., Savoie, D. L., and Prospero, J. M.: Composition of the troposphere over the Indian Ocean during the monsoonal transition, J. Geophys. Res., 102, 18981-18995, 1997.

Roberts, G. C., Ramana, M. V., Corrigan, C., Kim, D., and Ramanathan, V.: Simultaneous observations of aerosol-cloudalbedo interactions with three stacked unmanned aerial vehicles, P. Natl. Acad. Sci. USA, 105, 7370-7375, 2008.

Roca, R., Viollier, M., Picon, L., and Desbois, M.: A multisatellite analysis of deep convection and its moist environment over the Indian Ocean during the winter monsoon, J. Geophys. Res., 107, 8012, doi:10.1029/2000JD000040, 2002.

Roeckner, E., Bengtsson, L., Feichter, J., Lelieveld, J., and Rodhe, H.: Transient climate change simulations with a coupled atmosphere-ocean GCM including the tropospheric sulfur cycle, J. Climate, 12, 3004-3032, 1999.

Roelofs, G. J., Scheeren, H. A., Heland, J., Ziereis, H., and Lelieveld, J.: A model study of ozone in the eastern Mediterranean free troposphere during MINOS (August 2001), Atmos. Chem. Phys., 3, 1199-1210, doi:10.5194/acp-3-1199-2003, 2003.

Rotstayn, L. D. and Lohmann, U.: Tropical Rainfall Trends and the Indirect Aerosol Effect, J. Climate, 15, 2103-2116, 2002.

Roy, S., Beig, G., and Jacob, D.: Seasonal distribution of ozone and its precursors over the tropical Indian region using regional chemistry-transport model, J. Geophys. Res., 113, D21307, doi:10.1029/2007JD009712, 2008.

Roy, S. D., Beig, G., and Ghude, Sachin D.: Exposure-plant response of ambient ozone over the tropical Indian region, Atmos. Chem. Phys., 9, 5253-5260, doi:10.5194/acp-9-5253-2009, 2009.

Sadasivan, S.: Trace elements in size separated aerosols over sea, Atmos. Environ., 12, 1677-1683, 1978.

Sadasivan, S.: Trace constituents in cloud water, rainwater and aerosol samples collected near the west coast of India during the southwest monsoon, Atmos. Environ., 14, 33-38, 1980.

Safai, P. D., Rao, P. S. P., Momin, G. A., Ali, K., Chate, D. M., and Praveen, P. S.: Chemical composition of precipitation during
1984-2002 at Pune, India, Atmos. Environ., 38, 1705-1714, 2004.

Sahu, L. K., Lal, S., and Venkataramani, S.: Distributions of $\mathrm{O}_{3}$, $\mathrm{CO}$ and hydrocarbons over the Bay of Bengal: a study to assess the role of transport from southern India and marine regions during September-October 2002, Atmos. Environ., 40, 4633-4645, 2006.

Salam, A., Bauer, H., Kassin, K., Mohammed Ullah, S., and Puxbaum, H.: Aerosol chemical characteristics of an island site in the Bay of Bengal (Bhola-Bangladesh), J. Environ. Monitor., 5, 483-490, 2003.

Salisbury, G., Williams, J., Holzinger, R., Gros, V., Mihalopoulos, N., Vrekoussis, M., Sarda-Estève, R., Berresheim, H., von Kuhlmann, R., Lawrence, M., and Lelieveld, J.: Ground-based PTR-MS measurements of reactive organic compounds during the MINOS campaign in Crete, July-August 2001, Atmos. Chem. Phys., 3, 925-940, doi:10.5194/acp-3-925-2003, 2003.

Sander, R., Keene, W. C., Pszenny, A. A. P., Arimoto, R., Ayers, G. P., Baboukas, E., Cainey, J. M., Crutzen, P. J., Duce, R. A., Hönninger, G., Huebert, B. J., Maenhaut, W., Mihalopoulos, N., Turekian, V. C., and Van Dingenen, R.: Inorganic bromine in the marine boundary layer: a critical review, Atmos. Chem. Phys., 3, 1301-1336, doi:10.5194/acp-3-1301-2003, 2003.

Saraf, N., Beig, G., and Schultz, M.: Tropospheric distribution of ozone and its precursors over the tropical Indian Ocean, J. Geophys. Res., 108, 4636, doi:10.1029/2003JD003521, 2003.

Satheesh, S. K.: Radiative forcing by aerosols over Bay of Bengal region, Geophys. Res. Lett., 29, 2083, doi:10.1029/2002GL01,334, 2002.

Satheesh, S. K. and Lubin, D.: Short wave versus long wave radiative forcing by Indian Ocean aerosols: Role of sea-surface winds, Geophys. Res. Lett., 30, 1695, doi:10.1029/2003GL017499, 2003.

Satheesh, S. K., Moorthy, K. K., and Murthy, B. V. K.: Spatial Gradients in Aerosol Characteristics over the Arabian Sea and Indian Ocean, J. Geophys. Res., 103, 26183-26192, 1998.

Satheesh, S. K., Ramanathan, V., Holben, B. N., Krishna Moorthy, K., Loeb, N. G., Maring, H., Prospero, J. M., and Savoie, D.: Chemical, microphysical, and radiative effects of Indian Ocean aerosols, J. Geophys. Res., 107, 4725, doi:10.1029/2002JD002463, 2002.

Satheesh, S. K., Moorthy, K. K., Kaufman, Y. J., and Takemura, T.: Aerosol optical depth, physical properties and radiative forcing over the Arabian Sea, Met. Atmos. Phys., 91, 45-62, 2006 a.

Satheesh, S. K., Srinivasan, J., and Moorthy, K. K.: Spatial and temporal heterogeneity in aerosol properties and radiative forcing over Bay of Bengal: Sources and role of aerosol transport, J. Geophys. Res., 111, D08202, doi:10.1029/2005JD006374, 2006 b.

Satheesh, S. K., Morthy, K. K., Babu, S. S., Vinoj, V., and Dutt, C. B. S.: Climate implications of large warming by elevated aerosol over India, Geophys. Res. Lett., 35, L19809, doi:10.1029/2008GL034944, 2008.

Satheesh, S. K., Krishna Moorthy, K., Suresh Babu, S., Vinoj, V., Nair, V. S., Naseema Beegum, S., Dutt, C. B. S., Alappattu, D. P., and Kunhikrishnan, P. K.: Vertical structure and horizontal gradients of aerosol extinction coefficients over coastal India inferred from airborne lidar measurements during the Integrated Campaign for Aerosol, Gases and Radiation 
Budget (ICARB field campaign, J. Geophys. Res., 114, D05204, doi:10.1029/2008JD011033, 2009.

Scheeren, H. A., Lelieveld, J., de Gouw, J. A., van der Veen, C., and Fischer, H.: Methyl chloride and other chlorocarbons in polluted air during INDOEX, J. Geophys. Res., 107, 8015, doi:10.1029/2001JD001121, 2002.

Scheeren, H. A., Lelieveld, J., Roelofs, G. J., Williams, J., Fischer, H., de Reus, M., de Gouw, J. A., Warneke, C., Holzinger, R., Schlager, H., Klüpfel, T., Bolder, M., van der Veen, C., and Lawrence, M.: The impact of monsoon outflow from India and Southeast Asia in the upper troposphere over the eastern Mediterranean, Atmos. Chem. Phys., 3, 1589-1608, doi:10.5194/acp-31589-2003, 2003.

Schoeberl, M. R., Duncan, B. N., Douglass, A. R., Waters, J., Livesey, N., Read, W., and Filipak, M.: The carbon monoxide tape recorder, Geophys. Res. Lett., 33, L12811, doi:10.1029/2006GL026178, 2006.

Schuck, T. J., Brenninkmeijer, C. A. M., Baker, A. K., Slemr, F., von Velthoven, P. F. J., and Zahn, A.: Greenhouse gas relationships in the Indian summer monsoon plume measured by the CARIBIC passenger aircraft, Atmos. Chem. Phys., 10, 39653984, doi:10.5194/acp-10-3965-2010, 2010.

Sheridan, P. J., Jefferson, A., and Ogren, J. A.: Spatial variability of submicrometer aerosol radiative properties over the Indian Ocean during INDOEX, J. Geophys. Res., 107, 8011, doi:10.1029/2000JD000166, 2002.

Sikka, D. R.: Evaluation of monitoring and forecasting of summer monsoon over India and a review of monsoon drought of 2002, P. Indian Nat. Sci. Acad., 69, 479-504, 2003.

Simpson, M. and Raman, S.: Development and propagation of a pollution gradient in the marine boundary layer during INDOEX (1999), J. Earth Syst. Sci., 114, 3-16, 2005.

Simpson, M. D. and Raman, S.: Role of the land plume in the transport of ozone over the ocean during INDOEX (1999), Bound. Lay. Meteorol., 111, 133-152, 2004.

Simpson, M. D. and Raman, S.: Observations and numerical simulation of the sea and land breeze circulations along the west coast of India, Indian J. Mar. Sci., 35, 139-152, 2006.

Singh, M., Singh, D., and Pant, P.: Aerosol characteristics at Patiala during ICARB-2006, J. Earth Syst. Sci., 117, 407-411, 2008.

Singh, S., Singh, B., Gera, B., Srivastava, M. K., Dutta, H., Garg, S., and Singh, R.: A study of aerosol optical depth in the central Indian region $(17.3-8.60 \mathrm{~N})$ during ISRO-GBP field campaign, Atmos. Environ., 40, 6494-6503, doi:10.1016/j.atmosenv.2006.01.033, 2006.

Spencer, M. T., Holecek, J. C., Corrigan, C. E., Ramanathan, V., and Prather, K. A.: Size-resolved chemical composition of aerosol particles during a monsoonal transition period over the Indian Ocean, J. Geophys. Res., 113, D16305, doi:10.1029/2007JD008657, 2008.

Srinivasan, J. and Gadgil, S.: Asian Brown Cloud - fact and fantasy, Curr. Sci. India, 83, 586-592, 2002.

Stefanutti, L., MacKenzie, A., Santacesaria, V., Adriani, A., Balestri, S., Borrmann, S., Khattatov, V., Mazzinghi, P., Mitev, V., Rudakov, V., Schiller, C., Toci, G., Volk, C., Yushkov, V., Flentje, H., Kiemle, C., Redaelli, G., Carslaw, K., Noone, K., and Peter, T.: The APE-THESEO Tropical Campaign: An Overview, J. Atmos. Chem., 48, 1-33, 2004.
Stehr, J. W., Ball, W. P., Dickerson, R. R., Doddridge, B. G., Piety, C. A., and Johnson, J. E.: Latitudinal gradients in $\mathrm{O}_{3}$ and CO during INDOEX 1999, J. Geophys. Res., 107, 8015, doi:10.1029/2001JD000446, 2002.

Stevens, B. and Feingold, G.: Untangling aerosol effects on clouds and precipitation in a buffered system, Nature, 461, 607-613, 2009.

Stier, P., Feichter, J., Kinne, S., Kloster, S., Vignati, E., Wilson, J., Ganzeveld, L., Tegen, I., Werner, M., Balkanski, Y., Schulz, M., Boucher, O., Minikin, A., and Petzold, A.: The aerosolclimate model ECHAM5-HAM, Atmos. Chem. Phys., 5, 11251156, doi:10.5194/acp-5-1125-2005, 2005.

Stohl, A., Forster, C., Huntrieser, H., Mannstein, H., McMillan, W. W., Petzold, A., Schlager, H., and Weinzierl, B.: Aircraft measurements over Europe of an air pollution plume from Southeast Asia -aerosol and chemical characterization, Atmos. Chem. Phys., 7, 913-937, doi:10.5194/acp-7-913-2007, 2007.

Stone, E. A., Lough, G. C., Schauer, J. J., Praveen, P. S., Corrigan, C. E., and Ramanathan, V.: Understanding the origin of black carbon in the atmospheric brown cloud over the Indian Ocean, J. Geophys. Res., 112, D22S23, doi:10.1029/2006JD008118, 2007.

Streets, D. G., Bond, T. C., Carmichael, G. R., Fernandes, S. D., Fu, Q., He, D., Klimont, Z., Nelson, S. M., Tsai, N. Y., Wang, M. Q., Woo, J., and Yarber, K. F.: An inventory of gaseous and primary aerosol emissions in Asia in the year 2000, J. Geophys. Res., 108, 8809, doi:10.1029/2002JD003093, 2003.

Streets, D. G., Zhang, Q., Wang, L., He, K., Hao, J., Wu, Y., Tang, Y., and Carmichael, G. R.: Revisiting China's CO emissions after the Transport and Chemical Evolution over the Pacific (TRACE-P) mission: Synthesis of inventories, atmospheric modeling, and observations, J. Geophys. Res., 111, D14306, doi:10.1029/2006JD007118, 2006.

Subrahamanyam, D. B., Gupta, K. S., Ravindran, S., and Krishnan, P.: Study of sea breeze and land breeze along the west coast of Indian sub-continent over the latitude range $15^{\circ} \mathrm{N}$ to $8^{\circ} \mathrm{N}$ during INDOEX IFP-99 (SK-141) cruise, Curr. Sci. India, 80, 85-88, 2001.

Subrahamanyam, D. B., Kumar, N. V. P. K., Dutt, C. B. S., Anurose, T. J., Kunhikrishnan, P. K., and Mohan, M.: Characterization of airsea interaction processes over the Bay of Bengal during the winter phase of ICARB field experiment, Atmos. Res., doi:10.1016/j.atmosres.2010.09.005, in press, 2010.

Sumanth, E., Mallikarjuna, K., Stephen, J., Moole, M., Vinoj, V., Satheesh, S. K., and Moorthy, K. K.: Measurements of aerosol optical depths and black carbon over Bay of Bengal during post-monsoon season, Geophys. Res. Lett., 31, L16115, doi:10.1029/2004GL020681, 2004.

Tahnk, W. R. and Coakley, Jr., J. A.: Aerosol optical depth and direct radiative forcing for INDOEX derived from AVHRR: Observations, January-March 1996-2000, J. Geophys. Res., 107, 8010, doi:10.1029/2000JD000183, 2002.

Thampi, B. V., Rajeev, K., Parameswaran, K., and Mishra, M. K.: Spatial distribution of the Southeast Asian smoke plume over the Indian Ocean and its radiative heating in the atmosphere during the major fire event of 2006, Geophys. Res. Lett., 36, L16808, doi:10.1029/2009GL039316, 2009.

Thompson, A. M., Doddridge, B. G., Witte, J. C., Hudson, R. D., Luke, W. T., Johnson, J. E., Johnson, B. J., Oltmans, S. J., and 
Weller, R.: A Tropical Atlantic Paradox: Shipboard and Satellite Views of a Tropospheric Ozone Maximum Wave-one in JanuaryFebruary 1999, Geophys. Res. Lett., 27, 3317-3320, 2000.

Traub, M. and Lelieveld, J.: Cross-tropopause transport over the eastern Mediterranean, J. Geophys. Res., 108, 4712, doi:10.1029/2003JD003754, 2003.

Traub, M., Fischer, H., de Reus, M., Kormann, R., Heland, H., Ziereis, H., Schlager, H., Holzinger, R., Williams, J., Warneke, C., de Gouw, J., and Lelieveld, J.: Chemical characteristics assigned to trajectory clusters during the MINOS campaign, Atmos. Chem. Phys., 3, 459-468, doi:10.5194/acp-3-459-2003, 2003.

Tripathi, S. N., Tare, V., Chinnam, N., Srivastava, A. K., Dey, S., Agarwal, A., Kishore, S., Lal, R. B., Manar, M., Kanwade, V. P., Chauhan, S. S. S., Sharma, M., Reddy, R. R., Gopal, K. R., Narasimhulu, K., Reddy, L. S. S., Gupta, S., and Lal, S.: Measurements of atmospheric parameters during Indian Space Research Organization Geosphere Biosphere Programme Land Campaign II at a typical location in the Ganga basin: 1. Physical and optical properties, J. Geophys. Res., 111, D23209, doi:10.1029/2006JD007278, 2006.

Twomey, S.: Pollution and the Planetary Albedo, Atmos. Environ., 8, 1251-1256, 1974.

Twomey, S.: The Influence of Pollution on the Shortwave Albedo of Clouds, J. Atmos. Sci., 34, 1149-1152, 1977.

Varshney, C. K. and Aggarwal, M.: Ozone pollution in the urban atmosphere of Delhi, Atmos. Environ., 26, 291-294, 1992.

Venkataraman, C., Konda Reddy, C., Josson, S., and Shekar Reddy, M.: Aerosol size and chemical characteritics at Mumbai, India, during the INDOEX-IFP (1999), Atmos. Environ., 36, 19791991, 2002.

Venkataraman, C., Habib, G., Eiguren-Fernandez, A., Miguel, A. H., and Friedlander, S. K.: Residental Biofuels in South Asia: Carbonaceous Aerosol Emissions and Climate Impacts, Science, 307, 1454-1456, 2005.

Verma, S., Boucher, O., Venkataraman, C., Reddy, M. S., Müller, D., Chazette, P., and Crouzille, B.: Aerosol lofting from sea breeze during the Indian Ocean Experiment, J. Geophys. Res., 111, D07208, doi:10.1029/2005JD005953, 2006.

Verma, S., Venkataraman, C., Boucher, O., and Ramachandran, S.: Source evaluation of aerosols measured during the Indian Ocean Experiment using combined chemical transport and back trajectory modeling, J. Geophys. Res., 112, D11210, doi:10.1029/2006JD007698, 2007.

Verma, S., Venkataraman, C., and Boucher, O.: Origin of surface and columnar Indian Ocean Experiment (INDOEX) aerosols using source- and region-tagged emissions transport in a general circulation model, J. Geophys. Res., 113, D24211, doi:10.1029/2007JD009538, 2008.

Verver, G. H. L., Sikka, D. R., Lobert, J. M., Stossmeister, G., and Zachariasse, M.: Overview of the meteorological conditions and atmospheric transport processes during INDOEX 1999, J. Geophys. Res., 106, 28399-28413, 2001.

Vinoj, V., Babu, S. S., Satheesh, S. K., Moorthy, K., and Kaufman, Y. J.: Radiative forcing by aerosols over the Bay of Bengal region derived from shipborne, island-based, and satellite (ModerateResolution Imaging Spectroradiometer) observations, J. Geophys. Res., 109, D05203, doi:10.1029/2003JD004329, 2004.
Vinoj, V., Anjan, A., Sudhakar, M., Satheesh, S. K., Srinivasan, J., and Krishna Moorthy, K.: Latitudinal variation of aerosol optical depths from northern Arabian Sea to Antarctica, Geophys. Res. Lett., 34, L10807, doi:10.1029/2007GL029419, 2007.

Vogt, R., Crutzen, P. J., and Sander, R.: A mechanism for halogen release from sea-salt aerosol in the remote marine boundary layer, Nature, 383, 327-330, 1996.

von Glasow, R., Sander, R., Bott, A., and Crutzen, P. J.: Modeling halogen chemistry in the marine boundary layer 2 . Interactions with sulfur and the cloud-covered MBL, J. Geophys. Res., 107, 4323, doi:10.1029/2001JD000943, 2002.

Wagner, V., von Glasow, R., Fischer, H., and Crutzen, P. J.: Are $\mathrm{CH}_{2}$ Omeasurements in the marine boundary layer suitable for testing the current understanding of $\mathrm{CH}_{4}$ photooxidation?: a model study, J. Geophys. Res., 107, 4029, doi:10.1029/2001JD000722, 2002.

Wang, C., Jeong, G. R., and Mahowald, N.: Particulate absorption of solar radiation: anthropogenic aerosols vs. dust, Atmos. Chem. Phys., 9, 3935-3945, doi:10.5194/acp-9-3935-2009, 2009.

Warneke, C. and de Gouw, J. A.: Organic trace gas composition of the marine boundary layer over the northwest Indian Ocean in April 2000, Atmos. Environ., 35, 5923-5933, 2001.

Webster, P. J., Magana, V. O., Palmer, T. N., Shukla, J., and Tomas, R. A.: Monsoons: processes, predictability, and the prospects for prediction, J. Geophys. Res., 103, 14451-14510, 1998.

Weigel, R., Borrmann, S., Curtius, J., Kunkel, D., Vicani, S., Shur, G. N., Belyaev, G. V., Schiller, C., Volk, C. M., and Stohl, A.: Observations of new particle formation events in the tropical UT/LS: On the role of ion induced nucleation, Atmos. Chem. Phys., in preparation, 2010.

Weigelt, A., Hermann, M., van Velthofen, P. F. J., Brenninkmeijer, C. A. M., Schlaf, G., Zahn, A., and Wiedensohler, A.: Influence of clouds on aerosol particle number concentrations in the upper troposphere, J. Geophys. Res., 114, D01204, doi:10.1029/2008JD009805, 2009.

Welton, E. J., Voss, K. J., Quinn, P. K., Flatau, P., Markowicz, K., Campbell, J., Spinhirne, J. D., Gordon, H. R., and Johnson, J.: Measurements of aerosol vertical profiles and optical properties during INDOEX 1999 using micropulse lidars, J. Geophys. Res., 107, 8019, doi:10.1029/2000JD000038, 2002.

Wilcox, E. M. and Ramanathan, V.: The impact of observed precipitation upon the transport of aerosols from South Asia, Tellus, 56, 435-450, 2004.

Williams, J., Fischer, H., Wong, S., Crutzen, P. J., Scheele, M. P., and Lelieveld, J.: Near equatorial $\mathrm{CO}$ and $\mathrm{O}_{3}$ profiles over the Indian Ocean during the winter monsoon: $\mathrm{High}_{3}$ levels in the middle troposphere and interhemispheric exchange, J. Geophys. Res., 107, 8007, doi:10.1029/2001JD001126, 2002.

Wisthaler, A., Hansel, A., Dickerson, R. R., and Crutzen, P. J.: Organic trace gas measurements by PTR-MS during INDOEX 1999, J. Geophys. Res., 107, 8024, doi:10.1029/2001JD000576, 2002.

Worden, J., Jones, D. B. A., Liu, J., Parrington, M., Bowman, K., Stajner, I., Beer, R., Jiang, J., Thouret, V., Kulawik, S., Li, J. F., Verma, S., and Worden, H.: Observed vertical distribution of tropospheric ozone during the Asian summertime monsoon, J. Geophys. Res., 114, D13304, doi:10.1029/2008JD010560, 2009. 
Wuebbles, D. J., Lei, H., and Lin, J.: Intercontinental transport of aerosols and photochemical oxidants from Asia and its consequences, Environ. Pollut., 150, 65-84, 2007.

Xiong, X., Houweling, S., Wei, J., Maddy, E., Sun, F., and Barnet, C.: Methane plume over south Asia during the monsoon season: satellite observation and model simulation, Atmos. Chem. Phys., 9, 783-794, doi:10.5194/acp-9-783-2009, 2009.

Xu, B., Cao, J., Hansen, J., Yao, T., Joswia, D. R., Wang, N., Wu, G., Wang, M., Zhao, H., Yang, W., Liu, X., and He, J.: Black soot and the survival of Tibetan glaciers, P. Natl. Acad. Sci. USA, 106, 22114-22118, 2009.

Yasunari, T. J., Bonasoni, P., Laj, P., Fujita, K., Vuillermoz, E., Marinoni, A., Cristofanelli, P., Duchi, R., Tartari, G., and Lau, K.-M.: Estimated impact of black carbon deposition during pre-monsoon season from Nepal Climate Observatory -Pyramid data and snow albedo changes over Himalayan glaciers, Atmos. Chem. Phys., 10, 6603-6615, doi:10.5194/acp-10-6603-2010, 2010.

Ye, D. and Wu, G.: The role of the heat source of the Tibetan Plateau in the general circulation, Met. Atmos. Phys., 67, 181-198, 1998.
Young, L., Benson, D. R., Montanaro, W. M., et al.: Enhanced new particle formation observed in the northern midlatitude tropopause region, J. Geophys. Res., 112, D10218, doi:10.1029/2006JD008109, 2007.

Zachariasse, M., van Velthoven, P. F. J., Smit, H. G. J., Lelieveld, J., Mandal, T. K., and Kelder, H.: Influence of stratospheretroposphere exchange on tropospheric ozone over the tropical Indian Ocean during the winter monsoon, J. Geophys. Res., 105, 15403-15416, 2000.

Zachariasse, M., Smit, H. G. J., van Velthoven, P. F. J., and Kelder, H.: Cross-tropopause and interhemispheric transports into the tropical free troposphere over the Indian Ocean, J. Geophys. Res., 106, 28441-28452, 2001.

Zhang, L., Jacob, D. J., Boersma, K. F., Jaffe, D. A., Olson, J. R., Bowman, K. W., Worden, J. R., Thompson, A. M., Avery, M. A., Cohen, R. C., Dibb, J. E., Flock, F. M., Fuelberg, H. E., Huey, L. G., McMillan, W. W., Singh, H. B., and Weinheimer, A. J.: Transpacific transport of ozone pollution and the effect of recent Asian emission increases on air quality in North America: an integrated analysis using satellite, aircraft, ozonesonde, and surface observations, Atmos. Chem. Phys., 8, 6117-6136, doi:10.5194/acp-8-6117-2008, 2008. 